MAURO SERGIO BRAGA

SISTEMAS OPTOELETRÔNICOS PORTÁTEIS PARA DETECÇÃO DE GASES, OXIGÊNIO DISSOLVIDO E DE METAIS PESADOS APLICADOS NO CONTROLE AMBIENTAL 


\section{SISTEMAS OPTOELETRÔNICOS PORTÁTEIS PARA DETECÇÃO DE GASES, OXIGÊNIO DISSOLVIDO E DE METAIS PESADOS APLICADOS NO CONTROLE AMBIENTAL}

Tese apresentada à Escola Politécnica da Universidade de São Paulo para obtenção do título de Doutor em Ciências.

Área de concentração: Microeletrônica

Orientador: Prof. Livre-Docente Walter Jaimes Salcedo 
Este exemplar foi revisado e corrigido em relação à versão original, sob responsabilidade única do autor e com a anuência de seu orientador.

São Paulo, de de

Assinatura do autor:

Assinatura do orientador:

Catalogação-na-publicação

\section{Braga, Mauro Sergio}

SISTEMAS OPTOELETRÔNICOS PORTÁTEIS PARA DETECĈ̃O DE GASES, OXIGÊNIO DISSOLVIDO E DE METAIS PESADOS APLICADOS NO CONTROLE AMBIENTAL / M. S. Braga -- versão corr. -- São Paulo, 2016. $190 \mathrm{p}$.

Tese (Doutorado) - Escola Politécnica da Universidade de São Paulo. Departamento de Engenharia de Sistemas Eletrônicos.

1.Sistemas portáteis de monitoramento ambiental 2.Oxigênio dissolvido 3 . Íons metálicos 4.Colorimetria 5.Fluorimetria I.Universidade de São Paulo. Escola Politécnica. Departamento de Engenharia de Sistemas Eletrônicos II.t. 
Dedico este trabalho a Isabella e a Sophia, minhas melhores razões de existir. 


\section{AGRADECIMENTOS}

Agradeço a Deus por ter aproximado de mim tantas pessoas extraordinárias, tantos ombros amigos nos quais pude me apoiar no decorrer desses anos e que, direta ou indiretamente, contribuíram para a realização deste trabalho.

Aos meus pais Braga e Maria Augusta, irmãos Edmilson, Roberto e Solange, que desde os meus primeiros passos me instruíram a caminhar de modo honesto e digno pelas estradas da vida.

À minha esposa Isabella, que sempre de maneira companheira e afetiva esteve ao meu lado em todos os momentos.

À minha pequena Sophia, que se despede apegada todos os dias de manhã quando saio a trabalhar.

Ao meu orientador e amigo Prof. Dr. Walter Jaimes Salcedo e sua esposa Prof. ${ }^{\text {a }}$ Dr. ${ }^{\text {a }}$ Ruth Vera, por me acompanharem nos desafios e vitórias, projetos e realizações.

Ao meu amigo Prof. Dr. Francisco Javier Ramirez Fernandez, por seu apoio no grupo do Laboratório de Microeletrônica.

Aos professores Dr. Claudio Augusto Oller do Nascimento e Dr. Jorge Alberto Soares Tenório, pela receptividade e por oferecer recursos técnicos e instrumentais nas instalações do CEPEMA-USP e a todos os amigos e funcionários do centro de pesquisas que contribuíram direta e indiretamente para a conclusão do trabalho.

À amiga Prof. a Márcia Rosa de Mendonça Silva, pelo apoio incondicional e reconhecimento aos pesquisadores da cidade de Cubatão, e à importância dos trabalhos desenvolvidos em benefício do Meio Ambiente.

À minha amiga Fátima Cristina de Oliveira, pelos laços de colaboração científica, parceria e amizade que se tornaram tão sólidos durante todos esses anos.

Aos técnicos do laboratório do CEPEMA-USP, Osmar Gomes, Luciano Maia, Nilson Roman, Rafaela Araújo, Marcela Galluzzi, Rui Azevedo, Daniel Barbosa e Paulo Firmino, que por inúmeras vezes me ajudaram na preparação de reagentes e instrumentais, elucidando dúvidas e sugerindo possibilidades para melhoria do trabalho. 
À pesquisadora Daniela de Souza Dairiki, pela contribuição no desenvolvimento do sistema de medida de fase e intensidade fotoluminescente de sensores multiespectrais (LOCK IN).

À pesquisadora Paula Larangeira Garcia Martins, pela contribuição na preparação e síntese dos reagentes.

Ao pesquisador Keth Rousbergue pela troca de experiências nos métodos de detecção de $\mathrm{O}_{2}$, utilizando a molécula de PtOEP.

Aos colegas de pós-graduação, pelos valorosos comentários e discussões e, em especial, aos amigos Walter Borysow, Victor Borges, Elen Aquino, Louise Gracioso, Luciana Jandelli, Ingrid Avanzi, Bruno Karolski, Tâmira Maia, Miriam Abreu, Diogo Ogawa, Leticia Cardoso, Felipe Santana, Rina Huamanrayme, Hipolito Alan e Filipe Magalhães.

Às amigas da comunicação, administração e PJ-MAIS do CEPEMA-USP em especial Jéssica Borges, Danielle Correa, Vanessa Santos, Palmira Barros, Priscila, Elaine Rocha, Davi Martins e Alex Cruz pelo apoio e divulgação dos resultados durante toda a pesquisa.

Aos meus amigos e alunos de iniciação científica Guilherme Marciano, Daniel Amorim, Agnaldo Junior e Jorge P. Silva, todos do IFSP, campus de Cubatão, que não economizaram esforços em colaborar na realização dos preparativos experimentais dos ensaios e ilustrações.

Ao Prof. Robson Nunes da Silva, diretor do IFSP, campus de Cubatão, e aos diretores que o antecederam, Prof. ${ }^{a}$ Márcia Helena Marques Rabelo e Prof. Humberto Hickel de Carvalho, pelos recursos oferecidos na divulgação e publicação dos trabalhos realizados em eventos nacionais e internacionais.

Aos técnicos da Poli-Elétrica dos setores de sala limpa, sala de medidas e oficina mecânica em especial ao Henrique, Jair (sala de medidas), Rita, Cristina, João, Gerson, Jair (mecânica) e Raimundo, pela dedicação no auxílio na preparação e confecção dos dispositivos MOS e câmara de ensaios.

À empresa alemã MAZeT pela cooperação, suporte e doação dos dispositivos detectores multiespectrais e amplificadores de transimpedância, utilizados no desenvolvimento do sistema eletrônico multifuncional colorimétrico e fluorimétrico de detecção portátil de gases, oxigênio dissolvido e íons de metais pesados.

A todos, o meu muito obrigado! 


\section{RESUMO}

O monitoramento ambiental de forma contínua e em tempo real são desafios da realidade atual dos grandes centros urbanos, com a finalidade de prevenir desastres ambientais que possam pôr em perigo a saúde dos seres humanos e a existência de sistemas biológicos. Na presente tese foram propostos e desenvolvidos sistemas optoeletrônicos portáteis aplicados na detecção de $\mathrm{O}_{2}, \mathrm{OD}$ e íons de metais pesados, visando seu emprego no monitoramento de sistemas hidrológicos como mares, rios, lagos e lençóis freáticos. A definição final da estrutura do sistema portátil foi atingida após o desenvolvimento sistemático de diferentes ensaios experimentais. Primeiramente, foram estudadas e analisadas matrizes hospedeiras em estado sólido que fossem capazes de hospedar sistemas moleculares corantes sensíveis a certas substâncias específicas. A seguir, foi proposta e executada a integração direta dos filmes hospedeiros, dopados com moléculas corantes ativas, diretamente na superfície ativa de dispositivos fotodetectores para detecção de $\mathrm{O}_{2}$ e OD. Os resultados obtidos com estes sistemas que integram o detector e o filme ativo mostraram o mesmo nível de desempenho aos espectrômetros de bancada. Finalmente, de posse destes resultados, foi projetado e desenvolvido um sistema colorimétrico e fluorimétrico portátil e embarcado em uma placa de aquisição (myRIO1900) da National Instruments, aplicado na deteç̧ão e classificação de íons metálicos. Destaque principal é outorgado à aplicação do colorímetro que, juntamente com o processamento de sinais e análises de padrões, utilizando o método de discriminante de Fisher, permitiu obter resultados excelentes na detecção e classificação dos íons de $\mathrm{Pb}^{2+}, \mathrm{Cd}^{2+}, \mathrm{Zn}^{2+}, \mathrm{Cu}^{2+}, \mathrm{Fe}^{3+}$ e $\mathrm{Ni}^{2+}$, com os mesmos níveis de desempenho que os obtidos a partir de espectrômetros de bancada de elevada resolução espectral. O sistema portátil desenvolvido sugere sua aplicação no controle ambiental in situ e em tempo real, podendo ser integrado em uma rede de sensores que possam fornecer dados de maneira contínua e receber comandos de centros de controle de monitoramento ambiental. No entanto, seria necessária a formulação de algoritmos eficientes no processo de mineração de dados da rede de sensores.

Palavras-chave: Sistemas portáteis de monitoramento ambiental, Oxigênio dissolvido, Íons metálicos, Colorimetria, Fluorimetria. 


\begin{abstract}
The continuous and in real time environmental monitoring are challenges of the current days of large urban centers, with the aim of preventing environmental disasters that could endanger human health and the existence of biological systems. In this thesis we have proposed and developed portable optoelectronic systems applied to the detection of $\mathrm{O}_{2}, \mathrm{OD}$ and heavy metal ions, aiming its use in monitoring hydrological systems such as oceans, rivers, lakes and groundwater. The final definition of the portable system structure was achieved after the systematic development of different experimental assays. First, host matrices were studied and analyzed in solid state which were able to host dye molecular systems sensitive to certain substances. Then, we proposed and executed the direct integration of the host film, doped with active dye molecules directly on the active surface of photodetector devices to the detection of $\mathrm{O}_{2}$ and $\mathrm{OD}$. The results obtained with these systems that integrate the detector and the active film showed the same level of performance than those of benchtop spectrometers. Finally, with these results, we designed and developed a colorimetric and fluorimetric portable system with an embedded acquisition board (myRIO-1900) from National Instruments, applied to the detection and classification of metal ions. Main focus is given to the application of the colorimeter which, along with the signal processing and pattern analysis using the Fisher discriminant method, allowed to obtain excellent results in the detection and classification of $\mathrm{Pb}^{2+}, \mathrm{Cd}^{2+}, \mathrm{Zn}^{2+}, \mathrm{Cu}^{2+}$, $\mathrm{Fe}^{3+}$ and $\mathrm{Ni}^{2+}$ ions, with the same level of performance related to those obtained from high spectral resolution benchtop spectrometers. The portable system developed in the present thesis suggests its application in environmental control in situ and in real time, so that it can be integrated in a network of sensors that may provide continuous data and receive commands from environmental monitoring control center; nevertheless, requiring for that the development of efficient algorithms in data mining process of the sensor network.
\end{abstract}

Keywords: Portable environmental monitoring systems, Dissolved oxygen, Metal ions, Colorimetric, Fluorimetry. 


\section{LISTA DE ILUSTRAÇÕES}

Figura 1 - Reação entre cromógeno PAN e um íon metálico (CHENG; BRAY, 1955)

Figura 2 - Esquema da reação química da H2tpp com íon metálico de $\mathrm{Hg}^{2+}(\mathrm{CHAN}$; YANG; WANG, 2001) .36

Figura 3 - Estrutura molecular do 2,7-Dichlorofluorescein. 38

Figura 4- Complexos de Platina e Paládio comumentes utilizados em sensoriamento de $\mathrm{O}_{2}$ e OD, (a) Octaetilporfirina de Platina (PtOEP) (b) Octaetilporfirina de Paládio (PdOEP).

Figura 5 - llustração do deslocamento de fase na emissão fluorescente (MCDONAGH et al., 2001).

Figura 6 - Ilustração esquemática do revestimento por rotação (spin coating). A substância a ser depositada é gotejada sobre o substrato que é rotacionado por 10 s sob velocidades de 1000 e 3000 RPM. .55

Figura 7 - Tela de configuração sistema de diluição dos gases de $\mathrm{O}_{2}$ e $\mathrm{N}_{2}$ (SANTOS, BRAGA, SALCEDO, 2013)

Figura 8 - Diagrama esquemático do arranjo do sistema de diluição de oxigênio e nitrogênio para a caracterização das estruturas Vidro/PS(PtOEP) e ox.p.Si/PtOEP.

Figura 9 - Diagrama esquemático do arranjo sistema de controle de oxigênio dissolvido em água deionizada.

Figura 10 - Diagrama esquemático do arranjo do sistema de controle de oxigênio dissolvido para ensaios de cinética e tempo de resposta. .59

Figura 11 - À esquerda, vista 3D e em corte da câmara de ensaios; à direita, imagem da câmara real com os filmes sensíveis depositados no interior da câmara fixada no suporte do fluorímetro. A câmara possui uma saída para os gases, aberta à atmosfera (MATOS, 2011). .60

Figura 12 - À esquerda, vista 3D e em corte da câmara de ensaios; à direita, imagem da câmara real com os filmes sensíveis depositados no interior da câmara fixada no suporte do fluorímetro. A câmara possui uma saída de líquidos, em circuito fechado pela bomba peristáltica. 
Figura 13 - Detalhes construtivos do espectrofotômetro de fluorescência (fluorímetro), modelo Cary Eclipse e marca Varian.

Figura 14 - Espectro de excitação normalizado de um filme de poliestireno dopado com moléculas corantes de PtOEP em substrato de vidro (Vidro/PS(PtOEP)) e moléculas PtOEP adsorvidas na camada de silício poroso oxidada (ox.p.Si/PtOEP). .63

Figura 15 - a) Espectros de emissão fotoluminescente do dispositivo Vidro/PtOEP/PS em condição de deposição do filme em 1000RPM. b) Espectros de emissão fotoluminescente do dispositivo Vidro/PtOEP/PS em condição de deposição do filme em 3000RPM. .65

Figura 16 - a) Espectros de emissão fotoluminescente do dispositivo $L 55$ e estrutura de ox.p.Si/PtOEP b) Espectros de emissão fotoluminescente do dispositivo $L 63$ e estrutura de ox.p.Si/PtOEP. 65

Figura 17 - Curvas de Stern-Volmer da intensidade de supressão fotoluminescente da molécula de PtOEP para os dispositivos: a) Vidro/PtOEP/PS (1000RPM e 3000RPM) e b) ox.p.Si/PtOEP (L 55 e L 63), respectivamente.

Figura 18 - Curvas de Stern-Volmer da intensidade de supressão fotoluminescente da molécula de PtOEP para os dispositivos Vidro/PtOEP/PS (3000RPM) e ox.p.Si/PtOEP (L 55), respectivamente.

Figura 19 - Resposta dinâmica dos sensores (a) Vidro/PtOEP/PS (3000 RPM) e (b) ox.p.Si/PtOEP (L 55), respectivamente.

Figura 20 - Variação da intensidade fotoluminescente para ambientes de $100 \% \mathrm{~N}_{2} \mathrm{e}$ $100 \% \mathrm{O}_{2}$ (a) Vidro/PtOEP/PS (3000 RPM) e (b) ox.p.Si/PtOEP (L 55), respectivamente.

Figura 21 - Variação da intensidade fotoluminescente para ambientes de $100 \% \mathrm{~N}_{2} \mathrm{e}$ $100 \% \mathrm{O}_{2}$ com a colocação de filtro gradeado metálico de 1,5 Abs (a) Vidro/PtOEP/PS (3000 RPM) e (b) ox.p.Si/PtOEP (L 55), respectivamente.

Figura 22 - a) Espectros de emissão fotoluminescente do dispositivo Vidro/PtOEP/PS (3000 RPM) b) Espectros de emissão fotoluminescente do dispositivo ox.p.Si/PtOEP (L 55).

Figura 23 - Curvas de Stern-Volmer da intensidade de supressão fotoluminescente da molécula de PtOEP obtidas a partir de diferentes concentrações de 
oxigênio dissolvido em água DI. (a) Vidro/PtOEP/PS (3000 RPM) e (b) ox.p.Si/PtOEP (L 55), respectivamente............................................75

Figura 24 - Resposta dinâmica dos sensores a ambientes contendo 0\% de OD e $100 \%$ OD (40 mg/l) (a) Vidro/PtOEP/PS (3000 RPM) e (b) ox.p.Si/PtOEP ( $L 55)$, respectivamente .77

Figura 25 - Etapas de fabricação do capacitor MOS 83

Figura 26 - Detalhe construtivo do capacitor MOS com a película de polietileno tereftalato (PET) sobreposta a grade interdigital

Figura 27 - a) Película de PS-PET funcionalizada disposta sobre o capacitor MOS;

b) Capacitor MOS com película de PS-PET dentro de câmara de ensaios; c) LED/UV (377nm) instalado sobre janela de vidro para excitação luminosa sobre o sensor MOS; e d) Arranjo experimental do sistema de detecção de $\mathrm{O}_{2}$. 85

Figura 28 - Diagrama eletrônico do amplificador de transimpedância. 86

Figura 29 - Diagrama esquemático do arranjo do sistema de diluição de $\mathrm{O}_{2}$ e $\mathrm{N}_{2} \mathrm{e}$ esquema de ligação do método de medição da intensidade fotoluminescente do sensor MOS.

Figura 30 - a) Diagrama experimental da geração de uma fotocorrente em um dispositivo MOS, onde Фo é a intensidade de fótons; b) intensidade dos pulsos de luz e sinais de corrente em função do tempo 88

Figura 31 - Resposta do capacitor MOS a diferentes concentrações de $\mathrm{O}_{2}$. A curva de linha vermelha corresponde ao ajuste dos pontos experimentais com uma curva exponencial.

Figura 32 - Primeira derivada da resposta aproximada de fotocorrente do dispositivo MOS para diferentes concentrações de $\mathrm{O}_{2}$

Figura 33 - Diagrama de ligação do dispositivo óptico TCS3200 para medidas de saídas de frequência correspondentes as intensidades nos comprimentos de onda da luz - RGB. 96

Figura 34 - Detalhes construtivos do circuito integrado TCS3200 e perfil de deposição de membranas ativas de PtOEP imobilizadas em matrizes hospedeiras de poliestireno (PS) e policloreto de vinila (PVC) (ams AG, 2016).

Figura 35 - Diagrama esquemático do arranjo do sistema de controle de oxigênio dissolvido em água deionizada para dispositivos TCS3200. 
Figura 36 - a) Detalhe da instalação dos sensores TAOS/PS(PtOEP) e TAOS/PVC(PtOEP) no interior da câmara de ensaios; b) Arranjo experimental do sistema de diluição dos gases de $\mathrm{O}_{2}$ e $\mathrm{N}_{2}$ para ensaios de sensibilidade de $\mathrm{O}_{2}$ e OD. .99

Figura 37 - Curvas de resposta de saída dos dispositivos TCS3200 com membranas ativas formadas por TAOS/PS(PtOEP) e TAOS/PVC(PtOEP) na presença de diferentes concentrações de $\mathrm{O}_{2}$ em $\mathrm{N}_{2}$. 100

Figura 38 - Curvas de calibração com aproximação bi-exponencial de resposta das saídas de filtros vermelhos dos dispositivos TAOS/PS(PtOEP) e TAOS/PVC(PtOEP) na presença de diferentes concentrações de $\mathrm{O}_{2}$ em $\mathrm{N}_{2}$. 101

Figura 39 - Curvas de aproximação exponencial de resposta das saídas de filtros vermelhos dos dispositivos TAOS/PS(PtOEP) e TAOS/PVC(PtOEP) na presença de diferentes concentrações de OD. 103

Figura 40 - Sistema eletrônico multiespectral para detecção de gases, oxigênio dissolvido e íons de metais pesados. 110

Figura 41 - Sensor Multiespectral MMCS6CS (MAZET, 2013a). .111

Figura 42 - Resposta típica de sensibilidade relativa do MMCS6CS (MAZET, 2013b).

Figura 43 - Descrição dos terminais do circuito integrado do amplificador de transimpedância MTI04 (MAZET, 2013b). 112

Figura 44 - Diagrama esquemático eletrônico parcial contendo 8 canais do módulo amplificador de transimpedância de 16 canais e ganho programável.

Figura 45 - Diagrama esquemático eletrônico do circuito multiplexador de 32 canais. 116

Figura 46 - Gerador de funções (UDB1203S, 2012).

Figura 47 - Diagrama esquemático eletrônico do módulo gerador de função e condicionamento de sinais de 4 canais para excitação luminosa de LEDs

Figura 48 - Módulo eletrônico de aquisição e processamento de sinais NI myRIO1900 (HUSSAIN; ZEPHERIN, 2015)

Figura 49 - Diagrama de blocos da arquitetura do sistema LOCK-IN. 122 
Figura 50 - Tela de leitura dos sinais de tensão eficaz AC ( $\left.\mathrm{V}_{\mathrm{RMS}}\right)$, fase $\left({ }^{\circ}\right)$ e tensão em nível DC (V) desenvolvida em ambiente LabVIEW - National Instruments .123

Figura 51 - Tela de seleção dos sensores multiespectrais, com os campos de configuração do tempo de permanência em cada uma das saídas ...124

Figura 52 - Demonstração da lei de Beer-Lambert através da absorção da luz em meios líquidos 125

Figura 53 - Representação esquemática do espectrômetro UV-VIS de duplo feixe. 126

Figura 54 - Funções de combinações de cores CIE1931XYZ. ..........................127

Figura 55 - Diagrama de cromaticidade CIExy..........................................128

Figura 56 - Diagrama esquemático de ligação do sistema embarcado portátil de detecção de íons de metais pesados pelo método colorimétrico com de reagente cromógeno e sensor óptico multiespectral. 130

Figura 57 - Fotografia ilustrativa real do sistema embarcado portátil de detecção de íons de metais pesados pelo método colorimétrico.

Figura 58 - a) Detalhes construtivos da câmara de ensaios para medidas de colorimetria com sensor MMCS6CS posicionado frontalmente ao LED branco; b) Esquema ilustrativo da câmara de ensaios com dimensões equivalentes ao posicionamento do sensor MMCS6CS/LED. 131

Figura 59 - Diagrama esquemático de ligação do sistema embarcado portátil de detecção de íons de metais pesados pelo método fluorimétrico com uso de reagente fluoróforo e sensor óptico multiespectral. .134

Figura 60 - a) Detalhes construtivos da câmara de ensaios para medidas de fluorimetria com sensor MMCS6CS posicionado 90ำ em relação aos LEDs de excitação fluorescente; b) Esquema ilustrativo da câmara de ensaios com dimensões equivalentes ao posicionamento ortogonal do sensor MMCS6CS/LED. .135

Figura 61- Síntese do fluoróforo de 5,10,15,20-tetra-(3-bromo-4-hidroxifenil)porfirina (TBHPP). 136

Figura 62 - a) Registro fotográfico da etapa final de refluxo da reação. b) Separação das fases do TBHPP em funil. 
Figura 63 - Espectros de transmitância do cromógeno PAN na presença de íons de $\mathrm{Pb}^{2+}$ a) Espectrômetro UV-VIS Cary 50 - Varian b) Sensor Multiespectral MMCS6CS.

Figura 64 - Espectros de transmitância do cromógeno PAN na presença de íons de $\mathrm{Cd}^{2+}$ a) Espectrômetro UV-VIS Cary 50 - Varian b) Sensor Multiespectral MMCS6CS. 141

Figura 65 - Espectros de transmitância do cromógeno PAN na presença de íons de $Z^{2+}$ a) Espectrômetro UV-VIS Cary 50 - Varian b) Sensor Multiespectral MMCS6CS. 141

Figura 66 - Espectros de transmitância do cromógeno PAN na presença de íons de $\mathrm{Cu}^{2+}$ a) Espectrômetro UV-VIS Cary 50 - Varian b) Sensor Multiespectral MMCS6CS.

Figura 67 - Espectros de transmitância do cromógeno PAN na presença de íons de $\mathrm{Fe}^{3+}$ a) Espectrômetro UV-VIS Cary 50 - Varian b) Sensor Multiespectral MMCS6CS. 142

Figura 68 - Espectros de transmitância do cromógeno PAN na presença de íons de $\mathrm{Ni}^{2+}$ a) Espectrômetro UV-VIS Cary 50 - Varian b) Sensor Multiespectral MMCS6CS. 142

Figura 69 - Curvas de respostas obtidas pelo espectrômetro UV-VIS em diferentes concentrações de íons de metais pesados no comprimento de onda de $525 \mathrm{~nm}$. .144

Figura 70 - Curvas de respostas obtidas pela saída de $525 \mathrm{~nm}$ do sensor multiespectral MMCS6CS em diferentes concentrações de íons de metais pesados.

Figura 71 - Plano de cromaticidade bidimensional xy para concentrações iônicas de $\mathrm{Pb}^{2+}$. a) CIE1931XYZ - espectrômetro (425-650nm); b) CIE1931XYZ MMCS6CS - $\lambda(425-675 \mathrm{~nm})$. 146

Figura 72 - Plano de cromaticidade bidimensional xy para concentrações iônicas de $\mathrm{Cd}^{2+}$. a) CIE1931XYZ - espectrômetro (425-650nm); b) CIE1931XYZ MMCS6CS - $\lambda(425-675 \mathrm{~nm})$. 146

Figura 73 - Plano de cromaticidade bidimensional xy para concentrações iônicas de $Z^{2+}$. a) CIE1931XYZ - espectrômetro (425-650nm); b) CIE1931XYZ MMCS6CS - $\lambda(425-675 \mathrm{~nm})$. 
Figura 74 - Plano de cromaticidade bidimensional xy para concentrações iônicas de $\mathrm{Cu}^{2+}$. a) CIE1931XYZ - espectrômetro (425-650nm); b) CIE1931XYZ MMCS6CS - $\lambda(425-675 \mathrm{~nm})$.

Figura 75 - Plano de cromaticidade bidimensional xy para concentrações iônicas de $\mathrm{Fe}^{3+}$. a) CIE1931XYZ - espectrômetro (425-650nm); b) CIE1931XYZ MMCS6CS - $\lambda(425-675 \mathrm{~nm})$. 148

Figura 76 - Plano de cromaticidade bidimensional xy para concentrações iônicas de $\mathrm{Ni}^{2+}$. a) CIE1931XYZ - espectrômetro (425-650nm); b) CIE1931XYZ -

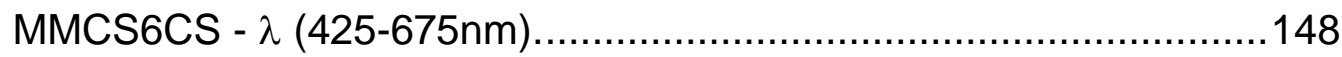

Figura 77 - CIE1931XYZ - espectrômetro UV-VIS (425-650nm) ........................149

Figura 78 - CIE1931XYZ - MMCS6CS (425-675nm) ......................................150

Figura 79 - CIExyY - Espectrômetro UV-VIS (425-650nm) ...............................151

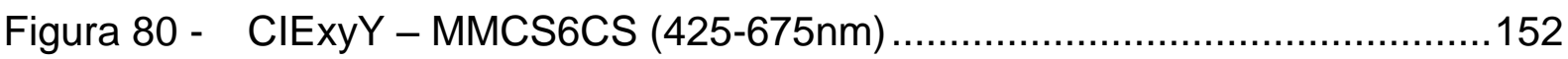

Figura 81 - Representação das classes correspondentes aos íons $\mathrm{Pb}^{2+}, \mathrm{Cd}^{2+}, \mathrm{Zn}^{2+}$, $\mathrm{Cu}^{2+}, \mathrm{Fe}^{3+}$ e $\mathrm{Ni}^{2+}$ obtidas pelo método descriminante linear de Fisher, respectivamente. Dados de treino obtidos dos parâmetros de cromaticidade xyY, correspondente aos espectros do espectrômetro UVVIS.

Figura 82 - Representação das classes correspondentes aos íons $\mathrm{Pb}^{2+}, \mathrm{Cd}^{2+}, \mathrm{Zn}^{2+}$, $\mathrm{Cu}^{2+}, \mathrm{Fe}^{3+}$ e $\mathrm{Ni}^{2+}$ obtidas pelo método descriminante linear de Fisher, respectivamente. Dados de treino obtidos dos parâmetros de cromaticidade $x y Y$, correspondente aos espectros do sistema MMCS6CS. 155

Figura 83 - Espectro de absorção do reagente fluoróforo de tetra-(3-bromo-4hidroxifenil)-porfirina (TBHPP) diluído em metanol $(9,0 \mu \mathrm{M})$. 157

Figura 84 - Espectro de fluorescência do reagente fluoróforo de TBHPP sob interação com diferentes íons metálicos. a) $\mathrm{Pb}^{2+}$, b) $\mathrm{Ni}^{2+}$, c) $\mathrm{Cd}^{2+}$ e d) $\mathrm{Zn}^{2+}$ 158

Figura 85 - Curvas de calibração de respostas obtidas pelo fluorímetro em diferentes concentrações de íons de metais pesados no comprimento de onda de $675 \mathrm{~nm}$. As curvas tracejadas correspondem aos ajustes exponenciais do reagente fluoróforo de TBHPP sob interação com diferentes íons metálicos. 
Figura 86 - Curvas de respostas de tensão VRMS obtidas pelo sensor multiespectral MMCS6CS em diferentes concentrações de íons de metais pesados na saída de comprimento de onda de $675 \mathrm{~nm}$. As curvas tracejadas correspondes às curvas de ajuste exponenciais do reagente fluoróforo de TBHPP, sob interação com diferentes íons metálicos. 161

Figura 87 - Pontos experimentais das respostas de fase obtidas pelo sensor multiespectral MMCS6CS em diferentes concentrações de íons de metais pesados na saída de comprimento de onda de $675 \mathrm{~nm}$ e suas curvas de ajuste exponenciais do reagente fluoróforo de TBHPP, sob interação com diferentes íons metálicos. 162

Figura 88 - Espectro de absorção do reagente fluoróforo de 2,7-Dichlorofluorescein diluído em metanol $(16,6,0 \mu \mathrm{M})$. 163

Figura 89 - Espectro de fluorescência do reagente fluoróforo de 2,7Dichlorofluorescein sob interação com diferentes íons metálicos. a) $\mathrm{Pb}^{2+}$, b) $\mathrm{Ni}^{2+}$, c) $\mathrm{Cd}^{2+}, \mathrm{Zn}^{2+}$ e $\mathrm{Cu}^{2+}$ 165

Figura 90 - Pontos experimentais das respostas de calibração com ajustes exponenciais obtidas pelo fluorímetro em diferentes concentrações de íns de metais pesados $\left(\mathrm{Pb}^{2+}, \mathrm{Ni}^{2+}, \mathrm{Cd}^{2+}, \mathrm{Zn}^{2+} \mathrm{e} \mathrm{Cu}^{2+}\right)$ sob interação com o reagente fluoróforo de 2,7-Dichlorofluorescein no comprimento de onda de $525 \mathrm{~nm}$. As curvas tracejadas correspondem ao ajuste por curvas exponenciais 167

Figura 91 - Curvas de respostas de calibração ( $V_{\mathrm{RMS}}$ ) com ajustes exponenciais obtidas pelo sensor multiespectral MMCS6CS em diferentes concentrações de íons de metais pesados $\left(\mathrm{Pb}^{2+}, \mathrm{Ni}^{2+}, \mathrm{Cd}^{2+}, \mathrm{Zn}^{2+} \mathrm{e} \mathrm{Cu}^{2+}\right)$ sob interação com o reagente fluoróforo de 2,7-Dichlorofluorescein no comprimento de onda de $525 \mathrm{~nm}$. As curvas tracejadas correspondem aos ajustes dos pontos experimentais com curvas exponenciais. .....168

Figura 92 - Curvas de respostas de calibração (fase) com ajustes exponenciais obtidas pelo sensor multiespectral MMCS6CS em diferentes concentrações de íons de metais pesados $\left(\mathrm{Pb}^{2+}, \mathrm{Ni}^{2+}, \mathrm{Cd}^{2+}, \mathrm{Zn}^{2+} \mathrm{e} \mathrm{Cu}^{2+}\right)$ sob interação com o reagente fluoróforo de 2,7-Dichlorofluorescein no comprimento de onda de $525 \mathrm{~nm}$. 169

Figura 93 - Diagrama de ligação do sistema de detecção de $\mathrm{O}_{2}$ e $\mathrm{NO}_{2}$ com base em dispositivo óptico MMCS6CS para medidas de intensidade luminosa 
(VRMs) e fase (graus) realizadas por aplicativo LOCK-IN desenvolvido em placa de aquisição embarcada NI myRIO-1900.

Figura 94 - Perfil de deposição de membrana ativa de PtOEP imobilizada em matriz hospedeira de policloreto de vinila (PVC).

Figura 95 - Diagrama esquemático do arranjo do sistema de diluição de gases de $\mathrm{O}_{2}$ e $\mathrm{NO}_{2}$ e do sistema de aquisição, controle e processamento de sinais provenientes do sensor multiespectral (MMCS6CS). 178

Figura 96 - Curvas de respostas normalizadas do filme ativo de PtOEP imobilizado em matriz hospedeira de policloreto de vinila (PVC) depositados sobre dispositivo multiespectral (MMCS6CS) em diferentes concentrações de oxigênio em nitrogênio.

Figura 97 - Curvas de respostas normalizadas do filme ativo de PtOEP imobilizado em matriz hospedeira de policloreto de vinila (PVC) depositados sobre dispositivo multiespectral (MMCS6CS) em diferentes concentrações de dióxido de nitrogênio em nitrogênio.

Figura 98 - a) Derivada das curvas de resposta de saída do dispositivo multiespectral para medidas de INTENSIDADE (V $\mathrm{V}_{\mathrm{RMS}}$ ); b) Curvas da derivada de resposta à presença de diferentes concentrações de $\mathrm{NO}_{2}$ em $\mathrm{N}_{2}$; c) Curvas da derivada de resposta à presença de diferentes concentrações de $\mathrm{O}_{2}$ em $\mathrm{N}_{2}$. 182

Figura 99 - a) Derivada das curvas de resposta de saída do dispositivo multiespectral para medidas de FASE (graus); b) Curvas da derivada de resposta à presença de diferentes concentrações de $\mathrm{NO}_{2}$ em N2; c) Curvas da derivada de resposta à presença de diferentes concentrações de $\mathrm{O}_{2}$ em N2. 183

Figura 100 - Resposta dinâmica do dispositivo MMCS6CS com estrutura MAZeT/PVC(PtOEP) na presença de diferentes concentrações de $\mathrm{O}_{2}$ 184

Figura 101-Resposta dinâmica do dispositivo MMCS6CS com estrutura MAZeT/PVC(PtOEP) na presença de diferentes concentrações de $\mathrm{NO}_{2}$... 185 


\section{LISTA DE TABELAS}

Tabela 1 - Parâmetros de configuração do fluorímetro para obtenção do espectro de fotoluminescência das amostras.

Tabela 2 - Taxa Io/l relacionada a $0 \%$ e $100 \%$ ou $50 \%$ de concentração de $\mathrm{O}_{2}$ e os coeficientes de Stern-Volmer.

Tabela 3 - Modelo de ajuste polinominal de $2^{\mathrm{a}}$ ordem (válido para os primeiros 60 min de ensaio). 71

Tabela 4 - Modelo de ajuste linear (válido para os primeiros 60 min de ensaio)...71

Tabela 5 - Modelo de ajuste polinominal de $2^{\mathrm{a}}$ ordem (válido para os primeiros 60 min de ensaio.

Tabela 6 - Valores de Stern-Volmer para as duas condições de ensaios $\left(\mathrm{O}_{2}\right.$ gasoso e OD em $\mathrm{H}_{2} \mathrm{O}-\mathrm{DI}$ ). .75

Tabela 7 - Parâmetros de ajuste exponencial para a curva de calibração de resposta do capacitor MOS a diferentes concentrações de oxigênio...90

Tabela 8 - Parâmetros de ajuste exponencial para a curva de resposta do sensor TAOS/PVC(PtOEP) de filtros vermelhos.

Tabela 9 - Parâmetros de ajuste exponencial para a curva de resposta do sensor TAOS/PS(PtOEP) de filtros vermelhos. 102

Tabela 10 - Parâmetros de ajuste exponencial para a curva de resposta do sensor TAOS/PVC(PtOEP) de filtros vermelhos. 103

Tabela 11 - Parâmetros de ajuste exponencial para a curva de resposta do sensor TAOS/PS(PtOEP) de filtros vermelhos. 104

Tabela 12 - Fatores dos estágios de amplificação e seus respectivos códigos de seleção.

Tabela 13 - Valores de pH das soluções iônicas preparadas para os ensaios de colorimetria 132

Tabela 14 - Parâmetros dos ajustes exponenciais das curvas de calibração de respostas obtidas pelo fluorímetro em diferentes concentrações dos íons de metais pesados no comprimento de onda de $675 \mathrm{~nm}$. 160

Tabela 15 - Parâmetros dos ajustes exponenciais das curvas de calibração de respostas $V_{\text {RMS }}$ obtidas pelo sensor multiespectral em diferentes 
concentrações dos íons de metais pesados na saída de comprimento de onda de $675 \mathrm{~nm}$.

Tabela 16 - Parâmetros dos ajustes exponenciais das curvas de calibração de respostas de fase obtidas pelo sensor multiespectral em diferentes concentrações dos íons de metais pesados na saída de comprimento de onda de $675 \mathrm{~nm}$. 163

Tabela 17 - Parâmetros dos ajustes exponenciais das curvas de calibração de respostas obtidas pelo fluorímetro em diferentes concentrações dos íons de metais pesados no comprimento de onda de $525 \mathrm{~nm}$. 167

Tabela 18 - Parâmetros dos ajustes exponenciais das curvas de calibração (VRMs) de respostas obtidas pelo sensor multiespectral MMCS6CS em diferentes concentrações dos íons de metais pesados no comprimento de onda de $525 \mathrm{~nm}$. 168

Tabela 19 - Parâmetros dos ajustes exponenciais das curvas de calibração (fase) de respostas obtidas pelo sensor multiespectral MMCS6CS em diferentes concentrações dos íons de metais pesados no comprimento de onda de $525 \mathrm{~nm}$. 169 


\section{LISTA DE SÍMBOLOS, SIGLAS E ABREVIATURAS}

A: $\quad$ Medida de absorbância.

AC: $\quad$ Corrente alternada.

$\mathrm{Ag}^{+}$: ĺon de prata.

Al: $\quad$ Entrada analógica.

ANA: Agência Nacional das Águas.

AO: $\quad$ Saída analógica.

ASV: $\quad$ Anodic Stripping Voltammetry.

Av: $\quad$ Ajuste de ganho de tensão.

$\mathrm{Cd}^{2+}: \quad$ Ín de cádmio.

$\mathrm{CdCl}_{2}$ : $\quad$ Cloreto de cádmio.

CEPEMA: Centro de Capacitação e Pesquisa em Meio Ambiente.

CETESB: $\quad$ Companhia de Tecnologia de Saneamento Ambiental do Estado de São Paulo.

C: $\quad$ Concentração molar da espécie química.

$\mathrm{CH}_{3} \mathrm{OH}: \mathrm{H}_{2} \mathrm{O}$ : Solução de metanol e água na proporção 1:1.

Cl: $\quad$ Circuito integrado.

CIE: $\quad$ Comissão Internationale de l'Eclairage.

CMOS: $\quad$ Complementary Metal Oxide Semiconductor.

$\mathrm{Cu}^{2+}$ : $\quad$ ĺon de cobre.

CV-AAS: $\quad$ Espectrometria de absorção atômica de vapor frio.

$\mathrm{Cr}^{6+}$ : $\quad$ ĺon de cromo.

CSV: $\quad$ Adsorptive Cathodic Stripping Voltammetry.

CuSO4: Sulfato de cobre.

DC: $\quad$ Corrente direta ou contínua.

DDS: $\quad$ Direct Digital Synthesis.

DI: Deionizada.

DNA: Ácido desoxirribonucléico.

DOS: $\quad$ Bis(2-ethylhexyl) sebacate.

$\varepsilon: \quad$ Absorvidade molar.

EDTA: Ácido de etilenodiaminotetracético. 
E/S: $\quad$ Entrada/Saída.

EPUSP: $\quad$ Escola Politécnica da Universidade de São Paulo.

фo: $\quad$ Intensidade de luz emitida pelas moléculas de PtOEP.

f: $\quad$ Frequência de modulação da luz.

$\mathrm{Fe}^{3+}$ : $\quad$ ĺon de ferro.

$\mathrm{FeN}_{3} \mathrm{O}_{9} \quad$ Nitrato de ferro III.

FED: $\quad$ Dispositivos de efeito de campo.

FEM: $\quad$ Força eletromotriz.

FER: $\quad 3$-(2-pyridyl)-5,6-diphenyl-1,2,4-triazine-4',4"-disulfonic acid sodium salt.

FPGA: $\quad$ Field Programmable Gate Array.

GF-AAS: $\quad$ Espectrometria de absorção atômica com forno de grafite.

GND: $\quad$ Potencial de referência - 0 (zero) Volts.

$\mathrm{H}_{2} \mathrm{SO}_{4}$ : $\quad$ Ácido sulfúrico.

H2tpp: $\quad$ 5,10,15,20-tetrafenilporfirina.

$\mathrm{Hg}^{2+}$ : $\quad$ ĺon de mercúrio.

HPLC-MS: Cromatografia líquida acoplada à espectrometria de massas.

I: Intensidade fluorescente na presença do supressor.

Iamostra: $\quad$ Corrente gerada pelo fotodiodo de comprimento de onda $\left(\lambda_{n}\right)$

$I^{2} \mathrm{C}: \quad$ Inter-Integrated Circuit.

lo: Intensidade fluorescente na ausência do supressor.

IF: $\quad$ Corrente direta nominal.

Ig: Corrente gerada em um circuito externo pela excitação luminosa em um dispositivo MOS.

li: $\quad$ Intensidade de luz incidente a um dado comprimento de onda.

ILED branco: Corrente gerada pelo fotodiodo de comprimento de onda $(\lambda n)$ sob condição de excitação do LED branco.

It: Intensidade de luz transmitida.

ICP-AES: Espectrometria de emissão atômica com plasma indutivamente acoplado.

ICP-MS: $\quad$ Espectrometria de massa com plasma indutivamente acoplado.

ICP-OES: Espectrometria de emissão óptica com plasma indutivamente acoplado. 
ISFET: Ion-Sensitive Field-Effect Transistor.

$\mathrm{K}^{+}$: $\quad$ Ín de potássio.

$\mathrm{K}_{\mathrm{q}}$ : $\quad$ Constante de supressão bimolecular.

Ksv: $\quad$ Constante global de supressão (Stern-Volmer).

I: $\quad$ Distância do caminho óptico.

$\lambda$ : $\quad$ Comprimento de onda da luz.

$\lambda_{\text {em: }} \quad$ Comprimento de onda de emissão.

$\lambda_{\text {exc: }} \quad$ Comprimento de onda de excitação.

$\lambda_{n}$ : $\quad$ Saídas de respostas dos fotodiodos com os filtros ópticos de 425, 475, $525,575,625$ e $675 \mathrm{~nm}$ integrados ao sensor multiespectral MMCS6CS - MAZeT.

Lw: $\quad$ Espectro de luz incidente.

LAPS: $\quad$ Sensores potenciométricos de luz endereçável.

LED: $\quad$ Diodo emissor de luz.

$\mathrm{Li}^{+}$: $\quad$ ĺon de lítio.

LME: $\quad$ Laboratório de Microeletrônica.

$\quad \quad \mu T A S: \quad$ Micro total analysis system.

$\mathrm{Mg}^{2+}$ : $\quad$ Íon de magnésio.

MLAPS: $\quad$ Sensor potenciométrico de luz endereçável de múltipla detecção.

MFC: $\quad$ Mass Flow Controller.

MOS: Metal-Óxido-Semicondutor.

$\mathrm{Na}^{+}: \quad$ ĺon de sódio.

$\mathrm{N}_{2}$ : $\quad$ Nitrogênio.

$\mathrm{NaOH}: \quad$ Hidróxido de sódio.

NI: National Instruments.

$\mathrm{NiCl}_{2}$ : Cloreto de níquel.

$\mathrm{Ni}^{2+}: \quad$ Ín de níquel.

$\mathrm{NO}_{2}: \quad$ Dióxido de nitrogênio.

$\mathrm{O}_{2}: \quad$ Oxigênio.

${ }^{1} \mathrm{O}_{2}$ : Oxigênio singlete.

OD: Oxigênio dissolvido.

PMÁx: $\quad$ Potência máxima.

PAN: 1- (2-Pyridylazo) -2-naphthol. 
PAR: (2-pyridylazo) resorcinol.

$\mathrm{Pb}^{2+}: \quad$ Ín de chumbo.

$\mathrm{Pb}\left(\mathrm{NO}_{3}\right)_{2}$ : $\quad$ Nitrato de chumbo.

PET: $\quad$ Polietileno tereftalato.

pH: Potencial hidrogeniônico.

PLD: $\quad$ Deposição por Laser Pulsado.

PS: Poliestireno.

PSD: $\quad$ Detector sensível à fase.

PtOEP: Octaetilporfirina de platina.

PVC: $\quad$ Poly(vinyl chloride) - Poli(cloreto de vinila).

PW: $\quad$ Sinal de saída de intensidade luminosa do fotodiodo sem filtro do sensor multiespectral MAZeT MMCS6CS.

PWM: $\quad$ Pulse Width Modulation.

q: $\quad$ Carga do elétron.

Q: $\quad$ Supressor fotoluminescente.

[Q]: $\quad$ Concentração do supressor fotoluminescente.

R: $\quad$ Fator de amplificação do transimpedância.

RGB: Red, Green e Blue.

RPM: $\quad$ Rotações por minuto.

RT: $\quad$ Real Time.

$\mathrm{Si}_{3} \mathrm{~N}_{4}: \quad$ Nitreto de silício.

SIM: $\quad$ Grupo de Sensores Integráveis e Microssistemas.

SINGREH: Sistema Nacional de Gerenciamento de Recursos Hídricos.

$\mathrm{SiO}_{2}$ : $\quad$ Dióxido de silício.

Si-p: $\quad$ Lâmina de silício tipo $p$.

SnO: $\quad$ Óxido de estanho.

SPI: $\quad$ Serial Peripheral Interface.

SYNC: $\quad$ Sinal de sincronismo.

$\tau$ : $\quad$ Tempo de decaimento luminescente na presença do supressor.

to: $\quad$ Tempo de decaimento luminescente na ausência do supressor.

$\theta: \quad$ Fase do sinal emitido na presença do supressor.

$\theta_{0}$ : $\quad$ Fase do sinal emitido na ausência do supressor. 
T: $\quad$ Coeficiente de transmitância na presença de íons metálicos em solução.

To: $\quad$ Coeficiente de transmitância na ausência de íons metálicos em solução.

TAN: $\quad$ 1- (2-thiazolylazo) -2-naphtol.

TBHPP: $\quad$ 5,10,15,20-tetra- (3-bromo-4-hydroxyphenyl) porphyrin.

THF: Tetrahidrofurano.

THPP: $\quad$ 5,10,15,20-tetrakis (hydroxylphenyl) porphyrin.

TTL: $\quad$ Transistor-Transistor Logic.

UART: $\quad$ Universal Asynchronous Receiver/Transmitter.

UV: $\quad$ Ultravioleta.

VDD: $\quad$ Tensão de alimentação DC do amplificador de transimpedância.

VHDL: Hardware Description Language.

VI: $\quad$ Virtual Instruments.

VIN: $\quad$ Tensão de entrada.

Vpp: $\quad$ Tensão de pico a pico.

Vout: $\quad$ Tensão de saída do amplificador de transimpedância MTI04CS MAZeT.

VREF: $\quad$ Tensão de referência de entrada utilizada para deslocamento da tensão de saída do amplificador de transimpedância MTI04CSMAZeT.

VRMS: $\quad$ Tensão eficaz.

$\mathrm{x}: \quad$ Coordenada de cromaticidade.

Y: Luminância.

$\mathrm{Zn}^{2+}: \quad \quad$ ĺon de zinco.

ZnSO $4: \quad$ Sulfato de zinco. 


\section{SUMÁRIO}

Prefácio

Capítulo 1

1. Introdução

1.1. Sensores de detecção de íons de metais pesados .33

1.2. Sensores para detecção de oxigênio e oxigênio dissolvido ........................38

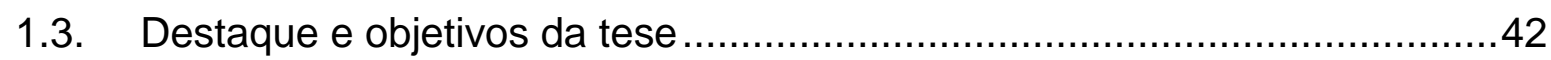

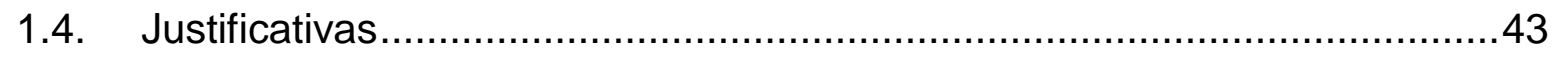

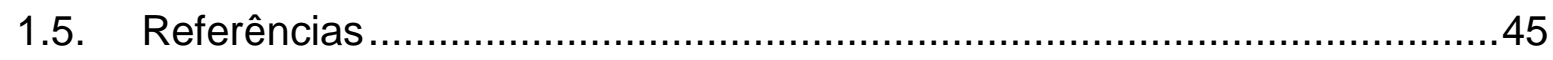

Capítulo 2 .52

2. Sensores de Oxigênio e Oxigênio Dissolvido Baseados na Emissão Fotoluminescente de Corante de Octaetilporfirina de Platina Imobilizados em Filmes Finos de Silício Poroso Oxidado e Poliestireno.....................................52

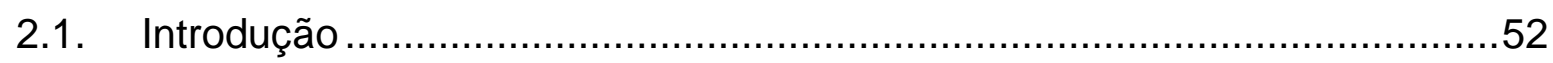

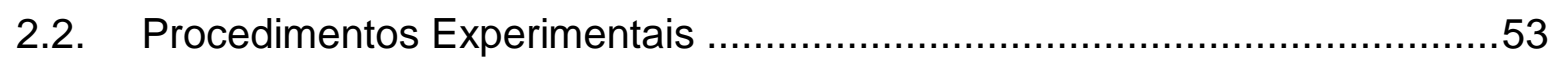

2.2.1. Preparação dos substratos de vidro para deposição de matriz polimérica de Octaetilporfirina de Platina - PtOEP e fabricação de dispositivo de estrutura

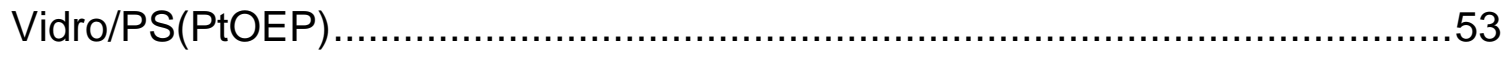

2.2.1.1. Diluição das moléculas de PtOEP no poliestireno............................54

2.2.1.2. Deposição da matriz polimérica sobre as lâminas de vidro...............54

2.2.2. Fabricação dos sensores ópticos de Si-p com matriz de silício poroso para

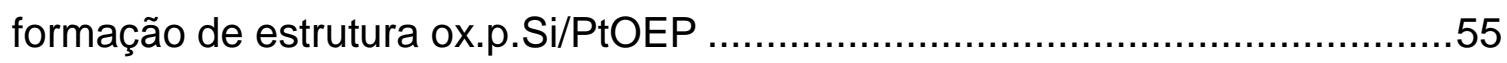

2.2.2.1. Preparo de solução de PtOEP e deposição sobre as lâminas $L 55$ e $L$

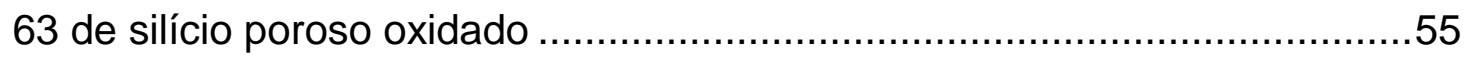

2.2.3. Sistema de diluição dos gases de $\mathrm{O}_{2}$ e $\mathrm{N}_{2}$ para controle de oxigênio diluído

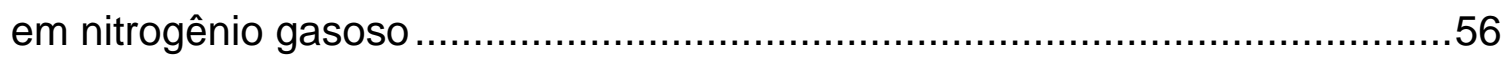

2.2.4. Sistema de controle de oxigênio dissolvido em água deionizada............57 
2.2.5. Arranjo experimental do sistema de medida do tempo de resposta e regeneração dos dispositivos para ambientes líquidos

2.2.6. Câmara de ensaios para montagem dos sensores para teste em ambientes gasosos e líquidos 60

2.2.7. Medidas de fluorescência

2.3. Resultados e Discussões .63

2.3.1. Emissão luminescente da molécula de PtOEP em substratos de vidro e silício poroso 63

2.3.2. Análise de resposta de sensibilidade dos sensores Vidro/PtOEP/PS e ox.p.Si/PtOEP em ambientes de $\mathrm{O}_{2}$.

2.3.3. Resposta dinâmica dos dispositivos Vidro/PtOEP/PS (3000 RPM) e ox.p.Si/PtOEP $(\mathrm{L} 55)$ para ambiente de $\mathrm{O}_{2}$ e inerte $\left(\mathrm{N}_{2}\right)$.

2.3.4. Efeitos de fotodegradação das moléculas de PtOEP para ambientes oxigenados nos dispositivos de Vidro/PtOEP/PS (3000 RPM) e ox.p.Si/PtOEP (L 55) .70

2.3.5. Análise de resposta de sensibilidade dos sensores Vidro/PtOEP/PS e ox.p.Si/PtOEP ao oxigênio dissolvido em água deionizada (OD em $\left.\mathrm{H}_{2} \mathrm{O}-\mathrm{DI}\right)$....73 2.3.6. Resposta dinâmica dos dispositivos Vidro/PtOEP/PS (3000 RPM) e ox.p.Si/PtOEP ( $L 55$ ) ao oxigênio dissolvido em água deionizada (OD em $\mathrm{H}_{2} 0$ DI) .76

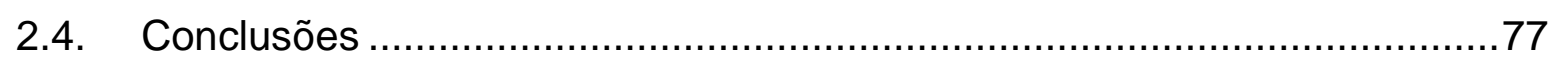

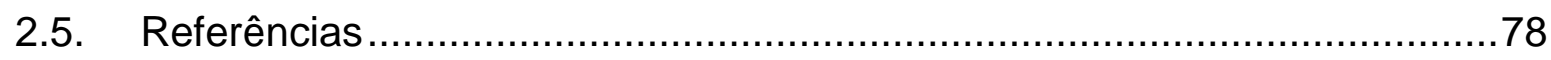

Capítulo 3

3. Capacitor MOS como sensor portátil de detecção de oxigênio 81

3.1. Introdução 81

3.2. Procedimentos Experimentais 82

3.2.1. Fabricação de dispositivo MOS/PS-PET(PtOEP) para medidas de fotoluminescência das moléculas de PtOEP aplicadas na detecção de oxigênio. 82

3.2.1.1. Produção de filme ativo de PET com molécula de PtOEP imobilizada em poliestireno. 
3.2.2. Arranjo experimental de medida de intensidade de fotoluminescência para determinação da concentração de $\mathrm{O}_{2}$ em estrutura MOS/PS-PET(PtOEP) ........85

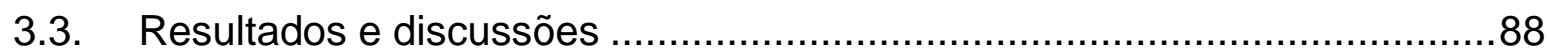

3.3.1. Resposta de sensibilidade do dispositivo MOS/PS-PET(PtOEP) sob diferentes concentrações de $\mathrm{O}_{2}$ em $\mathrm{N}_{2}$

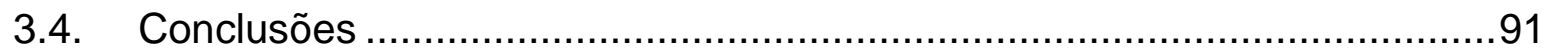

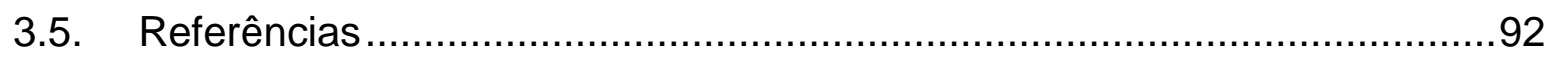

Capítulo 4

4. Sensor portátil de oxigênio e oxigênio dissolvido com uso de detector de cores RGB comercial integrado

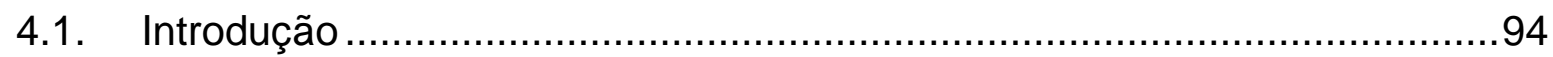

4.2. Procedimentos Experimentais .................................................... 95

4.2.1. Fabricação dos sensores de detecção de $\mathrm{O}_{2}$ e $\mathrm{OD}$ com membranas de $\mathrm{PS}$ e PVC para formação de estruturas TAOS/PS(PtOEP) e TAOS/PVC(PtOEP) ..95 4.2.2. Sistema de diluição dos gases de $\mathrm{O}_{2}$ e $\mathrm{N}_{2}$ para ensaios de sensibilidade de $\mathrm{O}_{2}$ e $\mathrm{OD}$ e arranjo experimental de medida de intensidade de fotoluminescência dos dispositivos de estruturas TAOS/PS(PtOEP) e

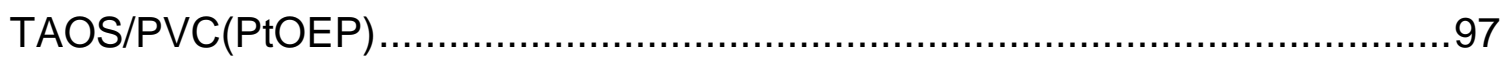

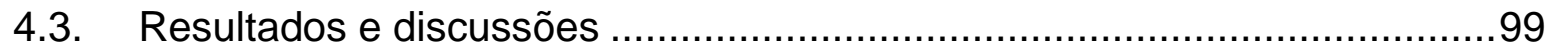

4.3.1. Análise de resposta dos sensores de TAOS/PS(PtOEP) e

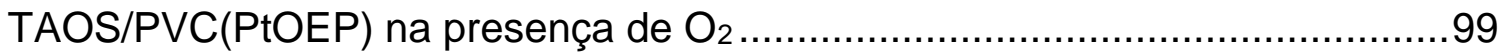

4.3.2. Respostas dos dispositivos TAOS/PS(PtOEP) e TAOS/PVC(PtOEP) na presença de diferentes concentrações de OD. ..........................................102

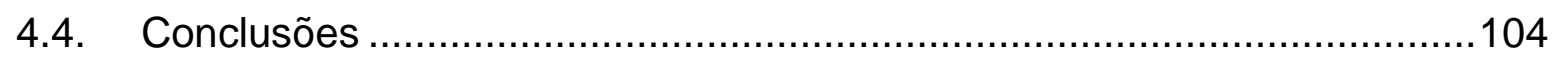

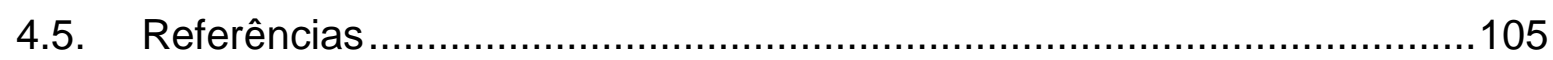

Capítulo 5 107

5. Sistema portátil colorimétrico e fluorimétrico para detecção de íons de metais pesados em meios líquidos. ..............................................................107

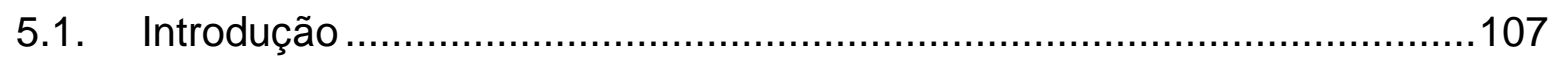


5.2. Procedimentos Experimentais 108

5.2.1. Desenvolvimento de sistema eletrônico multifuncional colorimétrico e fluorimétrico de detecção portátil de gases, oxigênio dissolvido e íons de metais pesados. 108

5.2.1.1. Sensor de Cor Multiespectral de 6 canais - MAZeT 110

5.2.1.2. Módulo amplificador de transimpedância de 16 canais com ganho programável.

5.2.1.3. Circuito multiplexador de 32 canais para seleção de sinais provenientes de sensores MMCS6CS - MAZeT

5.2.1.4. Módulo gerador de função e condicionamento de sinais de 4 canais para excitação luminosa de diodos emissores de luz (LED) 116

5.2.1.5. Sistema de aquisição, controle e processamento de sinais provenientes de sensor multiespectral MMCS6CS - MAZeT com uso de amplificador LOCK-IN digital 119

5.2.2. Sistema embarcado portátil de detecção de íons de metais pesados por métodos colorimétricos e uso de sensor óptico multiespectral

5.2.2.1. Arranjo experimental colorimétrico com uso sensor multiespectral MMCS6CS

5.2.2.2. Reagentes e materiais - 1-(2-pyridylazo)-2-naphthol (PAN) 132 5.2.3. Sistema embarcado portátil de detecção de íons de metais pesados por métodos fluorimétricos e uso de sensor óptico multiespectral 132

5.2.3.1. Reagentes e materiais - Síntese e caracterização do tetra-(3-bromo4-hidroxifenil)-porfirina (TBHPP). 135

5.2.3.2. Reagentes e materiais - 2,7-Dichlorofluorescein 138

5.3. Resultados e Discussões 139

5.3.1. Análise de resposta de sensibilidade do sensor Multiespectral MMCS6CS na detecção de íons de metais pesados de $\mathrm{Pb}^{2+}, \mathrm{Cd}^{2+}, \mathrm{Zn}^{2+}, \mathrm{Cu}^{2+}, \mathrm{Fe}^{3+}, \mathrm{Ni}^{2+}$ pelo método colorimétrico e uso de reagente cromógeno de 1-(2-pyridylazo)-2naphthol (PAN) 139

5.3.2. Análise de resposta de sensibilidade do sensor Multiespectral MMCS6CS na detecção de íons de metais pesados de $\mathrm{Pb}^{2+}, \mathrm{Ni}^{2+}, \mathrm{Cd}^{2+}$ e $\mathrm{Zn}^{2+}$ pelo método fluorimétrico e uso de reagente fluoróforo de tetra-(3-bromo-4-hidroxifenil)porfirina (TBHPP) 156 
5.3.3. Análise de resposta de sensibilidade do sensor Multiespectral MMCS6CS na detecção de íons de metais pesados de $\mathrm{Pb}^{2+}, \mathrm{Ni}^{2+}, \mathrm{Cd}^{2+}, \mathrm{Zn}^{2+}$ e $\mathrm{Cu}^{2+}$ pelo método fluorimétrico e uso de reagente fluoróforo de 2,7-Dichlorofluorescein 163

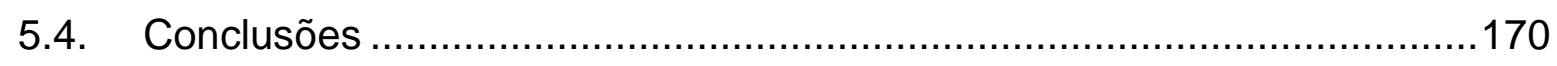

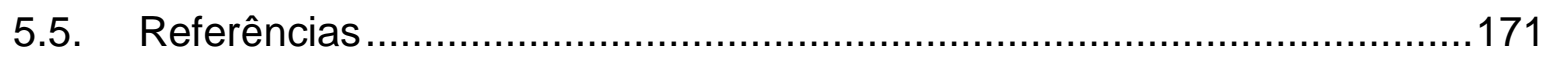

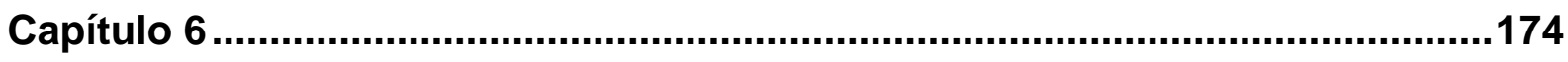

6. Sensor Óptico Multiespectral Integrado para Detecção de $\mathrm{O}_{2}$ e $\mathrm{NO}_{2} \ldots . . . . .174$

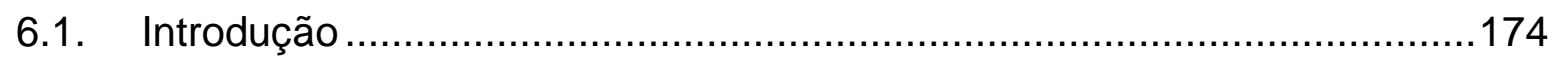

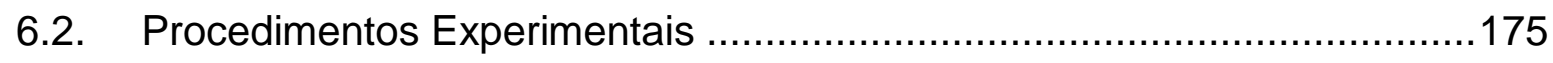

6.2.1. Sistema de Detecção de $\mathrm{O}_{2}$ e $\mathrm{NO}_{2}$ e Fabricação do Sensor Multiespectral com Membrana de PtOEP imobilizada em PVC .........................................175 6.2.2. Sistema de diluição dos gases de $\mathrm{O}_{2}$ e $\mathrm{NO}_{2}$ em $\mathrm{N}_{2}$ para ensaios de

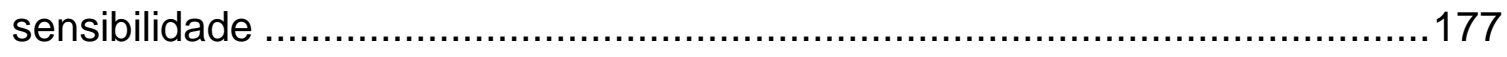

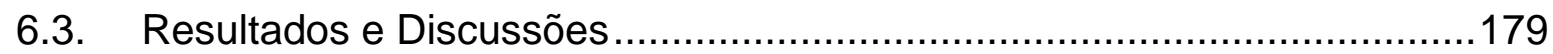

6.3.1. Análise de Resposta de Sensibilidade do Sensor Multiespectral MAZeT/PVC(PtOEP) na Presença de $\mathrm{O}_{2}$ e $\mathrm{NO}_{2}$ em N2 ..............................179

6.3.2. Resposta dinâmica do dispositivo MMCS6CS com estrutura de MAZeT/PVC(PtOEP) na presença de diferentes concentrações de $\mathrm{O}_{2}$ e $\mathrm{NO}_{2} 184$

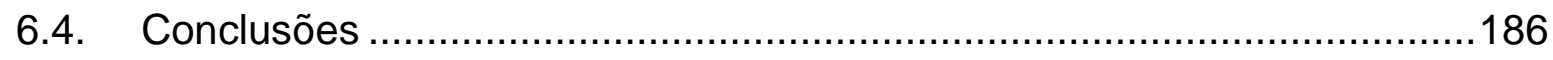

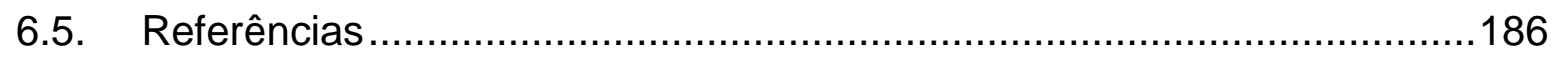

7. Conclusões e Perspectivas Futuras ..........................................................188 


\section{Prefácio}

A tese apresenta contribuições científicas e técnicas relevantes no desenvolvimento de sistemas optoeletrônicos portáteis de detecção de gases, oxigênio dissolvido e íons de metais pesados $\left(\mathrm{Pb}^{2+}, \mathrm{Cd}^{2+}, \mathrm{Zn}^{2+}, \mathrm{Cu}^{2+}, \mathrm{Fe}^{3+}\right.$ e $\left.\mathrm{Ni}^{2+}\right)$ com uso de reagentes cromógenos e fluoróforos dissolvidos em solventes orgânicos, ou imobilizados em matrizes hospedeiras de poliestireno, PVC e silício poroso.

Foram desenvolvidas estratégias e métodos instrumentais dedicados para a detecção, classificação e quantificação dos meios sob análise, baseados em princípios de medição por colorimetria, fluorimetria, processamento de sinais e métodos de reconhecimento de padrões, tendo como referências comparativas os mais atuais métodos utilizados nos tradicionais laboratórios industriais e de pesquisas empregados na detecção analítica de íons metálicos.

Procedimentos e métodos de preparo de soluções, síntese de reagentes e tecnologias de imobilização de corantes ativos de porfirinas foram descritos e empregados na funcionalização de sensores em substrato de vidro, silício semicondutor, sensores optoeletrônicos comerciais (RGBs) e multiespectrais.

Toda a tecnologia de quantificação e classificação dos íons de metais pesados com uso de sensores optoeletrônicos multiespectrais foi totalmente integrada a um hardware embarcado com tecnologia FPGA (Field Programmable Gate Array) e softwares baseados em instrumentação virtual (NI LabView®) para monitoramento contínuo on line e in loco, sugerindo o seu uso em aplicações no monitoramento de efluentes de rios, estuários, praias e mares.

O projeto foi desenvolvido com recursos disponíveis dentro do grupo de "Sensores Integráveis e Microssistemas" (SIM) do Laboratório de Microeletrônica (LME), da Escola Politécnica da Universidade de São Paulo (EPUSP), Instituto Federal de São Paulo, campus Cubatão-SP, e no Centro de Capacitação e Pesquisa em Meio Ambiente - CEPEMA-USP, localizado na cidade de Cubatão-SP.

Sob condições de colaboração conjunta para a produção de artigos em desenvolvimento tecnológico, o presente trabalho contou com a parceria da empresa alemã MAZeT GmbH para o fornecimento de todos os dispositivos ópticos multiespectrais e acessórios para a conclusão da tese. 
A tese contou também com a contribuição das pesquisadoras Daniela de Souza Dairiki e Paula Larangeira Garcia Martins que desenvolveram o aplicativo LOCK IN digital para myRIO-1900 (National Instruments) e a síntese do reagente 5,10,15,20-tetra-(3bromo-4-hidroxifenil)-porfirina (TBHPP), respectivamente.

Os detalhes e as discussões dos resultados atingidos na presente tese foram sistematicamente organizados em seis capítulos.

No capítulo 1 são apresentadas as justificativas, técnicas e relatos dos princípios de medição e quantificação de oxigênio dissolvido e íons de metais pesados, com a utilização de membranas de reagentes cromógenos e fluoróforos dissolvidos em solventes orgânicos e vidros calcogenetos depositados sobre dispositivos semicondutores.

Em sequência, no capítulo 2, sensores fotoluminescentes de oxigênio $\left(\mathrm{O}_{2}\right)$ e oxigênio dissolvido (OD) foram implementados, com a utilização de moléculas de octaetilporfirina de platina (PtOEP), imobilizadas em matrizes hospedeiras de substratos de silício poroso oxidado e poliestireno em vidro. A detecção das concentrações de $\mathrm{O}_{2}$ e $\mathrm{OD}$ foi obtida pelo monitoramento das intensidades de fluorescência, através do uso de um fluorímetro, verificando-se condições de sensibilidade em uma ordem de grandeza maior para a matriz de silício poroso quando comparada à matriz de poliestireno em vidro. Foram apresentados também os métodos, estratégias e a instrumentação de controle de diluição dos gases de $\mathrm{O}_{2}$ em $\mathrm{N}_{2}$ e do processo de obtenção de diferentes concentrações de oxigênio dissolvido em água deionizada (DI) para medidas de sensibilidade, fotodegradação e tempo de resposta dos dispositivos. Os resultados e o estudo do comportamento óptico da molécula de porfirina de PtOEP nos ensaios indicaram total compatibilidade do seu uso de forma imobilizada em matrizes hospedeiras para aplicações em sistemas de detecção portáteis.

No capítulo 3, é apresentado o desenvolvimento de um sistema portátil de detecção de $\mathrm{O}_{2}$, baseado em um capacitor MOS fabricado em sala limpa, e utilizado como fotodetector, em comprimentos de onda na região do vermelho (640nm). A parte ativa do sensor foi integrada a uma membrana de polietileno tereftalato (PET) e poliestireno, com moléculas de PtOEP incorporadas, indicando a viabilidade construtiva para aplicações em sistemas de monitoramento ambiental. São descritos o princípio de funcionamento de detecção e a instrumentação utilizada nos ensaios de sensibilidade ao $\mathrm{O}_{2}$. 
No capítulo 4, sensores optoeletrônicos comerciais de detecção de cores (RGB) foram utilizados como elementos detectores portáteis de $\mathrm{O}_{2}$ e OD. As superfícies dos sensores foram recobertas com matrizes hospedeiras de poliestireno e PVC. Os resultados dos ensaios de sensibilidade mostram diferentes faixas de trabalho para as matrizes utilizadas, isso sugere possíveis diferenças nos mecanismos de adsorção do $\mathrm{O}_{2}$ sobre as superfícies ativas. Adicionalmente, a presença de filtros ópticos seletivos integrados ao sensor RGB possibilita sensibilidades de detecção de comprimentos de onda diferentes da faixa do vermelho, o que mostra grande potencial de utilização de moléculas com emissões fotoluminescentes na região do azul e verde para detecção de vários tipos de gases e compostos químicos.

No capítulo 5, é apresentado um sistema multifuncional colorimétrico e fluorimétrico de detecção portátil de íons de metais pesados $\left(\mathrm{Pb}^{2+}, \mathrm{Cd}^{2+}, \mathrm{Zn}^{2+}, \mathrm{Cu}^{2+}, \mathrm{Fe}^{3+}\right.$ e $\left.\mathrm{Ni}^{2+}\right)$ em meios líquidos, com uso de reagentes cromógenos e fluoróforos dissolvidos em solventes orgânicos. Foi implementada uma instrumentação com características de operação independente e portátil que indicou possibilidades de sua utilização em um sistema "nariz ou língua optoeletrônica" composto de matriz de sensores multiespectrais funcionalizados com membranas seletivas a gases tóxicos, compostos químicos, $\mathrm{pH}$, oxigênio dissolvido e íons de metais pesados, aplicados em monitoramento ambiental.

Finalmente, no capítulo 6, é apresentada uma aplicação do sistema de monitoramento portátil, descrito no capítulo 5, para detecção dos gases de $\mathrm{O}_{2}$ e $\mathrm{NO}_{2}$. A molécula seletiva de PtOEP foi imobilizada em matriz hospedeira de PVC, sendo integrada diretamente na superfície do sensor multiespectral. Foram realizados ensaios para a determinação do tempo de resposta e sensibilidade, utilizando métodos de quantificação das concentrações dos gases pelas análises das respostas de intensidade de fluorescência ( $V_{\text {RMS }}$ ) e fase (graus). Os resultados mostraram o potencial do sistema de detecção multiespectral desenvolvido também para análise de gases. 


\section{Capítulo 1}

\section{Introdução}

Essencial à vida, a água constitui um bem precioso e necessário para quase todas as atividades do ser humano. De uma simples gota de orvalho à composição de uma paisagem, a água permite a geração de energia elétrica, o abastecimento necessário para o uso doméstico e produção industrial, a irrigação de plantações agrícolas, além de servir como via de transporte de produtos e commodities em rios e mares.

No Brasil, desde 1997, foi instituída a "Lei das Águas" (Lei n 9.433/1997), que estabeleceu a Política Nacional de Recursos Hídricos e criou o Sistema Nacional de Gerenciamento de Recursos Hídricos (SINGREH), com o intuito de coordenar e gerir administrativamente o uso responsável das águas para garantir a preservação e a recuperação dos recursos hídricos no país. Foi então, que a partir do ano 2000, com a criação da Agência Nacional das Águas (ANA), consolidou-se um mecanismo de fiscalização, avaliação e controle de ações relacionadas ao uso sustentável das águas de domínio da União. Atualmente, a ANA oferece dentre o rol de serviços prestados, atividades de monitoramento de variáveis de nível e vazão dos rios, quantidade de sedimentos, indicativos de qualidade das águas, bem como da situação das chuvas em bacias brasileiras.

No Estado de São Paulo, além dos procedimentos de análise e identificação de poluentes realizados pela ANA, a CETESB (Companhia de Tecnologia de Saneamento Ambiental do Estado de São Paulo) oferece conjuntamente os serviços de avaliação da qualidade das águas subterrâneas e superficiais, através de redes de monitoramento distribuídas em diferentes regiões em todo o Estado.

Apesar dos esforços empenhados pelos órgãos de controle e proteção ambiental, o crescimento desordenado na elaboração, fabricação e aplicação de produtos químicos, observado nas últimas décadas, tem sido causa de sérios e reincidentes casos de contaminação do meio ambiente, comprometendo diretamente a saúde da população situada nos grandes centros urbanos.

Dessa forma, a utilização de instrumentos analíticos associados a procedimentos e métodos experimentais de detecção de $\mathrm{pH}$, oxigênio dissolvido (OD) e íons de metais 
pesados, aparece como alternativa aos tradicionais métodos e equipamentos laboratoriais comumente empregados pelos centros reguladores nas análises de contaminantes ambientais em meios aquáticos.

Com exceção dos instrumentos de medição de pH e OD, os equipamentos para determinação de concentrações da ordem de submicrogramas de metais pesados são extremamente caros, requerem custos elevados de operação e manutenção periódica, necessitam de condições experimentais bem controladas, além de possuírem etapas complicadas do processo de pré-tratamento das amostras. Segundo reportado na literatura (PRESTEL; GAHR; NIESSNER, 2000; PINHEIRO, et al., 2010), os equipamentos mais utilizados para esta finalidade são: espectrometria de emissão atômica com plasma indutivamente acoplado (ICP-AES), espectrometria de emissão óptica com plasma indutivamente acoplado (ICP-OES), espectrometria de massa com plasma indutivamente acoplado (ICP-MS), espectrometria de absorção atômica de vapor frio (CV-AAS), espectrometria de absorção atômica com forno de grafite (GF-AAS), dentre outros. Em contraste, os métodos de detecção de íons de metais pesados baseados em sensores eletroquímicos íon-seletivos (VASILEV; RADONOVA; BOYCHEVA, 2012), sensores potenciométricos de luz endereçável (LAPS) (LI et al., 2009), e ópticos fluorescentes e colorimétricos (KIM et al., 2012), oferecem vantagens diferenciadas em termos de sensibilidade, seletividade, tempo de resposta, medição in loco, dentre outras. Além disso, nos casos de detecção remota, é possível o uso de fibras ópticas como dispositivos analíticos miniaturizados, imobilizadas na ponta de uma sonda (WANG; WOLFBEIS, 2013), por exemplo. Portanto, esforços consideráveis estão sendo realizados para o desenvolvimento de instrumentação analítica, baseado em conceitos de utilização in loco e portátil para a detecção de íons catiônicos, pH e OD.

Mais de trinta anos se passaram desde que Bergveld, em sua pesquisa, apresentou estudos sobre sistemas biológicos utilizando estruturas ISFET - Ion-Sensitive FieldEffect Transistor (BERGVELD, 1970). Desde então, variados dispositivos de efeito de campo baseados em semicondutores (FEDs) foram desenvolvidos e aplicados a macromoléculas carregadas, tais como camadas de polieletrólito ou DNA (ácido desoxirribonucléico) (POGHOSSIAN et al., 2005), células vivas (LEHMANN et al., 2001), receptores ou microorganismos (SCHROTH et al., 2001), vidros calcogenetos para a detecção de íons de metais pesados (KLOOCK et al., 2006; MILOCHOVA; KASSEM; BYCHKOV, 2013; TUREK et al., 2009), dentre outros. Desta forma, a 
combinação dos elementos biológicos e/ou materiais de vidros calcogenetos com tecnologias semicondutoras complexas deu margem a possibilidades na implementação de sistemas biosensores, obtendo-se melhorias na sensibilidade e seletividade dos dispositivos. Assim, com a miniaturização dos FEDs e sua compatibilidade com os processos de fabricação de dispositivos semicondutores, foi possível, ainda, a criação de sistemas analíticos miniaturizados, como os $\mu$ TAS (micro total analysis system) (MAIRHOFER; ROPPERT; ERTL, 2009), lab on chip (YAGER et al., 2006) e línguas eletrônicas (WILSON et al., 2012).

Dentro deste contexto, várias pesquisas científicas têm impulsionado o desenvolvimento de sistemas sensores como ferramentas analíticas capazes de fornecer respostas rápidas, confiáveis e com menor custo para detecção de agentes contaminadores do meio ambiente.

Como método analítico alternativo, dispositivo denominado de "língua eletrônica" tem sido aplicado. Um sistema de "língua eletrônica" é formado por uma matriz de sensores e uma unidade de processamento de dados e sinais. O sensor normalmente é formado por membranas de materiais que permitem a seletividade química a diferentes elementos em uma amostra. A combinação dos métodos de reconhecimento de padrões unidos a sistemas multissensíveis faz da "língua eletrônica" um instrumento potencial frente aos métodos analíticos de detecção.

\subsection{Sensores de detecção de íons de metais pesados}

Vidros calcogenetos são exemplos de membranas empregadas na detecção de íons de metais pesados $\left(\mathrm{Pb}^{2+}, \mathrm{Cd}^{2+}, \mathrm{Cu}^{2+}, \mathrm{Hg}^{2+}\right.$ etc.) em soluções aquosas, como sistemas "línguas eletrônicas" (MEN, et al., 2005). Essa tecnologia de filmes de vidros, combinada a métodos de produção de dispositivos de tecnologia planar do silício, permitiu a criação de uma nova geração de sensores baseados na deteç̧ão de íons, abrindo perspectivas para o desenvolvimento de sistemas analíticos para a detecção de íons de metais pesados.

Vlasov e Bychkov (1987) propuseram em seu trabalho, a ideia original de um eletrodo de vidro calcogeneto para a análise de espécies catiônicas e aniônicas em soluções eletrolíticas. Mais tarde, filmes finos de vidros calcogenetos foram funcionalizados 
como superfícies ativas no desenvolvimento de dispositivos ISFETs, sensíveis a íons de cobre, ferro, chumbo, cromo, cádmio e mercúrio (TARANTOV et al., 1990; VLASOV; BYCHKOV; LEGIN, 1994). Recentes estudos mostram que a técnica de Deposição por Laser Pulsado (PLD) está sendo aplicada para a elaboração de sensores de estado sólido de filmes finos calcogenetos (MOURZINA et al., 2001) e sensores potenciométricos de luz endereçável (LAPS) (KLOOCK, et al., 2006).

Em 2005, Men (MEN, et al., 2005) implementou um tipo de língua eletrônica com base em um arranjo formado por um sensor potenciométrico de luz endereçável de múltipla deteç̧ão de íons de metais pesados (MLAPS), combinando as técnicas Anodic Stripping Voltammetry (ASV) e Adsorptive Cathodic Stripping Voltammetry (CSV). O dispositivo foi construído em substrato de silício, tipo $\mathrm{N}$, com camada isolante de dióxido de silício $\left(\mathrm{SiO}_{2}\right)$, passivada com nitreto $\left(\mathrm{Si}_{3} \mathrm{~N}_{4}\right)$. Essa formação serviu de base para deposição das camadas íon-seletivas. Foram utilizados filmes de vidros calcogenetos sensíveis a $\mathrm{Fe}^{3+}$ e $\mathrm{Cr}^{6+}$, além de uma região limitada e exposta de $\mathrm{Si}_{3} \mathrm{~N}_{4}$ para compensação dos efeitos do $\mathrm{pH}$, durante as medidas das soluções dos íons metálicos.

Utilizando também filmes de vidros calcogenetos dopados, Kloock et al. (2004) propuseram a fabricação de um dispositivo matricial com propriedades eletroquímicas de múltipla seletividade de íons metálicos, aplicando o princípio de medição potenciométrica para detecção de $\mathrm{Pb}^{2+}, \mathrm{Cd}^{2+} \mathrm{e} \mathrm{Cu}^{2+}$. A técnica utilizada consistiu em medir a FEM (força eletromotriz) de uma célula composta de um eletrodo de referência e um eletrodo sensível (medição), à espécie iônica de interesse. O eletrodo de medição foi fabricado em substrato de silício com etapas de produção baseadas em processos de oxidação térmica, litografia e deposição de vidros calcogenetos dopados (Pb-Ag-As-I-S, Cd-Ag-As-I-S e Cu-Ag-As-Se) (KLOOCK et al., 2004).

No campo de dispositivos ópticos, outros princípios de detecções de íons de metais pesados são vastamente reportados na literatura e baseiam-se em métodos convencionais de absorção ou espectroscopia de fluorescência (ENSAFI; FAR; MEGHDADI, 2009; GOSWAMI et al., 2010; KIM et al., 2012; NEUPANE et al., 2011). Estes detectores normalmente utilizam reagentes cromógenos e fluoróforos, como indicadores seletivos iônicos em meios líquidos (GOSWAMI; BARUAH; DAS, 2010; SARKER; ULLAHA, 2013; SRIJARANAI et al, 2011), ou imobilizados em matrizes hospedeiras poliméricas, na formação de filmes finos como superfície ativa (ISLAM; LASKAR; AHMAD, 2010; VUKOVIĆ; AVIDAD; CAPITÁN-VALLVEY, 2012). 
Alguns reagentes cromógenos são empregados e se caracterizam pela alta seletividade multielementar de íons, a saber: dithizone (TAVALLALI et al., 2014), 1- (2-Pyridylazo) -2-naphthol (PAN) (SAFARI; GHOLIVAND; HOSSEINZADEH, 2011), (2-pyridylazo) resorcinol (PAR) (ZHOU; NIE; DU, 2015), 3- (2-pyridyl) -5,6-diphenyl1,2,4-triazine-4",4"-disulfonic acid sodium salt (FER) (HARA et al., 2014), 1- (2thiazolylazo) -2-naphtol (TAN) (VUKOVIĆ; AVIDAD; CAPITÁN-VALLVEY, 2012), entre outros.

Dentre os reagentes citados, o PAN foi o reagente escolhido na presente tese para a obtenção da quantificação e classificação de íons de metais pesados pelo método colorimétrico e se destaca pela habilidade de complexação com a maioria dos metais de transição (CHENG; BRAY, 1955), através do grupo orto-hidroxilo, situado o mais proximamente do anel fenólico e o átomo de nitrogênio heterocíclico (MALIK et al, 2004).

A reação pode ser descrita, conforme apresentado na Figura 1:

PAN

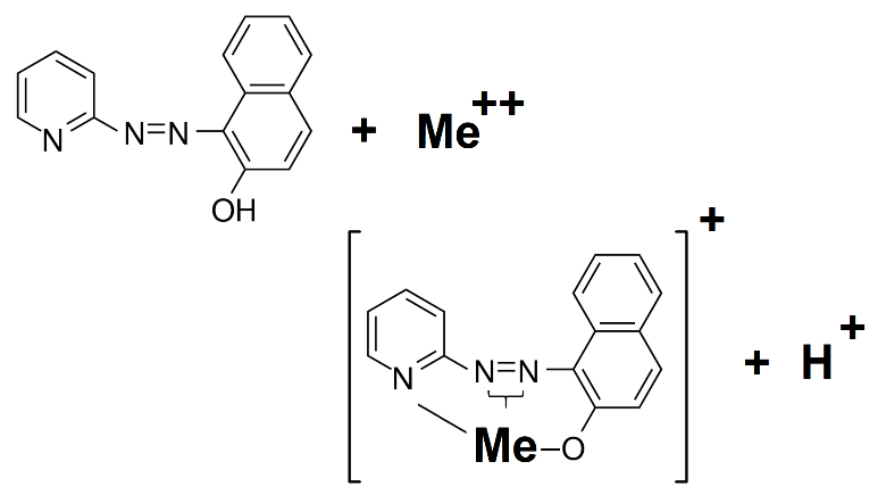

Figura 1 -Reação entre cromógeno PAN e um íon metálico (CHENG; BRAY, 1955).

A alteração de cor do PAN sob reação com o íon metálico se dá pela mudança dos orbitais dos anéis aromáticos na presença dos íons metálicos.

No caso de materiais fluoróforos, moléculas de porfirinas (YANG et al., 2009) e corantes (HU et al., 2010; LUO et al., 2015) têm sido utilizados como reagentes fluorescentes para determinação de cátions metálicos, devido às suas altas taxas de rendimentos quânticos de fluorescência (eficiência na produção de efeito luminoso) e por mudanças significativas de deslocamentos por efeitos Stokes.

Chan; Yang e Wang (2001) utilizaram moléculas de 5,10,15,20-tetrafenilporfirina (H2tpp) dissolvida em uma membrana plastificada de cloreto de polivinila (PVC) para detecção de íons de mercúrio. Neste filme formado, a H2tpp imobilizada na membrana 
do PVC não age apenas como molécula seletiva a $\mathrm{Hg}^{2+}$, mas também como um transdutor de fluorescência. O mecanismo de sensibilidade desse dispositivo envolve extração do íon $\mathrm{Hg}^{2+}$ da solução aquosa para dentro da fase da membrana com a complexação pelo fluoróforo H2tpp, por perda de dois prótons dos átomos de nitrogênio (Figura 2).

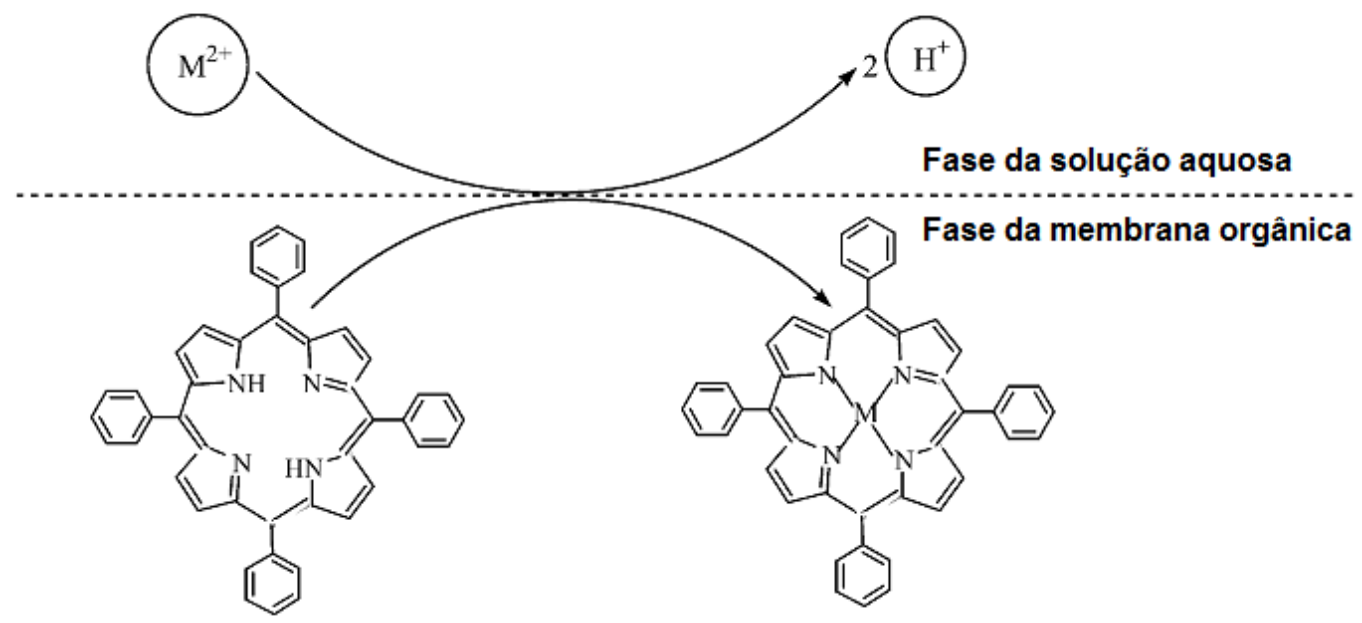

Figura 2 -Esquema da reação química da $\mathrm{H} 2 \mathrm{tpp}$ com íon metálico de $\mathrm{Hg}^{2+}$ (CHAN; YANG; WANG, 2001)

Este processo de troca iônica é determinado pela eletroneutralidade na fase da membrana orgânica, resultando na supressão da fluorescência pela H2tpp. O limite

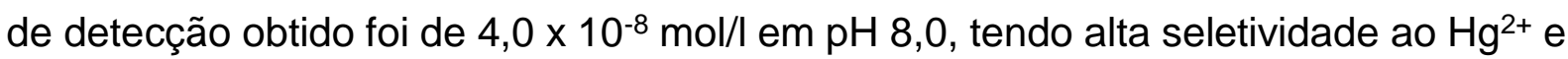
baixa interferência aos íons de $\mathrm{Li}^{+}, \mathrm{Na}^{+}, \mathrm{K}^{+}, \mathrm{Mg}^{2+}, \mathrm{Cd}^{2+}, \mathrm{Cu}^{2+}, \mathrm{Fe}^{3+}, \mathrm{Ag}^{+}$e $\mathrm{Pb}^{2+}$.

Nesta modalidade de sensores luminescentes a grande maioria dos dispositivos sensíveis a íons de metais pesados apresentam efeitos de supressão de luz por interação iônica com metais de transição incorporados no filme. No caso de supressão estática (VALEUR, 2001) haverá interação entre o fluoróforo (indicador fluorescente) e o supressor (íon metálico) em seu estado energético fundamental. Por outro lado, em uma supressão dinâmica (VALEUR, 2001), com uma interação colisional, isso ocorrerá somente em estado excitado, promovendo a redução da fluorescência e do tempo de decaimento (tempo de vida) (OEHME; WOLFBEIS, 1997). Os processos fotofísicos da supressão dinâmica são totalmente reversíveis, ou seja, não há nesses processos o consumo do indicador. A relação entre a intensidade da supressão e a concentração do analito é descrita por Stern-Volmer pela Equação 1 (OEHME; WOLFBEIS, 1997): 


$$
\frac{I_{0}}{I}-1=K_{S V}[Q]=K_{q} \tau_{0}[Q]
$$

Onde: Io e I são as intensidades fluorescentes na ausência e presença do supressor $Q$, respectivamente, em uma dada concentração [Q]. Ksv é a constante global de supressão (Stern-Volmer), e $\mathrm{K}_{\mathrm{q}}$ a constante de supressão bimolecular. Em meios com altas concentrações do supressor, os gráficos obtidos pela relação de Stern-Volmer normalmente apresentam comportamento linear.

Como mencionado anteriormente, a supressão dinâmica não afeta somente a intensidade luminescente, mas também o tempo de vida. A equação de Stern-Volmer dessa maneira relaciona esta situação pela Equação 2 (OEHME; WOLFBEIS, 1997):

$$
\frac{\tau_{0}}{\tau}-1=K_{S V}[Q]=K_{q} \tau_{0}[Q]
$$

Onde $\tau_{0}$ e $\tau$ são os tempos de decaimentos luminescentes na ausência e presença do supressor $Q$, respectivamente, em uma dada concentração [Q]. A probabilidade da supressão aumenta com o tempo de vida do fluoróforo.

A quantificação da sensibilidade do sensor pode ser obtida pela determinação do valor da constante de Stern-Volmer. Quanto mais elevado for o valor de Ksv, maior será a sensibilidade do dispositivo óptico luminescente (GEDDES; LAKOWICZ, 2005).

Em 2009, Bozkurt (BOZKURT; AYATA; KAYNAK, 2009) utilizando uma porfirina de 5,10,15,20-tetrakis (hydroxylphenyl) porphyrin (THPP) sob processo de síntese orgânica para incorporação de elementos de bromo à estrutura de 5,10,15,20-tetra(3-bromo-4-hydroxyphenyl) porphyrin (TBHPP) desenvolveu um sensor capaz de quantificar preferencialmente íons de $\mathrm{Pb}^{2+}$ em diferentes matrizes hospedeiras de etanol e PVC.

Levando em conta as características de sensibilidade seletiva em baixas concentrações de íons metálicos, o TBHPP foi sintetizado em nosso laboratório de síntese orgânica (CEPEMA-USP), de acordo com processos descritos por Bozkurt; Ayata e Kaynak (2009) e utilizado como elemento fluoróforo em parte dos ensaios de fluorescência na deteç̧ão de íons metálicos na presente tese.

Considerando os mecanismos de transferência de elétrons (PET) (VALEUR, 2001), o reagente 2,7-Dichlorofluorescein (Figura 3) foi também utilizado como elemento 
fluoróforo para detectar preferencialmente íons de $\mathrm{Cd}^{2+}$. Goswani; Baruah e Das (2010) comprovam e quantificam experimentalmente o número de íons de $\mathrm{Cd}^{2+}$ que se ligam a molécula de 2,7-Dichlorofluorescein. O princípio de detecção óptica é baseado na interação iônica com os dois pares de grupos $-\mathrm{Cl}$ e $-\mathrm{OH}$, o que resulta na intensificação da fluorescência emitida na região de comprimentos de onda, compreendidos entre 510 e $600 \mathrm{~nm}$.

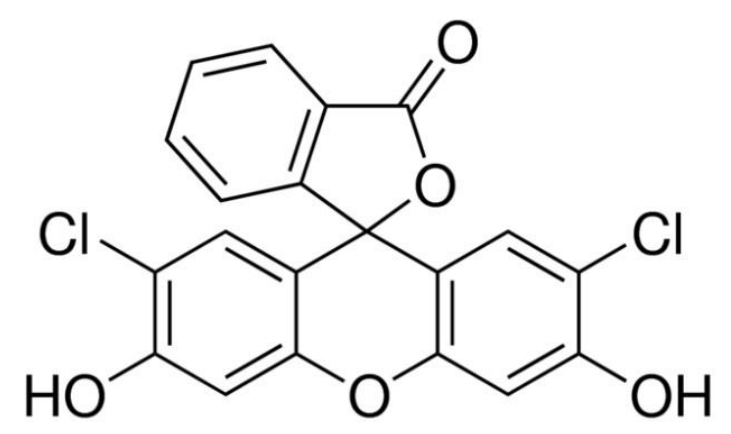

Figura 3 - Estrutura molecular do 2,7-Dichlorofluorescein.

Para validação do sistema multifuncional colorimétrico e fluorimétrico de deteç̧ão portátil de íons de metais pesados $\left(\mathrm{Pb}^{2+}, \mathrm{Cd}^{2+}, \mathrm{Zn}^{2+}, \mathrm{Cu}^{2+}, \mathrm{Fe}^{3+}\right.$ e $\left.\mathrm{Ni}^{2+}\right)$ em meios líquidos, o reagente cromógeno PAN e fluoróforos de TBHPP e 2,7Dichlorofluorescein foram diluídos em solventes e inseridos em câmara óptica dedicada com uso de LEDs de diferentes comprimentos de onda $(\lambda)$ e sensor multiespectral para ensaios de colorimetria e fluorimetria, sob interação com íons metálicos, em variadas condições de $\mathrm{pH}$.

\subsection{Sensores para detecção de oxigênio e oxigênio dissolvido}

A determinação de concentrações de oxigênio é importante em muitas áreas da indústria, medicina e meio ambiente. Em particular, na indústria alimentícia, o monitoramento do oxigênio permite certificar a integridade microbiológica e a qualidade das vedações de produtos em embalagens plásticas, tubulações e tanques de armazenamento em processos de pasteurização de leite, sucos de frutas, cervejas etc. Nas estações de tratamento de água, a medição de baixas concentrações do oxigênio dissolvido pode indicar a presença de um alto teor de matéria orgânica, provocando mudanças no sabor e emissões de odores desagradáveis. 
Um dos métodos tradicionais de determinação da concentração do oxigênio dissolvido utiliza como elemento sensor um eletrodo amperométrico denominado de Clark (CLARK, 1993). Este sistema polarográfico se baseia na aplicação de uma determinada tensão entre dois eletrodos, provocando o surgimento de uma corrente de baixa intensidade pela redução eletrolítica do oxigênio dissolvido na solução. Esses eletrodos costumam ser frágeis, consomem oxigênio e são suscetíveis a efeitos de agitação.

Em estudos recentes, mostrou-se que sensores de oxigênio baseados na supressão fotoluminescente de moléculas corantes apresentam elevada sensibilidade e robustez por serem mais fáceis de calibrar, não consumirem oxigênio da solução sob análise, e serem imunes a efeitos de campos eletromagnéticos e menos susceptíveis a alterações na intensidade do sinal, devido a flutuações instrumentais (HOLMESSMITH et al., 1999).

A maioria destes sensores utiliza moléculas de porfirinas com propriedades fotoluminescentes de complexos metálicos de transição, imobilizados em matrizes quimicamente resistentes de sol-gel, polimérica ou silício poroso (EBELING et al, 2009; PĂTULEA; BĂRAN; CĂLUŞARU, 2012; WANG et al, 2009). Estas matrizes permitem a dissolução da porfirina em sua estrutura e são permeáveis ao oxigênio, além de possuírem propriedades hidrofóbicas ao meio. O silício poroso em particular oferece grande número de vantagens e admite alterar suas propriedades ópticas, através do controle dos parâmetros eletroquímicos de processo. Dentre suas características estruturais, o silício poroso possui elevada área efetiva superficial, o que permite a adsorção de variados tipos de moléculas sensíveis na superfície ativa, aumentando sua potencialidade e sensibilidade como dispositivo óptico (CANHAM, 1997; CULLIS; CANHAM; CALCOTT, 1997; SALCEDO; RAMIREZ-FERNANDEZ; RUBIM, 2004). Essa tecnologia de superfície empregada a partir do silício cristalino não é nova, ela já vem sendo desenvolvida desde os anos 50 , porém o aproveitamento de suas propriedades ópticas teve maior ênfase a partir de 1990. A literatura reporta que uma das propriedades mais interessantes do silício poroso é sua fotoluminescência. Entretanto, uma vez oxidado, o silício poroso tem sua fotoluminescência extinta, resultado de mudanças estruturais na camada de silício poroso. Isto permite um desacoplamento óptico entre o substrato do silício poroso e as moléculas sensíveis. Para aplicações como dispositivos sensores, essa característica é de fundamental importância, uma vez que não se deseja que a 
luminescência do silício interfira na emissão óptica do filme molecular adsorvido no silício poroso.

Compostos de metais de transição de rutênio (HARTMANN; MARC; LIPPITSCH, 1995; ZAHARIEV; MILANOVA; TODOROVSKY, 2011), rênio (SACKSTEDER et al, 1993), ósmio (MCLAURIN et al., 2009) e irídio (DI MARCO et al., 1998; WANG et al., 2013), além das metaloporfirinas de platina (AMAO; MIYASHITA; OKURA, 2001; EATON; DOUGLAS, 2002; LEE; OKURA, 1998; ZHANG et al., 2016) e paládio (HAN; MANNERS; MITCHELL, 2005) (Figura 4a e Figura 4b) são especialmente utilizados em sensoriamento de oxigênio. As metaloporfirinas citadas, quando em estado excitado, possuem forte interação spin-orbital entre o elétron do subnível "d" do metal e o orbital antiligante $\mathrm{p}^{*}$ dos anéis da porfirina promovendo um decaimento para um estado excitado triplete. Assim, a maior emissão vem do estado triplete de menor energia, o qual pode ser suprimido pelo oxigênio, razão pela qual esses complexos apresentam excelente sensibilidade a esse gás.

a)

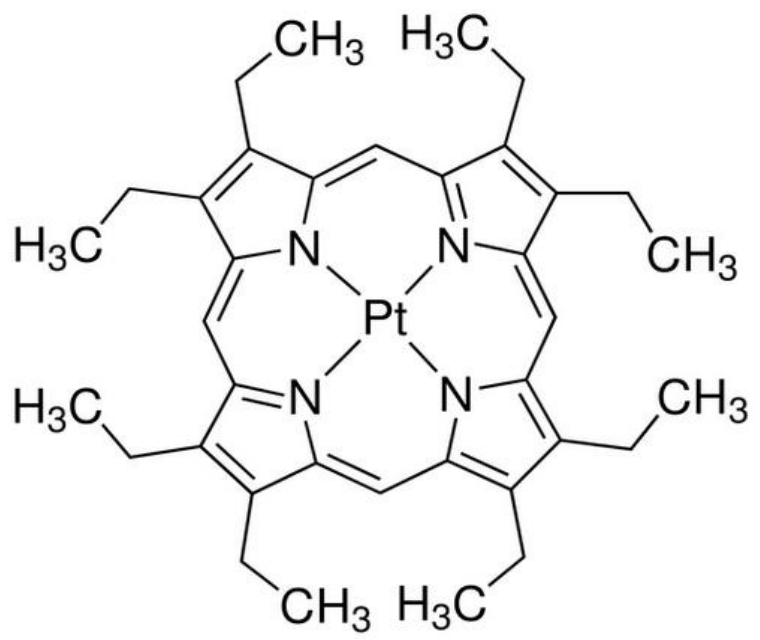

b)

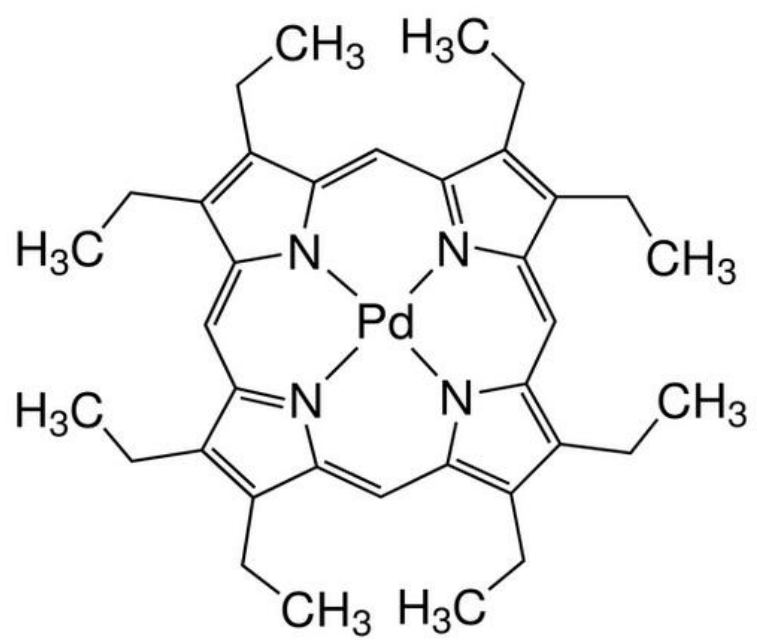

Figura 4 -Complexos de Platina e Paládio comumentes utilizados em sensoriamento de $\mathrm{O}_{2} \mathrm{e}$ OD, (a) Octaetilporfirina de Platina (PtOEP) (b) Octaetilporfirina de Paládio (PdOEP).

Dentre os compostos, a Octaetilporfirina de Platina (PtOEP) se destaca pelo elevado rendimento quântico de emissão, quando em filme de estado sólido, e por apresentar maior intensidade de emissão na região visível do espectro, característica desejada em sistemas de detecção portátil, com uso de dispositivos optoeletrônicos.

Dessa forma, as porfirinas de Platina, especialmente a PtOEP (escolhida para a obtenção dos dispositivos sensíveis a $\mathrm{O}_{2}$ e OD na presente tese), apresentam elevada 
sensibilidade (determinada pela constante de Stern-Volmer) e facilidade de transdução (propriedade determinada pelo elevado rendimento quântico de emissão), quando na constituição de filmes sensíveis baseados em poliestireno e silício poroso, devido à permeabilidade do filme ao oxigênio. Entretanto, em ensaios com exposições da luz incidente e longo tempo de duração sobre os dispositivos com moléculas de porfirinas, estes estarão susceptíveis a sofrerem reduções nas intensidades de emissões fluorescentes, devido à fotodegradação da membrana com o fluoróforo imobilizado. Desta forma, a utilização de métodos de espectroscopia de tempo de vida e fase tem sido aplicada, por apresentarem melhores condições de estabilidade temporal e detecção eletrônica, além de independerem de variações nas características do sistema óptico (GRILLO et al., 2005).

$\mathrm{Na}$ técnica de modulação de fase, os parâmetros de deslocamento de um sinal modulado de emissão óptica da molécula sensível (fluoróforo), são medidos como função da concentração do supressor no meio. Com um sinal senoidal de excitação, será produzida uma resposta de emissão fluorescente na mesma frequência de modulação, porém com um deslocamento de fase em relação ao sinal de excitação (Figura 5).

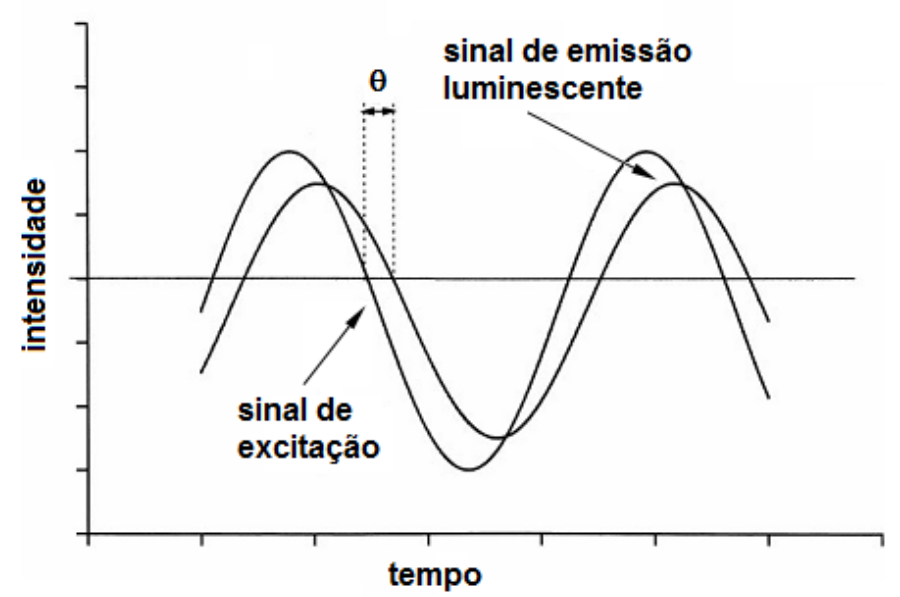

Figura 5 -llustração do deslocamento de fase na emissão fluorescente (MCDONAGH et al., 2001).

A relação entre o tempo de vida, $\tau$, e o ângulo de fase, $\theta$, para um decaimento exponencial simples é dada pela Equação 3 (MCDONAGH et al., 2001):

$$
\tan \theta=2 . \pi . f . \tau
$$


Onde: $f$ é a freqüência de modulação.

A melhor frequência, que maximiza a sensibilidade, geralmente é encontrada ajustando-a de tal forma que o deslocamento entre os extremos (0 e 100\% da concentração do supressor) seja maximizado em seu valor angular.

Com base nas tecnologias de sensoriamento óptico apresentadas e estratégias de medidas de transmitância e fluorescência, a presente tese apresenta soluções de desenvolvimento de instrumentação portátil, baseadas em hardware eletrônico embarcado e sensores optoeletrônicos multiespectrais, mostrando possibilidades de aplicações em sistemas de monitoramento ambiental.

\subsection{Destaque e objetivos da tese}

A tese teve como objetivo o desenvolvimento de sistemas portáteis de detecção de

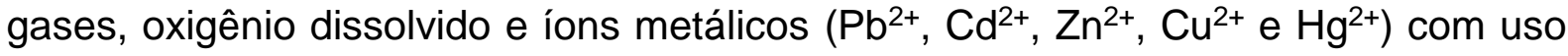
de reagentes cromógenos e fluoróforos dissolvidos em solventes ou imobilizados em matrizes hospedeiras de poliestireno, PVC e silício poroso. O destaque é outorgado aos métodos, soluções de instrumentação portátil e processos de classificação e quantificação que foram baseados em princípios de medição por colorimetria e fluorimetria, tendo como referência, os atuais métodos analíticos utilizados nos tradicionais laboratórios. O sistema foi totalmente integrado a um hardware embarcado com tecnologia FPGA (Field Programmable Gate Array) e softwares baseados em instrumentação virtual (NI LabView®), cujo processamento de sinais e análises de padrões foram baseados em métodos matemáticos de discriminante de Fisher, com possibilidades de aplicações no monitoramento contínuo on line e in loco de efluentes de rios, estuários, canais e praias. 


\subsection{Justificativas}

$\mathrm{Na}$ Baixada Santista, a cidade de Cubatão é a que mais se destaca em potencial de estudo ambiental, pois abriga um dos mais importantes polos industriais do Brasil, com aproximadamente 100 indústrias, sendo estas as principais responsáveis pela poluição do Meio Ambiente na região. Desde os anos 80 , as emissões descontroladas de substâncias gasosas provenientes das indústrias químicas, petroquímicas, de fertilizantes e siderurgia, além das emissões de sedimentos sólidos e líquidos, colocaram a cidade de Cubatão no centro das discussões ambientais mundiais. Dentro deste cenário, Cubatão foi considerada, na época, "uma das cidades mais poluídas do mundo", e seus problemas, com visibilidade nacional e internacional, foram frequentemente citados como mau exemplo, passando a ser conhecida pela alcunha de "Vale da Morte", devido à grande incidência de doenças associadas a poluição ambiental. Com tal destaque negativo, a partir da década de 80 , começaram a surgir programas governamentais para o controle da poluição na região, surtindo efeitos positivos para os dias de hoje.

Como política de controle e avaliação dos métodos de análise de poluentes, a CETESB oferece atualmente, como uma das prioridades de investimentos na Unidade de Gerenciamento de Recursos Hídricos (UGHRI) da Baixada Santista, o incentivo de ações de criação e desenvolvimento de postos meteorológicos, fluviométricos e de monitoramento de qualidade das águas, a fim de permitir a implantação de sistemas de informações georreferenciadas, compatíveis com as necessidades regionais. Em especial, as sub-bacias dos Rios Aguapeú, Cubatão, Piaçabuçu, Mogi e Itapanhaú. Nesse contexto, o ramo de atividades em sensores se apresenta como um dos principais tópicos no segmento de monitoramento ambiental, com abrangência e aplicações nas diferentes áreas da biotecnologia, nanotecnologia, biomedicina, indústria farmacêutica, siderúrgica, petroquímica e de alimentos, fertilizantes, tecnologia de processos, segurança, dentre outros. A interdisciplinaridade do conhecimento em eletroquímica, bioengenharia, física de superfície, estado sólido, bionanoestruturas e tecnologia integrada de silício, juntamente às ferramentas de processamento de sinais, oferecem inúmeras possibilidades de criação de novos sensores bioquímicos e sistemas sensores. 
Dessa forma, a necessidade de continuidade da implantação e aperfeiçoamento dos sistemas de controle da poluição do ar e em ambientes aquáticos, no controle de $\mathrm{pH}$, oxigênio dissolvido (OD) e de íons de metais pesados, aliados a uma política de sustentabilidade urbana, faz da presente tese uma alternativa aos tradicionais métodos e equipamentos laboratoriais comumente empregados pelos centros reguladores nas análises de contaminantes ambientais, destacando-se por fornecer respostas rápidas, eficiência no mapeamento das fontes poluidoras, custo reduzido e por permitir a identificação dos poluentes de forma on line e in loco aos centros de pesquisa e monitoramento.

Adicionalmente, na presente tese foi realizada a síntese de alguns reagentes, bem como o emprego de moléculas de porfirinas e compostos cromógenos. Estes compostos são normalmente utilizados em análises laboratoriais e necessitam ser dissolvidos em solventes em fase líquida para a detecção de agentes poluidores e condições químicas do meio (íons de metais pesados, pH etc.). Estes ensaios são realizados com soluções preparadas previamente e uma vez submetidas às análises são inutilizadas após o uso. Em alguns laboratórios por não haver uma política adequada de descarte de produtos químicos residuais, estes acabam promovendo contaminações ao meio ambiente. Desta forma, o emprego de porfirinas e polímeros, em estado sólido, imobilizados na forma de matrizes hospedeiras nos dispositivos sensores, mostrado como estratégia de emprego na presente tese, além de gerar menos resíduos, nos processos de fabricação, permite, em alguns casos, a reutilização dos elementos ativos em mais de uma centena de análises químicas.

Outro destaque a ser apresentado na presente tese foi a utilização de métodos de medição de fase como alternativa às estratégias de medição por intensidade luminosa (LOCK-IM) para quantificação dos elementos a serem detectados $\left(\mathrm{O}_{2}\right.$, OD e íons de metais pesados) nas análises. Este procedimento permitiu otimizar a utilização dos dispositivos por minimizar os efeitos da fotodegradação dos filmes seletivos e possibilitar a geração de padrões de sinais de forma mais confiável e reprodutível para o sistema de detecção. 


\subsection{Referências}

AMAO, Y.; MIYASHITA, T.; OKURA, I. Novel optical oxygen sensing material: platinum octaethylphorphyrin immobilized in a copolymer film of isobutyl methacrylate tetrafluoropropyl methacrylate. Reactive \& Functional Polymers, v. 47, p. 49-54, 2001.

BERGVELD, P. Development of an ion-sensitive solid-state device for europhysiological measurements, IEEE Trans. Biomed. Engineering, v. 17, p. 70, 1970.

BOZKURT, S. S.; AYATA, S.; KAYNAK, I. Fluorescence-based sensor for $\mathrm{Pb}$ (II) using tetra-(3-bromo-4-hydroxyphenyl)porphyrin in liquid and immobilized medium. Spectrochimica Acta Part A, v. 72, p. 880-883, 2009.

CANHAM, L. (Ed.). Properties of Porous Silicon. London: The Institution of Engineering and Technology, 1997. 416p.

CHAN, W. H.; YANG, R. H.; WANG, K. M. Development of a mercury ion-selective optical sensor based on fluorescence quenching of 5,10,15,20-tetraphenylporphyrin. Analytica Chimica Acta, v. 444, p. 261-269, 2001.

CHENG, K. L.; BRAY, R. H. 1-(2-Pyridylazo)-2-naphthol as Possible Analytical Reagent. Anal. Chem., v. 27 (5), pp. 782-785, 1955.

CLARK, L. C. Jr "GUEST EDITORIAL”, Biosensors \& Bioelectronics, vol. 8, n. 1, pp. iii-vi, 1993.

CULLIS, 1. G.; CANHAM, L. T.; CALCOTT, P. D. J. The structural and luminescence properties of porous silicon. Journal of Applied Physics, v. 82, n. 3, p. 909-965, 1997.

DI MARCO, G. et al. Luminescent Mononuclear and Dinuclear Iridium (III) Cyclometalated Complexes Immobilized in a Polymeric Matrix as Solid-State Oxygen Sensors. Analytical Chemistry, n. 70, p. 5019-5023, 1998.

EATON, K.; DOUGLAS, P. Effect of humidity on the response characteristics of luminescent PtOEP thin film optical oxygen sensors. Sensors and Actuators B, v. 82, n. 1, p. 94-104, 2002. 
EBELING, D.; PATEL, V.; FINDLAY, M.; STETTER, J. "Electrochemical ozone sensor and instrument with characterization of the electrode and gas flow effect". Sensor and Actuators. B, vol. 137, pp. 129-133, 2009.

ENSAFI, A. A.; FAR, A. K.; MEGHDADI, S. Highly selective optical-sensing film for lead(II) determination in water samples. Journal of Hazardous Materials, v. 172, p. 1069-1075, 2009.

GEDDES, C. D.; LAKOWICZ, J. R. Reviews in Fluorescence, Springer, 2005.

GOSWAMI, P.; BARUAH, S.; DAS, D. K. 2,7-Dichlorofluorescein, a fluorescent sensor to detect $\mathrm{Cd}^{2+}$ over $\mathrm{Na}^{+}, \mathrm{K}^{+}, \mathrm{Ca}^{2+}, \mathrm{Cu}^{2+}, \mathrm{Ni}^{2+}$ and $\mathrm{Zn}^{2+}$. Indian Journal of Chemistry, $\mathrm{v}$. 49a, pp. 1617-1620, 2010.

GOSWAMI, S. et al. Highly selective colorimetric fluorescence sensor for $\mathrm{Cu}^{2+}$ : cationinduced 'switching on' of fluorescence due to excited state internal charge transfer in the red/near-infrared region of emission spectra. Tetrahedron Letters, v. 51, p. 55635566, 2010.

GRILLO, G. J. et al. Amplitude and Phase Fluorescence-Spectroscopy Methods for Dissolved Oxygen. Instrumentation and Measurement Technology Conference, p. 922-924, 2005.

HAN, B-H; MANNERS, I.; WINNIK, M. A. Oxygen Sensors Based on Mesoporous Silica Particles on Layer-by-Layer Self-assembled Films. Chem. Mater. v.17, p. 31603171, 2005.

HARA, H. et al. Determination of Dissolved Iron in Seta River Water by Spectrophotometry using the Colored Complex of Ferrozine and Iron(II) and Graphite Furnace Atomic Absorption Spectrometry. Faculty of Education, Shiga University, n. 64, pp. 105-120, 2014.

HARTMANN, P.; MARC, J. P., LIPPITSCH, M. E. Luminescence Quenching Behavior of an Oxygen Sensor Based on a Ru(II) Complex Dissolved in Polystyrene. Analytical Chemistry, n. 67, p. 88-93, 1995. 
HOLMES-SMITH, A. S. et al. Electropolymerised platinum porphyrin polymers for dissolved oxygen sensing. Analyst, v. 124, p. 1463-1466, 1999.

$\mathrm{HU}, \mathrm{Z}-\mathrm{Q}$. Highly sensitive and selective turn-on fluorescent chemosensor for $\mathrm{Pb} 2+$ and $\mathrm{Hg}^{2+}$ based on a rhodamine-phenylurea conjugate. Chem. Commun,v. 46,p. 37653767, 2010.

ISLAM, A.; LASKAR, A.; AHMAD, A. Characterization and Application of 1-(2Pyridylazo)-2-naphthol Functionalized Amberlite XAD-4 for Preconcentration of Trace Metal lons in Real Matrices. J. Chem. Eng. Data, v. 55, p. 5553-5561, 2010.

$\mathrm{KIM}, \mathrm{H}$. N. et al. Fluorescent and colorimetric sensors for detection of lead, cadmium, and mercury ions. Chem. Soc. Rev., v. 41, p. 3210-3244, 2012.

KLOOCK, J. P. et al. Inorganic Thin-film Sensor Membranes with PLD-prepared Chalcogenide Glasses: Challenges and Implementation. Sensors, v. 4, p. 156-162, 2004.

KLOOCK, J. P. et al. PLD-prepared cadmium sensors based on chalcogenide glass ISFET, LAPS and $\mu$ ISE semiconductor structures. Sensors and Actuators B, v. 118, $p$ 149-155, 2006.

LEE, S-K.; OKURA, I. Photoluminescent determination of oxygen using metalloporphyrin-polymer sensing systems. Spectrochimica Acta Part A, n. 54, p. 91 100, 1998.

LEHMANN, M. et al. Simultaneous measurement of cellular respiration and acidification with a single CMOS ISFET. Biosensors and Bioelectronics, v. 16, Issue 3 , p.195-203, 2001.

LI, Y. et al. The Improved Data Processing Method For Electronic Tongue Based On Multi-Ion LAPS. Olfaction and Electronic Nose: Proceedings of the 13th International Symposium on Olfaction and Electronic Nose, AIP Conference Proceedings; v. 1137, p. $558,2009$. 
LUO, Y. et al. Reactive fluorescent dye functionalized cotton fabric as a "Magic Cloth" for selective sensing and reversible separation of $\mathrm{Cd}^{2+}$ in water. Journal of Materials Chemistry C, v. 3, p. 8485-8489, 2015.

MAIRHOFER, J.; ROPPERT, K.; ERTL, P. Microfluidic Systems for Pathogen Sensing: A Review. Sensors, v. 9, p. 4804-4823, 2009.

MALIK, A. K. et al. Column Preconcentration and Spectrophotometric Determination of Ziram and Zineb in Commercial Samples and Foodstuffs Using (1,24-Pyridylazo)-2naphthol (PAN)-Naphthalene as Adsorbate. J. Agric. Food Chem., v. 52, p. 7763-7767, 2004.

MCDONAGH, C. et al. Phase fluorometric dissolved oxygen sensor. Sensors and Actuators B, v. 74, 124-130, 2001.

MCLAURIN, E. J. et al. Two-Photon Absorbing Nanocrystal Sensors for Ratiometric Detection of Oxygen. J. Am. Chem. Soc. v. 131(36), p. 12994-13001, 2009.

MEN, H. et al. A novel electronic tongue combined MLAPS with stripping voltammetry for environmental detection. Sensor and Actuators B, v. 110, p. 350-357, 2005.

MILOCHOVA, M.; KASSEM, M.; BYCHKOV, E. Chalcogenide Glass Chemical Sensor for Cadmium Detection in Industrial Environment. ECS Transactions, v. 50, issue 12, p. 357-362, 2013.

MOURZINA, Y. et al. lon-selective light-addressable potentiometric sensor (LAPS) with chalcogenide thin film prepared by pulsed laser deposition. Sensors and Actuators B: Chemical, v. 80, Issue 2, p. 136-140, 2001.

NEUPANE, L. N. et al. Highly selectively monitoring heavy and transition metal ions by a fluorescent sensor based on dipeptide. Talanta, v. 85, p. 1566-1574, 2011.

OEHME, T; WOLFBEIS, O. S. Optical Sensors for Determination of Heavy Metal lons. Mikrochim. Acta, v. 126, p. 177-192, 1997.

PĂTULEA, A.; BĂRAN, N.; CĂLUŞARU, M. "Measurements of Dissolved Oxygen Concentration in Stationary Water". World Environment, vol. 2(5), pp. 104-109, 2012. 
PINHEIRO, S. C. L. et al. Simultaneous determination of copper, mercury and zinc in water with a tailored fluorescent bipyridine ligand entrapped in silica sol-gel. Anal Bioanal Chem v. 398, p. 3127-3138, 2010.

POGHOSSIAN, A. et al. Possibilities and limitations of label-free detection of DNA hybridization with field-effect-based devices. Sensor and Actuators B, v. 111-112, p.470-480, 2005.

PRESTEL, H.; GAHR A.; NIESSNER, R. Detection of heavy metals in water by fluorescence spectroscopy: On the way to a suitable sensor system. Fresenius J Anal Chem., v. 368, p. 182-191, 2000.

SACKSTEDER, L.; LEE, M.; DEMAS, J. N.; DEGRAFF, B. A. Long-lived, highly luminescent rhenium(I) complexes as molecular probes: intra- and intermolecular excited-state interactions. J Am Chem Soc., v. 115(18), p. 8230-8238, 1993.

SAFARI, Z.; GHOLIVANDB, M.B.; HOSSEINZADEHC, L. Spectrophotometric study of complex formations between 1-(2-pyridylazo)-2-naphthol (PAN) and some metal ions in organic solvents and the determination of thermodynamic parameters. Spectrochimica Acta Part A 78, p. 1606-1610, 2011.

SALCEDO, W. J.; RAMIREZ-FERNANDEZ, F. J.; RUBIM, J. C. Photoluminescence quenching effect on porous silicon films for gas sensors application. Spectrochimica Acta Part A: Molecular and Biomolecular Spectroscopy, v. 60, n. 5, p. 1065-1070, 2004.

SARKER, K. C.; ULLAHA, R. Determination of Trace Amount Of Copper (Cu) Using Uv-Vis Spectrophotometric Method. International Journal of scientific research and management (IJSRM), v. 1, Issue 1, p. 23-44, 2013.

SCHROTH, P. et al. Characterising an insect antenna as a receptor for a biosensor by means of impedance spectroscopy. Electrochimica Acta, v. 47, Issue 1-2, p.293-297, 2001.

SRIJARANAI, S. et al. Use of 1-(2-pyridylazo)-2-naphthol as the post column reagent for ion exchange chromatography of heavy metals in environmental samples. Microchemical Journal, v. 99, p. 152-158, 2011. 
TARANTOV, Y. A. et al. Physical and chemical processes in ISFETs with chalcogenide membranes. Sensors and Actuators B, v.1, Issue 1-6, p. 390-394, 1990.

TAVALLALI, $\mathrm{H}$ et al. Dithizone as novel and efficient chromogenic probe for cyanide detection in aqueous media through nucleophilic addition into diazenylthione moiety. Spectrochimica Acta Part A: Molecular and Biomolecular Spectroscopy, v. 121, p. 139-146, 2014.

TUREK, M. et al. Artificial intelligence/fuzzy logic method for analysis of combined signals from heavy metal chemical sensors. Electrochimica Acta, v.54, p. 6082-6088, 2009.

VASILEV, V.; RADONOVA, M.; BOYCHEVA, S. Pb(II)-Ion Selective Sensors with Chalcogenide Glassy Membranes for Water Media Analysis. Advances in Natural Science: Theory \& Applications, v. 1, n. 2, p. 103-114, 2012.

VALEUR, B. Molecular Fluorescence - Principles and Applications. Wiley-VCH Verlag GmbH, ISBNs: 3-527-29919-X, 2001.

VLASOV, Y. G.; BYCHKOV, E. A. Elecrochemical ion-selective sensors based on chalcogenide glasses. Sensors and Actuators, v. 12, p. 275-283, 1987.

VLASOV, Y. G.; BYCHKOV, E. A.; LEGIN, A. V. Chalcogenide glass chemical sensors: Research and Analytical Applications. Talanta, v. 41, n. 6, pp. 1059-1063, 1994.

VUKOVIĆ, J.; AVIDAD, M. A.; CAPITÁN-VALLVEY, L. F. Characterization of disposable optical sensors for heavy metal determination. Talanta, V. 94, p. 123-132, 2012.

WANG, X.; LIU, M.-L.; CHENG, X.-L.; LIN, J.-M. "Flow-based luminescence-sensing methods for environmental water analysis". Trends in Analytical Chemistry, vol. 28, n. 1, pp. 75-87, 2009.

WANG, X.; WOLFBEIS, O. S. Fiber-Optic Chemical Sensors and Biosensors (2008-2012). Anal. Chem., v. 85, p. 487-508, 2013.

WANG, X-D. et al. Ultra-small, highly stable, and membrane-impermeable fluorescent nanosensors for oxygen. Methods Appl. Fluoresc, v. 1, p. 1-7, 2013. 
WILSON, et al. Potentiometric electronic tongue-flow injection analysis system for the monitoring of heavy metal. Biosorption Processes, v. 93, p. 285-292, 2012.

YAGER, P. et al. Microfluidic Diagnostic Technologies for Global Public Health. Nature Biotechnol., v. 442, p. 412-418, 2006.

YANG, Y. et al. An optical sensor for mercury ion based on the fluorescence quenching of tetra(p-dimethylaminophenyl)porphyrin. Anal Chim Acta, v. 636(1), p. 83-88, 2009.

ZAHARIEVA, J. MILANOVA, M., TODOROVSKY, D. SiO2/polyester hybrid for immobilization of $\mathrm{Ru}(\mathrm{II})$ complex as optical gas-phase oxygen sensor. J. Mater. Chem., v. 21, p. 4893-4903, 2011.

ZHANG et al. PtOEP/PS composite particles based on fluorescent sensor for dissolved oxygen detection. Materials Letters, v. 172, p. 112-115, 2016.

ZHOU, X.; NIE, J.; DU, B. 4-(2-Pyridylazo)-resorcinol Functionalized Thermosensitive Ionic Microgels for Optical Detection of Heavy Metal lons at Nanomolar Level. ACS Appl. Mater. Interfaces, v. 7, p. 21966-21974, 2015. 


\section{Capítulo 2}

\section{Sensores de Oxigênio e Oxigênio Dissolvido Baseados na Emissão} Fotoluminescente de Corante de Octaetilporfirina de Platina Imobilizados em Filmes Finos de Silício Poroso Oxidado e Poliestireno

\subsection{Introdução}

Para garantia da qualidade das águas e preservação dos recursos hídricos disponíveis, a utilização de instrumentos analíticos associados a procedimentos e métodos experimentais na detecção de oxigênio dissolvido tem sido vastamente empregada (EBELING et al., 2009; PĂTULEA; BĂRAN; CĂLUŞARU, 2012; WANG et al., 2009). Nesse contexto, o uso de sensores fotoluminescentes na detecção de oxigênio molecular tem alcançado inúmeras vantagens quando comparado aos tradicionais métodos de sensoriamento eletroquímico, por apresentar boa estabilidade, ser imune a efeitos de campos eletromagnéticos, não consumir oxigênio do meio, além de não sofrer interferências em processos de agitação.

A maioria destes sensores são baseados na emissão fotoluminescente de moléculas corantes organometálicas imobilizadas em camadas poliméricas de poliestireno, PVC ou de sol-gel (AMAO; ISHIKAWA; OKURA, 2005; KOSE, 2005; LEE; OKURA, 1997). Estes dispositivos não são compatíveis com a tecnologia de silício, uma vez que normalmente utilizam lâminas de vidro como substrato. Em contrapartida, sensores baseados em silício poroso para detecção de $\mathrm{O}_{2}$ passam a ser uma alternativa por apresentarem total compatibilidade com a tecnologia planar do silício e admitir alterar suas propriedades ópticas, através do controle de parâmetros eletroquímicos nos processos de fabricação. Dentre suas características estruturais, o silício poroso possui elevada área efetiva superficial, o que permite a adsorção de variados tipos de moléculas sensíveis na superfície ativa, aumentando sua potencialidade e sensibilidade como dispositivos ópticos. 
Neste capítulo é descrito o desenvolvimento de sensores fotoluminescentes de oxigênio $\left(\mathrm{O}_{2}\right)$ e oxigênio dissolvido $(\mathrm{OD})$, utilizando moléculas de octaetilporfirina de platina (PtOEP), imobilizadas em matrizes hospedeiras de substratos de silício poroso oxidado e poliestireno em vidro. A detecção das concentrações $\mathrm{O}_{2}$ e OD foi obtida pelo monitoramento das intensidades de fluorescência através do uso de um fluorímetro. Serão apresentadas as ferramentas de controle de diluição dos gases de $\mathrm{O}_{2}$ em $\mathrm{N}_{2}$ e do processo de obtenção de oxigênio dissolvido em água deionizada (DI). Os resultados mostraram alta seletividade da molécula de PtOEP para a detecção de oxigênio, compatíveis com a emissão fotoluminescente em 644 nm.

\subsection{Procedimentos Experimentais}

Serão apresentados os materiais, os procedimentos para a fabricação dos dispositivos ópticos e a metodologia dos ensaios para a caracterização dos sensores em ambos os substratos de vidro e silício poroso. Para os substratos de vidro e silício, os filmes obtidos utilizam poliestireno e silício poroso como matrizes hospedeiras, formando estruturas Vidro/PS(PtOEP) e ox.p.Si/PtOEP.

\subsubsection{Preparação dos substratos de vidro para deposição de matriz polimérica de Octaetilporfirina de Platina - PtOEP e fabricação de dispositivo de estrutura Vidro/PS(PtOEP)}

Para produção dos dispositivos em substrato de vidro, foram utilizadas lâminas de vidro polido (padrão de microscopia) como substrato de $1 \mathrm{~mm}$ de espessura e dimensões quadradas aproximadas de $10 \mathrm{~mm}$ de lado.

Inicialmente, todas as lâminas foram identificadas com numeração gravada no substrato à caneta com ponta de diamante.

Após a identificação, as lâminas foram lavadas com detergente em água potável e, em seguida, em etanol, e deixadas em imersão no álcool por $10 \mathrm{~min}$. Na sequência, os substratos foram lavados com água deionizada. Para concluir essa etapa de 
limpeza, as lâminas foram mantidas em um béquer com água deionizada sob ultrassom por $20 \mathrm{~min}$, e secas em forno a $120^{\circ} \mathrm{C}$ por $20 \mathrm{~min}$.

\subsubsection{Diluição das moléculas de PtOEP no poliestireno}

A membrana sensível foi obtida pela diluição de $7,0047 \mathrm{mg}$ de PtOEP em solução contendo $69,59 \mathrm{mg}$ de poliestireno e $5 \mathrm{ml}$ de clorofórmio $\left(2,0.10^{-3} \mathrm{~mol} / \mathrm{l}\right)$. A solução foi condicionada em um béquer sob ultrassom para homogeneização e completa diluição por $30 \mathrm{~min}$.

\subsubsection{Deposição da matriz polimérica sobre as lâminas de vidro}

Os filmes foram depositados sobre lâminas de vidro pelo processo de revestimento por rotação (spin coating - Figura 6). Para otimização e identificação de melhores condições de espessuras dos filmes de PtOEP na detecção de $\mathrm{O}_{2}$ e OD, a solução preparada foi gotejada sobre 2 (duas) lâminas de vidro, sendo ajustada para cada lâmina, uma velocidade de rotação que proporcionasse espessuras diferenciadas entre si. Assim, o módulo spin coating foi parametrizado sob velocidades de rotações de 1000 e 3000 RPM (rotações por minuto). Cada deposição teve duração de $10 \mathrm{~s}$, de modo que o filme fosse homogeneamente espalhado sobre a superfície das lâminas.

Para secagem dos filmes, os dispositivos foram inseridos em forno térmico a vácuo em temperatura de $60{ }^{\circ} \mathrm{C}$ por $2 \mathrm{~h}$.

Ao final desta etapa, foram obtidas espessuras aproximadas de filmes de PtOEP imobilizadas em matriz de poliestireno de 160 e $120 \mathrm{~nm}$. 


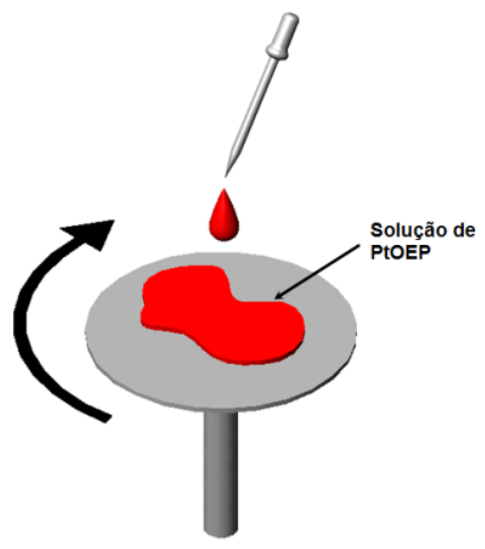

Figura 6 -Ilustração esquemática do revestimento por rotação (spin coating). A substância a ser depositada é gotejada sobre o substrato que é rotacionado por $10 \mathrm{~s}$ sob velocidades de 1000 e 3000 RPM.

\subsubsection{Fabricação dos sensores ópticos de Si-p com matriz de silício poroso para formação de estrutura ox.p.Si/PtOEP}

Os dispositivos baseados em substrato de silício poroso ( $L 55$ e L 63) foram fabricados por processo eletroquímico, dando origem a uma camada de silício poroso de $10 \mu \mathrm{m}$ de espessura (HUANCA, 2007). Posteriormente, a amostra L 55 foi submetida ao processo de recozimento a $300^{\circ} \mathrm{C}$ por $60 \mathrm{~min}$, seguido de temperatura de $900 \stackrel{\circ}{\mathrm{C}}$ por 30 min e, finalmente, a $1.100^{\circ} \mathrm{C}$ por $10 \mathrm{~min}$ em ambiente com oxigênio. Já a amostra L 63 foi submetida apenas ao processo de oxidação a $300^{\circ} \mathrm{C}$ por $60 \mathrm{~min}$, seguido de temperatura de oxidação a $900^{\circ} \mathrm{C}$ por 30 min.

O processo de recozimento foi realizado de maneira a evitar qualquer emissão fotoluminescente da camada de silício poroso, preservando, desta forma, sua grande área de superfície ativa, onde as moléculas de PtOEP foram posteriormente depositadas e adsorvidas.

\subsubsection{Preparo de solução de PtOEP e deposição sobre as lâminas}

\section{55 e L 63 de silício poroso oxidado}

Para a obtenção do polímero dopado, uma quantidade de 3,0 mg de PtOEP foi diluída em solução contendo $3,0 \mathrm{ml}$ de clorofórmio $\left(1,37 \cdot 10^{-3} \mathrm{~mol} / \mathrm{l}\right)$. Para homogeneização e 
diluição completa do PtOEP, a mistura foi condicionada em um béquer sob ultrassom durante $5 \mathrm{~min}$.

A seguir, a solução de moléculas de PtOEP diluídas em clorofórmio foi depositada sobre a superfície oxidada das amostras $L 55$ e $L$ 63, por processo de spin coating a 3.000 RPM, durante $10 \mathrm{~s}$.

Finalmente, ambos os dispositivos foram levados a forno de vácuo térmico a $60 \stackrel{\circ}{\circ}$ por 2 h para evaporação completa do solvente.

\subsubsection{Sistema de diluição dos gases de $\mathrm{O}_{2}$ e $\mathrm{N}_{2}$ para controle de oxigênio diluído em nitrogênio gasoso}

Nos ensaios de sensibilidade dos sensores (Vidro/PS(PtOEP) e ox.p.Si/PtOEP) para ambientes com diferentes concentrações de oxigênio e nitrogênio utilizou-se um arranjo de dois controladores de fluxos MFC-1 e MFC-2 da marca MKS Instruments Type 1179 A, alimentados por cilindros contendo oxigênio (99,999\% de pureza) e nitrogênio $(99,999 \%$ de pureza). Para o controle e temporização do sistema de diluição de gases de $\mathrm{O}_{2}$ e OD uma ferramenta desenvolvida em ambiente LabView® com uso de placa de aquisição mod. NI-6009 foi implementada em conjunto com Santos (2013). Os valores de setpoint de cada um dos controladores para se obter uma determinada concentração foram enviados por duas saídas analógicas (AOs) situadas na placa de aquisição. Os sinais de vazão correspondentes foram fornecidos pelos controladores MFC-1 e MFC-2 e conectados eletricamente em duas entradas analógicas (Als) para monitoramento contínuo durante os ensaios. O programa permitiu a configuração de 10 (dez) estágios individuais com possibilidade de seleção do tipo de gás, concentração da mistura e tempo corrente para conclusão de cada um dos estágios. A Figura 7 mostra detalhes da tela de configuração do tempo e concentrações dos estágios. Na sequência, a Figura 8 ilustra detalhes do diagrama de ligações e do arranjo do sistema de diluição de oxigênio e nitrogênio para a caracterização das estruturas Vidro/PS(PtOEP) e ox.p.Si/PtOEP. 


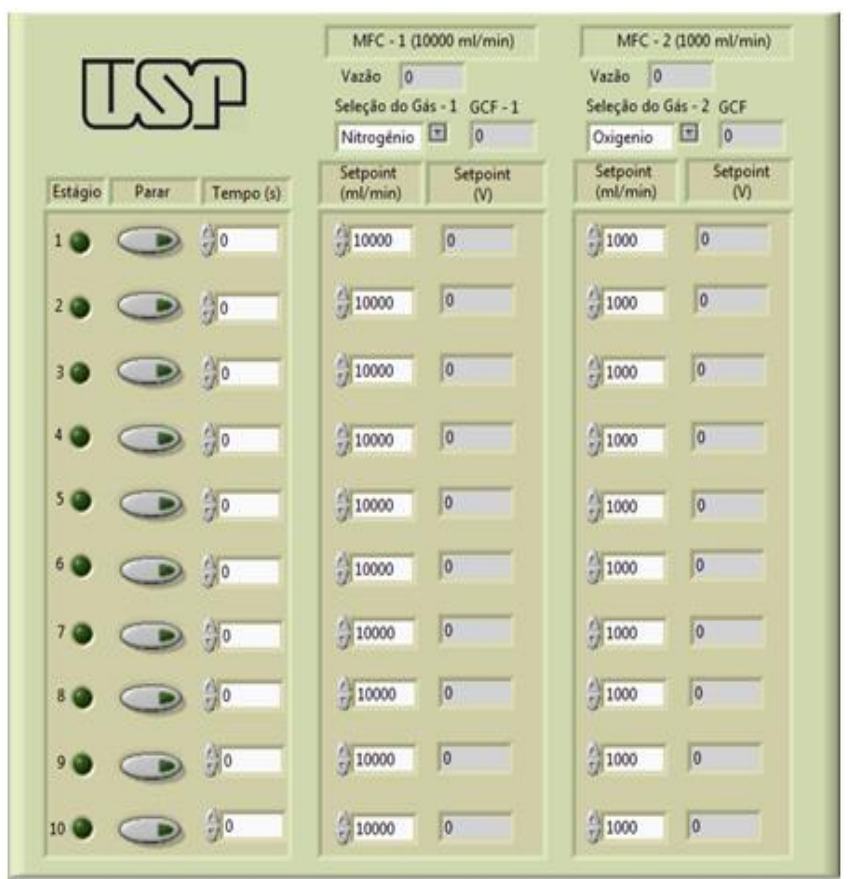

Figura 7 -Tela de configuração sistema de diluição dos gases de $\mathrm{O}_{2}$ e $\mathrm{N}_{2}$ (SANTOS, BRAGA, SALCEDO, 2013).

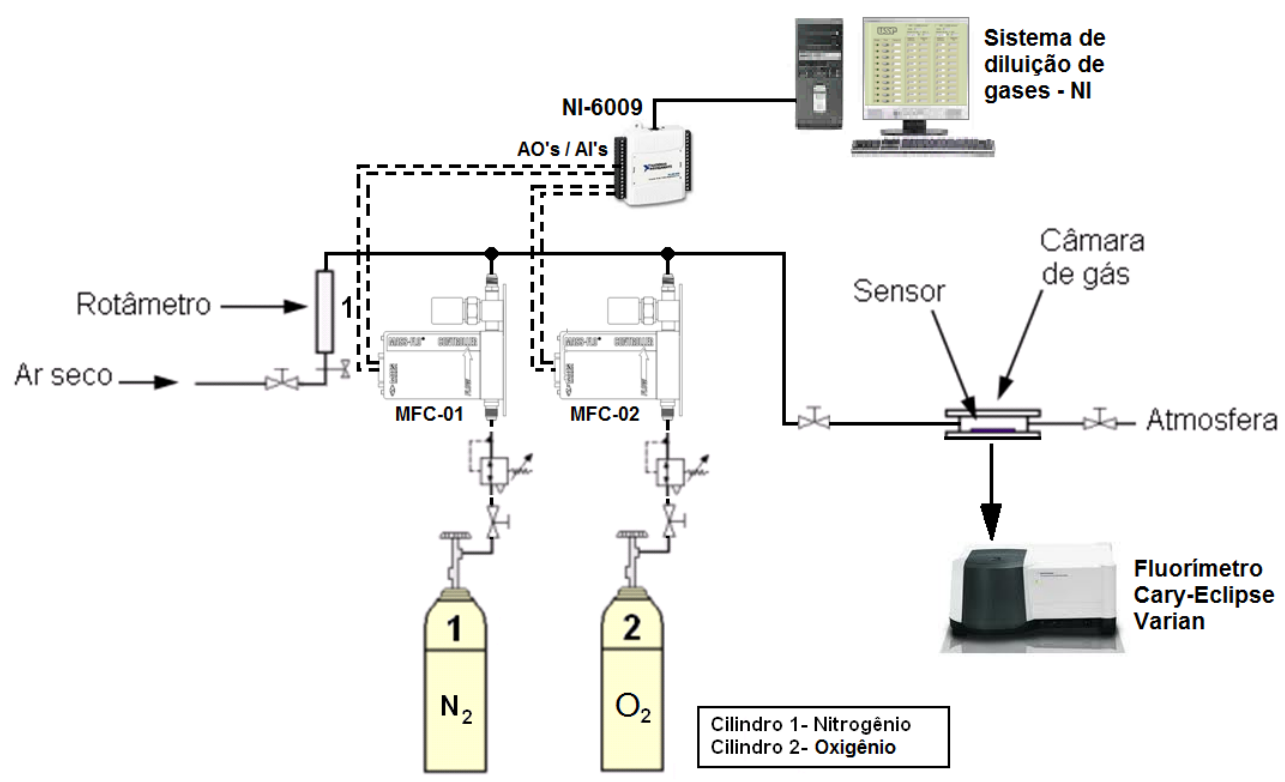

Figura 8 -Diagrama esquemático do arranjo do sistema de diluição de oxigênio e nitrogênio para a caracterização das estruturas Vidro/PS(PtOEP) e ox.p.Si/PtOEP.

\subsubsection{Sistema de controle de oxigênio dissolvido em água deionizada}

Para a injeção dos gases de $\mathrm{O}_{2}$ e $\mathrm{N}_{2}$ (processo de oxigenação e desoxigenação) no sistema de controle de oxigênio dissolvido em água DI, utilizou-se um frasco kitasato de $250 \mathrm{ml}$, com eletrodo do tipo Clark submerso em $200 \mathrm{ml}$ de água deionizada e 
conectado a um oxímetro digital Digimed, modelo DM-4P. A utilização deste instrumento permitiu o monitoramento contínuo do oxigênio dissolvido no meio, durante os ensaios. A injeção da mistura gasosa de $\left(\mathrm{O}_{2}\right.$ e $\left.\mathrm{N}_{2}\right)$ no interior do kitasato foi realizada por meio de um borbulhador metálico a fim de se reduzir ao máximo o tamanho das bolhas, facilitando a oxigenação ou desoxigenação do meio líquido e permitindo a redução do tempo morto do sistema de controle. O bombeamento da água deionizada com oxigênio dissolvido controlado foi realizado por uma bomba peristáltica marca Milan, mod. 204. A Figura 9 mostra o diagrama esquemático do sistema utilizado para a obtenção de diferentes concentrações de oxigênio dissolvido.

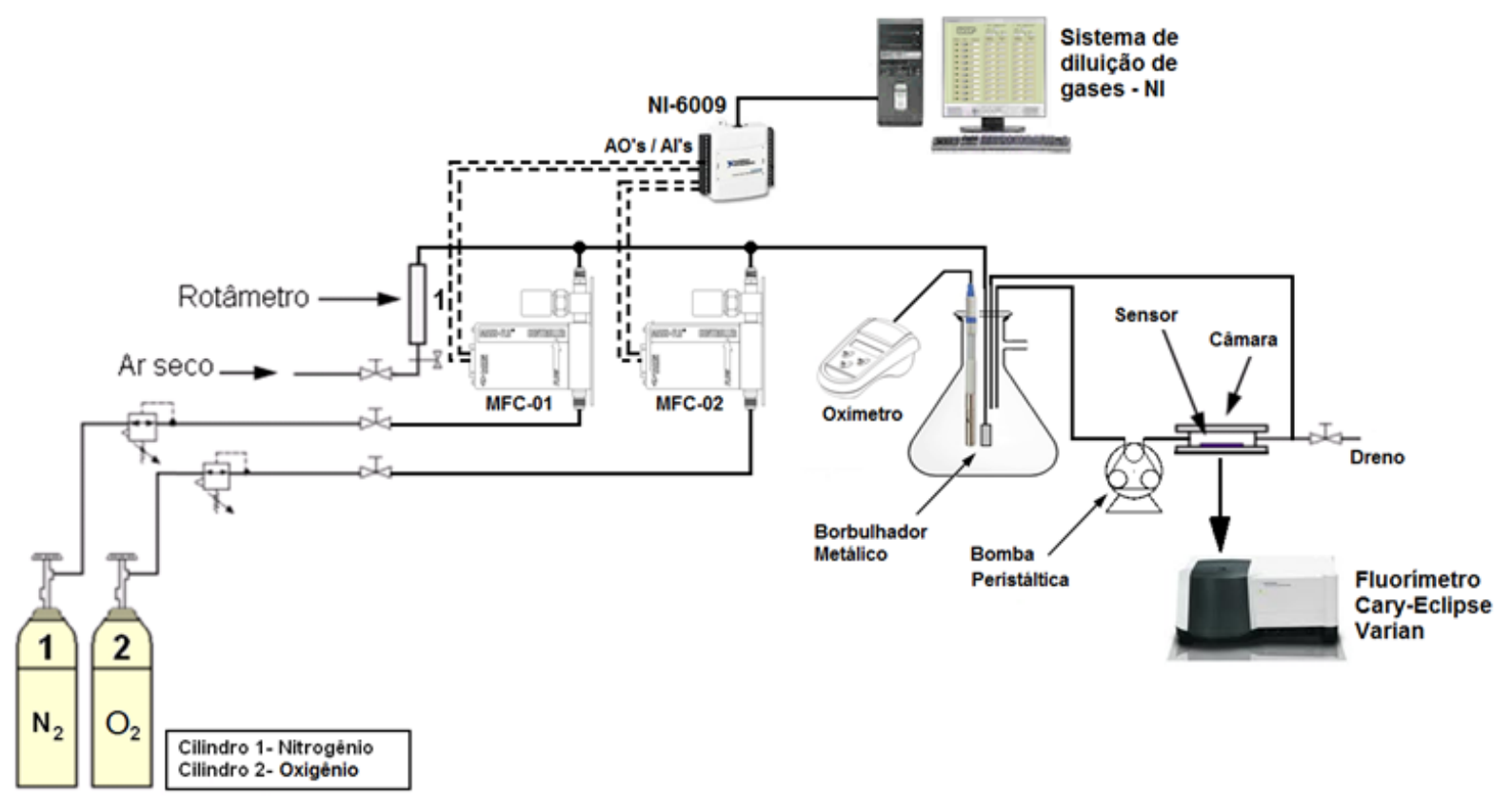

Figura 9 -Diagrama esquemático do arranjo sistema de controle de oxigênio dissolvido em água deionizada.

Para os ensaios da resposta espectral de fluorescência, as amostras de vidro e silício foram caracterizadas por um espectrofotômetro de fluorescência, modelo Cary Eclipse, da marca Varian. Para todos os ensaios o comprimento de onda da energia de excitação foi $380 \mathrm{~nm}$, o que corresponde ao máximo da banda de absorção das moléculas de PtOEP. Adicionalmente, este aparelho foi usado para identificar as bandas de absorção das moléculas de PtOEP utilizando espectros de excitação através da fixação da energia de emissão em $644 \mathrm{~nm}$, que é o ponto máximo da emissão fotoluminescente das moléculas de PtOEP. 


\subsubsection{Arranjo experimental do sistema de medida do tempo de resposta e regeneração dos dispositivos para ambientes líquidos}

Nos ensaios do tempo de resposta e regeneração dos dispositivos para ambientes com oxigênio dissolvido, uma válvula de controle direcional $5 / 2$ vias, com acionamento por duplo solenoide foi utilizada para permitir a transição de ambiente de oxigênio dissolvido quase nulo, presente em KT-01 (0,4 mg/l), para uma concentração de 100\% de oxigênio dissolvido, presente em KT-02 (aprox. 40,0 mg/l), inserido à uma câmara hermeticamente fechada, a ser detalhada e ilustrada na próxima seção. O controle foi realizado pelo acionamento das válvulas solenoides S1 e S2 comandadas pelo aplicativo por duas saídas digitais localizadas na placa de aquisição e controle. Para evitar variações na concentração do OD internamente em cada um dos kitasatos (KT01 e KT-02), uma válvula de controle direcional 3/2 vias, com acionamento por solenoide e retorno por mola foi instalada na saída da câmara. $\mathrm{O}$ acionamento desta válvula (S3) ocorre sempre segundos após S1 ou S2 ser acionada, pois permite que todo líquido remanescente dentro da linha e da câmara, seja retornado para seu correspondente kitasato, sob condições bem próximas àquelas encontradas antes da nova condição de ensaio. As vazões das bombas peristálticas B01 e B02 foram mantidas iguais e constantes, durantes os ensaios. A Figura 10 mostra o diagrama esquemático do arranjo do sistema de controle de oxigênio dissolvido para ensaios de cinética e tempo de resposta.

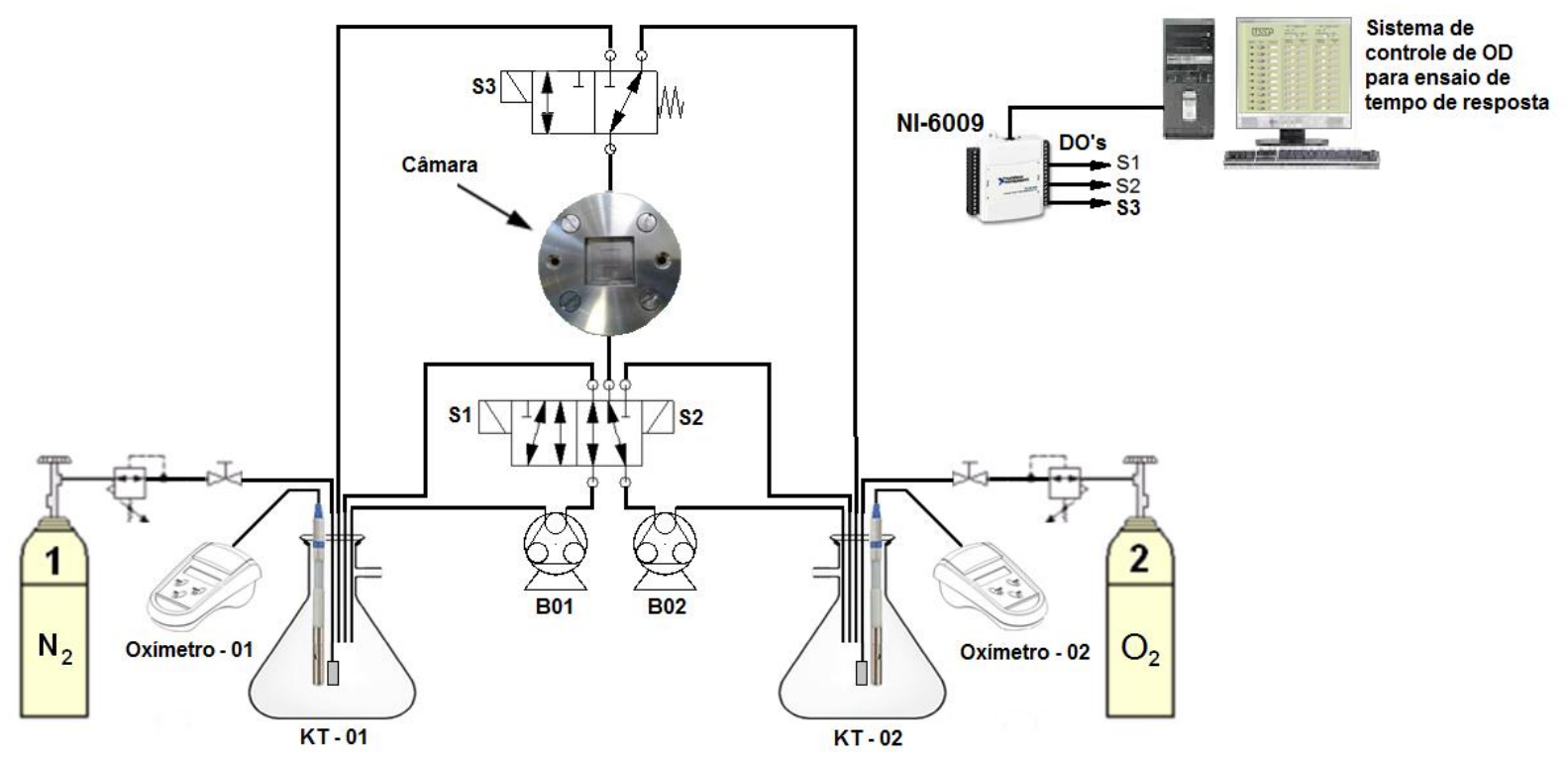

Figura 10 -Diagrama esquemático do arranjo do sistema de controle de oxigênio dissolvido para ensaios de cinética e tempo de resposta. 


\subsubsection{Câmara de ensaios para montagem dos sensores para teste em ambientes gasosos e líquidos}

Para condicionamento dos sensores (Vidro/PS(PtOEP), ox.p.Si/PtOEP), em ambientes de $\mathrm{O}_{2}$ e OD, foram projetados dois modelos de câmara de ensaio.

Em ambientes gasosos, os sensores foram inseridos dentro de uma câmara construída em alumínio com janela de vidro para entrada e saída da luz (Figura 11). Esta câmara foi desenvolvida por Matos (2011), e utilizada neste trabalho para ensaios em ambientes gasosos de $\mathrm{N}_{2}$ e $\mathrm{O}_{2}$.

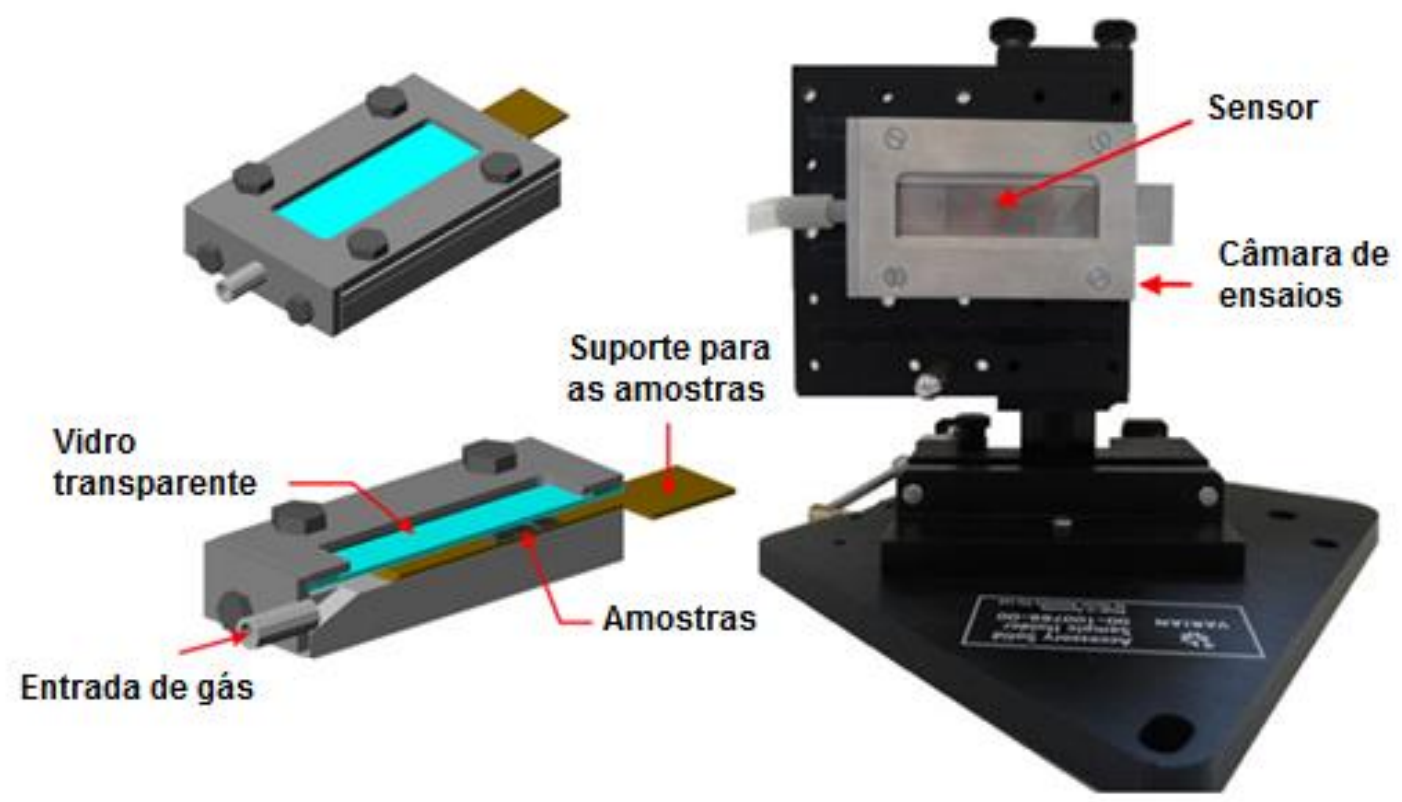

Figura 11 -À esquerda, vista 3D e em corte da câmara de ensaios; à direita, imagem da câmara real com os filmes sensíveis depositados no interior da câmara fixada no suporte do fluorímetro. A câmara possui uma saída para os gases, aberta à atmosfera (MATOS, 2011).

Já para os ensaios em ambientes líquidos, foi desenvolvida uma câmara metálica, com volume interno de $12 \mathrm{~cm}^{3}$. A câmara é composta por uma base de aço inox, com dois orifícios de acessibilidade ao interior da câmara, para a entrada e a saída dos líquidos em análise. Os orifícios são limitados por um o'ring de borracha e passam internamente do corpo da base até à borda, sendo conectados em dois terminais do tipo espigão $(\Phi=4 \mathrm{~mm})$, utilizados para acoplar uma mangueira de silicone à bomba peristáltica. Na parte superior da base, há uma tampa também fabricada em aço inox com uma janela de vidro para permitir a entrada e a saída da luz. Os detalhes podem ser vistos na Figura 12. 

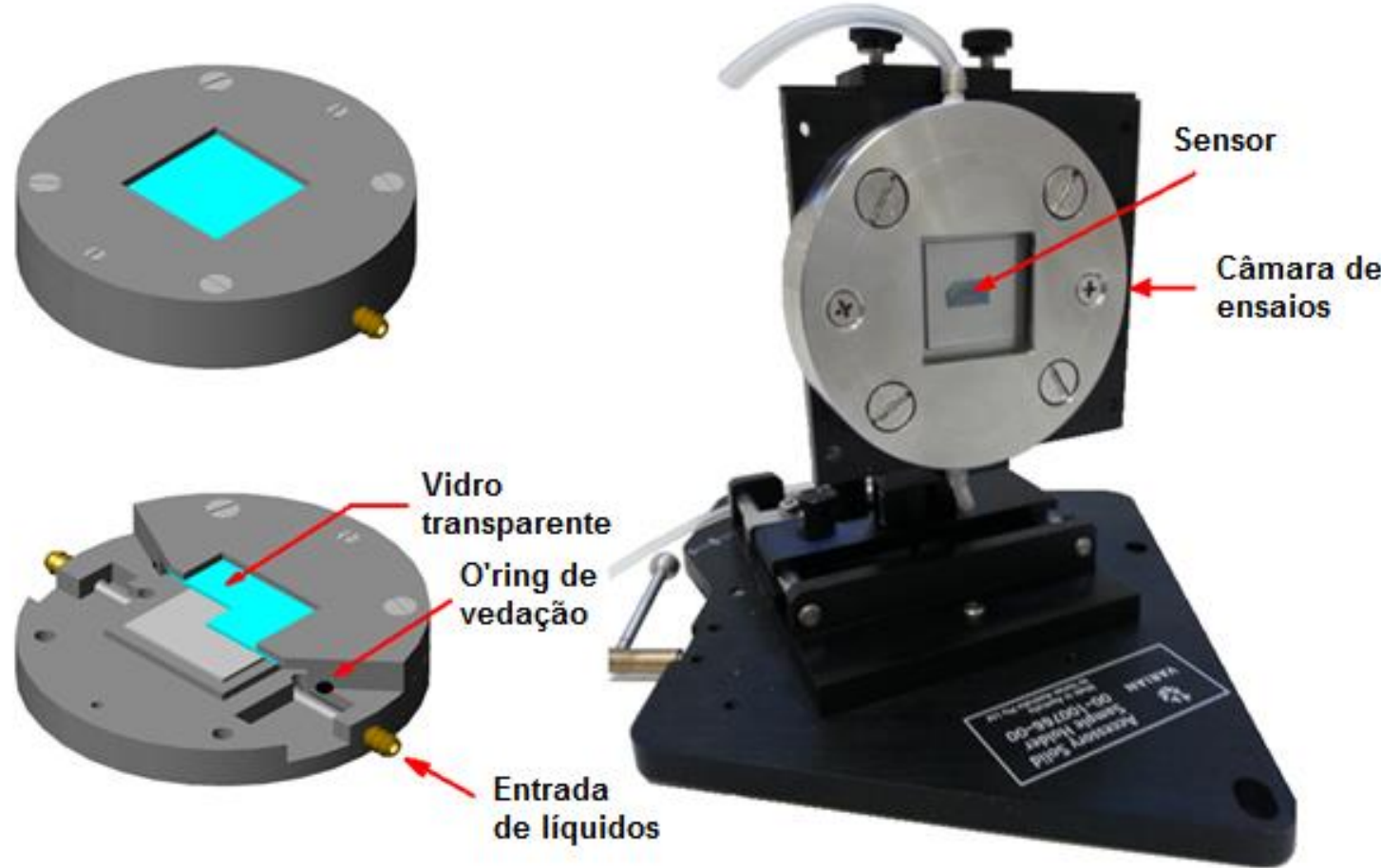

Figura 12 -À esquerda, vista 3D e em corte da câmara de ensaios; à direita, imagem da câmara real com os filmes sensíveis depositados no interior da câmara fixada no suporte do fluorímetro. A câmara possui uma saída de líquidos, em circuito fechado pela bomba peristáltica.

\subsubsection{Medidas de fluorescência}

Para medição da resposta fotoluminescente das amostras aos ambientes de $\mathrm{O}_{2}$ e $\mathrm{OD}$, utilizou-se um equipamento denominado de fluorímetro, cujo princípio de funcionamento baseia-se na medição da fluorescência pela excitação de uma fonte de luz colocada a um ângulo de $90^{\circ}$ em relação ao posicionamento do detector de emissão. A radiação de excitação é fornecida por uma lâmpada de xenônio controlada por um circuito flash que permite obter larguras de pulsos de aproximadamente 2 a 3 $\mu \mathrm{s}$ e disparos até 80 vezes por segundo. Esta energia luminosa é adquirida por um sistema coletor Schwartzchild e então focalizada através de uma lente até a abertura regulável de uma fenda. A partir daí, a luz passa por um monocromador de excitação até à superfície da amostra. A fluorescência resultante passa através de um monocromador de emissão e é detectada por um fotomultiplicador. Ambos os monocromadores são do tipo Czerny-Turner, com as seguintes características: grade de dispersão (30 x $35 \mathrm{~mm}, 1200$ linhas / mm), precisão de $\pm 1,0 \mathrm{~nm}$ e repetibilidade no ajuste do comprimento de onda de $\pm 0,2 \mathrm{~nm}$. A rotação da grade dentro de cada 
monocromador permite a seleção do comprimento de onda. A Figura 13 ilustra os principais componentes internos de um fluorímetro.

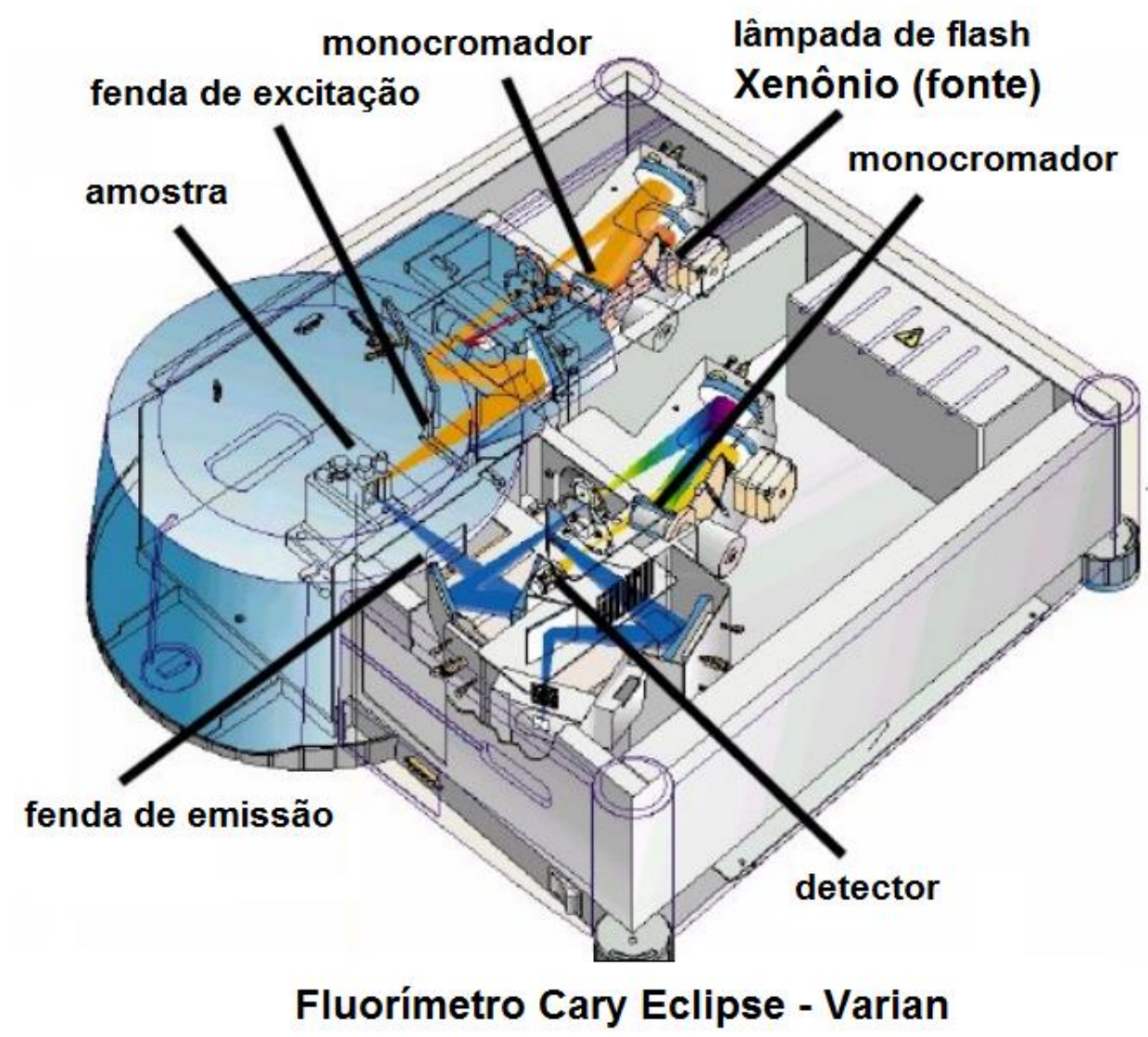

Figura 13 -Detalhes construtivos do espectrofotômetro de fluorescência (fluorímetro), modelo Cary Eclipse e marca Varian.

Para a realização dos ensaios de fluorescência foi utilizado o fluorímetro da marca Varian, modelo Cary Eclipse, com parâmetros de leitura apresentados na Tabela 1.

Tabela 1 - Parâmetros de configuração do fluorímetro para obtenção do espectro de fotoluminescência das amostras.

\begin{tabular}{llc}
\hline \multicolumn{2}{c}{ Modo de operação } & Fluorescência \\
\hline Comprimento & Excitação & $382 \mathrm{~nm}$ \\
\cline { 2 - 3 } de onda $(\boldsymbol{\lambda})$ & Emissão & $600 \sim 780 \mathrm{~nm}$ \\
\hline \multirow{2}{*}{ Fendas } & Excitação & $5 \mathrm{~nm}$ \\
\cline { 2 - 3 } & Emissão & $5 \mathrm{~nm}$ \\
\hline \multirow{2}{*}{ Filtros } & Excitação & Automático \\
\cline { 2 - 3 } & Emissão & Aberto \\
\hline
\end{tabular}




\subsection{Resultados e Discussões}

\subsubsection{Emissão luminescente da molécula de PtOEP em substratos de vidro e silício poroso}

A Figura 14 apresenta o espectro de excitação normalizado a partir do filme de poliestireno dopado com moléculas corantes de PtOEP em substrato de vidro (Vidro/PS(PtOEP)) e moléculas de PtOEP diluídas em clorofórmio adsorvidas na camada de silício poroso oxidada (ox.p.Si/PtOEP), respectivamente.

$O$ ensaio para obtenção do espectro foi realizado em ambiente inerte $\left(N_{2}\right)$, sendo a emissão da fotoluminescência fixada em $644 \mathrm{~nm}$ e faixa de varredura configurada de $250 \mathrm{~nm}$ a $580 \mathrm{~nm}$.

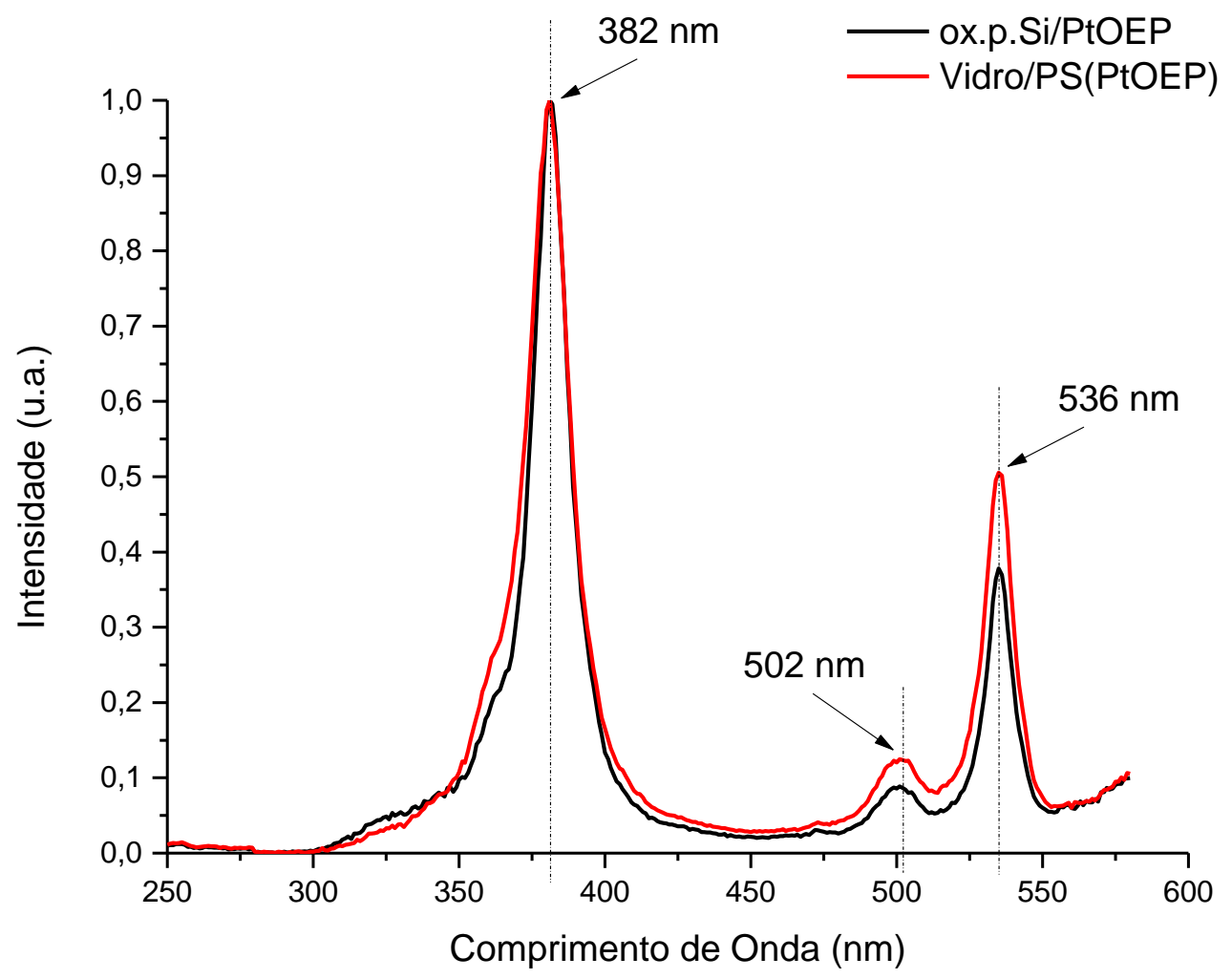

Figura 14 -Espectro de excitação normalizado de um filme de poliestireno dopado com moléculas corantes de PtOEP em substrato de vidro (Vidro/PS(PtOEP)) e moléculas PtOEP adsorvidas na camada de silício poroso oxidada (ox.p.Si/PtOEP). 
A molécula de PtOEP caracteriza-se por uma banda Soret de alta intensidade próxima a $382 \mathrm{~nm}$, seguida por duas outras bandas com picos menores (502 e $536 \mathrm{~nm}$ ), denominadas bandas Q (YIN et al., 2011). Nenhum deslocamento espectral de bandas foi observado entre os espectros das amostras de Vidro/PS(PtOEP) e ox.p.Si/PtOEP, sugerindo que as moléculas corantes não reagiram quimicamente com os substratos hospedeiros. Por outro lado, há uma diferença relativa de intensidade da banda Soret para a banda $Q$, sendo observado que a taxa para a amostra Vidro/PtOEP/PS é mais alta do que ox.p.Si/PtOEP. Esta diferença pode ser atribuída a diferentes adsorções superficiais da molécula PtOEP em cada um dos substratos.

É importante mencionar que as moléculas de PtOEP têm pontos de excitação nas regiões violeta (382 $\mathrm{nm}$ ) e verde $(536 \mathrm{~nm})$, as quais podem ser obtidas por dispositivos LEDs comerciais, oferecendo alta possibilidade de aplicação em sistemas sensores.

\subsubsection{Análise de resposta de sensibilidade dos sensores Vidro/PtOEP/PS e ox.p.Si/PtOEP em ambientes de $\mathrm{O}_{2}$.}

Os ensaios dos sensores foram realizados seguindo os procedimentos e métodos relatados nos itens 2.2.3 e 2.2.6, sendo obtidos os espectros de fotoluminescência dos dispositivos formados pela estrutura de Vidro/PtOEP/PS em duas diferentes condições de deposição do filme de PtOEP/PS pelo processo de spin coating (1000 e 3000 RPM). No caso das amostras de ox.p.Si/PtOEP (L 55 e L 63), os espectros obtidos foram distinguidos a partir de duas condições de oxidação utilizadas para passivação do silício poroso, relatadas na seção 2.2.2. Para ambos os tipos de dispositivos, as amostras foram excitadas por uma fonte de luz com comprimento de onda de $382 \mathrm{~nm}$. Nestes ensaios os sensores foram submetidos a ambientes de diferentes concentrações de oxigênio, segundo o arranjo experimental ilustrado na Figura 8, com vazão controlada de $10 \mathrm{l} / \mathrm{min}$.

As mudanças na intensidade da fotoluminescência pela presença do oxigênio em estado fundamental triplete, sob interações eletrônicas, com a molécula de PtOEP, podem ser vistas na Figura 15a e na Figura 15b para Vidro/PtOEP/PS, nas condições de deposição em 1000 e 3000 RPM; e em seguida, na Figura 16a e na Figura 16b 
são apresentados os resultados para as amostras L 55 e L 63 de estrutura ox.p.Si/PtOEP, respectivamente.

a)

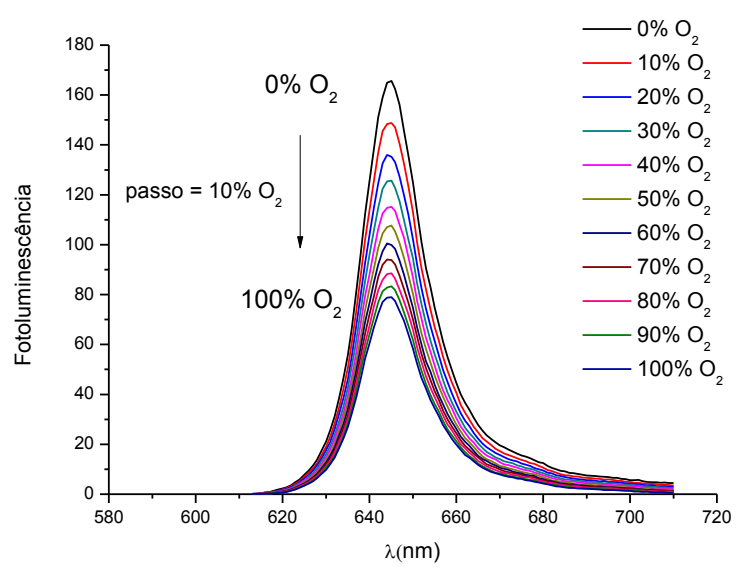

b)

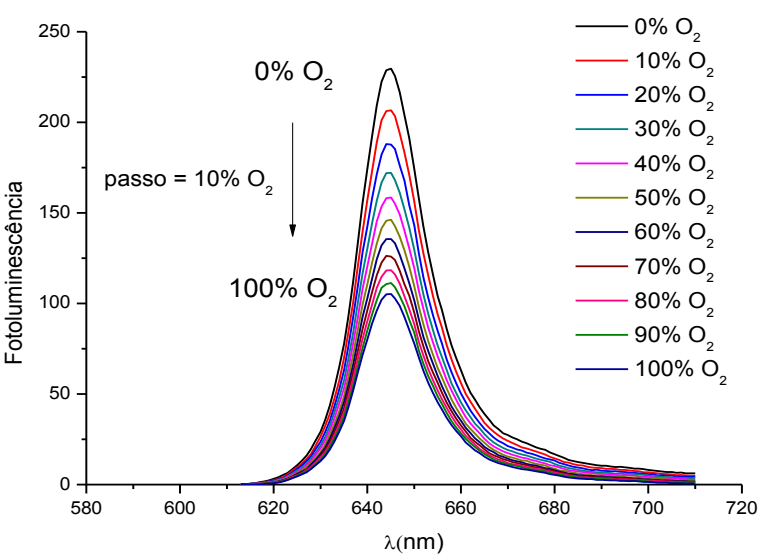

Figura 15 -a) Espectros de emissão fotoluminescente do dispositivo Vidro/PtOEP/PS em condição de deposição do filme em 1000RPM. b) Espectros de emissão fotoluminescente do dispositivo Vidro/PtOEP/PS em condição de deposição do filme em 3000RPM.

a)

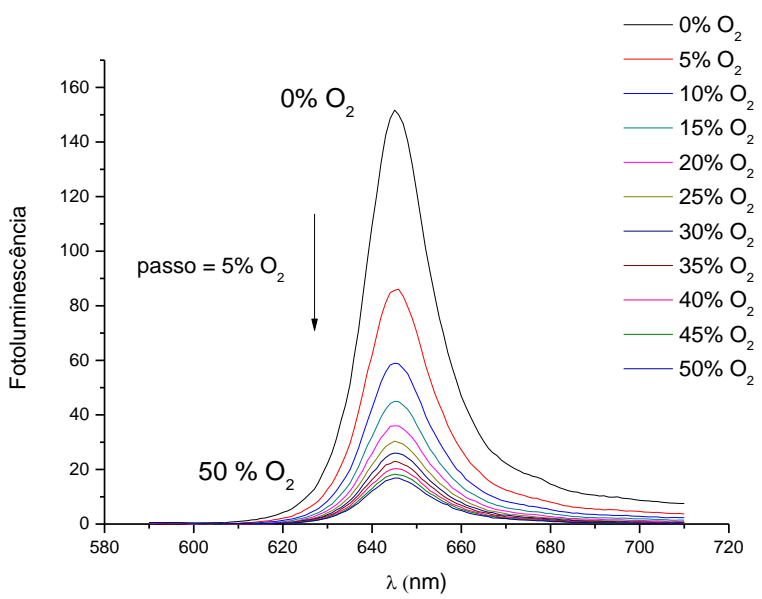

b)

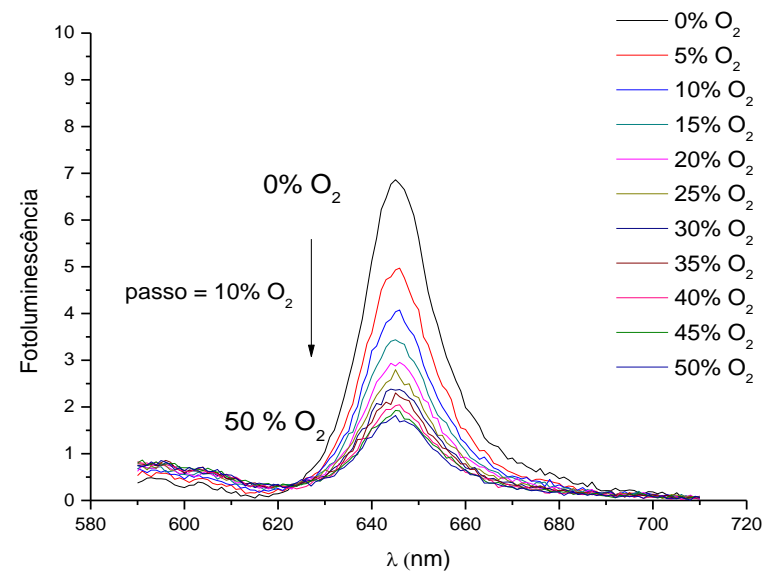

Figura 16 -a) Espectros de emissão fotoluminescente do dispositivo $L 55$ e estrutura de ox.p.Si/PtOEP b) Espectros de emissão fotoluminescente do dispositivo L 63 e estrutura de ox.p.Si/PtOEP.

Com base nos resultados obtidos e mostrados pelos gráficos, a supressão da emissão fotoluminescente para os dispositivos de Vidro/PtOEP/PS foi possível de ser realizada para uma variação de concentração de 0 a $100 \%$ de $\mathrm{O}_{2}$. Entretanto, para os dispositivos de ox.p.Si/PtOEP, as respostas ficaram restritas na faixa de 0 a 50\%. Isso se deve à alta eficiência de supressão do silício poroso oxidado com as moléculas de 
PtOEP por interação com o oxigênio, provocando a saturação em torno de $50 \%$ de $\mathrm{O}_{2}$.

Quando as moléculas corantes (PtOEP) são excitadas por uma fonte de luz em 382 $\mathrm{nm}$, o mecanismo de supressão da fotoluminescência na presença de $\mathrm{O}_{2}$ acontece devido à transição eletrônica do estado fundamental S0 para o estado excitado S1 e por haver uma forte interação spin-órbita entre o elétron do subnível "d" da Pt e o orbital antiligante $\pi^{\star}$ dos anéis da porfirina. Neste processo, o estado excitado S1 se relaxa e é convertido em estado triplete T1 (cruzamento intersistema). Esta transição possui quase 100\% de eficiência (KOSE, 2005; LEE; OKURA, 1997). Sendo a transição radioativa de T1 para S0 proibida por spin, o estado excitado terá longos tempos de vida (fosforescência) (KOSE, 2005; LEE; OKURA, 1997). Desta forma, se o sistema fotoluminescente for colocado em um ambiente oxigenado, haverá grande probabilidade de interação do estado triplete $\mathrm{T} 1$ da molécula de PtOEP com o $\mathrm{O}_{2}$, levando ao efeito de supressão da fotoluminescência. Assim, a alta sensibilidade dos dispositivos está associada aos grandes tempos de vida do estado triplete da molécula PtOEP, permitindo a interação com oxigênio em estado fundamental triplete que suprime a emissão fosforescente (KOSE, 2005; LEE; OKURA, 1997).

Apesar das mudanças nas intensidades das emissões ópticas da matriz hospedeira ao oxigênio darem margens à possibilidade de aplicações na fabricação de elementos sensores de oxigênio, os resultados das análises da resposta fotoluminescente desses dispositivos mostram comportamento não-linear que podem ser condicionados a metodologias de linearização de sinais. Tais sensores são baseados nas intensidades de luminescência pela concentração do supressor que, de acordo com a tradicional relação Stern-Volmer, deve proporcionar um modelo de calibração linear de acordo com a Equação 4 (CHUANG; ARNOLD, 1998):

$$
I_{0} / I=\tau_{0} / \tau=1+k_{q} \tau_{0}\left[O_{2}\right]
$$

Onde lo e I correspondem à intensidade fotoluminescente na ausência (0\%) e presença (não zero \%) de concentração de $\mathrm{O}_{2}$; $\tau_{0}$ e $\tau$ são os tempos de vida dos estados à ausência de oxigênio e à concentração de oxigênio, respectivamente. A constante $\mathrm{k}_{\mathrm{q}}$ é dependente das constantes físicas do sistema e, sob condições experimentais definidas, pode ser considerada constante. Através da Equação 4, é 
possível fazer medições dos tempos de vida ou das intensidades de luminescência e então relacionar essas medições às concentrações de oxigênio (AMAO; ISHIKAWA; OKURA, 2001; AMAO; TAKEUCHI, 2005). Pode-se também simplificar a Equação 4 para Equação 5, permitindo a partir da análise e caracterização das amostras, obter a constante de Stern-Volmer, que define sua sensibilidade e é dependente das moléculas fotoluminescentes e das características construtivas do dispositivo (DEMAS; DEORA; XUT, 1995).

$$
I_{0} / I=1+k_{S V}\left[O_{2}\right]
$$

Onde ksv é a constante de Stern-Volmer do sensor.

$\mathrm{Na}$ Figura 17a e na Figura 17b são apresentados os gráficos dos espectros de emissão fotoluminescente, conforme metodologia de linearização pela relação de Stern-Volmer para os dispositivos Vidro/PtOEP/PS e ox.p.Si/PtOEP, respectivamente.

a)

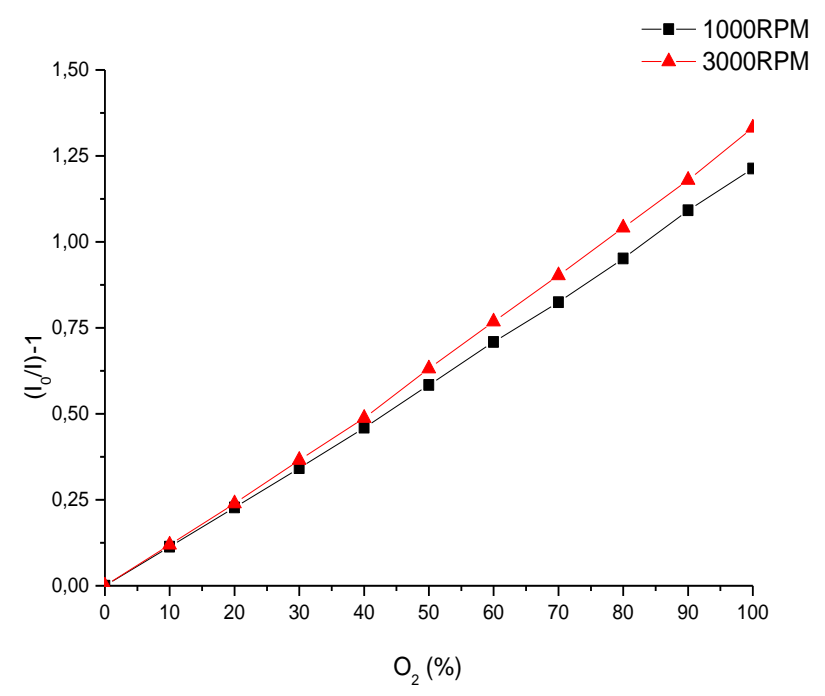

b)

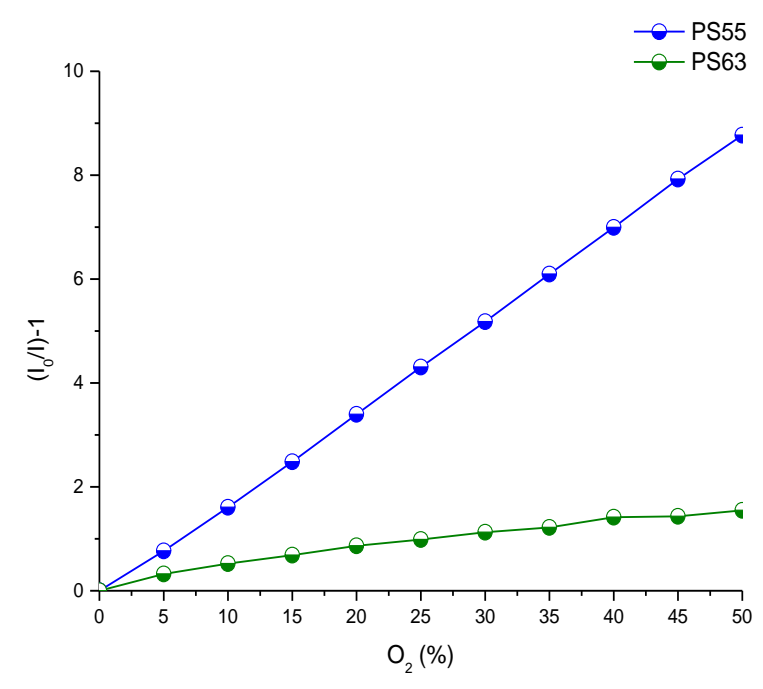

Figura 17 -Curvas de Stern-Volmer da intensidade de supressão fotoluminescente da molécula de PtOEP para os dispositivos: a) Vidro/PtOEP/PS (1000RPM e 3000RPM) e b) ox.p.Si/PtOEP (L 55 e L 63), respectivamente.

A Figura 17 mostra significativa melhoria da sensibilidade do dispositivo de ox.p.Si/PtOEP (L 55) comparado aos dispositivos de Vidro/PtOEP/PS (1000 RPM e 3000 RPM). Isso pôde ser comprovado pelos parâmetros de Ksv extraídos dos gráficos e evidenciam que as características estruturais da superfície ativa do silício 
poroso promovem deslocamento de range de operação para valores de concentração abaixo de $50 \%$.

Para uma análise comparativa e discussão dos resultados entre os dois dispositivos, a Figura 18 reúne a melhor condição de resposta de Vidro/PtOEP/PS (3000 RPM) e do dispositivo de ox.p.Si/PtOEP ( $L$ 55) para os ensaios de intensidade de supressão em função da concentração de $\mathrm{O}_{2}$.

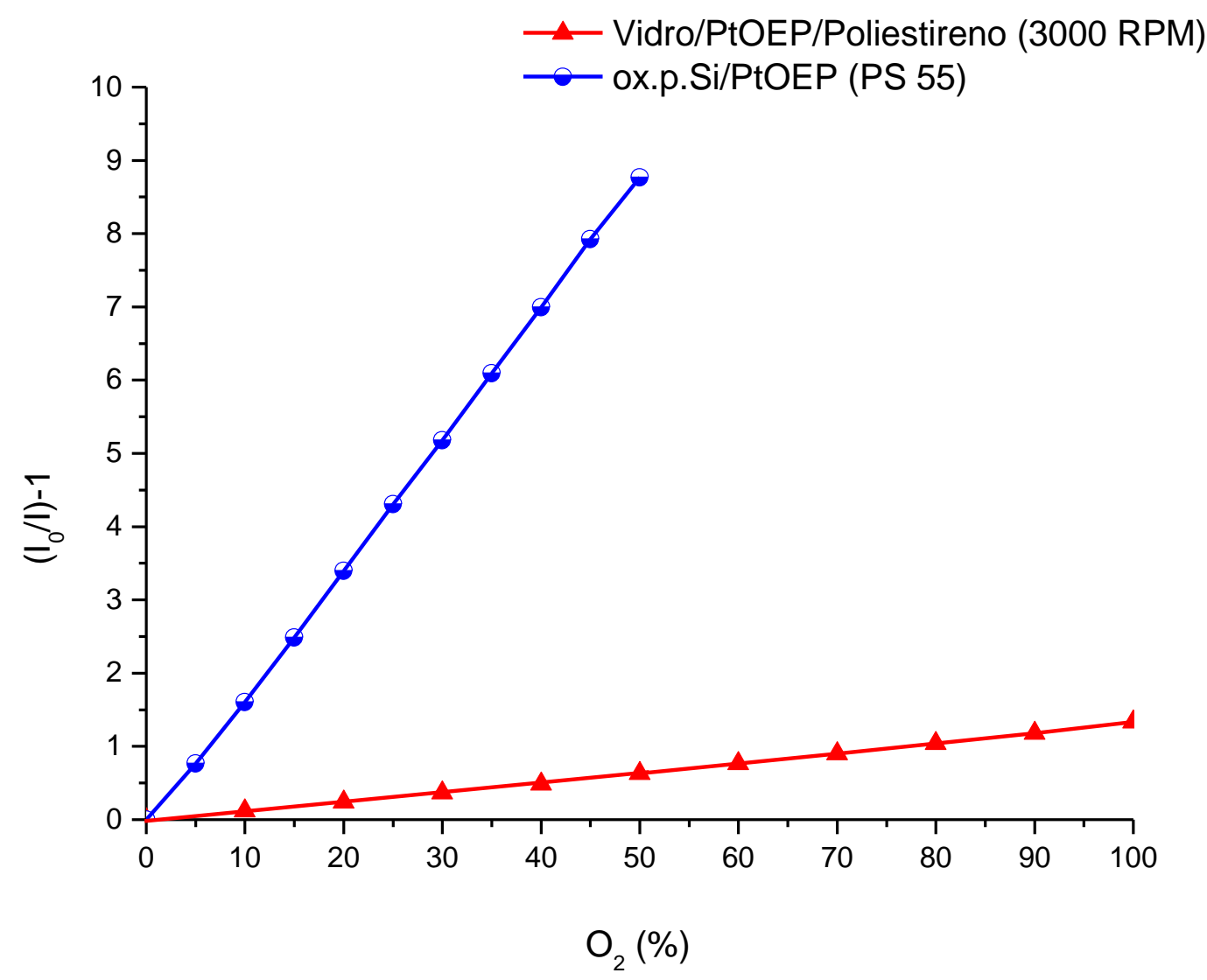

Figura 18 -Curvas de Stern-Volmer da intensidade de supressão fotoluminescente da molécula de PtOEP para os dispositivos Vidro/PtOEP/PS (3000RPM) e ox.p.Si/PtOEP (L 55), respectivamente.

É notável que a resposta de ambos os dispositivos segue a relação de Stern-Volmer, e, após uma adequação linear, os coeficientes foram 0.0133 e 0.1775 para Vidro/PtOEP/PS (3000 RPM) e ox.p.Si/PtOEP (L 55), respectivamente. A partir destes resultados evidencia-se que a resposta do sensor baseado em silício poroso oxidado foi treze vezes mais sensível do que o dispositivo de poliestireno em vidro. Sabe-se que o coeficiente depende do tempo de vida das moléculas corantes e do coeficiente de difusão de $\mathrm{O}_{2}$ na camada ativa do sensor. $\mathrm{O}$ argumento mais plausível para explicar este comportamento relaciona-se a diferentes probabilidades de cada colisão de moléculas de $\mathrm{O}_{2}$ causando supressão. Esta probabilidade poderia ser maior no 
dispositivo de silício poroso oxidado do que no filme de poliestireno, pois as moléculas corantes são adsorvidas somente na área superficial do silício poroso oxidado e por todo o volume no filme de poliestireno. A Tabela 2 apresenta os principais parâmetros de resposta dos sensores.

Tabela 2 - Taxa $\mathrm{I}_{0} / \mathrm{l}$ relacionada a $0 \%$ e $100 \%$ ou $50 \%$ de concentração de $\mathrm{O}_{2}$ e os coeficientes de Stern-Volmer.

\begin{tabular}{lll}
\hline Estrutura do dispositivo & Io/l & Ksv $\left(\%^{-1}\right)$ \\
\hline Vidro/PtOEP/PS & 2,20 & $0.013^{a}$ \\
\hline ox.p.Si/PtOEP & 8,90 & $0.18^{\mathrm{b}}$ \\
\hline
\end{tabular}

a. Concentrações de oxigênio variando de 0-100\%

b. Concentrações de oxigênio variando de 0-50\%

\subsubsection{Resposta dinâmica dos dispositivos Vidro/PtOEP/PS (3000 RPM) e ox.p.Si/PtOEP (L 55) para ambiente de $\mathrm{O}_{2}$ e inerte $\left(\mathrm{N}_{2}\right)$}

Na Figura 19a e na Figura 19b são apresentadas as respostas dinâmicas dos sensores Vidro/PtOEP/PS (3000 RPM) e ox.p.Si/PtOEP (L 55) obtidas após submetêlos a diferentes ambientes, alternando injeções de 100\% de nitrogênio e 100\% de oxigênio dentro da câmara. Nestes ensaios a temperatura permaneceu constante a $26 \stackrel{\circ}{\circ}$. O tempo de resposta do sensor Vidro/PtOEP/PS depois de injeção de $100 \%$ de $\mathrm{O}_{2}$ foi de $69 \mathrm{~ms}$ e $223 \mathrm{~ms}$ para ox.p.Si/PtOEP. Os tempos de recuperação dos sensores foram 140 ms e 2590 ms para poliestireno e silício poroso oxidado, respectivamente. Estes tempos foram obtidos por meio de avaliação dos instantes de $10 \%$ e $90 \%$ da distância da intensidade fotoluminescente inicial e final no processo de troca. Ambos os sensores apresentam rápidos tempos de resposta, entretanto, o tempo de recuperação de silício poroso é relativamente maior (2.59 s), sugerindo que o processo de difusão na camada de silício poroso é mais baixo do que na camada de poliestireno. Estes resultados podem sugerir que o tempo de resposta dos sensores é limitado pelo processo de difusão, mas a sensibilidade dos sensores é limitada pela probabilidade de colisão de $\mathrm{O}_{2}$, causando a supressão da emissão fotoluminescente de PtOEP. 
a)

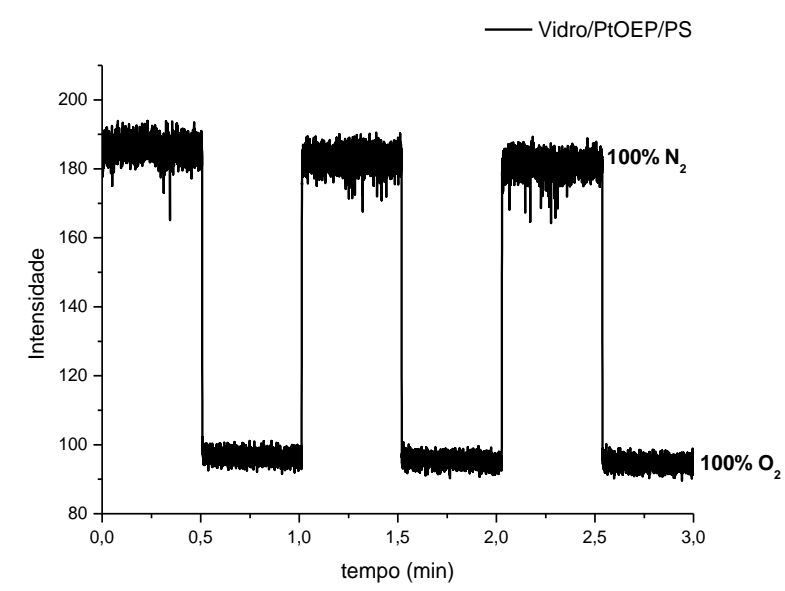

b)

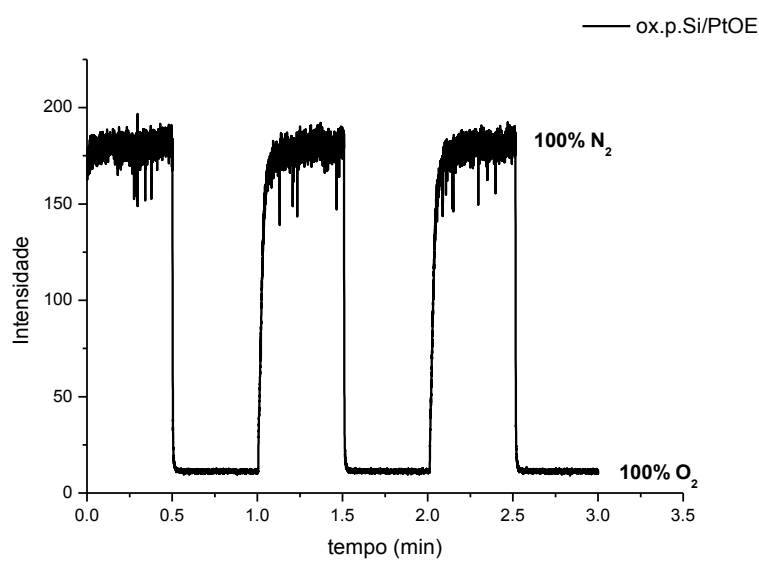

Figura 19 -Resposta dinâmica dos sensores (a) Vidro/PtOEP/PS (3000 RPM) e (b) ox.p.Si/PtOEP (L 55), respectivamente.

\subsubsection{Efeitos de fotodegradação das moléculas de PtOEP para ambientes oxigenados nos dispositivos de Vidro/PtOEP/PS (3000 RPM) e ox.p.Si/PtOEP (L 55)}

Para o estudo do comportamento dos dispositivos Vidro/PtOEP/PS (3000 RPM) e ox.p.Si/PtOEP ( $L 55)$ nos ensaios de fotodegradação foi utilizado o arranjo ilustrado na Figura 8, onde foram avaliadas as reduções da intensidade fotoluminescente dos dispositivos ao longo de 60 min de exposição contínua à fonte de excitação (lâmpada de xenônio) sem atenuador e na instalação de um filtro óptico de absorção de 1,5 Abs. Neste intervalo, foram efetuadas medições de intensidades de emissão das moléculas de PtOEP nas matrizes hospedeiras de poliestireno e silício poroso em meio gasoso de $100 \%$ de $\mathrm{N}_{2}$ e $100 \%$ de $\mathrm{O}_{2}$, de forma alternada. Nos ensaios foram observadas as reduções da intensidade de fotoluminescência, bem como as variações da supressão em todo intervalo de estudo. Todos os testes foram realizados em temperatura ambiente de $26 \stackrel{\circ}{\circ}$.

$\mathrm{Na}$ Figura 20a e na Figura 20b observam-se diminuições progressivas da intensidade de medida da fotoluminescência para os intervalos onde há presença do oxigênio no meio. 
a)

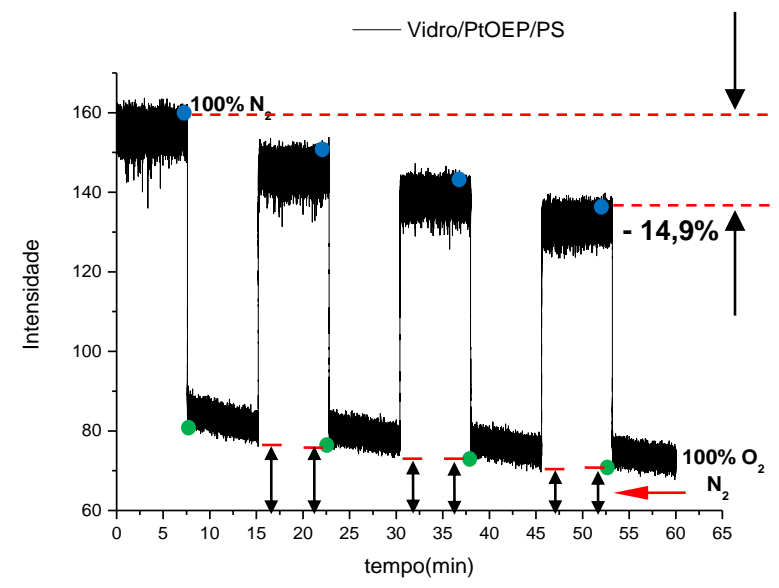

b)

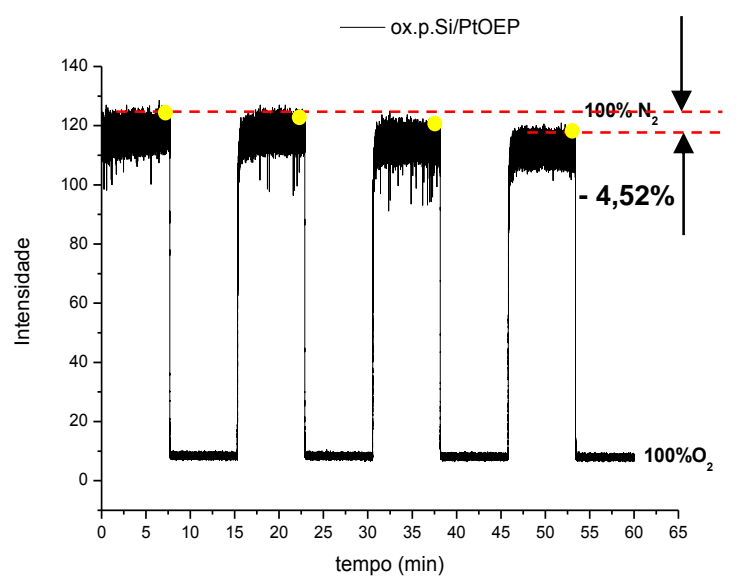

Figura 20 -Variação da intensidade fotoluminescente para ambientes de $100 \% \mathrm{~N}_{2}$ e $100 \% \mathrm{O}_{2}$ (a) Vidro/PtOEP/PS (3000 RPM) e (b) ox.p.Si/PtOEP (L 55), respectivamente.

Considerando o último valor de intensidade na transição de ambiente inerte para saturação de oxigênio (pontos azuis), nos quatro ciclos sucessivos, nota-se redução de aproximadamente $14,9 \%$ dos valores iniciais para ambiente inerte (parte superior do gráfico). Este comportamento pôde ser ajustado a um modelo polinominal de $2^{\mathrm{a}}$ ordem, sendo válido apenas para os $60 \mathrm{~min}$ de ensaio. A Tabela 3 mostra os parâmetros de ajuste.

Tabela 3 - Modelo de ajuste polinominal de $2^{\mathrm{a}}$ ordem (válido para os primeiros $60 \mathrm{~min}$ de ensaio).

\begin{tabular}{cccc}
\hline Equação & $\boldsymbol{y}=\boldsymbol{a} \cdot \boldsymbol{x}^{2}+\boldsymbol{b} \cdot \boldsymbol{x}+\boldsymbol{c}$ & Erro Padrão \\
\hline \multirow{2}{*}{ Valores } & $\mathrm{a}$ & 0,0051 & $8.20 \mathrm{E}-5$ \\
& $\mathrm{~b}$ & -0.85 & 0.0051 \\
& $\mathrm{c}$ & 167.65 & 0.065 \\
\hline
\end{tabular}

Nas condições de transição de ambiente saturado de oxigênio para ambiente inerte (pontos verdes), houve menor redução da intensidade fotoluminescente. Nos quatro ciclos sucessivos foram obtidos $12,1 \%$ de queda. Este comportamento pôde ser ajustado a um modelo linear, válido também para os 60 min de ensaio. A Tabela 4 mostra os parâmetros de ajuste.

Tabela 4 - Modelo de ajuste linear (válido para os primeiros 60 min de ensaio).

\begin{tabular}{lccc}
\hline \multicolumn{2}{l}{ Equação } & $\boldsymbol{y}=\boldsymbol{a}+\boldsymbol{b} \cdot \boldsymbol{x}$ & Erro Padrão \\
\hline \multirow{2}{*}{ Valores } & $\mathrm{a}$ & 82.79 & 0.071 \\
& $\mathrm{~b}$ & -0.22 & 0.0020 \\
\hline
\end{tabular}


Um detalhe importante para análise da fotodegradação é que no intervalo de 7,5 min, onde não houve a injeção do oxigênio (100\% de $\left.N_{2}\right)$ não se observou redução da fotoluminescência. A literatura reporta que os processos de fotodegradação dos fluoróforos (moléculas corantes) estão relacionados à formação de um subproduto ocorrido na dinâmica de supressão do $\mathrm{O}_{2}$, chamado de oxigênio singlete $\left({ }^{1} \mathrm{O}_{2}\right)$ (SCURLOCK; OGILBY, 1989). Este efeito é minimizado na ausência de oxigênio no meio. Hartmann; Leiner e Kohlbacher (1998) mostraram que o ataque do ${ }^{1} \mathrm{O}_{2}$ durante o mecanismo de detecção de $\mathrm{O}_{2}$ foi responsável pelo decréscimo do tempo de vida do fluoróforo de $\left[\mathrm{Ru}(\mathrm{dpp})_{3}\right]^{2+}$. $\mathrm{O}{ }^{1} \mathrm{O}_{2}$ neste caso promoveu a supressão da luminescência e mostrou uma banda de absorção em $600 \mathrm{~nm}$ que se sobrepôs ao espectro de emissão dos complexos de rutênio ( $\left.\lambda_{\text {em }}=605 \mathrm{~nm}\right)$.

Além do oxigênio presente no meio, três outros fatores podem propiciar mudanças nas condições de fotodegradação, são eles: a concentração da molécula corante (fluoróforo), tipo de matriz hospedeira e a intensidade da luz de excitação.

Os pontos em amarelo, indicados na Figura 20b, mostram que a estrutura de silício poroso sofreu menor ação da fotodegradação, tendo apenas $4,52 \%$ de redução na intensidade fotoluminescente comparados aos valores iniciais do ensaio. Este comportamento pôde ser ajustado a um modelo polinominal de $2^{\underline{a}}$ ordem, sendo válido apenas para os 60 min de ensaio. A Tabela 5 mostra os parâmetros de ajuste.

Tabela 5 - Modelo de ajuste polinominal de $2^{\mathrm{a}}$ ordem (válido para os primeiros $60 \mathrm{~min}$ de ensaio.

\begin{tabular}{cccc}
\hline Equação & $\boldsymbol{y}=\boldsymbol{a} \cdot \boldsymbol{x}^{\mathbf{2}}+\boldsymbol{b} \cdot \boldsymbol{x}+\boldsymbol{c}$ & Erro Padrão \\
\hline \multirow{2}{*}{ Valores } & $\mathrm{a}$ & -0.0012 & $5.38 \mathrm{E}-4$ \\
& $\mathrm{~b}$ & -0.049 & 0.033 \\
& $\mathrm{c}$ & 124.020 & 0.43 \\
\hline
\end{tabular}

A fim de minimizar os efeitos da fotodegradação, ambos os dispositivos foram submetidos ao mesmo protocolo de ensaio realizado anteriormente, porém com a colocação de um filtro gradeado de 1,5 Abs em frente ao ponto de excitação da luz de $382 \mathrm{~nm}$, internamente ao fluorímetro. A Figura 21a e a Figura 21b mostram 0 comportamento dos sensores de Vidro/PtOEP/PS (3000 RPM) e ox.p.Si/PtOEP (L 55) após a instalação do filtro. Esta adequação permitiu reduzir a intensidade luminosa sobre as amostras, reduzindo os efeitos da fotodegradação ao longo dos 60 min de ensaio. Há de se notar que este artifício por si só não resolve plenamente os 
problemas do método de medição do oxigênio, pois a relação sinal/ruído para estes ensaios foi menor comparado aos encontrados anteriormente.

a)

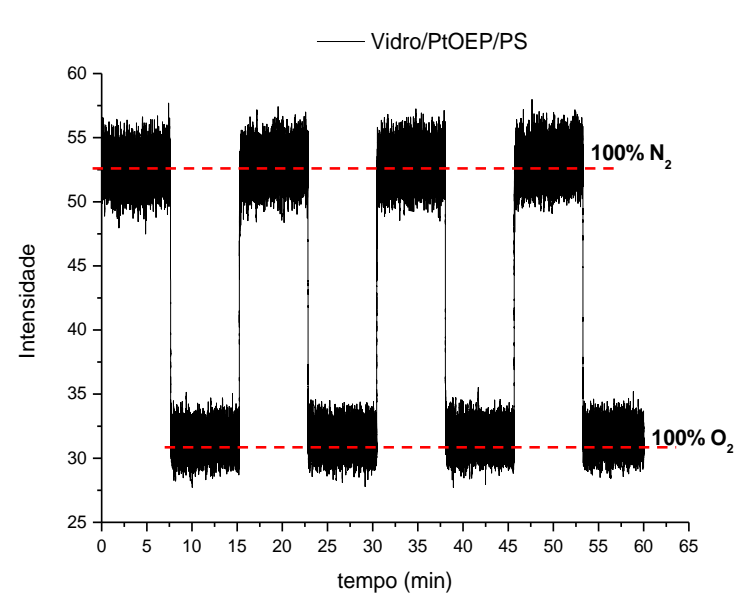

b)

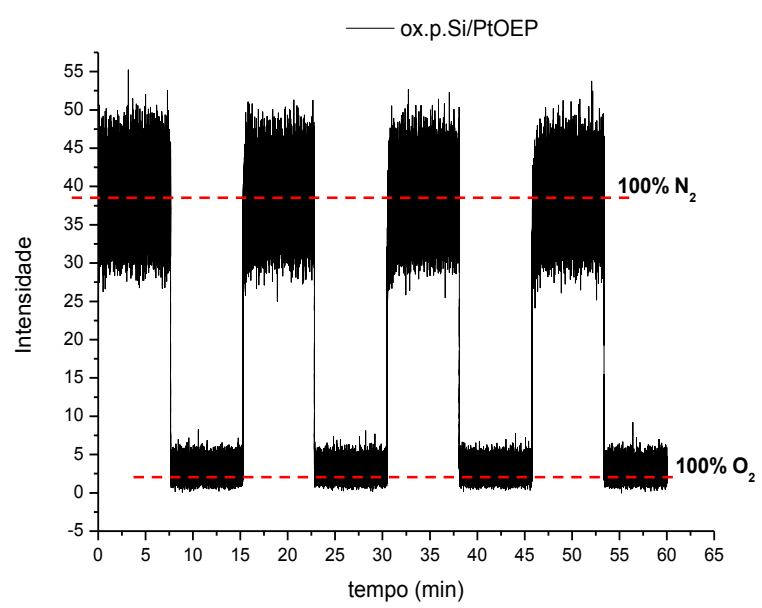

Figura 21 -Variação da intensidade fotoluminescente para ambientes de $100 \% \mathrm{~N}_{2}$ e $100 \% \mathrm{O}_{2}$ com a colocação de filtro gradeado metálico de 1,5 Abs (a) Vidro/PtOEP/PS (3000 RPM) e (b) ox.p.Si/PtOEP (L 55), respectivamente.

\subsubsection{Análise de resposta de sensibilidade dos sensores Vidro/PtOEP/PS e ox.p.Si/PtOEP ao oxigênio dissolvido em água deionizada (OD em $\mathrm{H}_{2} \mathrm{O}-\mathrm{DI}$ ).}

Os ensaios dos sensores Vidro/PtOEP/PS (3000 RPM) e ox.p.Si/PtOEP (L 55) para determinação da sensibilidade ao oxigênio dissolvido em água deionizada (DI) foram realizados seguindo os procedimentos e métodos relatados na seção 2.2.4. Para ambos os dispositivos, as amostras foram excitadas por uma fonte de luz com comprimento de onda de $382 \mathrm{~nm}$. Nestes ensaios os sensores foram submetidos em ambientes de diferentes concentrações de oxigênio dissolvido, segundo o arranjo experimental de controle, ilustrado na Figura 9. A injeção de água DI foi controlada, com vazão de aproximadamente $100 \mathrm{ml} / \mathrm{min}$ e mantida sob temperatura de $24^{\circ} \mathrm{C}$.

As mudanças na intensidade da fotoluminescência pela presença do oxigênio dissolvido sob diferentes concentrações, com interações com as moléculas de PtOEP, podem ser vistas na Figura 22a e na Figura 22b para Vidro/PtOEP/PS (3000 RPM) e estrutura ox.p.Si/PtOEP (L 55), respectivamente. 
a)

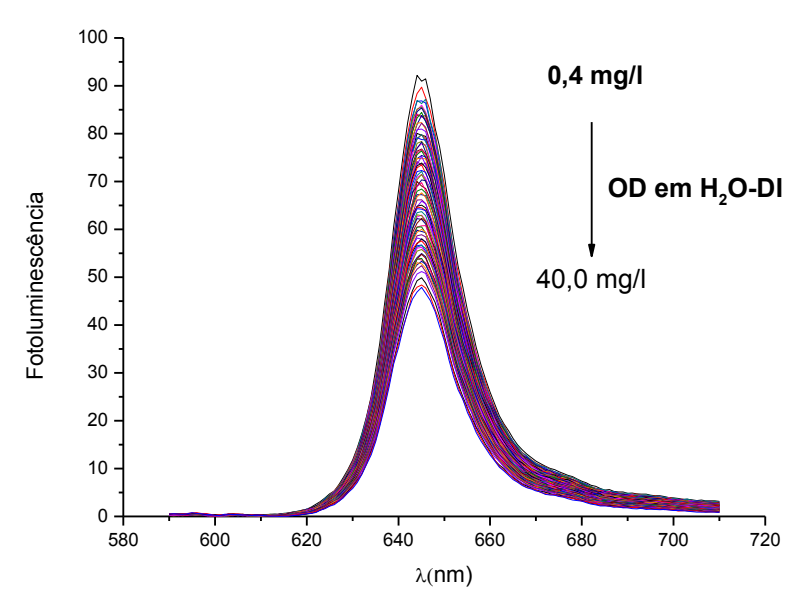

b)

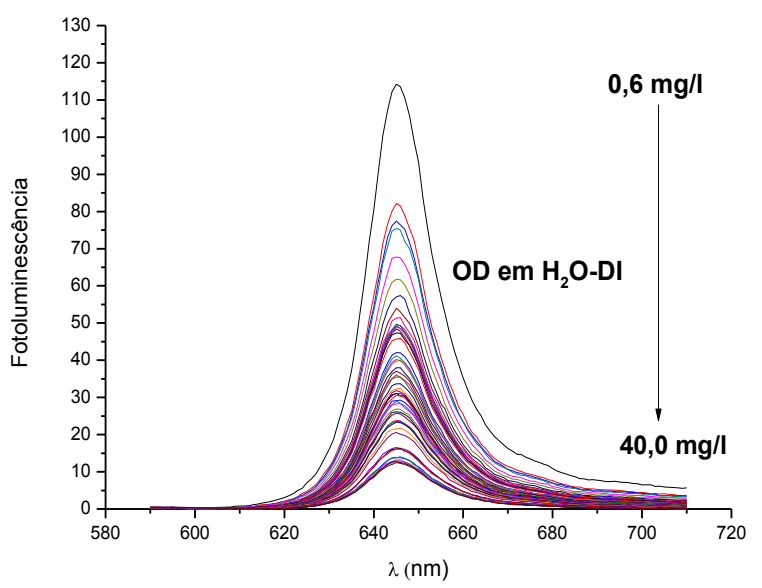

Figura 22 -a) Espectros de emissão fotoluminescente do dispositivo Vidro/PtOEP/PS (3000 RPM) b) Espectros de emissão fotoluminescente do dispositivo ox.p.Si/PtOEP (L 55).

A intensidade fotoluminescente a partir da molécula de PtOEP com emissão em $644 \mathrm{~nm}$ decresceu com o aumento da taxa de oxigênio dissolvido no meio. Para ambos os dispositivos a faixa de medição do OD esteve entre 0 e 40 mg/l (ou 40 ppm), e, após uma adequação linear, os coeficientes de Stern-Volmer (Ksv) encontrados foram 0,0242 e 0,2535 para Vidro/PtOEP/PS (3000 RPM) e ox.p.Si/PtOEP (L 55), respectivamente. A partir destes resultados das medidas de OD, evidencia-se que a resposta do sensor baseado em silício poroso oxidado passou de treze para dez vezes mais sensível do que o dispositivo de poliestireno em vidro, quando comparados aos ensaios em ambientes gasosos com o oxigênio. Entretanto, na análise das constantes de Stern-Volmer (Ksv), conforme apresentado na Figura 23, nota-se que o comportamento de sensibilidade apresentou ligeira melhora, quando comparado aos ensaios anteriores em ambientes gasosos. A Tabela 6 apresenta os valores de SternVolmer para as duas condições de ensaios $\left(\mathrm{O}_{2}\right.$ gasoso e $\mathrm{OD}$ em $\left.\mathrm{H}_{2} \mathrm{O}-\mathrm{DI}\right)$. 


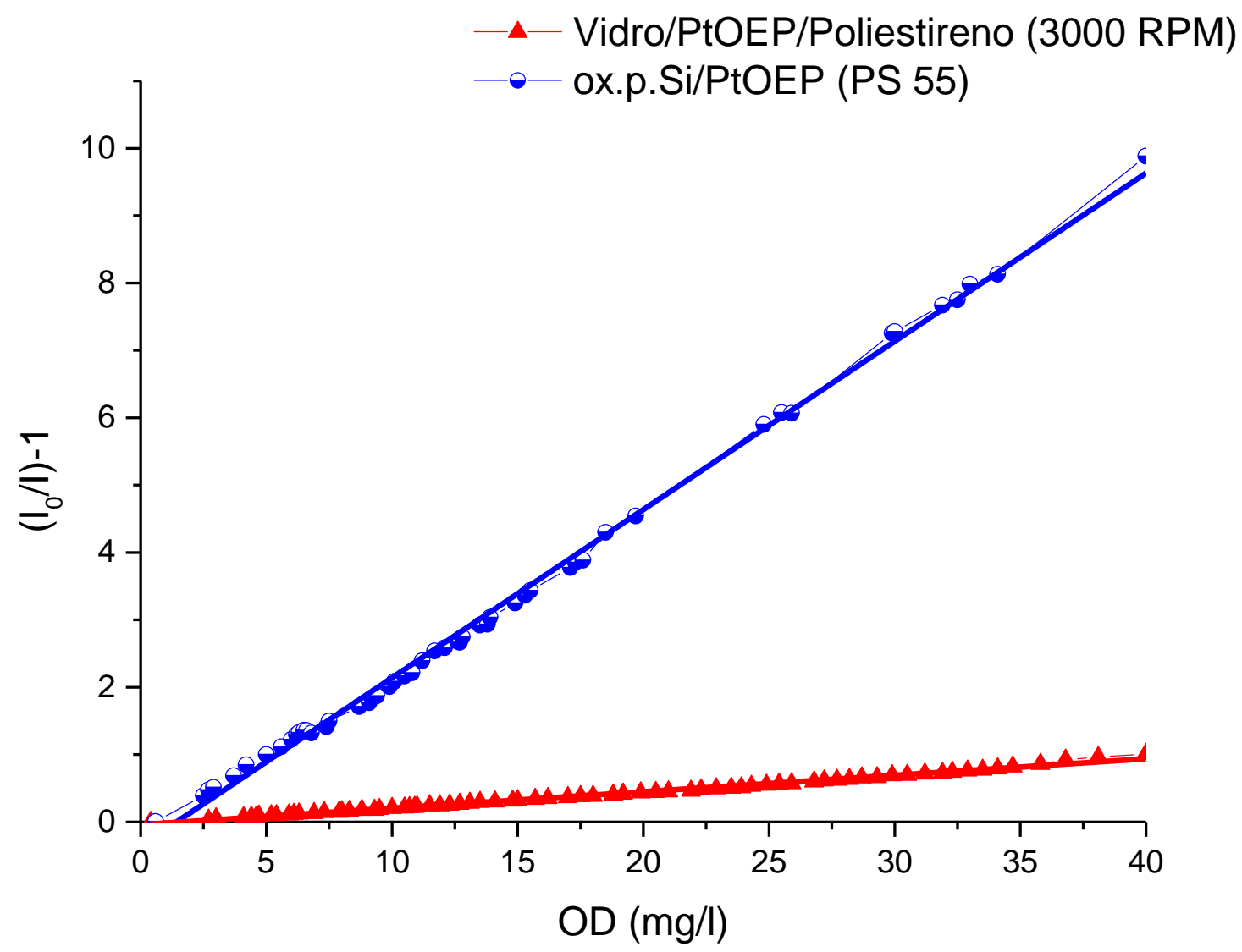

Figura 23 -Curvas de Stern-Volmer da intensidade de supressão fotoluminescente da molécula de PtOEP obtidas a partir de diferentes concentrações de oxigênio dissolvido em água DI. (a) Vidro/PtOEP/PS (3000 RPM) e (b) ox.p.Si/PtOEP (L 55), respectivamente.

Tabela 6 - Valores de Stern-Volmer para as duas condições de ensaios $\left(\mathrm{O}_{2}\right.$ gasoso e OD em $\mathrm{H}_{2} \mathrm{O}-\mathrm{DI}$ ).

\begin{tabular}{lllll}
\hline \multicolumn{1}{c}{$\begin{array}{c}\text { Estrutura do } \\
\text { dispositivo }\end{array}$} & \multicolumn{2}{c}{ Ambiente Gasoso } & \multicolumn{2}{c}{ Ambiente Líquido } \\
\cline { 2 - 5 } & $\mathrm{I}_{0} / \mathrm{l}$ & $\mathrm{Ksv}\left(\%^{-1}\right)$ & $\mathrm{I}_{0} / \mathrm{l}$ & $\mathrm{Ksv}\left(\%^{-1}\right)$ \\
\hline Vidro/PtOEP/PS & 2,20 & $0.013^{\mathrm{a}}$ & 1,97 & $0,024^{\mathrm{c}}$ \\
\hline ox.p.Si/PtOEP & 8,90 & $0.18^{\mathrm{b}}$ & 9,37 & $0,25^{\mathrm{c}}$ \\
\hline
\end{tabular}

a. Concentrações de oxigênio variando de $0-100 \%$

b.Concentrações de oxigênio variando de $0-50 \%$

c. Concentrações de oxigênio dissolvido variando de $0-40 \mathrm{mg} / \mathrm{l}$ 


\subsubsection{Resposta dinâmica dos dispositivos Vidro/PtOEP/PS ( 3000 RPM) e ox.p.Si/PtOEP ( $L$ 55) ao oxigênio dissolvido em água deionizada (OD em $\mathrm{H}_{2} \mathrm{O}-\mathrm{DI}$ ).}

$\mathrm{Na}$ Figura 24a e na Figura 24b são apresentadas as respostas dinâmicas dos sensores Vidro/PtOEP/PS (3000 RPM) e ox.p.Si/PtOEP (L 55) obtidas após submetêlos à diferentes ambientes, alternando injeções de 100\% de água deionizada com 0\% e 100\% (40 mg/l) de OD, dentro da câmara. Nestes ensaios a temperatura permaneceu constante a $24{ }^{\circ} \mathrm{C}$. A vazão de água DI injetada à câmara foi mantida constante em $200 \mathrm{ml} / \mathrm{min}$ para ambos os ensaios dos dispositivos. O tempo de resposta do sensor Vidro/PtOEP/PS depois de injeção de 100\% de OD foi de 2,55 s e 2,65 s para ox.p.Si/PtOEP. Os tempos de recuperação dos sensores foram 2,55 s e 48,27 s para poliestireno e silício poroso oxidado, respectivamente. Estes tempos foram obtidos por meio de avaliação dos instantes de 10\% e 90\% da distância da intensidade fotoluminescente inicial e final no processo de troca. O sensor Vidro/PtOEP/PS apresentou os mesmos tempos de resposta dinâmica na detecção, considerando a mudança do ambiente com ausência de OD para ambiente saturado de OD $(40 \mathrm{mg} / \mathrm{l})$. Já o dispositivo de ox.p.Si/PtOEP apesar de apresentar um tempo similar (2,65 s) ao dispositivo de Vidro/PtOEP/PS, após a injeção de 100\% de OD, o resultado mostrou acentuado atraso no tempo de resposta $(48,27 \mathrm{~s})$, sugerindo que 0 processo de dessorção do OD pelo silício poroso sofre maiores influências de tensões superficiais da camada de silício poroso por efeitos de forças de Van Der Walls e/ou pontes de Hidrogênio do que no dispositivo de Vidro/PtOEP/PS. 
a)

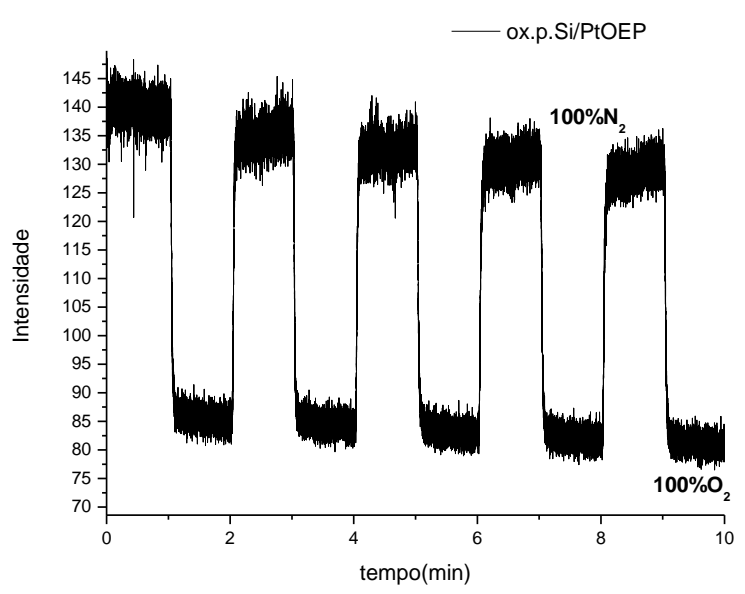

b)

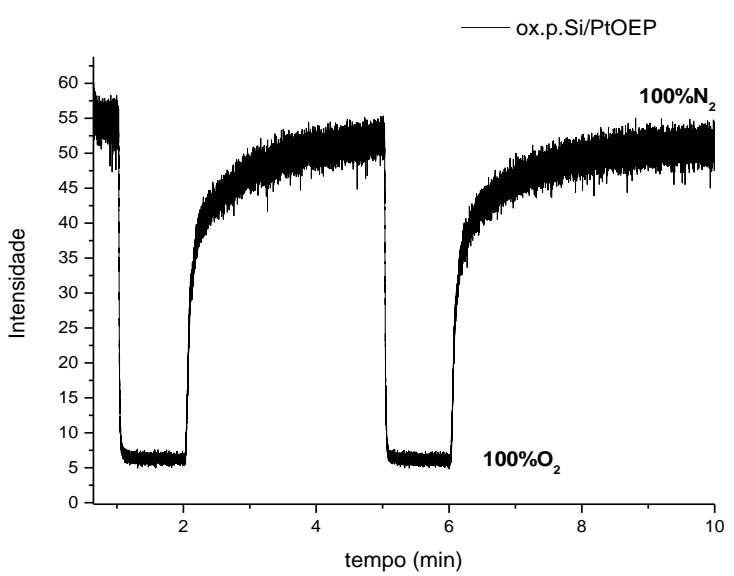

Figura 24 -Resposta dinâmica dos sensores a ambientes contendo 0\% de OD e 100\% OD (40 mg/l) (a) Vidro/PtOEP/PS (3000 RPM) e (b) ox.p.Si/PtOEP (L 55), respectivamente.

\subsection{Conclusões}

A ativação da superfície dos dispositivos fotodetectores com as moléculas de PtOEP foi realizada através da técnica de spin coating, apresentando bom recobrimento superficial e homogeneidade sobre a área ativa. Este processo mostrou que a espessura e a sensibilidade do filme fluoróforo estão diretamente relacionadas com a velocidade previamente ajustada da rotação do spinner.

Ambos os dispositivos fabricados em substrato de vidro e silício poroso mostraram elevada sensibilidade à presença de moléculas de $\mathrm{O}_{2}$ e OD em água DI. Entretanto, a sensibilidade apresentada pela matriz hospedeira de silício poroso mostrou-se 13 (treze) vezes mais sensível, comparada à obtida pela matriz de poliestireno na detecção de $\mathrm{O}_{2}$ e 10 (dez) vezes para OD, em ambiente líquido. Este comportamento deve-se a diferentes probabilidades de colisão do $\mathrm{O}_{2}$ sobre a superfície ativa dos dispositivos, o que promove a supressão da fotoluminescência das moléculas corantes imobilizadas no silício poroso ou camada de poliestireno, indicando que as moléculas corantes são adsorvidas somente na área superficial do silício poroso oxidado e por todo o volume no filme de poliestireno.

Nas análises do tempo de resposta foram obtidos rápidos tempos de detecção dinâmica dos gases de nitrogênio e oxigênio, porém com maior retardo apresentado 
na dessorção do oxigênio ou oxigênio dissolvido na matriz de silício poroso. Isto mostra que apesar dos poros do silício poroso serem responsáveis pela melhoria da sensibilidade do dispositivo, eles dificultam a remoção rápida do $\mathrm{O}_{2}$ nos meios líquidos ou gasosos.

Para ambos os substratos de vidro e silício poroso foram obtidas respostas lineares, após aplicação do método de linearização por Stern-Volmer.

Algumas limitações indicadas devido à fotodegradação podem ser contornadas, diminuindo o tempo de incidência da luz de UV (382 nm) sobre a membrana de porfirina de PtOEP. Em monitoramento contínuo, isto é viável, devido às condições de medidas in loco, onde o período de amostragem é relativamente longo, variando entre minutos e horas.

A utilização do fluorímetro demonstrou ser eficiente na análise laboratorial como método de referência e estudo do comportamento da molécula ativa de PtOEP imobilizada nas membranas de detecção de $\mathrm{O}_{2}$ e OD, porém, por se tratar de um equipamento de laboratório e portanto frágil, não se torna adequado para aplicações de monitoramento ambiental em ambientes externos, apesar de os resultados indicarem melhores tempos de resposta quando comparados ao método eletroquímico tradicional de medida de OD (eletrodo Clark).

Nos próximos capítulos serão apresentadas soluções portáteis desenvolvidas na presente tese na detecção de $\mathrm{O}_{2}$ e OD e outros contaminantes.

\subsection{Referências}

AMAO, Y.; ISHIKAWA, Y.; OKURA, I. Green luminescent iridium(III) complex immobilized in fluoropolymer film as optical oxygen-sensing material, Analytica Chimica Acta, v. 445, p. 177-182, 2001.

AMAO, Y.; TAKEUCHI, Y. "Materials for luminescent pressure-sensitive paint", Frontiers in chemical sensors, vol. 3, pp. 303-322, 2005.

CHUANG, H.; ARNOLD, M. A. Linear calibration function for optical oxygen sensors based on quenching of ruthenium fluorescence. Analytica Chimica Acta 368, p. 83-89, 1998. 
DEMAS, J. N.; DEORA, B. A.; XUT, W. "Modeling of Luminescence Quenching-Based Sensors: Comparison of Multisite and Nonlinear Gas Solubility Models". Anal. Chem. 67, pp. 1377-1380, 1995.

EBELING, D.; PATEL, V.; FINDLAY, M.; STETTER, J. "Electrochemical ozone sensor and instrument with characterization of the electrode and gas flow effect". Sensor and Actuators. B, vol. 137, pp. 129-133, 2009.

HARTMANN, P.; LEINER, M. J.P.; KOHLBACHER, P. Photobleaching of a ruthenium complex in polymers used for oxygen optodes and its inhibition by singlet oxygen quenchers. Sensors and Actuators B, v. 51, p. 196-202, 1998.

HUANCA, D. R. "Estruturas multicamadas de silício poroso para aplicação em dispositivos de cristais fotônicos". 2007. 110p. Dissertação (Mestrado) - Escola Politécnica, Universidade de São Paulo, São Paulo, 2007.

KOSE, M. E. Multi-Luminophore Coatings for Pressure Sensitive Paint Applications. 2005. 173p. Tese (Doutorado) - University of Florida, [Gainesville], Florida, EUA, 2005.

LEE, S-K; OKURA, I. "Photostable Optical Oxygen Sensing Material: Platinum Tetrakis(pentafluorophenyl)porphyrin Immobilized in polystyrene" Analytical Communications, 34, pp. 185-188, 1997.

MATOS, K. R. M "Filmes sensíveis a pressão pela técnica de fotoluminescência". 2011. 126p. Dissertação (Mestrado) - Escola Politécnica, Universidade de São Paulo, São Paulo, 2011.

PĂTULEA, A.; BĂRAN, N.; CĂLUŞARU, I. M. "Measurements of Dissolved Oxygen Concentration in Stationary Water". World Environment, vol. 2(5), pp. 104-109, 2012.

SANTOS, D. S.; BRAGA, M. S.; SALCEDO, W. J. "Sistema de Processamento de Sinais e Geração de Imagens Químicas para Sensores LAPS, FMOS e TAOS baseado em Dispositivos Lógicos Programáveis FPGA. Proceedings of Safety, Health and Environment World Congress, vol. 13, pp. 256-260, 2013. 
SCURLOCK, R. D.; OGILBY, P. R. "Singlet Molecular Oxygen ( $\left.{ }^{1} \Delta_{g} \mathrm{O}_{2},\right)$ Formation upon Irradiation of an Oxygen $\left({ }^{3} \sum_{g}^{-} O_{2}\right)$-Organic Molecule Charge-Transfer Absorption Band". The Journal of Physical Chemistry, vol. 93, n. 14, pp. 5493-5500,1989.

WANG, X.; LIU, M.-L.; CHENG, X.-L.; LIN, J.-M. "Flow-based luminescence-sensing methods for environmental water analysis". Trends in Analytical Chemistry, vol. 28, n. 1, pp. 75-87, 2009.

YIN, J.; WAN, J.; XU, J.; WANG, H.; ZHENG, X. "Photodecay dynamics of octaethylporphine in the condensed phase explored via resonance Raman spectroscopy and density functional theory calculation". Spectrochimica Acta Part A 78, pp. 1416-1423, 2011. 


\section{Capítulo 3}

\section{Capacitor MOS como sensor portátil de detecção de oxigênio}

\subsection{Introdução}

A crescente busca por ferramentas rápidas e eficientes de controle e monitoramento ambiental, com o intuito de se obter sistemas cada vez mais seguros na preservação da saúde ocupacional e dos processos produtivos, tem impulsionado o desenvolvimento de instrumentos portáteis para o monitoramento in loco de variáveis analíticas para a detecção de gases e vapores, diante dos tradicionais equipamentos de uso em laboratório e de instrumentação fixa em instalações de processos industriais.

Dentro deste contexto, estudos das propriedades elétricas das estruturas MOS e sua interação com meios gasosos, quando a eles expostas, têm sido objeto de pesquisas desde a década de 70 (LUNDSTRÖM et al., 1975), sendo aprimorados até os dias atuais para a melhoria dos resultados analíticos e das técnicas de detecção de hidrogênio (BRAGA; SALCEDO; FERNANDEZ, 2010; LUNDSTRÖM, 1981; SPETZ; ARMGARTH; LUNDSTRÖM, 1988), amônia (BRAGA; SALCEDO; FERNANDEZ, 2010; WINQUIST, et al.,1983), dióxido de nitrogênio (FILLIPINI; ARAGÓN; WEIMAR, 2001a \& FILLIPINI, 2001b), sulfeto de hidrogênio, (SHIRAVAMAN, 1976), monóxido de carbono (ZUBKANS, et al., 1995), vapores orgânicos e hidrocarbonetos (HORNIK, 1990), além de medidas dos estados de superfície, através da medição quase-estática CxV e estudos da fotoemissão.

Como parte da utilização dos dispositivos de efeito de campo na detecção de diferentes gases, os capacitores MOS com portas de paládio têm se tornado alvo da implementação de técnicas que possibilitam uma análise qualitativa e quantitativa das concentrações de vários compostos químicos, em especial o hidrogênio, apresentando grandes vantagens por sua simplicidade de fabricação, baixo custo, elevada estabilidade, baixos níveis de histerese e resistência a ambientes corrosivos (WAGNER; WIRTH, 2000). 
Diante desse cenário, neste capítulo será feito uma abordagem do desenvolvimento de capacitor MOS, como fotodetector de emissões de luz, em comprimentos de onda na região do vermelho $(640 \mathrm{~nm})$. A parte ativa do sensor foi integrada a uma membrana de polietileno tereftalato (PET) e poliestireno (PS), com moléculas de PtOEP incorporadas, indicando a viabilidade construtiva para aplicações em sistemas de monitoramento ambiental. Serão descritos o princípio de funcionamento de detecção e a instrumentação utilizada nos ensaios de sensibilidade ao $\mathrm{O}_{2}$.

\subsection{Procedimentos Experimentais}

Serão apresentados os materiais, procedimentos para a fabricação do capacitor MOS e a descrição do arranjo experimental de medida de intensidade de fotoluminescência para determinação da concentração de $\mathrm{O}_{2}$ em estrutura MOS/PS-PET(PtOEP).

\subsubsection{Fabricação de dispositivo MOS/PS-PET(PtOEP) para medidas de fotoluminescência das moléculas de PtOEP aplicadas na detecção de oxigênio}

Para fabricação do capacitor MOS foi utilizada uma lâmina de Si-p com orientação cristalográfica $\langle 100\rangle$ e resistividade de 3-10 $\Omega$.cm. Os processos de fabricação do capacitor MOS foram detalhados por Braga, Salcedo e Fernandez (2010). Na Figura 25 é mostrado um diagrama esquemático das diferentes etapas de fabricação do capacitor MOS, seguidas na presente tese. 
a.

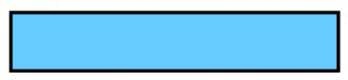

d.

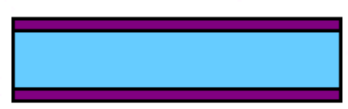

e.

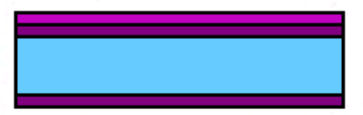

f.

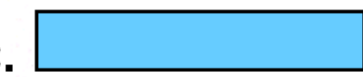

b.

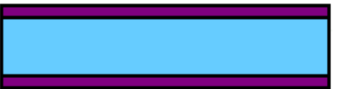

C.

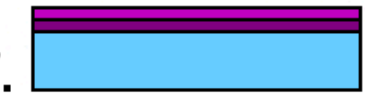

g.

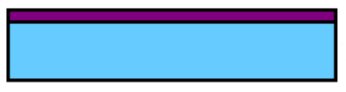

h.

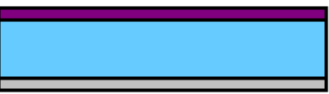

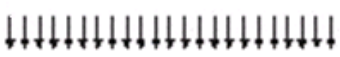

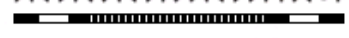

j.

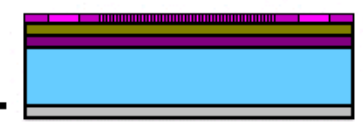

k.

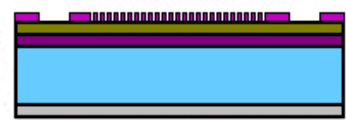

I.

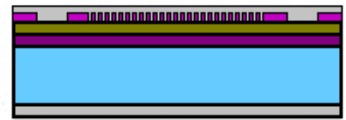

$\mathrm{m}$.

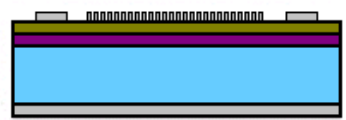

n.

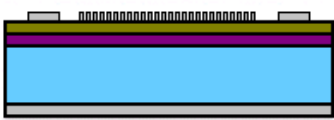

Figura 25 -Etapas de fabricação do capacitor MOS

Onde:

a) Limpeza química inicial da lâmina Si-p;

b) Oxidação de Gettering;

c) Remoção de Gettering;

d) Oxidação de porta;

e) Proteção do óxido de porta na parte frontal da lâmina com fotoresiste;

f) Remoção do óxido das "costas" da lâmina;

g) Remoção do fotoresiste;

h) Deposição de Alumínio no lado inferior da lâmina;

i) Deposição de Nitreto de Silício sobre a camada de óxido;

j) Fotogravação do filme da grade de Platina;

k) Abertura de janela para deposição de Platina;

l) Deposição de Platina sobre a camada de $\mathrm{Si}_{3} \mathrm{~N}_{4}$;

m) Remoção do excesso de Platina pelo processo Lift-Off; e

n) Realização do processo de sinterização para a formação da liga Al-Si 


\subsubsection{Produção de filme ativo de PET com molécula de PtOEP imobilizada em poliestireno.}

Na produção do filme de poliestireno dopado com moléculas corantes de PtOEP para funcionalização do dispositivo MOS, uma solução foi obtida pela diluição de $7,0 \mathrm{mg}$ de PtOEP e 69,85 mg de poliestireno (PS) em $5 \mathrm{ml}$ de clorofórmio $\left(1,92.10^{-3} \mathrm{~mol} / \mathrm{l}\right)$. $\mathrm{O}$ composto foi colocado em recipiente fechado e acondicionado em banho de ultrassom para homogeneização e diluição completa por 15 min.

A seguir, a solução foi gotejada sobre uma película de polietileno tereftalato (PET) de $100 \mu \mathrm{m}$ de espessura e utilizada como filme ativo (PtOEP-PS-PET). No processo de deposição o spinner foi parametrizado com rotação de 3000 RPM, durante $10 \mathrm{~s}$. A película ativada foi colocada em contato com o superfície do MOS (grade interdigital) para formação da estrutura MOS/PS-PET(PtOEP) (Figura 26).

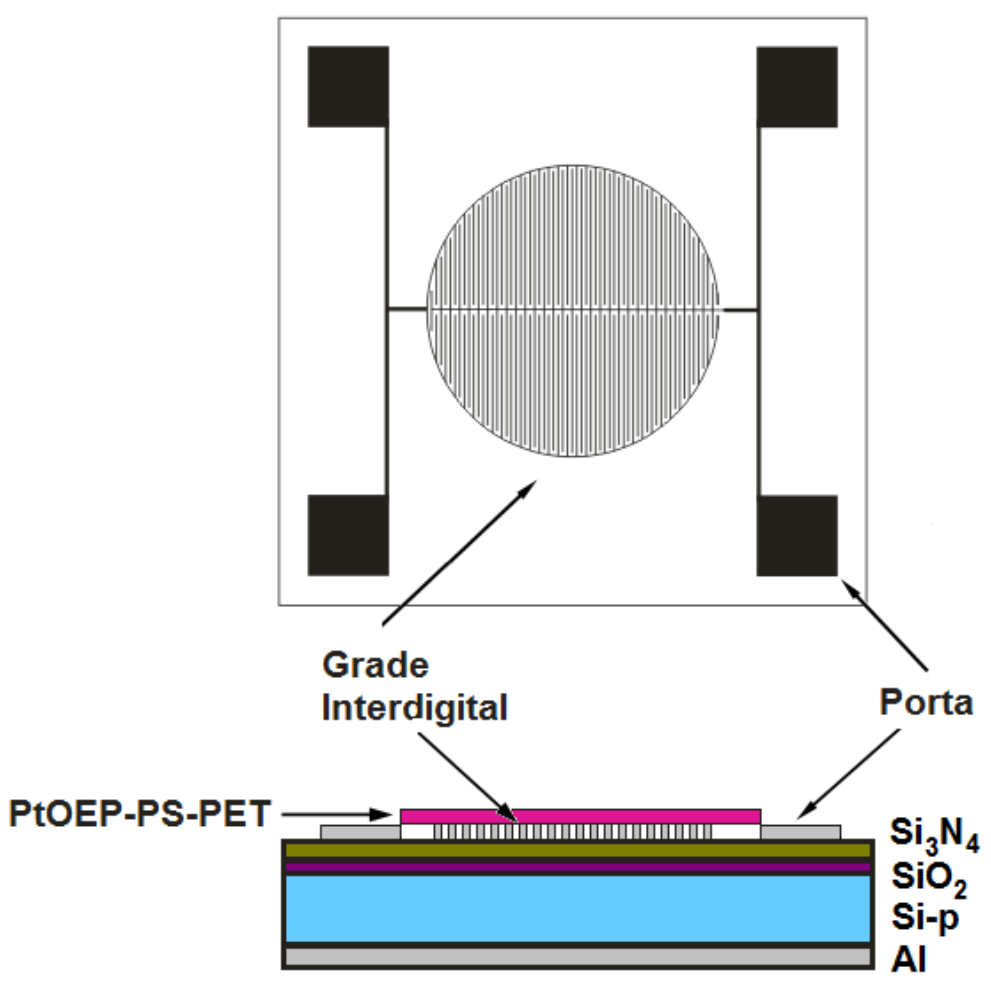

Figura 26 -Detalhe construtivo do capacitor MOS com a película de polietileno tereftalato (PET) sobreposta a grade interdigital. 


\subsubsection{Arranjo experimental de medida de intensidade de fotoluminescência para determinação da concentração de $\mathrm{O}_{2}$ em estrutura MOS/PS- PET(PtOEP)}

Os ensaios foram feitos com os terminais do capacitor MOS ligados a uma base de cobre e acondicionado no interior de uma câmara fabricada em teflon. Uma trava metálica sob pressão fixada por parafusos foi utilizada para permitir total estanqueidade aos gases inseridos à câmara de ensaios. A Figura 27 (a, b, c e d) ilustra detalhes das ligações elétricas do capacitor MOS dentro da câmara e do arranjo experimental.

a)

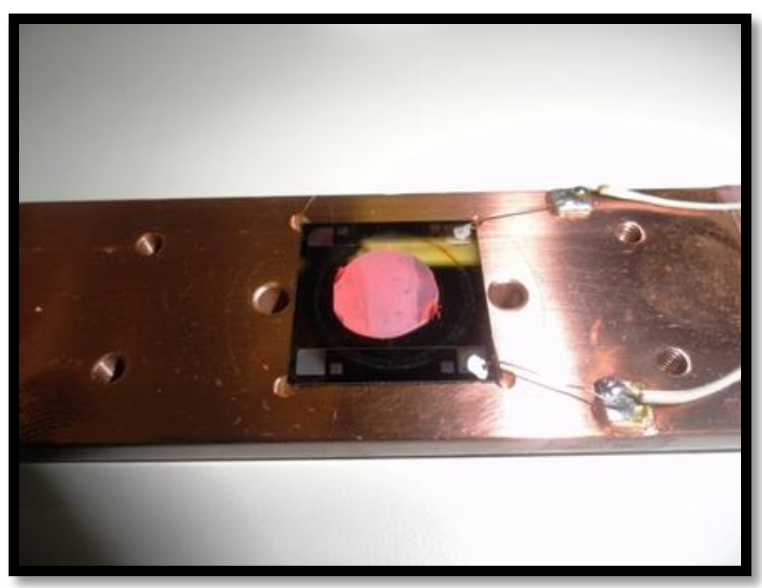

c)

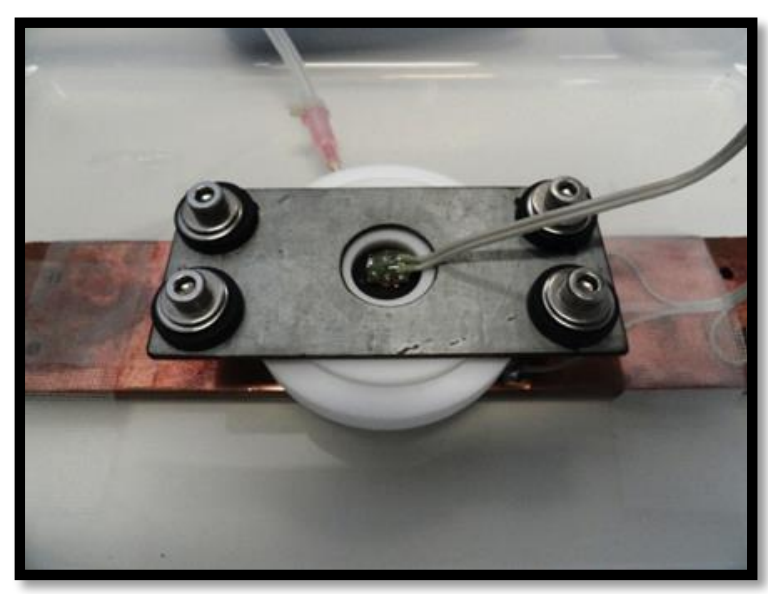

b)

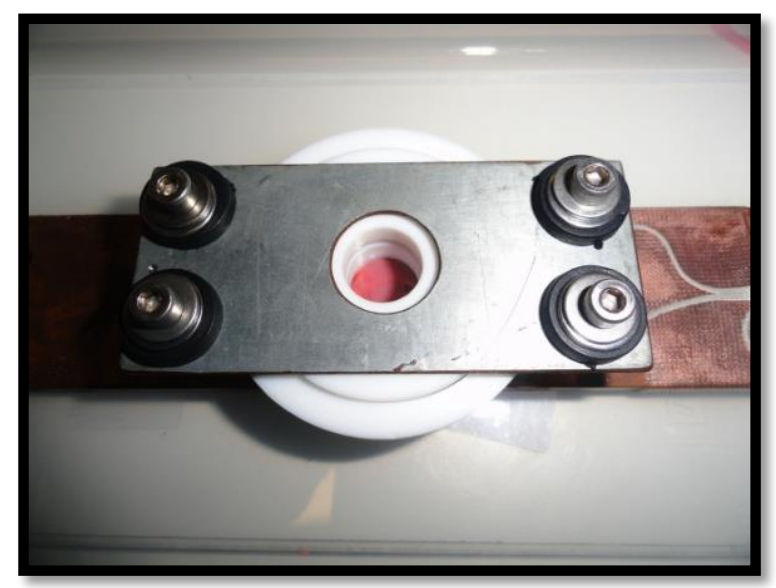

d)

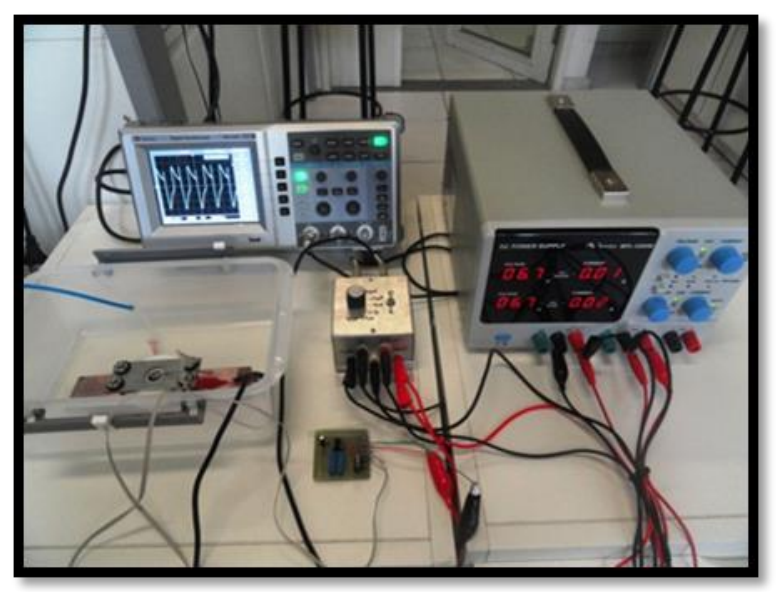

Figura 27 -a) Película de PS-PET funcionalizada disposta sobre o capacitor MOS; b) Capacitor MOS com película de PS-PET dentro de câmara de ensaios; c) LED/UV (377nm) instalado sobre janela de vidro para excitação luminosa sobre o sensor MOS; e d) Arranjo experimental do sistema de detecção de $\mathrm{O}_{2}$. 
A escolha do comprimento de onda $(\lambda)$ da luz de excitação sobre a molécula teve como referência a análise da resposta fotoluminescente obtida pelo espectrofotômetro de fluorescência mostrada na Figura 14. Como fonte luminosa para excitação da estrutura MOS/PS-PET(PtOEP) foi utilizado um diodo UV-LED (1,3 mW, $\lambda=377 \mathrm{~nm}$ ), fabricado pela empresa Lumex. $O$ feixe de luz foi modulado por um sinal de onda quadrada de frequência de $250 \mathrm{~Hz}$ e valor de tensão de pico de 3,6 V. O sinal proveniente do capacitor MOS foi inserido na entrada de um módulo amplificador de transimpedância, desenvolvido por Braga, Salcedo e Fernandez (2010) e utilizado como conversor I/V (corrente para tensão) para condicionamento do sinal a ser medido pelo osciloscópio digital. $\mathrm{O}$ fator de conversão $(\mathrm{R})$ do referido módulo possui aproximadamente $192 \mathrm{k} \Omega$.

De acordo com o diagrama esquemático mostrado na Figura 28, o sensor MOS/PSPET(PtOEP), neste caso funcionando como fonte de corrente, é conectado na entrada inversora do amplificador operacional $\mathrm{Cl} 1$ (LMC6001) e é polarizado por uma tensão $\mathrm{Vp}$, devido ao efeito de tensão de modo comum característico do amplificador operacional.

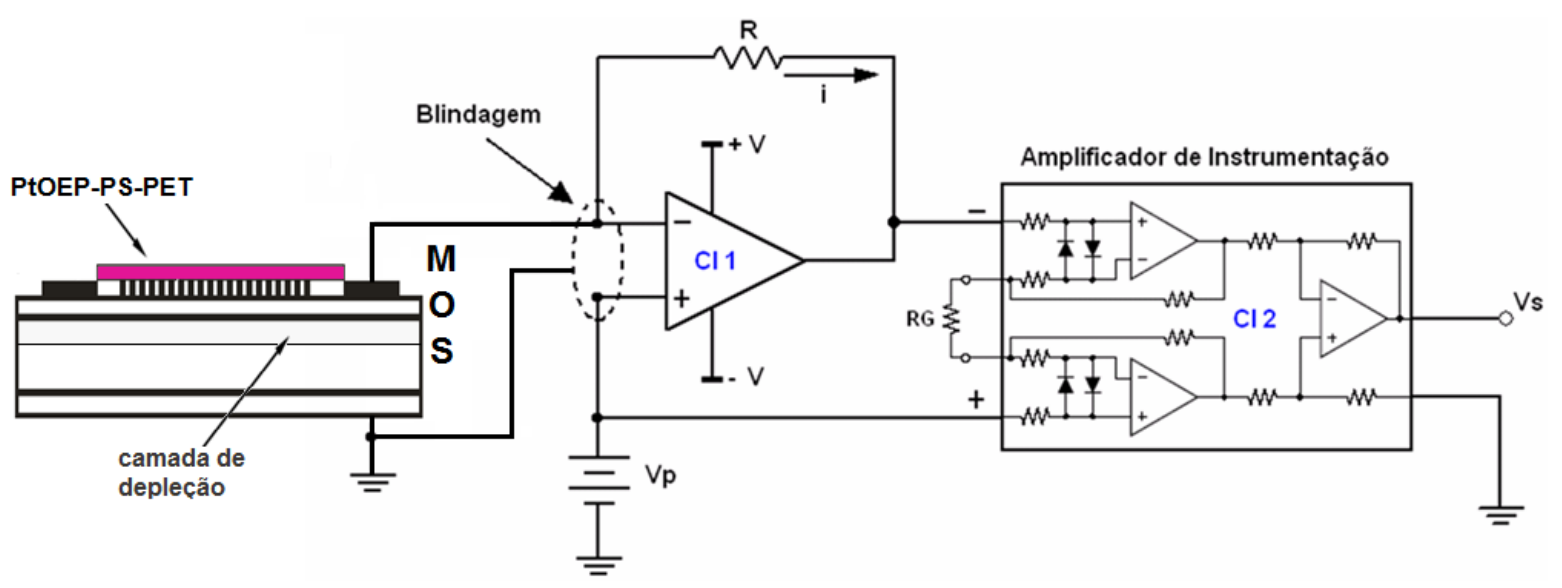

Figura 28 -Diagrama eletrônico do amplificador de transimpedância.

A corrente que passa pelo resistor $\mathrm{R}$ é equivalente a um valor $\mathrm{i}$, proveniente do sensor MOS, causando uma queda de tensão $V_{\mathrm{R}}$ sobre $\mathrm{R}$ igual a $-i \cdot R$. Esse potencial é somado a Vp e um amplificador de instrumentação de ganho unitário $\mathrm{Cl} 2\left(\mathrm{RG}_{\mathrm{G}}=\infty\right)$, subtrai a tensão de polarização da saída do amplificador operacional, deixando $V_{R}$ no terminal de saída do circuito, fazendo $V_{S}=V_{R}$, como desejado. $O$ uso de uma malha de blindagem aterrada ao redor das entradas no $\mathrm{Cl} 1$ reduz significativamente erros resultantes de correntes de fuga e rotas com capacitâncias parasitas. 
Talvez, a vantagem mais significativa pertinente a este leiaute é que a medição é feita permitindo polarizar o dispositivo sensor com uma tensão $\mathrm{Vp}$ em relação ao terra do sistema.

$\mathrm{O}$ valor de $\mathrm{R}$ e o modelo do dispositivo amplificador $(\mathrm{Cl}$ 1) podem ser otimizados dependendo da aplicação do circuito, especificamente com respeito à faixa de frequência de interesse e a ordem de grandeza da corrente medida.

O Cl amplificador de instrumentação utilizado foi o INA101, por possuir características interessantes tais como: alta imunidade a ruídos e boa resposta às frequências dos sinais envolvidos no experimento.

A Figura 29 mostra o diagrama esquemático do arranjo experimental e os detalhes do sistema utilizado para obtenção da mistura gasosa.

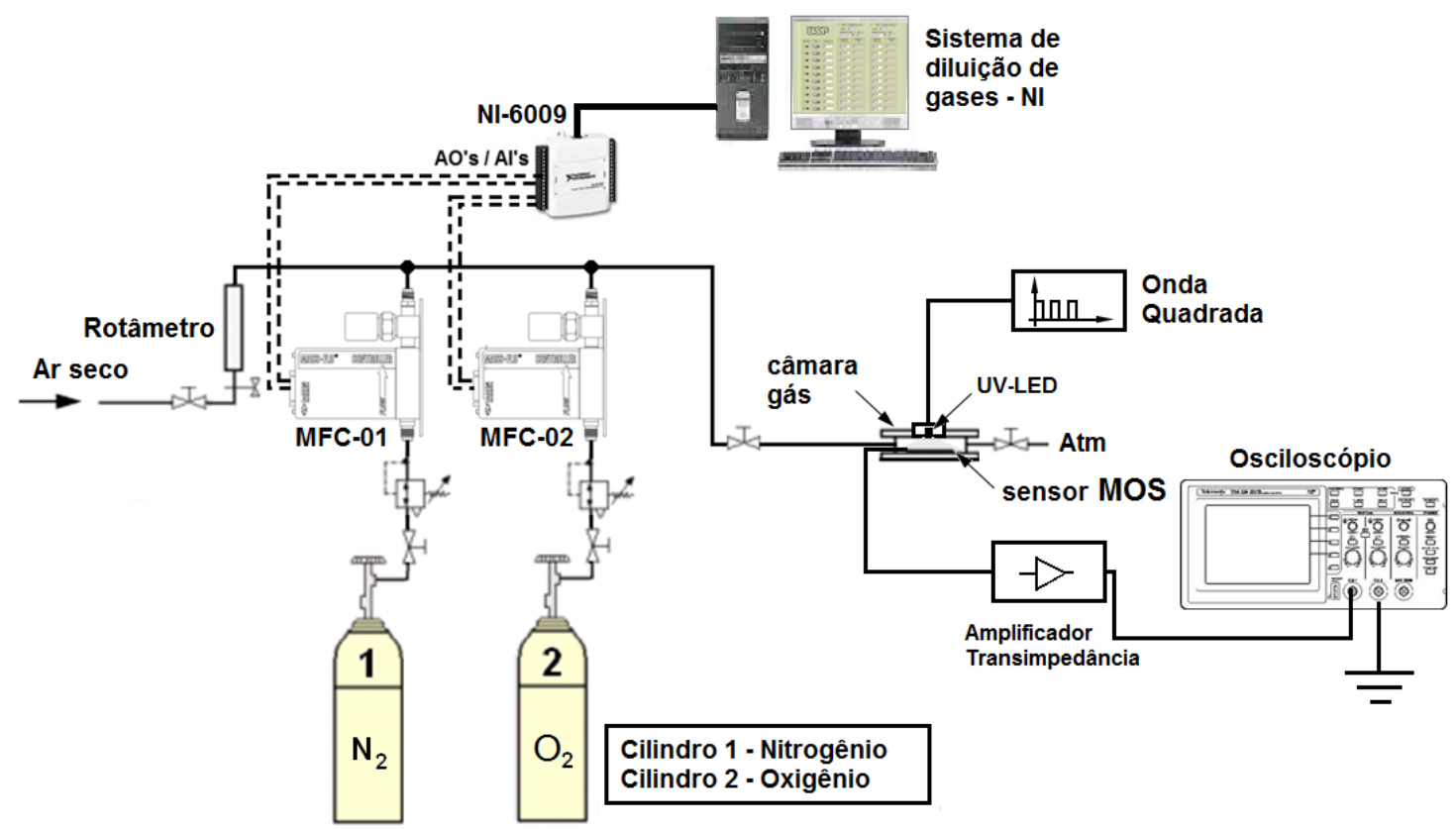

Figura 29 -Diagrama esquemático do arranjo do sistema de diluição de $\mathrm{O}_{2}$ e $\mathrm{N}_{2}$ e esquema de ligação do método de medição da intensidade fotoluminescente do sensor MOS. 


\subsection{Resultados e discussões}

\subsubsection{Resposta de sensibilidade do dispositivo MOS/PS-PET(PtOEP) sob diferentes concentrações de $\mathrm{O}_{2}$ em $\mathrm{N}_{2}$}

O princípio de deteç̧ão do oxigênio, a partir de uma estrutura MOS, com película de PS-PET sobreposta à região de porta do dispositivo está baseado na geração de uma fotocorrente na região de depleção do semicondutor após a incidência de um feixe de luz pulsado de intensidade constante e comprimento de onda fixo (Figura 30b). Um diagrama esquemático da técnica de medição do sinal proveniente do MOS é mostrado na Figura 30a (LUNDSTRÖM et al., 1991).

a)

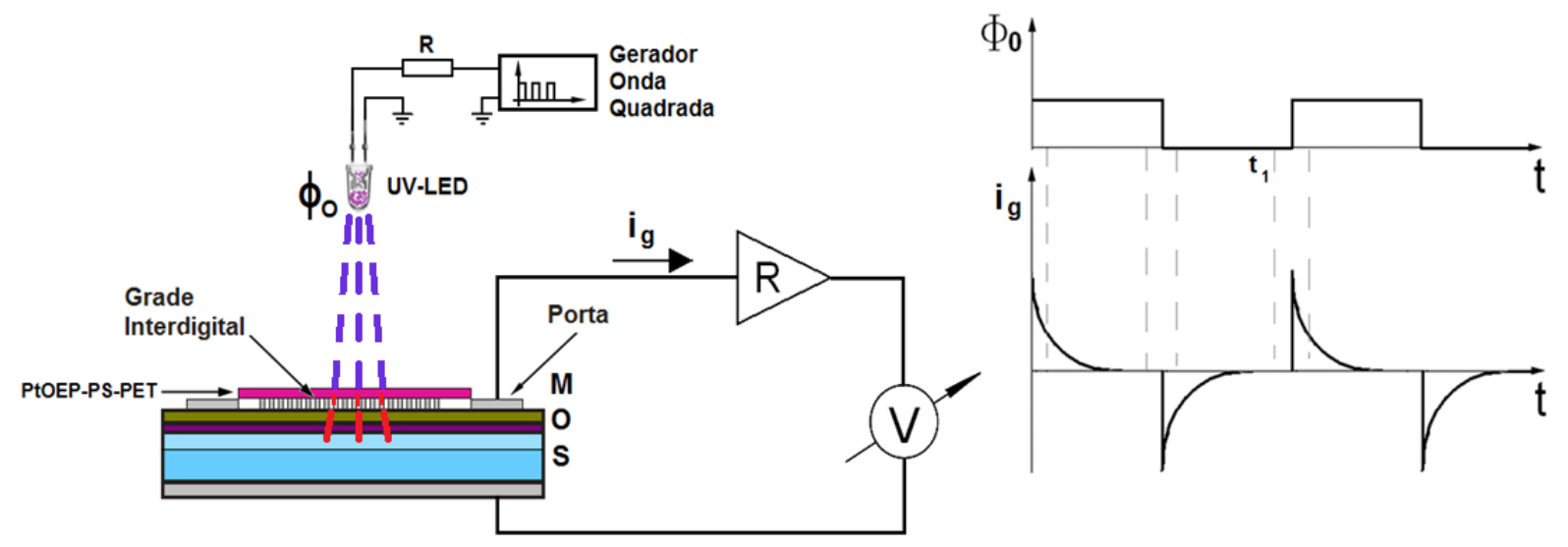

Figura 30 -a) Diagrama experimental da geração de uma fotocorrente em um dispositivo MOS, onde Фo é a intensidade de fótons; b) intensidade dos pulsos de luz e sinais de corrente em função do tempo.

O feixe de luz (visível) incidente com intensidade Фo passa através da porta metálica semitransparente e do óxido de silício do capacitor MOS, sendo posteriormente absorvido no substrato de silício. Se o dispositivo for excitado com um feixe de fótons de energia igual ou maior que a banda proibida do silício, então serão gerados pares elétron-lacuna no substrato de silício; os portadores gerados na região da camada de depleção estarão sujeitos à ação de um campo elétrico, podendo ser separados e assim contribuir com o aparecimento de uma fotocorrente. 
A quantidade de portadores de carga concentrados na interface da região de depleção no semicondutor é diretamente proporcional à energia luminosa $\left(\Phi_{0}\right)$ mantida para geração destes e o sinal de corrente lido no circuito externo (ig) é proporcional à geração de portadores de carga na região de depleção do semicondutor (ENGSTRÖM; CARLSSON, 1983).

No caso do sensor proposto com o dispositivo MOS, a intensidade de luz emitida pelas moléculas de PtOEP atua como fonte para a geração de pares elétron-lacuna no substrato do dispositivo MOS. Como a presença de $\mathrm{O}_{2}$ afeta a intensidade de emissão desta molécula, pode-se então, determinar a concentração do $\mathrm{O}_{2}$ pela medição da variação da corrente no circuito externo, conforme a Equação 6 (ENGSTRÖM; CARLSSON, 1983):

$$
i_{g}=q \cdot \phi_{o}
$$

Onde: q é a carga do elétron e Фo é a intensidade de luz emitida pelas moléculas de PtEOP.

A fim de se caracterizar o capacitor MOS como sensor de oxigênio, foram realizadas medidas de fotoluminescência em variadas concentrações de $\mathrm{O}_{2}$ diluídos em $\mathrm{N}_{2}$. $\mathrm{O}$ arranjo experimental utilizado seguiu a configuração ilustrada na Figura 29, com vazão controlada de $2 \mathrm{l} / \mathrm{min}$ e excitação luminosa de $377 \mathrm{~nm}$. Vale a pena mencionar que o comprimento de onda escolhido $(\lambda=377 \mathrm{~nm})$ para excitação das moléculas de PtOEP teve sua região de excitação próximo ao comprimento de onda de $382 \mathrm{~nm}$ (Figura 14), o que permitiu total compatibilidade com um dispositivo LED comercial, utilizado durante os ensaios com o dispositivo semicondutor MOS/PS-PET(PtOEP). Isto oferece variadas possibilidades de aplicações para sistemas de sensoriamento portátil.

Considerando o comprimento de onda de emissão da molécula de PtOEP como sendo de aproximadamente de $644 \mathrm{~nm}$, a resposta da eficiência quântica para a geração de portadores na região de depleção do dispositivo MOS para este comprimento de onda será elevada, já que a profundidade de penetração da luz no substrato de Si nestas condições é de aproximadamente $1 \mu \mathrm{m}$. Com efeito a fotocorrente originada pela emissão das moléculas de PtOEP foi intensa. Assim, foi construído um gráfico (Figura 
31) de resposta de intensidade da fotocorrente gerada, a partir dos valores de tensão RMS ( $V_{\mathrm{RMS}}$ ), convertidos pelo amplificador de transimpedância, em função da concentração do oxigênio, seguindo a Equação 7:

$$
\text { Resposta }=\frac{I_{0}-I}{I_{0}}
$$

Onde: Io e I referem-se as intensidades de fotocorrente gerada em valores de tensão RMS ( $\left.V_{R M S}\right)$ na ausência e presença de $\mathrm{O}_{2}$, respectivamente.

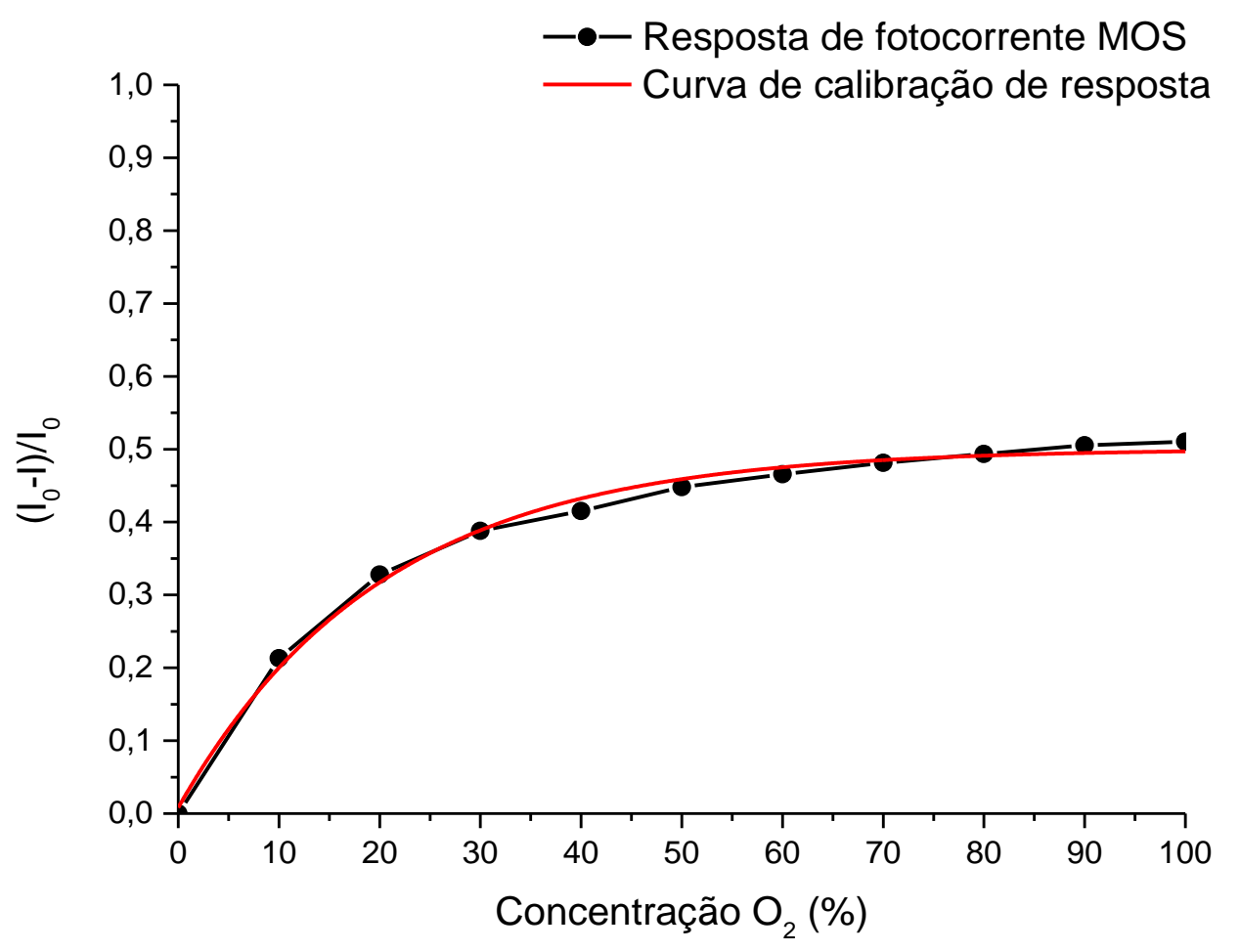

Figura 31 -Resposta do capacitor MOS a diferentes concentrações de $\mathrm{O}_{2}$. A curva de linha vermelha corresponde ao ajuste dos pontos experimentais com uma curva exponencial.

Os resultados mostram que o dispositivo detector de $\mathrm{O}_{2}$ apresenta boa sensibilidade e segue um modelo exponencial de resposta, cujos parâmetros de ajuste da curva de calibração estão indicados na Tabela 7.

Tabela 7 - Parâmetros de ajuste exponencial para a curva de calibração de resposta do capacitor MOS a diferentes concentrações de oxigênio.

\begin{tabular}{cccl}
\hline Equação & $y=a+b * \exp (-x / c)$ & Erro Padrão \\
\hline \multirow{3}{*}{ Valores } & a & 0,50 & 0,0067 \\
& $\mathrm{~b}$ & $-0,49$ & 0,012 \\
& $\mathrm{c}$ & 20,24 & 1,20 \\
\hline
\end{tabular}


Importante mencionar que a fotocorrente originada pela excitação direta do diodo $(\lambda=377 \mathrm{~nm})$ no dispositivo MOS sem filme de PtEOP-PS foi praticamente nula, resultado esperado já que o substrato de $\mathrm{Si}$ absorve a luz ultravioleta em sua superfície.

A sensibilidade da resposta do sensor em relação a concentração do $\mathrm{O}_{2}$ foi determinada através da derivada da resposta do dispositivo MOS "( $\left(1_{0}-1\right) / l_{0}$ " em relação a concentração de $\mathrm{O}_{2}$. O gráfico da curva de $\mathrm{d}\left(\mathrm{l}_{0}-\mathrm{I}\right) / \mathrm{l}_{0} / \mathrm{dO}_{2}$ em função de $\% \mathrm{O}_{2}$ é apresentado na Figura 32. A partir da curva pode ser identificada a região sensível do sensor, que está entre 0 e $50 \%$. Acima desta concentração a curva de sensibilidade se aproxima de zero.

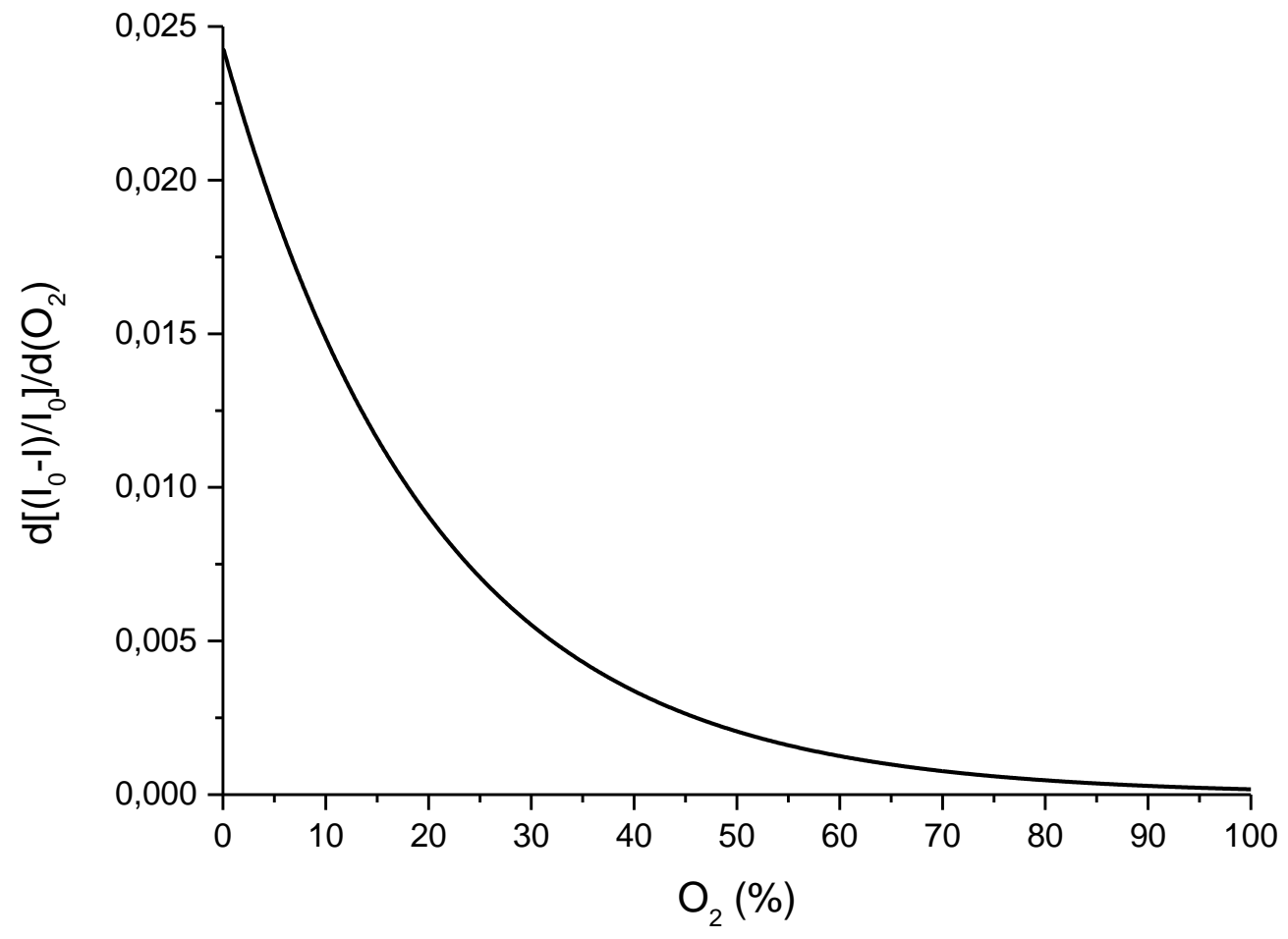

Figura 32 -Primeira derivada da resposta aproximada de fotocorrente do dispositivo MOS para diferentes concentrações de $\mathrm{O}_{2}$

\subsection{Conclusões}

Os resultados obtidos a partir do capacitor MOS utilizado como fotodetector de $\mathrm{O}_{2}$ indicam a possibilidade de fabricação de dispositivos sensores baseados em emissão fotoluminescente de moléculas corantes adsorvidas diretamente na superfície de 
dispositivos MOS. A ativação da superfície do dispositivo fotodetector com moléculas de PtOEP foi realizada através da técnica de spin coating. O dispositivo mostrou elevada sensibilidade à presença de moléculas de $\mathrm{O}_{2}$, mostrando resposta não linear na faixa de concentrações de oxigênio de 0 a 100\%. A curva de resposta foi perfeitamente ajustada com curva exponencial, sendo a região mais sensível na faixa de concentrações de $\mathrm{O}_{2}$ entre 0 e $50 \%$, em comprimento de onda de emissão da molécula de PtOEP na região do vermelho $(640 \mathrm{~nm})$. Isso acontece, por se tratar de uma estrutura de silício, onde há facilidade de geração de portadores fotogerados pela baixa absorção de luz no vermelho. Esta faixa de sensibilidade está dentro dos limites de concentração de $\mathrm{O}_{2}$ esperados para aplicações em controle ambiental. Esses resultados sugerem a aplicação do dispositivo a equipamentos portáteis de baixo custo, baseados em tecnologia de sistemas eletrônicos embarcados para medição de oxigênio e oxigênio dissolvido em monitoramento ambiental.

\subsection{Referências}

BRAGA, M. S.; SALCEDO, W. J.; FERNANDEZ, F. J. R. Image sensor for detection of gases: Development of MOS device as a chemical image sensor for the detection and classification of gases through the scanning light pulse technique. Frankfurt: VDM Verlag Dr. Müller, 2010. 108 p. ISBN-13: 978-3639256482.

ENGSTRÖM, O.; CARLSSON, A. Scanned light pulse technique for the investigation of insulator-semiconductor interfaces, Journal of Applied Physics, v. 54, p. 5245-5251, 1983.

FILLIPINI, D.; ARAGÓN, R.; WEIMAR, U. Gas sensing properties of copper gate metal-oxide-semiconductor capacitors. Journal of Vacuum Science \& Technology B: Microelectronics and Nanometer Structures, v. 19, n. 3, p. 825-828, $2001 \mathrm{a}$.

FILLIPINI, D. et al. New NO2 sensor based on Au gate field effect devices. Sensor and Actuators B, v. b78, p.195-201, 2001b.

HORNIK, W. A novel structure for detecting organic vapours and hydrocarbons based on a Pd-MOS sensor. Sensor and Actuators B, v. b1, p.35-39, 1990. 
LUNDSTRÖM, I. Hydrogen sensitive MOS-STRUCTURES Part. 1: Principles and Applications. Sensor and Actuators, v. 1, p.403-26, 1981.

LUNDSTRÖM, I. et al. A hydrogen-sensitive MOS field-effect transistor. Applied Physics Letters, v. 26, n.2, p.55-57, 1975.

LUNDSTRÖM, I. et al. Artificial "olfactory" images from a chemical sensor using a lightpulse technique. Nature, v. 352, p.47-50, 1991.

SHIVARAMAN, M. S. Detection of $\mathrm{H}_{2} \mathrm{~S}$ with Pd-gate MOS field-effect transistors. Journal of Applied Physics, v. 47, p. 3592, 1976.

SPETZ, A.; ARMGARTH, M.; LUNDSTRÖM, I. Hydrogen and ammonia response of metal-silicon dioxide-silicon structures with thin platinum gates. Journal of Applied Physics, v. 64, n.3, p.1274-83, 1988.

WAGNER, T. V.; WIRTH, G. I. Tecnologia de Implementação CMOS. In: Ricardo Augusto da Luz Reis. (Org.). Concepção de Circuitos Integrados. 2 ed. Porto Alegre: Editora Sagra Luzzatto - Série Livros Didáticos Inf. UFRGS, v., p. 9-12, 2000.

WISQUIST, F. et al. Modified palladium metal-oxide-semiconductor structures with increased ammonia gas sensitivity. Applied Physics Letters, v.43, n.9, p.839-41, 1983.

ZUBKANS, J. et al. In Situ Modification of the $\mathrm{NO}_{x}$ and $\mathrm{CO}$ sensitivity of thin Pt-Gate MOSFET's The 8th International Conference on Solid-State Sensors and Actuators, and Eurosensors IX, 1995. 


\section{Capítulo 4}

\section{Sensor portátil de oxigênio e oxigênio dissolvido com uso de detector de cores RGB comercial integrado}

\subsection{Introdução}

Os métodos atuais de sensoriamento e quantificação de oxigênio, sejam em misturas gasosas ou dissolvido em líquidos têm alcançado grande notoriedade, devido às diversificadas possibilidades de aplicações nas áreas da medicina, meio ambiente, segurança, indústria de alimentos, dentre outras (INGRAMA et al., 2013; JANAK et al., 2011; OLGAC et al., 2012; PĂTULEA; BĂRAN; CĂLUŞARU, 2012; WANG et al., 2009). Por exemplo, na medicina, o controle de injeção de oxigênio no interior de câmaras hiperbáricas permite tratar lesões e doenças diversas pela oxigenação direta dos tecidos quando submetidos a alta concentração de oxigênio (TOLENTINO et al., 2003). Nas estações de tratamento de água, a medição de baixas concentrações do oxigênio dissolvido (OD) pode indicar a presença de um alto teor de matéria orgânica, provocando mudanças no sabor e emissões de odores desagradáveis. Ainda, no desenvolvimento de atividades minerárias, o monitoramento da deficiência de oxigênio ambiente permite avaliar e garantir com segurança melhores condições de ventilação em regiões subterrâneas de trabalho.

Neste contexto, o uso de sensores fotoluminescentes na detecção de oxigênio molecular permite obter vantagens quando comparado aos tradicionais métodos de sensoriamento eletroquímico, por apresentar boa estabilidade, serem imunes a efeitos de campos eletromagnéticos, não consumirem oxigênio do meio, além de não sofrerem interferências em processos de agitação.

A maioria destes sensores utilizam moléculas de porfirinas com propriedades fotoluminescentes de complexos metálicos de transição, imobilizados em matrizes quimicamente resistentes de sol-gel, poliestireno (PS), policloreto de vinila (PVC), silício poroso, dentre outros (AMAO, 2003; BRAGA et al., 2013; LEE; OKURA, 1997; 
SALCEDO; FERNANADEZ; RUBIM, 2004). Estas matrizes possibilitam a dissolução da porfirina em sua estrutura e são permeáveis ao oxigênio.

Neste capítulo reportamos a resposta de sensibilidade de dispositivos optoeletrônicos comerciais de identificação de cores RGB (Red-Green-Blue), empregados para detecção de $\mathrm{O}_{2}$ e $\mathrm{OD}$, quando funcionalizados com moléculas corantes de octaetilporfirina de platina imobilizadas em matrizes hospedeiras de PS e PVC. Esta estratégia permitiu obter diferentes faixas de trabalho para as medidas de concentrações de $\mathrm{O}_{2}$ e OD, além de integrar a parte ativa dos sensores com os detectores da emissão fotoluminescente.

\subsection{Procedimentos Experimentais}

Nesta seção são apresentados os materiais, procedimentos para a fabricação dos sensores ópticos comerciais RGB detectores de $\mathrm{O}_{2}$ e OD e a metodologia de ensaios para caracterização dos dispositivos em diferentes concentrações de $\mathrm{O}_{2}$ e OD.

\subsubsection{Fabricação dos sensores de detecção de $\mathrm{O}_{2}$ e OD com membranas de PS e PVC para formação de estruturas TAOS/PS(PtOEP) e TAOS/PVC(PtOEP)}

Os sensores produzidos utilizam como elementos fotodetectores um circuito integrado composto por uma matriz de 64 fotodiodos $(8 \times 8)$ associados a um circuito conversor de corrente para frequência, encapsulados em um circuito integrado monolítico CMOS, tipo TCS3200, fabricado pela empresa ams AG. Neste dispositivo, há quatro grupos de 16 fotodiodos interdigitados, sendo três grupos com filtros individuais RGB (16 filtros vermelhos, 16 filtros verdes e 16 filtros azuis) e um grupo de 16 fotodiodos sem filtros. Todos os fotodiodos com filtros de mesma cor são ligados em paralelo e a seleção do grupo de fotodiodos (vermelho, verde, azul, sem filtros) que foram ativados é realizada através da combinação binária de duas entradas digitais no circuito integrado (pinos S2 e S3, Figura 33). A saída é provida de um sinal em onda quadrada (50\% duty cycle) com frequência diretamente proporcional à intensidade da 
luz incidente na superfície ativa do detector. A faixa de frequência de saída é selecionada pela combinação binária dos pinos S0 e S1 (Figura 33).

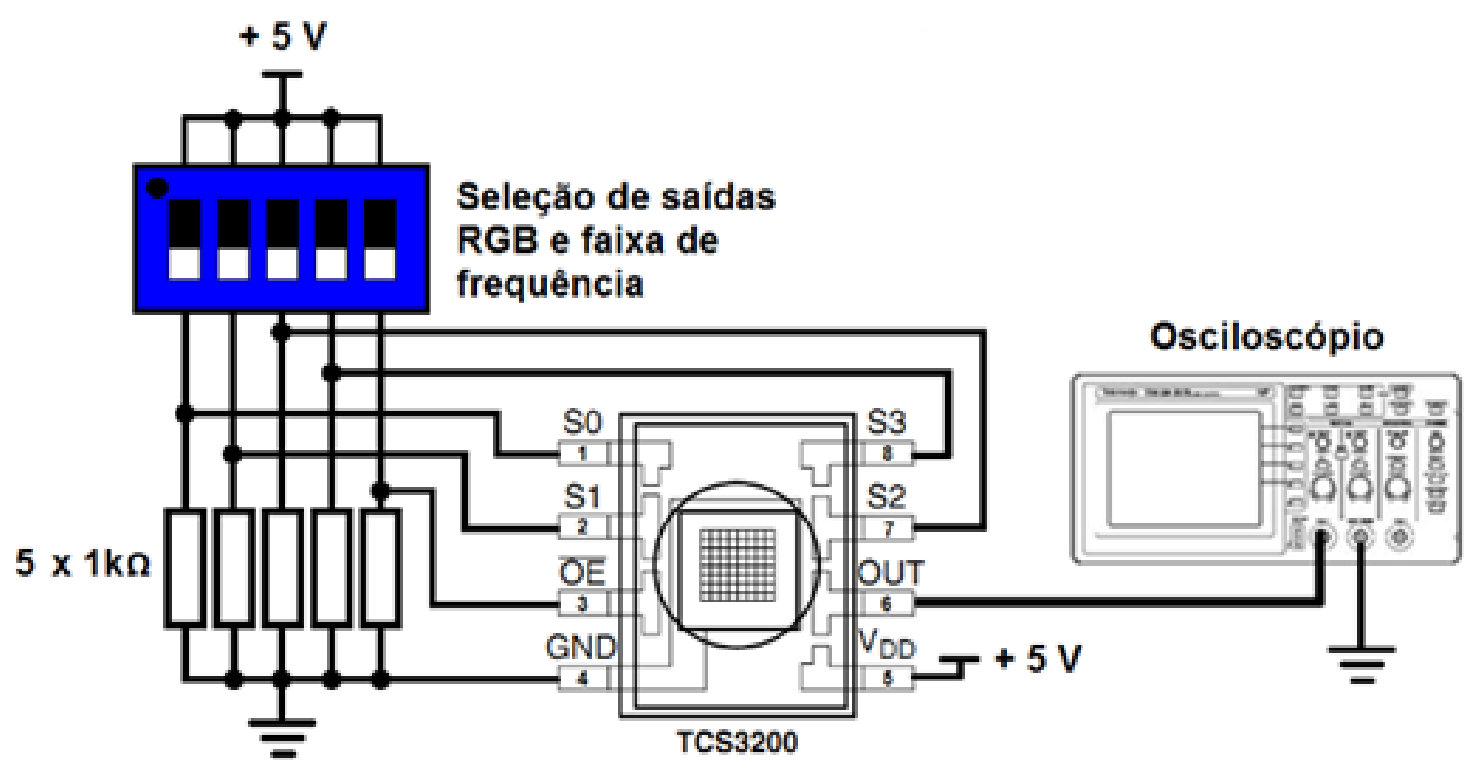

Figura 33 -Diagrama de ligação do dispositivo óptico TCS3200 para medidas de saídas de frequência correspondentes as intensidades nos comprimentos de onda da luz - RGB.

Para composição dos sensores de $\mathrm{O}_{2}$ e OD foram depositadas, sobre as superfícies ativas do fotodetector, membranas de poliestireno e PVC, contendo moléculas sensíveis de octaetilporfirina de platina (PtOEP). Para o sensor com matriz de poliestireno, uma quantidade de $2,5 \mathrm{mg}$ de PtOEP foi diluída em solução contendo 25 $\mathrm{mg}$ de poliestireno e 1,5 $\mathrm{ml}$ de tetrahidrofurano (THF) $\left(2,29 \cdot 10^{-3} \mathrm{~mol} / \mathrm{l}\right)$. Já para a solução contendo PVC os mesmos $2,5 \mathrm{mg}$ de PtOEP e 1,5 ml de THF $\left(2,29.10^{-3} \mathrm{~mol} / \mathrm{l}\right)$ foram utilizados para a solução com $38 \mathrm{mg}$ de PVC e $82 \mu \mathrm{L}$ de Bis(2-ethylhexyl) sebacate (DOS). Para homogeneização e diluição completa do PtOEP, ambas as misturas foram submetidas a agitação mecânica, por ultrassom, durante 30 min. Os filmes foram depositados pelo processo de imersão denominado de dip coating para formação das membranas ativas de PS(PtOEP) e PVC(PtOEP) fixadas diretamente no lado superior do encapsulamento transparente da matriz de fotodiodos, conforme mostrado na Figura 34. 

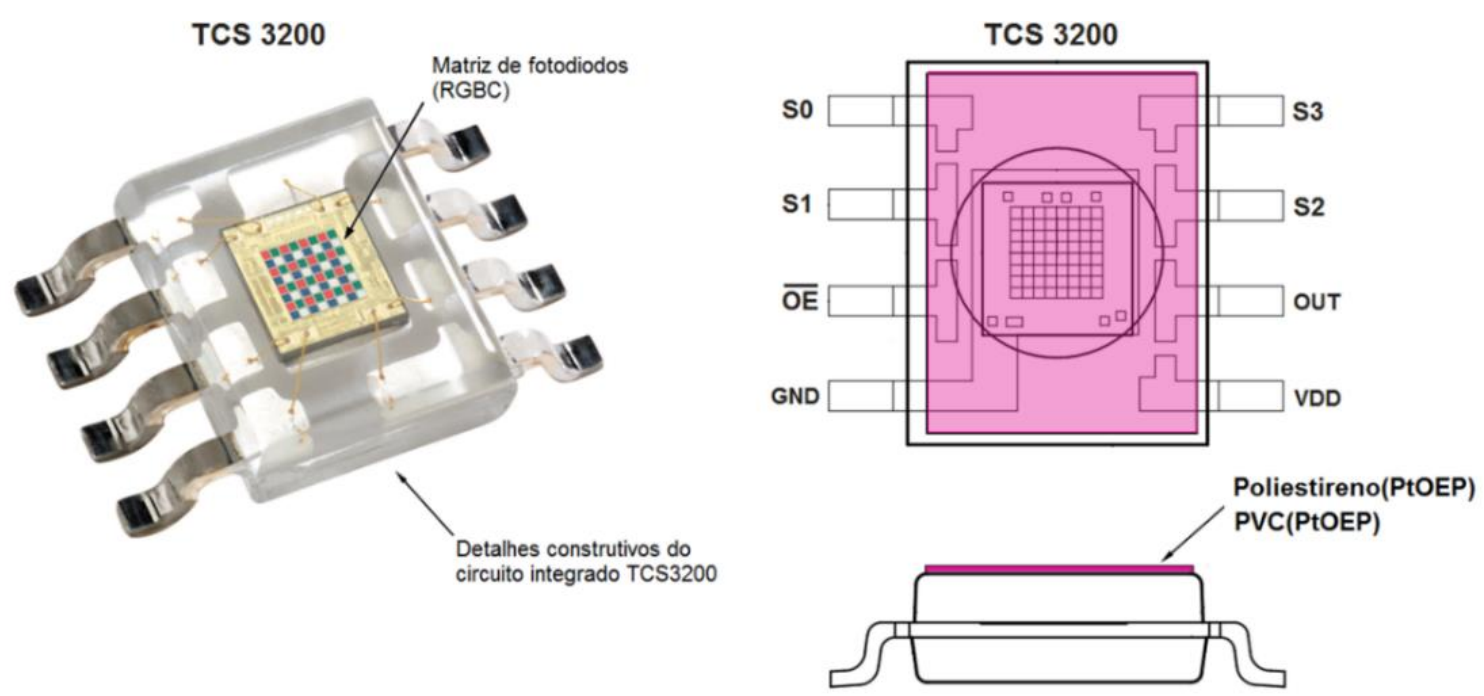

Figura 34 -Detalhes construtivos do circuito integrado TCS3200 e perfil de deposição de membranas ativas de PtOEP imobilizadas em matrizes hospedeiras de poliestireno (PS) e policloreto de vinila (PVC) (ams AG, 2016).

Para secagem dos filmes, os dispositivos foram inseridos em forno térmico a vácuo à temperatura de $60^{\circ} \mathrm{C}$ por $2 \mathrm{~h}$. Para ensaio de fotoluminescência $(P L)$ e caracterização dos filmes de PS e PVC dopados com PtOEP utilizou-se um espectrofotômetro de fluorescência, modelo Cary Eclipse e marca Varian.

4.2.2. Sistema de diluição dos gases de $\mathrm{O}_{2}$ e $\mathrm{N}_{2}$ para ensaios de sensibilidade de $\mathrm{O}_{2}$ e OD e arranjo experimental de medida de intensidade de fotoluminescência dos dispositivos de estruturas TAOS/PS(PtOEP) e TAOS/PVC(PtOEP)

Nos ensaios de sensibilidade dos sensores TAOS/PS(PtOEP) e TAOS/PVC(PtOEP) para ambientes com diferentes concentrações de oxigênio e nitrogênio utilizou-se um arranjo semelhante ao ilustrado na Figura 8, contendo dois controladores de fluxos MFC-1 e MFC-2 da marca MKS Instruments Type 1179 A, alimentados por cilindros de $\mathrm{O}_{2}\left(99,999 \%\right.$ de pureza) e $\mathrm{N}_{2}(99,999 \%$ de pureza).

Para a injeção dos gases de $\mathrm{O}_{2}$ e $\mathrm{N}_{2}$ (processo de oxigenação e desoxigenação) no sistema de controle de oxigênio dissolvido em água DI, utilizou-se um frasco kitasato de $250 \mathrm{ml}$, com eletrodo do tipo Clark submerso em $200 \mathrm{ml}$ de água deionizada e conectado a um oxímetro digital Digimed, modelo DM-4P. A utilização deste instrumento permitiu o monitoramento contínuo do oxigênio dissolvido no meio, 
durante os ensaios. A injeção da mistura gasosa de $\left(\mathrm{O}_{2}\right.$ e $\left.\mathrm{N}_{2}\right)$ no interior do kitasato foi realizada por meio de um borbulhador metálico a fim de se reduzir ao mínimo o tamanho das bolhas, facilitando a oxigenação ou desoxigenação do meio líquido e permitindo a redução do tempo morto do sistema de controle. O bombeamento da água deionizada com oxigênio dissolvido controlado foi realizado por uma bomba peristáltica marca Milan, mod. 204. A Figura 35 mostra o diagrama esquemático do sistema utilizado para a obtenção de diferentes concentrações de $\mathrm{O}_{2}$ e OD.

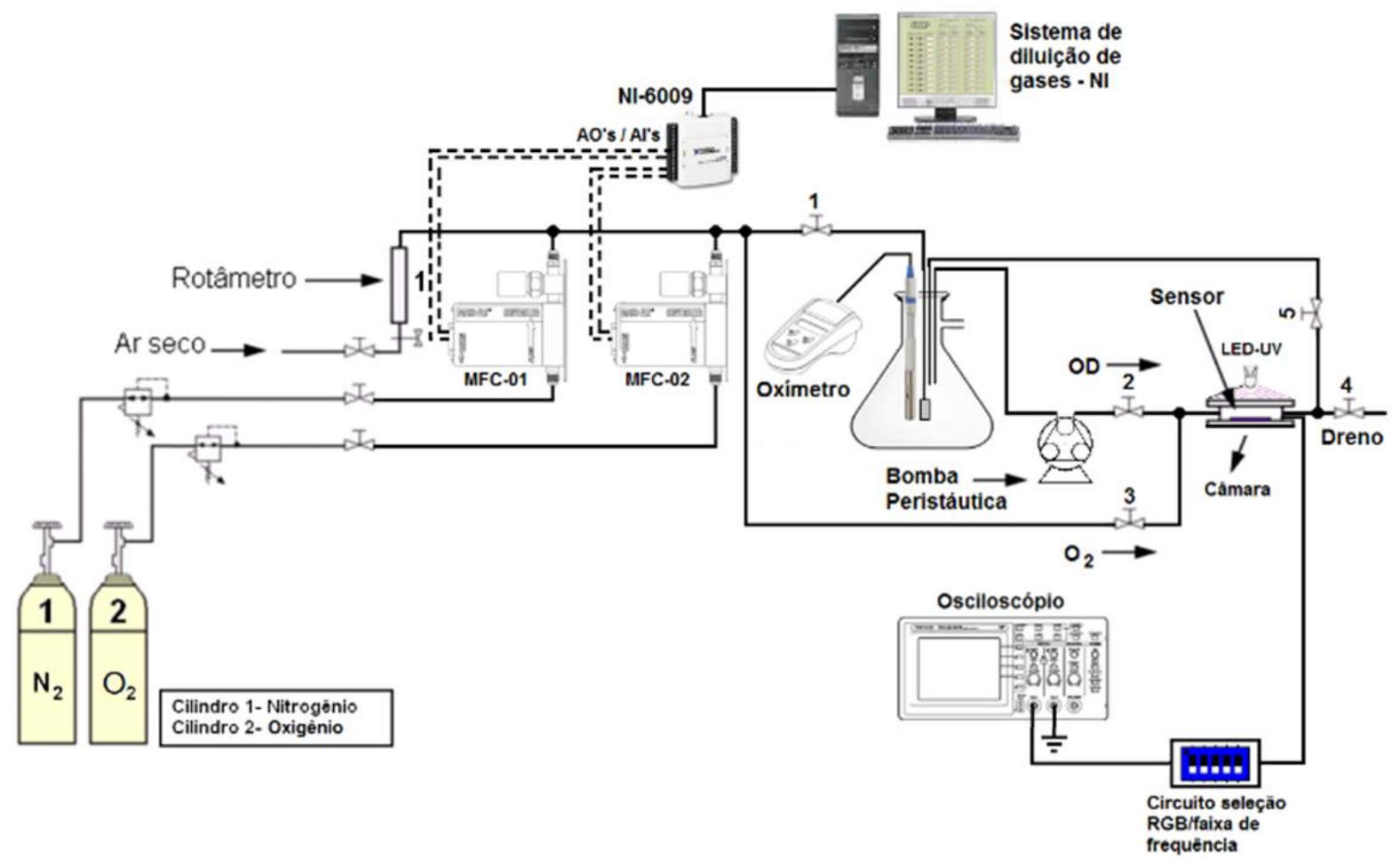

Figura 35 -Diagrama esquemático do arranjo do sistema de controle de oxigênio dissolvido em água deionizada para dispositivos TCS3200.

Os ensaios foram feitos com os dispositivos no interior da câmara de aço inox, conforme descrita na seção 2.2 .6 e com uma janela de vidro polido para entrada da luz. A Figura 36a mostra detalhes dos sensores TAOS/PS(PtOEP) e TAOS/PVC(PtOEP) no interior da câmara de ensaios e à direita na Figura 36b é mostrada uma vista superior do arranjo experimental. 
a)

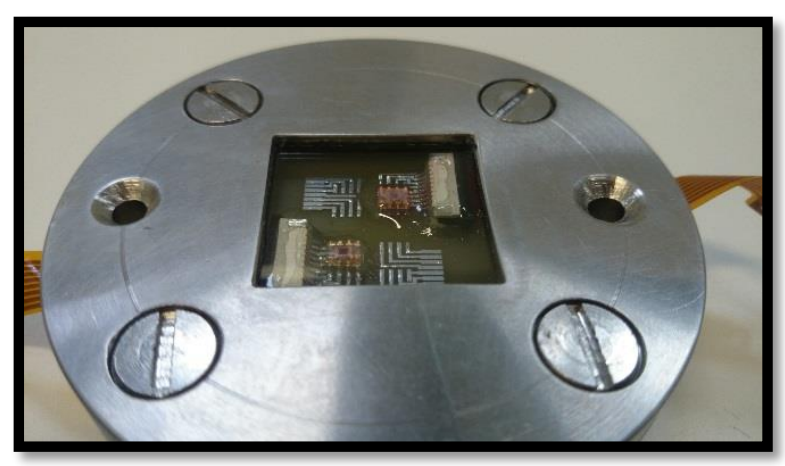

b)

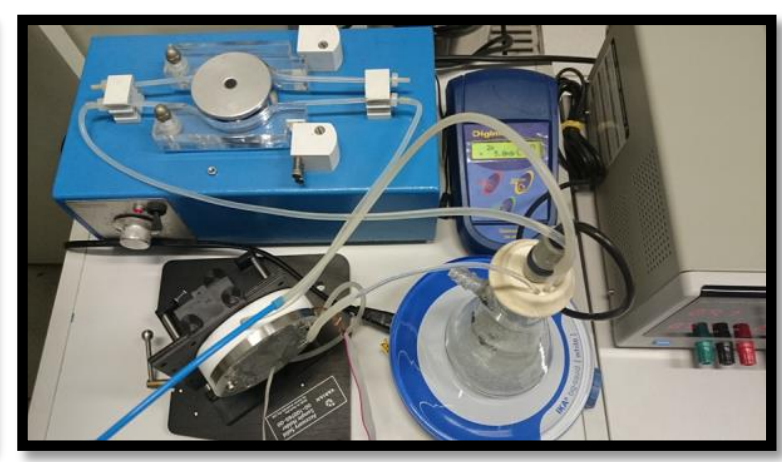

Figura 36 -a) Detalhe da instalação dos sensores TAOS/PS(PtOEP) e TAOS/PVC(PtOEP) no interior da câmara de ensaios; b) Arranjo experimental do sistema de diluição dos gases de $\mathrm{O}_{2}$ e $\mathrm{N}_{2}$ para ensaios de sensibilidade de $\mathrm{O}_{2}$ e OD.

A escolha do comprimento de onda $(\lambda)$ da luz de excitação sobre a molécula teve como referência a análise da resposta fotoluminescente obtida pelo espectrofotômetro de fluorescência, conforme indicado na seção 2.3.1.

Como fonte luminosa para excitação dos sensores foi utilizado um diodo UV-LED (1,3 $\mathrm{mW}, \lambda=377 \mathrm{~nm}$ ), fabricado pela empresa Lumex. Nos ensaios com os dispositivos TCS3200, a tensão de alimentação do UV-LED foi mantida constante em 3,6 V.

\subsection{Resultados e discussões}

\subsubsection{Análise de resposta dos sensores de TAOS/PS(PtOEP) e TAOS/PVC(PtOEP) na presença de $\mathrm{O}_{2}$}

Os ensaios dos sensores foram realizados pela aquisição dos sinais de frequência das saídas das matrizes de fotodiodos recobertos pela membrana ativa de PtOEP imobilizadas em poliestireno e PVC. As moléculas corantes (PtOEP) foram excitadas por uma fonte de luz em $377 \mathrm{~nm}$. O mecanismo de supressão da fotoluminescência desta molécula na presença de $\mathrm{O}_{2}$ foram amplamente descritas por (KOSE, 2005; LEE; OKURA, 1997) e no capítulo 2. Na Figura 37 são mostrados os dois grupos de respostas das saídas RGB dos dispositivos TAOS/PS(PtOEP) e TAOS/PVC(PtOEP) pela interação com diferentes concentrações de $\mathrm{O}_{2}$. 
Para melhor representação e análise comparativa entre os dois dispositivos ópticos, os dados de resposta de intensidade de luz nos comprimentos de onda RGB foram relacionados pela frequência de saída, de acordo com Equação 8:

$$
\text { Resposta }=\frac{I_{0}-I}{I_{0}}
$$

Onde: Io e I referem-se as intensidades dos valores de frequência na ausência e presença de $\mathrm{O}_{2}$, respectivamente.

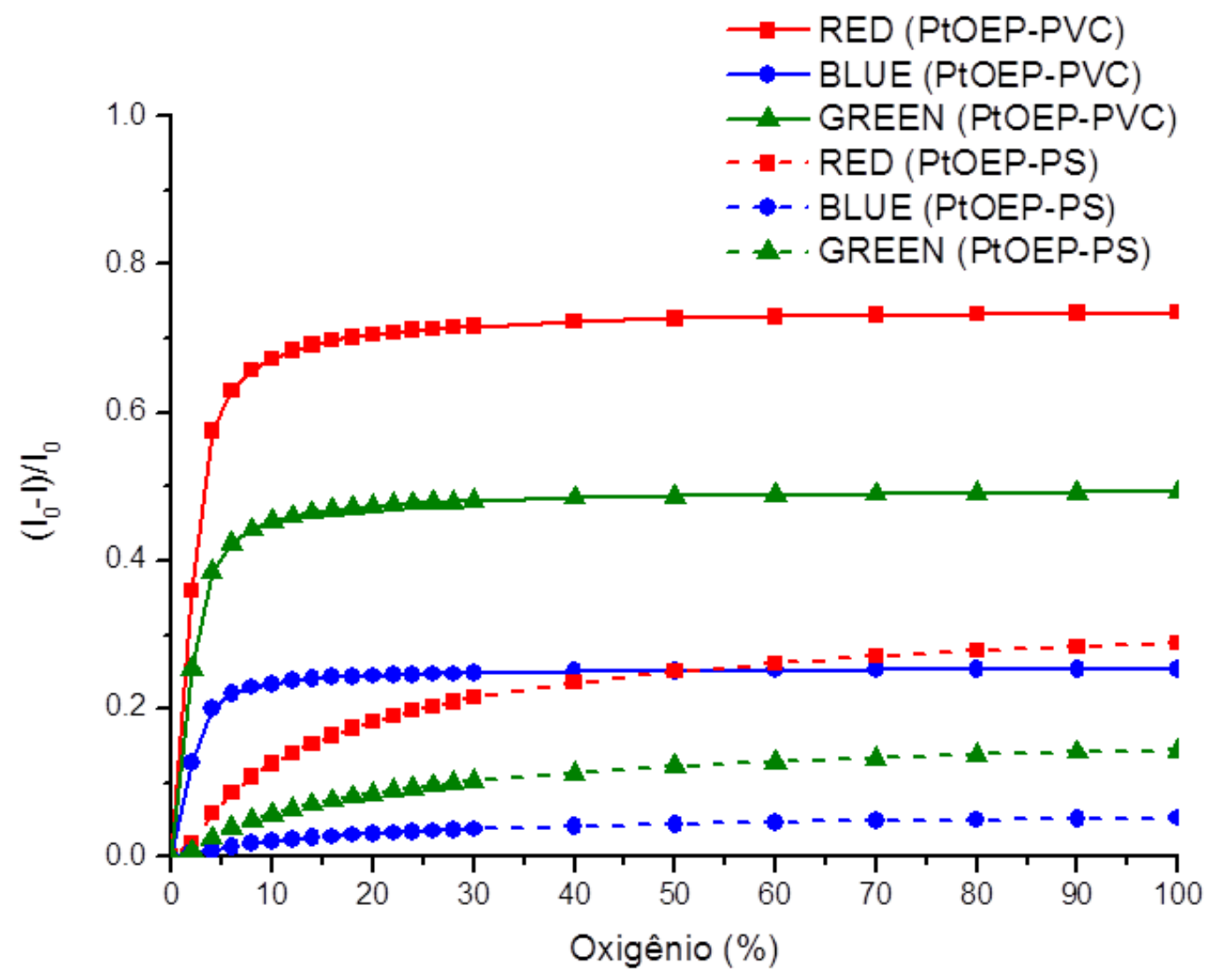

Figura 37 -Curvas de resposta de saída dos dispositivos TCS3200 com membranas ativas formadas por TAOS/PS(PtOEP) e TAOS/PVC(PtOEP) na presença de diferentes concentrações de $\mathrm{O}_{2}$ em $\mathrm{N}_{2}$.

Os resultados mostram total compatibilidade com aqueles reportados em Braga et al. (2013). No grupo de fotodiodos com filtros azuis e verdes, os dispositivos ópticos TCS3200 com membranas PtOEP-PVC e PtOEP-PS apresentaram baixa sensibilidade. Entretanto, em ambos casos, os fotodiodos com filtros vermelhos notam-se elevadas sensibilidades em ambientes com concentrações abaixo de $30 \%$ de $\mathrm{O}_{2}$, uma vez que a energia de emissão da molécula de PtOEP $(644 \mathrm{~nm})$ está dentro da faixa de passagem dos filtros vermelhos dos fotodiodos. Na Figura 38 são 
apresentadas as curvas de calibração de respostas dos dispositivos ópticos correspondentes aos fotodiodos vermelhos (melhor sensibilidade). Observa-se que as curvas de resposta não são lineares e em ambos os casos foram satisfatoriamente ajustadas por curvas bi exponenciais.

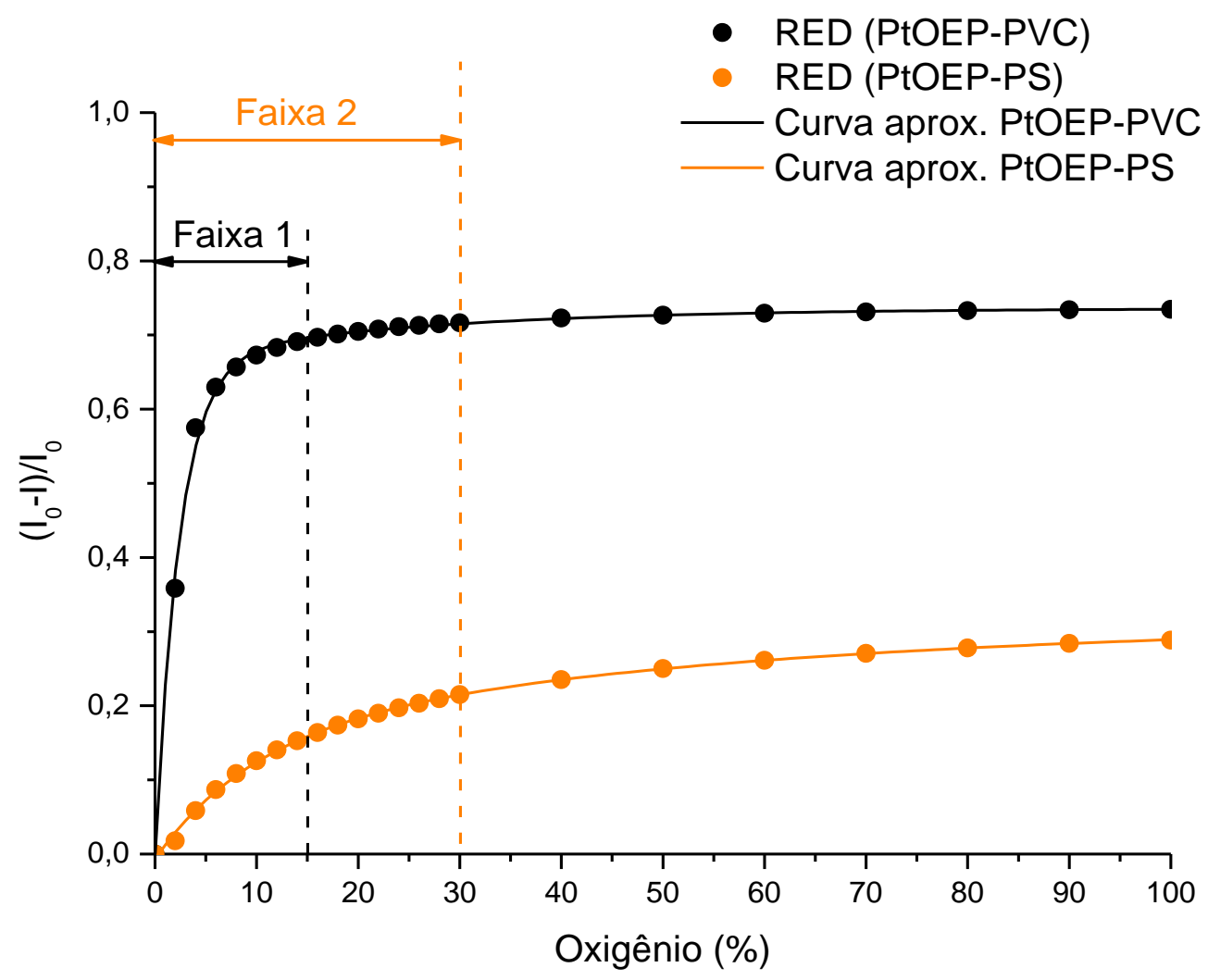

Figura 38 -Curvas de calibração com aproximação bi-exponencial de resposta das saídas de filtros vermelhos dos dispositivos TAOS/PS(PtOEP) e TAOS/PVC(PtOEP) na presença de diferentes concentrações de $\mathrm{O}_{2}$ em $\mathrm{N}_{2}$.

A Tabela 8 e a Tabela 9 apresentam os parâmetros dos ajustes bi-exponenciais das curvas de respostas para os sensores PtOEP-PVC e PtOEP-PS, com erros quadráticos médios de $6,87.10^{-5}$ e $1,10.10^{-5}$, respectivamente.

Tabela 8 - Parâmetros de ajuste exponencial para a curva de resposta do sensor TAOS/PVC(PtOEP) de filtros vermelhos.

\begin{tabular}{lcc}
\hline Equação & & $y=a+b * \exp (-x / c)+d * \exp (-x / e)$ \\
\hline \multirow{2}{*}{ Valores } & $\mathrm{a}$ & 0,74 \\
& $\mathrm{~b}$ & $-0,67$ \\
& $\mathrm{c}$ & 2,40 \\
& $\mathrm{~d}$ & $-0,071$ \\
& $\mathrm{e}$ & 24,40 \\
\hline
\end{tabular}


Tabela 9 - Parâmetros de ajuste exponencial para a curva de resposta do sensor TAOS/PS(PtOEP) de filtros vermelhos.

\begin{tabular}{lcc}
\hline Equação & & $y=a+b * \exp (-x / c)+d * \exp (-x / e)$ \\
\hline \multirow{3}{*}{ Valores } & $\mathrm{a}$ & 0,31 \\
& $\mathrm{~b}$ & $-0,16$ \\
& $\mathrm{c}$ & 52,66 \\
& $\mathrm{~d}$ & $-0,16$ \\
& $\mathrm{e}$ & 9,54 \\
\hline
\end{tabular}

Os parâmetros das curvas de ajuste mostram que a região mais sensível do sensor é representada pelas curvas exponenciais de menor constante de concentração $(2,40$ na Tabela 8 e 9.54 na Tabela 9), já as regiões de saturação são representadas pelas curvas com constante de concentração elevada (24,40 na Tabela 8 e 52.66 na Tabela 9). Estes resultados mostram que o sensor com o filme de PtOEP-PVC é mais sensível do que o sensor com filme de PtOEP-PS de tal forma que o sensor com matriz hospedeira de PVC satura prematuramente em concentrações em torno de $2,5 \%$ de $\mathrm{O}_{2}$, já o sensor com matriz de poliestireno satura em $9,5 \%$. Este efeito pode ser atribuído a um diferenciado processo de difusão do $\mathrm{O}_{2}$ nas matrizes hospedeiras de PVC e poliestireno, respectivamente.

\subsubsection{Respostas dos dispositivos TAOS/PS(PtOEP) e TAOS/PVC(PtOEP) na presença de diferentes concentrações de OD.}

Os sensores foram submetidos a ambientes de diferentes concentrações de oxigênio dissolvido em água deionizada (DI), segundo o arranjo experimental ilustrado na Figura 35, com vazão controlada de $100 \mathrm{ml} / \mathrm{min}$ e temperatura mantida constante em $23 \stackrel{\circ}{\circ}$. As respostas dos sensores foram monitoradas pela supressão da emissão fotoluminescente das moléculas de PtOEP na presença de moléculas de $\mathrm{O}_{2}$ dissolvidas em água DI. Os ensaios de supressão de fotoluminescência para ambos os dispositivos TAOS/PS(PtOEP) e TAOS/PVC(PtOEP) foram realizados em concentrações de OD de 0,0 a 20,0 mg/l.

Similarmente à resposta ao $\mathrm{O}_{2}$, neste caso também as curvas de resposta de ambos os sensores mostram uma característica não linear que foram ajustadas satisfatoriamente com curvas exponenciais (Figura 39). 


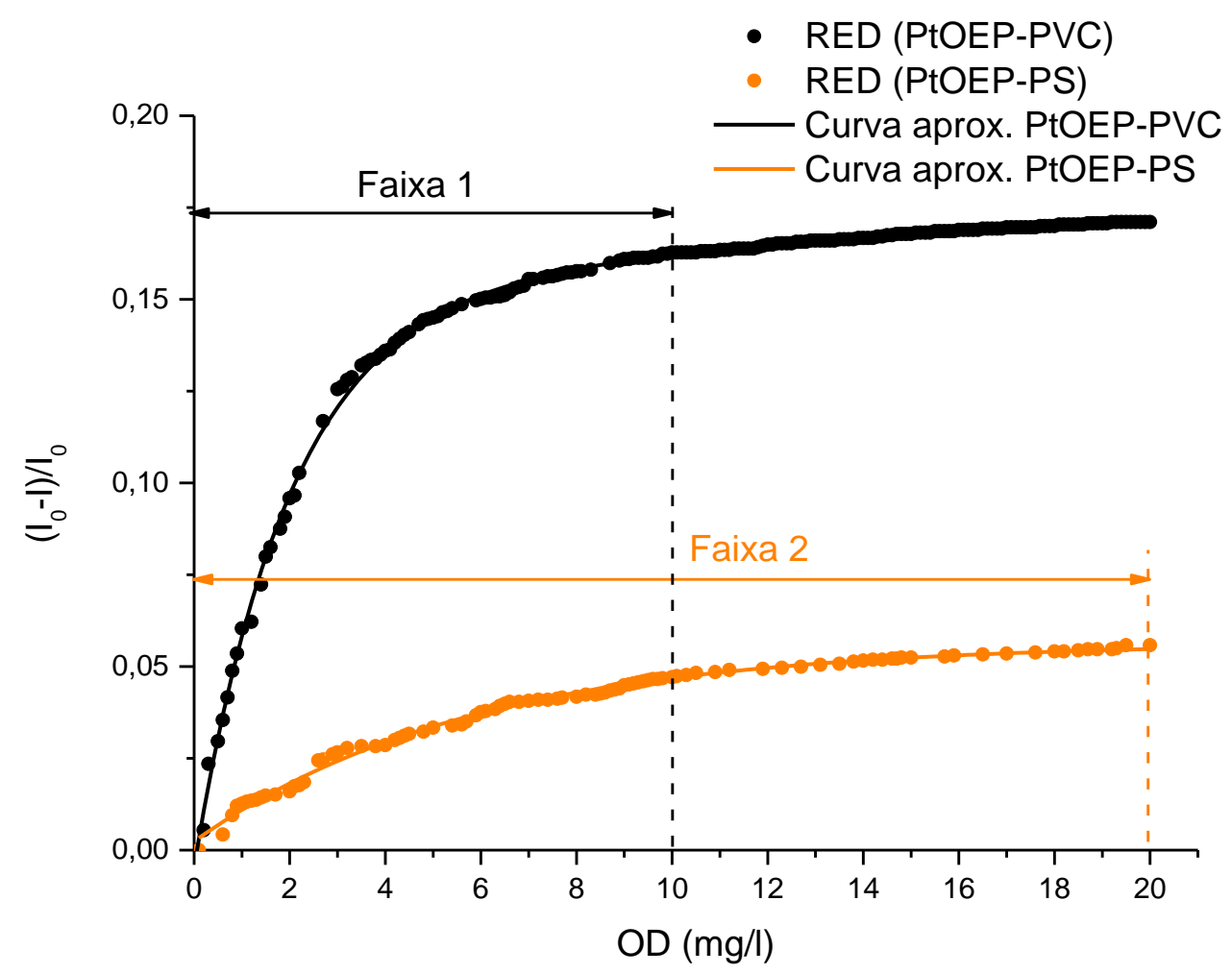

Figura 39 -Curvas de aproximação exponencial de resposta das saídas de filtros vermelhos dos dispositivos TAOS/PS(PtOEP) e TAOS/PVC(PtOEP) na presença de diferentes concentrações de OD.

Os resultados mostram que as intensidades de resposta dos sensores em meio líquido decaem em aproximadamente 5 (cinco) vezes em comparação aos encontrados em ambientes gasosos de $\mathrm{O}_{2}$. $\mathrm{O}$ argumento mais plausível para explicar esse comportamento relaciona-se à baixa probabilidades de colisão de moléculas de $\mathrm{O}_{2}$ dissolvidas com as moléculas de PtOEP. Novamente, observa-se que o sensor em matriz de PVC apresenta maior sensibilidade do que o sensor em matriz de poliestireno. A Tabela 10 e a Tabela 11 apresentam os parâmetros das curvas de ajuste para as curvas de resposta dos sensores TAOS/PS(PtOEP) e

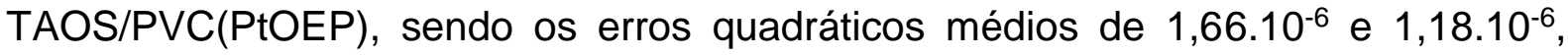
respectivamente.

Tabela 10 - Parâmetros de ajuste exponencial para a curva de resposta do sensor TAOS/PVC(PtOEP) de filtros vermelhos.

\begin{tabular}{lcc}
\hline Equação & & $y=a+b * \exp (-x / c)+d * \exp \left({ }^{-x} / e\right)$ \\
\hline \multirow{3}{*}{ Valores } & $\mathrm{a}$ & 0,19 \\
& $\mathrm{~b}$ & $-0,042$ \\
& $\mathrm{c}$ & 29,87 \\
& $\mathrm{~d}$ & $-0,16$ \\
& $\mathrm{e}$ & 2,00 \\
\hline
\end{tabular}


Tabela 11 - Parâmetros de ajuste exponencial para a curva de resposta do sensor TAOS/PS(PtOEP) de filtros vermelhos.

\begin{tabular}{llc}
\hline Equação & & $y=a+b * \exp \left({ }^{-x} / c\right)$ \\
\hline \multirow{3}{*}{ Valores } & $\mathrm{a}$ & 0,056 \\
& $\mathrm{~b}$ & $-0,054$ \\
& $\mathrm{c}$ & 5,79 \\
\hline
\end{tabular}

Os parâmetros de ajuste seguem a mesma tendência daqueles obtidos na resposta dos sensores ao $\mathrm{O}_{2}$. Estes resultados mostram que a intensidade de resposta destes sensores está limitada por processos de difusão do OD na matriz hospedeira de cada sensor.

\subsection{Conclusões}

Os resultados obtidos neste capítulo mostraram que os dispositivos sensores baseados em detectores optoeletrônicos, funcionalizados com filmes de moléculas de PtOEP apresentam respostas satisfatórias para detecções de $\mathrm{O}_{2}$ e $\mathrm{O}_{2}$ dissolvido em $\mathrm{H}_{2} \mathrm{O}$. Para ambas as detecções, o sensor fabricado com a matriz hospedeira de PVC mostrou maior sensibilidade do que o sensor com matriz hospedeira de poliestireno, devido, provavelmente, ao maior coeficiente de difusão do $\mathrm{O}_{2}$ sobre a matriz de PVC. Ambos os dispositivos sensores mostraram respostas não lineares na faixa de concentrações de 0 a $100 \%$ para $\mathrm{O}_{2}$ e de 0 a $20 \mathrm{mg} / \mathrm{l}$ para OD.

Esse sistema proposto permitiu integrar a membrana ativa ao dispositivo optoeletrônico comercial em diferentes matrizes hospedeiras de PVC e poliestireno em ranges totalmente compatíveis aos métodos tradicionais de detecção de $\mathrm{O}_{2}$ e OD. A integração do filme sensível do sensor diretamente na superfície do detector optoeletrônico dá abertura a uma gama enorme de possibilidades de aplicações deste tipo de sensor nas áreas médicas, industriais e ambientais.

O grande destaque deste arranjo foi permitir, diferentemente do dispositivo MOS, a possibilidade de detecção de emissões em outros comprimentos de onda, além do vermelho, dando margem à utilização de inúmeros elementos fluoróforos cujo ponto de emissão possa abranger uma gama maior de comprimento de onda do espectro da luz visível. 


\subsection{Referências}

AMAO, Y. Probes and Polymers for Optical Sensing of Oxygen. Microchim. Acta, v.143, pp. 1-12, 2003.

BRAGA, M. S.; SANTOS, D. S.; BORGES, V. F.; SALCEDO, W. J. "Sensores Ópticos Fotoluminescentes de Baixo Custo para Detecção de Oxigênio Aplicados em Sistemas de Controle e Monitoramento Ambiental". Proceedings of Safety, Health and Environment World Congress, v. I, p. 261, 2013.

INGRAMA, J. M. et al. FRET excited ratiometric oxygen sensing in living tissue. Journal of Neuroscience Methods, v. 214, p. 45, 2013.

JANAK, P. et al. Cholesterol Biosensors Based on Oxygen Sensing Alginate-Silica Microspheres. Biotechnology and Bioengineering, v. 108(9), 2011.

LEE, S.-K.; OKURA, I. Photostable Optical Oxygen Sensing Material: Platinum Tetrakis(pentafluorophenyl)porphyrin Immobilized in Polystyrene. Analytical Communications, v. 34, pp. 185-188, 1997.

KOSE, M. E. Multi-Luminophore Coatings for Pressure Sensitive Paint Applications. 2005. 173p. Tese (Doutorado) - University of Florida, [Gainesville], Florida, EUA, 2005.

OLGAC, E. et al. In Vitro Oxygen Sensing Using Intraocular Microrobots. IEEE Transactions on Biomedical Engineering, v. 59(11), p. 3104, 2012.

PĂTULEA, A.; BĂRAN, N.; CĂLUŞARU, I. M. Measurements of Dissolved Oxygen Concentration in Stationary Water. World Environment, v. 2(5), pp. 104-109, 2012.

SAlCEDO, W. J.; FERnANAdeZ, F. J. R.; RUBIM, J. C. Photoluminescence quenching effect on porous silicon films for gas sensors application. Spectrochimica Acta Part A., v. 60, p. 1077, 2004.

TOLENTINO, E. C. et al. Oxigenoterapia hiperbárica e regeneração hepática. Acta Cir. Bras., v. 18, suppl. 5, São Paulo, 2003. 
WANG, X. et al. Flow-based luminescence-sensing methods for environmental water analysis. Trends in Analytical Chemistry, v. 28, n. 1, pp. 75-87, 2009. 


\section{Capítulo 5}

\section{Sistema portátil colorimétrico e fluorimétrico para detecção de íons de metais pesados em meios líquidos.}

\subsection{Introdução}

Como agentes causadores de doenças relacionadas ao câncer, os metais pesados têm sido uma das principais ameaças para a saúde humana, devido às suas propriedades tóxicas, bioacumulativas e persistentes na natureza (JÄRUP, 2003).

Quando lançados juntamente com efluentes industriais em rios, mares ou estuários, próximos aos grandes centros urbanos, os metais pesados, que são normalmente encontrados na forma de íons catiônicos, podem ser absorvidos pela vegetação, por animais ou qualquer tipo de vida subaquática, provocando sérios problemas de intoxicações ao longo de toda cadeia alimentar.

Entre os métodos tradicionais de análises dos metais na forma de íons, os equipamentos para determinação de concentrações da ordem de submicrogramas de metais pesados são extremamente caros, requerem cuidados e equipamentos específicos no pré-tratamento das amostras, necessitam de mão de obra qualificada para operação e manutenção dos sistemas, não permitem conectividade on-line para monitoramento remoto, além de necessitarem de condições experimentais bem controladas. A literatura reporta os principais equipamentos para análise de íons de metais pesados em laboratório (PRESTEL; GAHR; NIESSNER, 2000; PINHEIRO, et al., 2010), são eles: espectrometria de emissão atômica com plasma indutivamente acoplado (ICP-AES), espectrometria de emissão óptica com plasma indutivamente acoplado (ICP-OES), espectrometria de massa com plasma indutivamente acoplado (ICP-MS), espectrometria de absorção atômica de vapor frio (CV-AAS), espectrometria de absorção atômica com forno de grafite (GF-AAS) etc.

Nos últimos anos tem sido observado grande interesse no desenvolvimento de sensores ópticos associados a sistemas micro-colorimétricos e microespectrométricos que utilizam elementos fotodetectores discretos multiespectrais 
formados por diferentes filtros ópticos sintonizados em todo espectro da luz visível (DITTRICH et al., 2015; HU et al., 2015), dando margens a inúmeras possibilidades de implementação de equipamentos portáteis no monitoramento in-loco de gases, compostos químicos e de íons de metais pesados, oferecendo vantagens por serem compactos, possibilitarem conectividade em sistemas de monitoramento remoto, serem imunes a ruídos provocados por efeitos eletromagnéticos, além de serem significativamente mais baratos e seguros.

Dentro desse contexto, o presente capítulo apresenta o desenvolvimento de um sistema multifuncional colorimétrico e fluorimétrico de detecção química portátil, para análises em meios líquidos, utilizando sensores optoeletrônicos multiespectrais seletivos a íons de metais pesados $\left(\mathrm{Pb}^{2+}, \mathrm{Cd}^{2+}, \mathrm{Zn}^{2+}, \mathrm{Cu}^{2+}, \mathrm{Fe}^{3+}\right.$ e $\left.\mathrm{Ni}^{2+}\right)$ e reagentes cromógenos e fluoróforos como indicadores em diferentes concentrações.

Sob condições de colaboração conjunta em desenvolvimento tecnológico, o presente trabalho contou com a parceria da empresa alemã MAZeT GmbH para o fornecimento de todos os dispositivos ópticos multiespectrais e acessórios para a conclusão da tese.

\subsection{Procedimentos Experimentais}

Nesta seção são apresentados os materiais, procedimentos para o desenvolvimento do sistema eletrônico multifuncional colorimétrico e fluorimétrico de detecção portátil de gases, oxigênio dissolvido e íons de metais pesados.

\subsubsection{Desenvolvimento de sistema eletrônico multifuncional colorimétrico e fluorimétrico de detecção portátil de gases, oxigênio dissolvido e íons de metais pesados}

Um sistema multifuncional colorimétrico e fluorimétrico de detecção química portátil, em meios líquidos foi desenvolvido com uso de instrumentação compacta, com características de operação independente e potencializada pela composição matricial de sensores optoeletrônicos multiespectrais seletivos a gases, oxigênio dissolvido e 
íons de metais pesados $\left(\mathrm{Pb}^{2+}, \mathrm{Cd}^{2+}, \mathrm{Zn}^{2+}, \mathrm{Cu}^{2+}, \mathrm{Fe}^{3+} \mathrm{e} \mathrm{Ni}^{2+}\right)$, na funcionalidade de um sistema "nariz ou língua optoeletrônica".

Para o processo de deteç̧ão, o sistema conta com uso de reagentes cromógenos e/ou fluoróforos dissolvidos em solventes orgânicos ou imobilizados em membranas plásticas de PVC ou poliestireno, a serem depositados diretamente na superfície dos dispositivos ópticos.

A matriz de sensores multiespectrais é composta por 4 (quatro) dispositivos ópticos individuais, sendo cada um formado por elementos fotodetectores discretos, tipo MMCS6CS, encapsulados em um mesmo invólucro, fabricado pela empresa MAZeT. Estes por sua vez, são conectados diretamente a 2 (dois) módulos amplificadores de transimpedância de 16 (dezesseis) canais com ganhos programáveis.

Após a etapa de amplificação, os sinais dos fotodetectores são selecionados por um multiplexador de 32 (trinta e dois) canais e direcionados ao processamento digital em um aplicativo embarcado, denominado de amplificador de sincronismo (LOCK-IN) para extração dos parâmetros de intensidade luminosa equivalentes em tensão $A C$ (VRMS), nível de tensão DC e defasagem (graus).

Como fonte luminosa para o sistema, são utilizados diodos emissores de luz (LED) com comprimentos de onda selecionados, conforme análises dos pontos de maior absorção das moléculas dos reagentes cromógenos e fluoróforos.

Os sinais de excitação dos LEDs são providos a partir de um módulo gerador de função e condicionamento de sinais de 4 (quatro) canais. A aquisição, controle e processamento dos sinais são realizados com base em tecnologia FPGA, tendo como ambiente de desenvolvimento a utilização de softwares baseados em instrumentação virtual (NI LabView $\AA$ ), fabricado pela National Instruments, modelo NI myRIO-1900. Na Figura 40 são mostrados os blocos funcionais do sistema eletrônico multifuncional colorimétrico e fluorimétrico de detecção portátil de gases, oxigênio dissolvido e íons de metais pesados. Na sequência, é apresentado um descritivo individual de cada bloco funcional. 


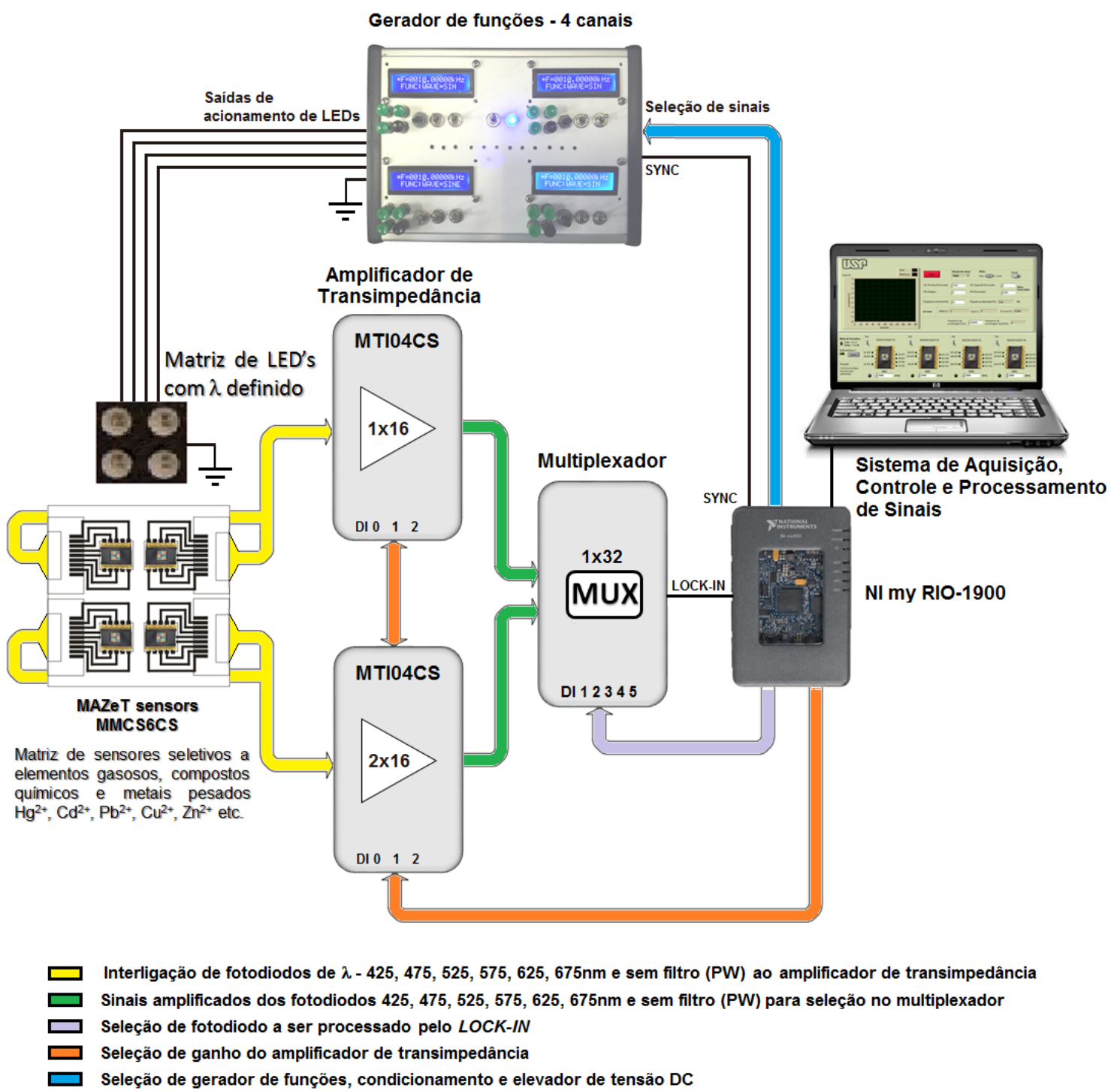

Figura 40 -Sistema eletrônico multiespectral para detecção de gases, oxigênio dissolvido e íons de metais pesados.

\subsubsection{Sensor de Cor Multiespectral de 6 canais - MAZeT}

O sensor de cor multiespectral é formado por elementos fotodetectores optoeletrônicos e composto por um conjunto de 18 (dezoito) fotodiodos $(3 \times 6)$ encapsulados em um circuito integrado, tipo MMCS6CS, fabricado pela empresa MAZeT. Neste dispositivo há três grupos de 6 (seis) fotodiodos seccionados simetricamente em uma estrutura circular de $2 \mathrm{~mm}$ de diâmetro (Figura 41). 


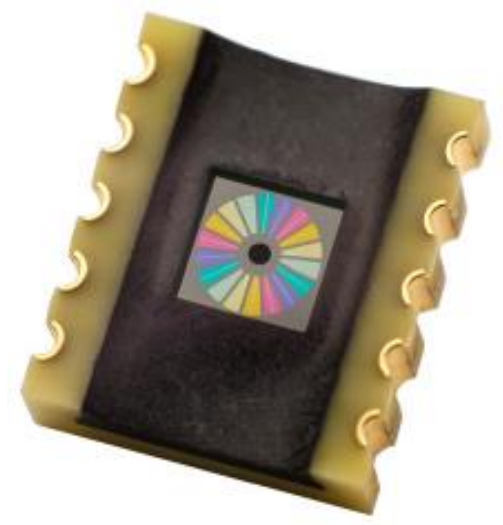

Figura 41 -Sensor Multiespectral MMCS6CS (MAZET, 2013a).

Para cada fotodiodo há um filtro espectral dielétrico que seleciona o comprimento de onda específico a ser detectado. A faixa espectral sensível dos fotodiodos está sintonizada entre $380 \mathrm{~nm}$ e $780 \mathrm{~nm}$, tendo como picos máximos valores de 425, 475, 525, 575, 625, $675 \mathrm{~nm}$ e sem filtro (PW). A Figura 42 apresenta a resposta típica de sensibilidade relativa do MMCS6CS escaneada por uma luz de banda larga, tendo um ângulo de incidência menor do que $10^{\circ}$.

\section{Sensibilidade espectral}

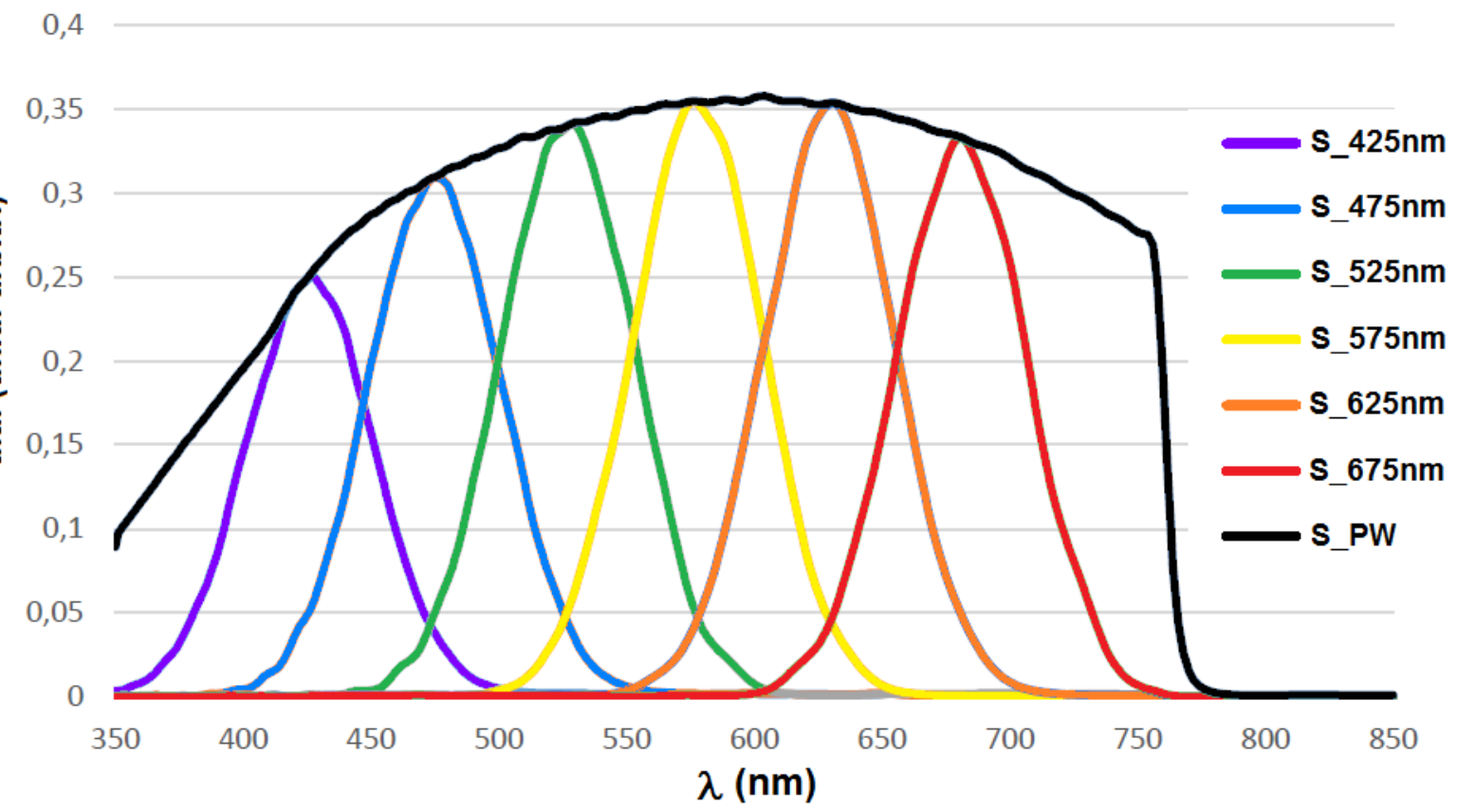

Figura 42 -Resposta típica de sensibilidade relativa do MMCS6CS (MAZET, 2013b). 


\subsubsection{Módulo amplificador de transimpedância de 16 canais com ganho programável}

Por serem formados por matrizes de fotodiodos, os sensores MAZeT, tipo MMCS6CS, possuem saídas de corrente que necessitam de amplificação e condicionamento para serem lidos e disponibilizados a hardwares de medição e aquisição de sinais. $O$ amplificador de transimpedância de 16 (dezesseis) canais, desenvolvido para o sistema de deteç̧ão, utiliza 4 (quatro) dispositivos de 4 (quatro) canais de amplificação integrados e ganhos programáveis, tipo MTI04CS. A Figura 43 e a Figura 44 mostram detalhes dos terminais de ligação do circuito integrado e do diagrama esquemático eletrônico parcial contendo 8 (oito) canais, respectivamente.

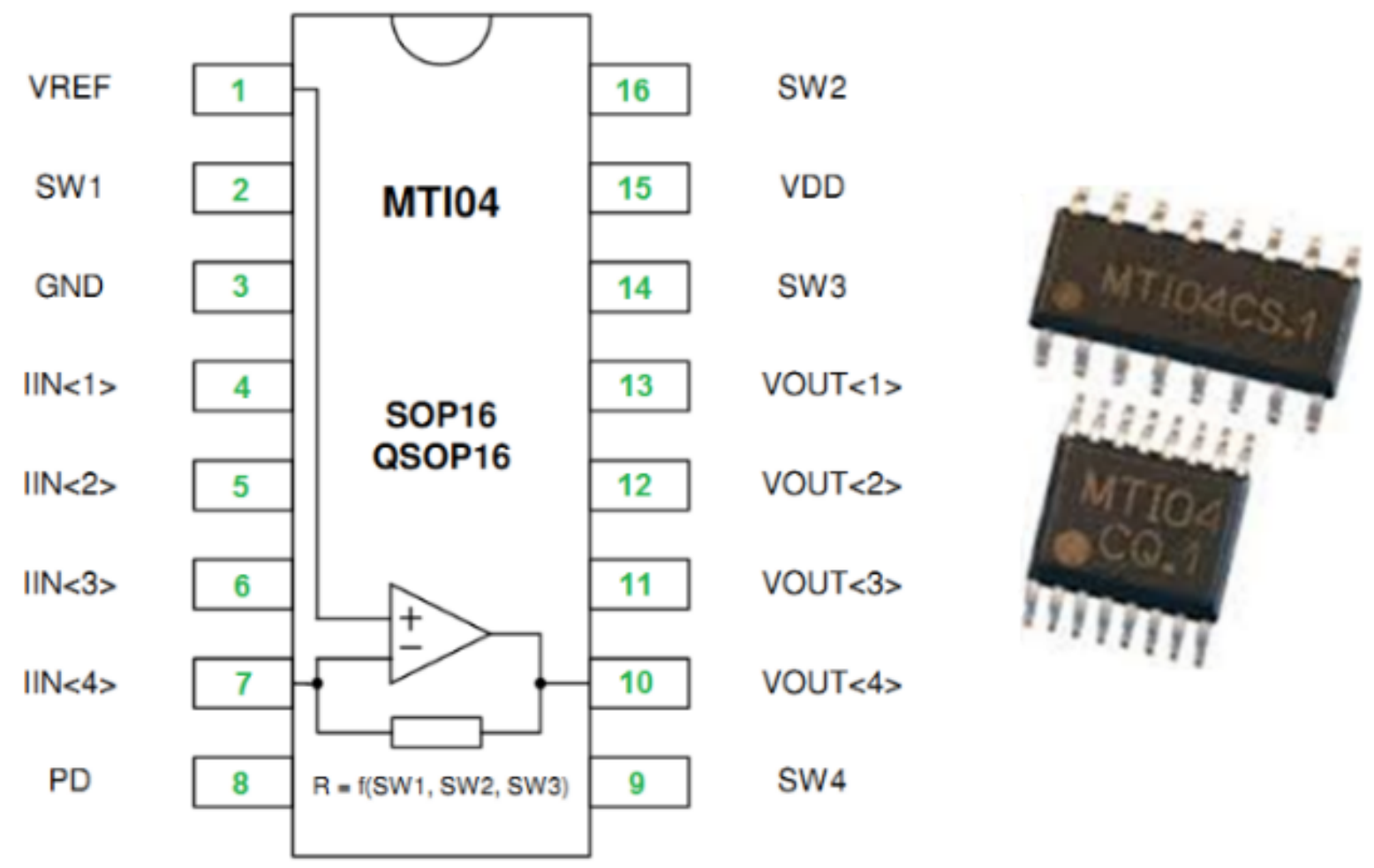

Figura 43 -Descrição dos terminais do circuito integrado do amplificador de transimpedância MTI04 (MAZET, 2013b). 


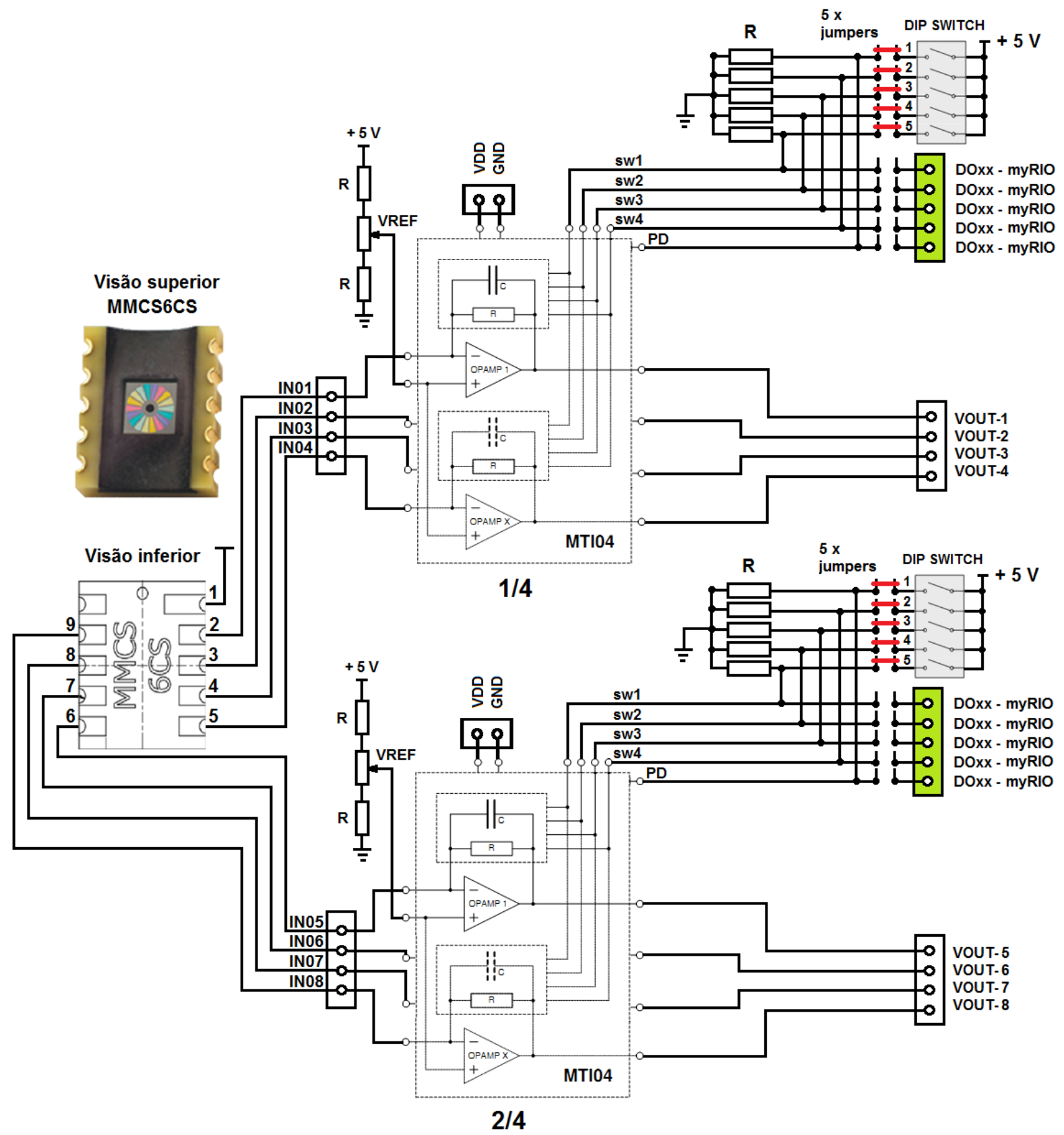

Figura 44 -Diagrama esquemático eletrônico parcial contendo 8 canais do módulo amplificador de transimpedância de 16 canais e ganho programável.

Em detalhe, na cor vermelha, 5 (cinco) jumpers de inserções em pinos de seleção possibilitam a configuração de dois modos de operação, seja em modo local, por chaves dip switches), ou através das saídas digitais controladas remotamente, via placa de aquisição myRIO - National Instruments. O fator de amplificação do amplificador de transimpedância é realizado pela combinação binária de 3 bits de entrada (SW1, SW2 e SW3) no circuito integrado MTI04CS, permitindo até 8 estágios diferentes de amplificação. $O$ amplificador de transimpedância opera sob duas faixas de frequências selecionáveis pela entrada digital SW4 e inibe a funcionalidade do 
módulo amplificador ao se introduzir $P D=V D D$. Desta forma, todas as saídas deste módulo estarão em modo tristate (desligada). Porém, na condição $P D=G N D$, a tensão de saída deverá operar, conforme a Equação 9:

$$
V_{O U T}=V_{R E F}-I_{I N} * R
$$

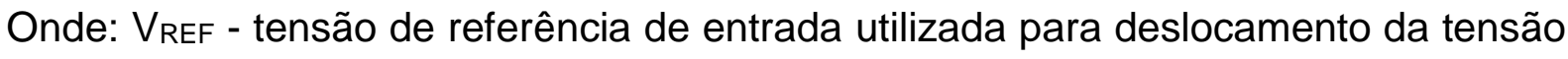
de saída

IIN - corrente de entrada provenientes dos fotodiodos integrados ao MMCS6CS

R - fator de amplificação do transimpedância (ganho)

A Tabela 12 mostra os fatores dos estágios de amplificação e seus respectivos códigos de seleção.

Tabela 12 - Fatores dos estágios de amplificação e seus respectivos códigos de seleção.

\begin{tabular}{cccr}
\hline \multicolumn{3}{c}{ Seleção das entradas } & \multirow{2}{*}{ digitais } \\
\cline { 1 - 2 } SW1 & SW2 & SW3 & \\
\hline VDD & VDD & VDD & $20 \mathrm{M} \Omega$ - estágio 1 \\
GND & VDD & VDD & $10 \mathrm{M} \Omega$ - estágio 2 \\
GND & VDD & GND & $5 \mathrm{M} \Omega$ - estágio 3 \\
VDD & GND & VDD & $2 \mathrm{M} \Omega$ - estágio 4 \\
GND & GND & VDD & $1 \mathrm{M} \Omega$ - estágio 5 \\
VDD & GND & GND & $500 \mathrm{k} \Omega$ - estágio 6 \\
VDD & VDD & GND & $100 \mathrm{k} \Omega$ - estágio 7 \\
GND & GND & GND & $25 \mathrm{k} \Omega$ - estágio 8 \\
\hline
\end{tabular}

\subsubsection{Circuito multiplexador de 32 canais para seleção de sinais provenientes de sensores MMCS6CS - MAZeT}

O método de detecção que utiliza o sensor MMCS6CS se baseia na análise dos sinais de saída pela medida da defasagem do sinal óptico e dos níveis de tensão $V_{R M S}$ e $V_{D C}$ obtidos pelo aplicativo LOCK-IN, processados pela placa de aquisição myRIO da National Instruments. 
Em operação com até 4 (quatro) sensores MMCS6CS, os 2 (dois) módulos dos amplificadores de transimpedância disponibilizam 28 (vinte e oito) vias amplificadas e condicionadas que devem ser conduzidas individualmente para leitura e armazenamento dos dados. Desta forma, o circuito multiplexador desenvolvido comporta até 32 (trinta e dois) canais de entrada e permite selecionar qualquer um dos sinais dos fotodiodos sintonizados para uma única saída a ser processada pelo LOCK-IN.

O circuito integrado utilizado (CD74HC4067) é baseado em tecnologia CMOS de baixo consumo e alta velocidade de seleção, comutação e propagação de sinais. $O$ controle de seleção é realizado pela combinação binária de 5 (cinco) entradas digitais (S0, S1, S2, S3 e E), provenientes da parametrização de chaves dip switch (modo local) ou remotamente, via saídas digitais da placa de aquisição. A Figura 45 mostra o diagrama esquemático eletrônico do multiplexador de 32 (trinta e dois) canais com seleção programável. 


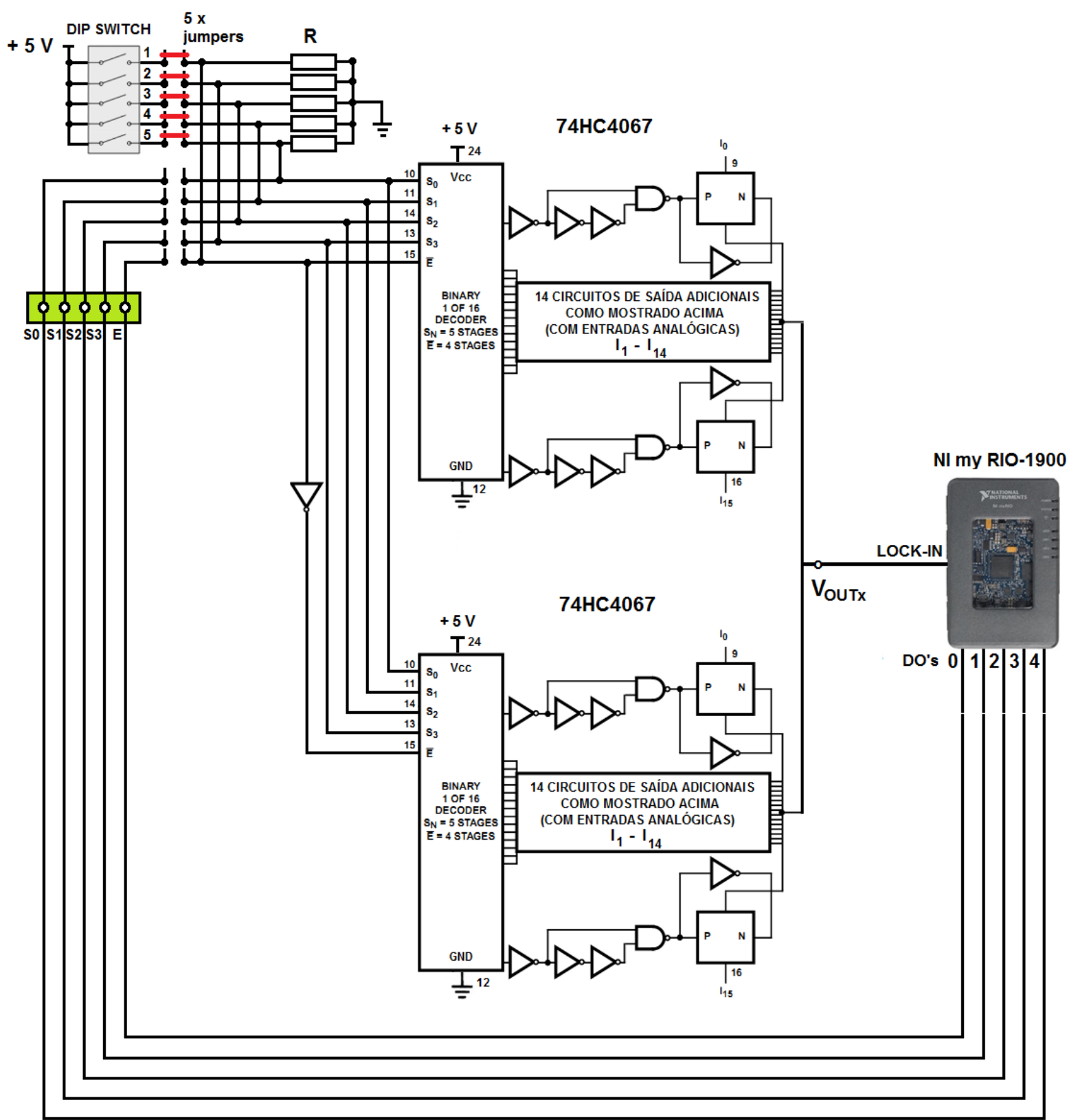

Figura 45 -Diagrama esquemático eletrônico do circuito multiplexador de 32 canais.

\subsubsection{Módulo gerador de função e condicionamento de sinais de 4} canais para excitação luminosa de diodos emissores de luz (LED)

Em sistemas embarcados de sensoriamento óptico para detecção de gases ou compostos químicos em meios líquidos, normalmente faz-se uso de reagentes fluoróforos e/ou cromógenos que se baseiam na mudança da resposta 
fotoluminescente ou por alterações na cor do meio a ser analisado. Esses reagentes devem ser excitados por feixes de luzes direcionados com comprimentos de ondas fixos e intensidades ou amplitudes bem definidas e constantes. O módulo gerador de função para condicionamento de sinais de excitação de LEDs, desenvolvido na presente tese, utiliza circuitos eletrônicos comerciais (UDB1203S) de geração de formas de onda senoidal, quadrada e triangular, fabricados com tecnologia DDS (Direct Digital Synthesis) e FPGA (Field Programmable Gate Array). Possui faixa de frequência de ajuste variando de $0,01 \mathrm{~Hz}$ a $3 \mathrm{MHz}$, com resolução de $10 \mathrm{mHz}$ e amplitude de sinal AC ajustável até $9 \mathrm{Vpp}$. A Figura 46 mostra detalhes da placa eletrônica do gerador de funções UDB1203S.

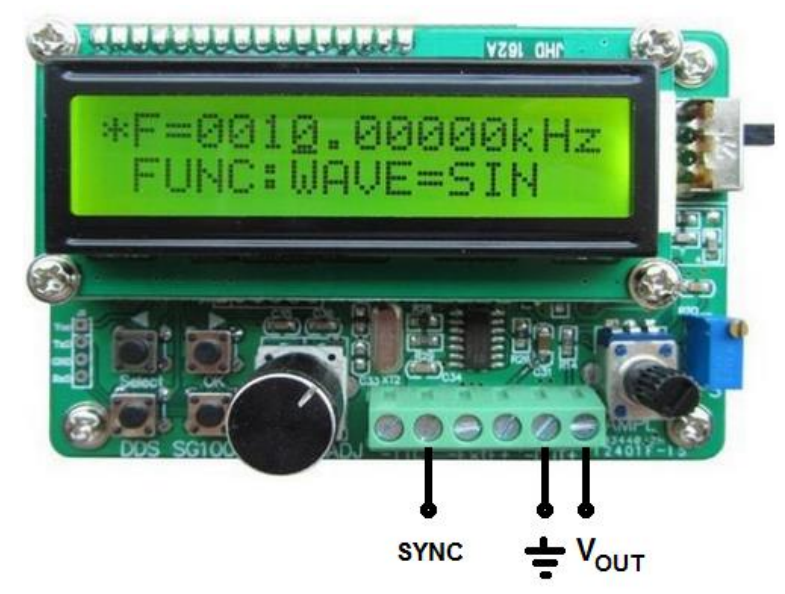

Figura 46 -Gerador de funções (UDB1203S, 2012).

O módulo utiliza 4 (quatro) geradores de funções que permite ajustes individuais de frequência e intensidade para cada LED do sistema. A fim de permitir a adequada polarização dos LEDs em seus respectivos pontos de operação para as mínimas e máximas intensidades correspondentes, em sinais de tensões senoidais $A C$, os circuitos elevadores de tensão foram implementados com ajustes de ganho (Av) e nível DC (NDC), utilizando um circuito integrado de quádruplo amplificador operacional, tipo TL074. A Figura 47 apresenta o diagrama esquemático eletrônico do módulo de condicionamento e geração de sinais para LEDs. 


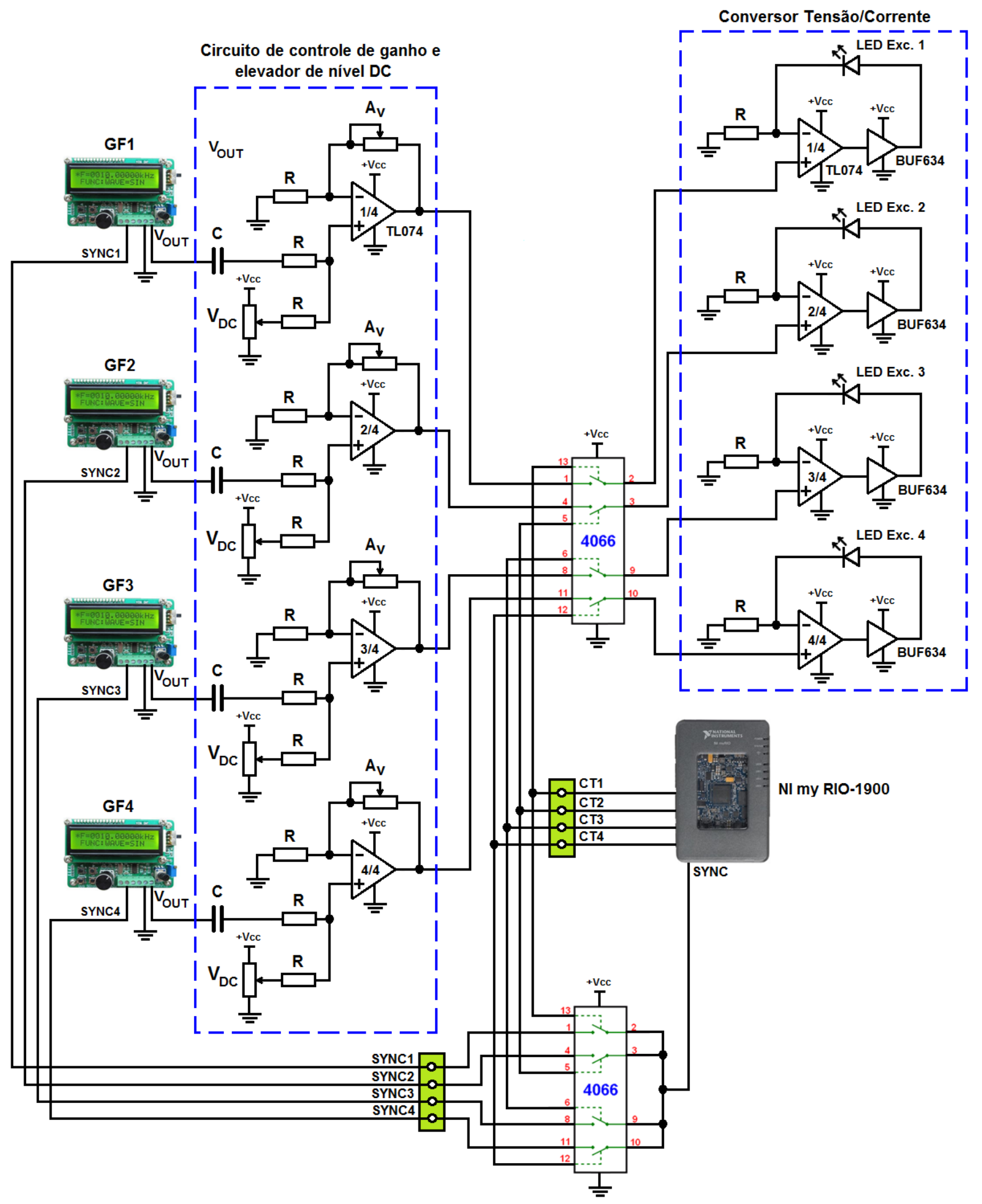

Figura 47 -Diagrama esquemático eletrônico do módulo gerador de função e condicionamento de sinais de $\mathbf{4}$ canais para excitação luminosa de LEDs

Como a intensidade luminosa de cada LED pode variar devido às possíveis mudanças de temperatura e à tensão aplicada em curto intervalo de tempo, circuitos de controle de corrente foram desenvolvidos de forma similar ao publicado por Santos e Pereira (2013). Nesta tese foram utilizados amplificadores operacionais (TL074) e circuitos 
buffers (BUF634) de interface, de maneira que a intensidade de cada um dos LEDs correspondesse a um comportamento linear a uma dada tensão aplicada.

Os sinais aplicados aos LEDs são controlados pela placa de aquisição por chaves analógicas (CD4066). Estas chaves conduzem os sinais dos geradores de funções (GF1-4) ao circuito conversor tensão/corrente, já condicionados pelo circuito de controle de ganho e elevador de nível DC. Simultaneamente, a NI-myRIO também seleciona por chaves analógicas, os sinais de sincronismo de saída (TTL) de cada um dos geradores de funções que são necessários para o processamento dos valores de fase, executados pelo módulo LOCK-IN.

\subsubsection{Sistema de aquisição, controle e processamento de sinais provenientes de sensor multiespectral MMCS6CS - MAZeT com uso de amplificador LOCK-IN digital}

Os sistemas de aquisição, controle e processamento de sinais destinados ao uso de sensores de qualquer natureza, normalmente requerem métodos flexíveis de linguagem de programação de softwares para o tratamento dos dados previamente armazenados, e devem permitir alterações nas condições de operação e funcionalidades, sem que haja a necessidade de mudanças no projeto de hardware. Por este motivo, a escolha dos recursos de hardware utilizado na presente tese buscou atender aos critérios apresentados abaixo:

- Arquitetura do hardware;

- Velocidade de processamento e capacidade de armazenamento de dados;

- Facilidade de uso da linguagem de programação, relacionada às ferramentas que possibilitem agilizar o desenvolvimento do projeto;

- Dimensões;

- Número de portas de Entrada/Saída (E/S) disponíveis;

- Conectividade; e

- Possibilidades de expansão.

Com base nos recursos de hardware e nas necessidades do projeto, optou-se pelo módulo embarcado myRIO-1900, que emprega tecnologia de E/S reconfiguráveis (RIO) da National Instruments Corporation®. Ele utiliza linguagem de programação 
LabVIEW, como ambiente de desenvolvimento para aquisição de sinal, análise de medidas e apresentação de dados. Essa arquitetura, baseada em duplo processador (ARM® ${ }^{\circledR}$ Cortex $^{\mathrm{TM}}$-A9 dual-core) possui memória e periféricos próprios e permite programação de forma independente. $\mathrm{O}$ grande destaque deste módulo é oferecer desempenho em tempo real de processamento e flexibilidade, graças aos blocos customizáveis do Xilinx Artix-7 FPGA (Field-Programmable Gate Array).

Tradicionalmente, FPGAs são programados por VHDL ou Verilog. O módulo LabVIEW FPGA® possibilita fácil programação, devido à "amigável" interface gráfica na myRIO1900. Isto ofereceu rapidez e reprodutibilidade durante o desenvolvimento do projeto, além de simplificar a geração do código FPGA.

Foram criados VIs (Virtual Instruments) para o processamento digital dos sinais, executados internamente ao dispositivo FPGA, combinando o acesso direto aos módulos de entrada e saída com aplicações determinísticas de tempo real, desenvolvidas no módulo LabVIEW Real-Time® ${ }^{\circledR}(\mathrm{RT})$.

O NI-myRIO é composto por rede Wi-Fi integrada, 10 (dez) entradas analógicas, 6 (seis) saídas analógicas, 2 (dois) canais de áudio I/O (estéreo), 40 (quarenta) linhas digitais de I/O (SPI, I²C, UART e PWM), além de um acelerômetro de 3 (três) eixos integrados à placa principal.

A National Instruments oferece ainda, uma ferramenta de programação gráfica chamada LabVIEW Web UI Builder ${ }^{\circledR}$ que pode ser utilizada para criação de páginas de internet, permitindo o monitoramento e envio de dados à distância. Assim, o usuário pode monitorar e controlar aplicações desenvolvidas em LabVIEW, através de uma simples web browser. A Figura 48 mostra detalhes construtivos do hardware myRIO1900 da National Instruments. 


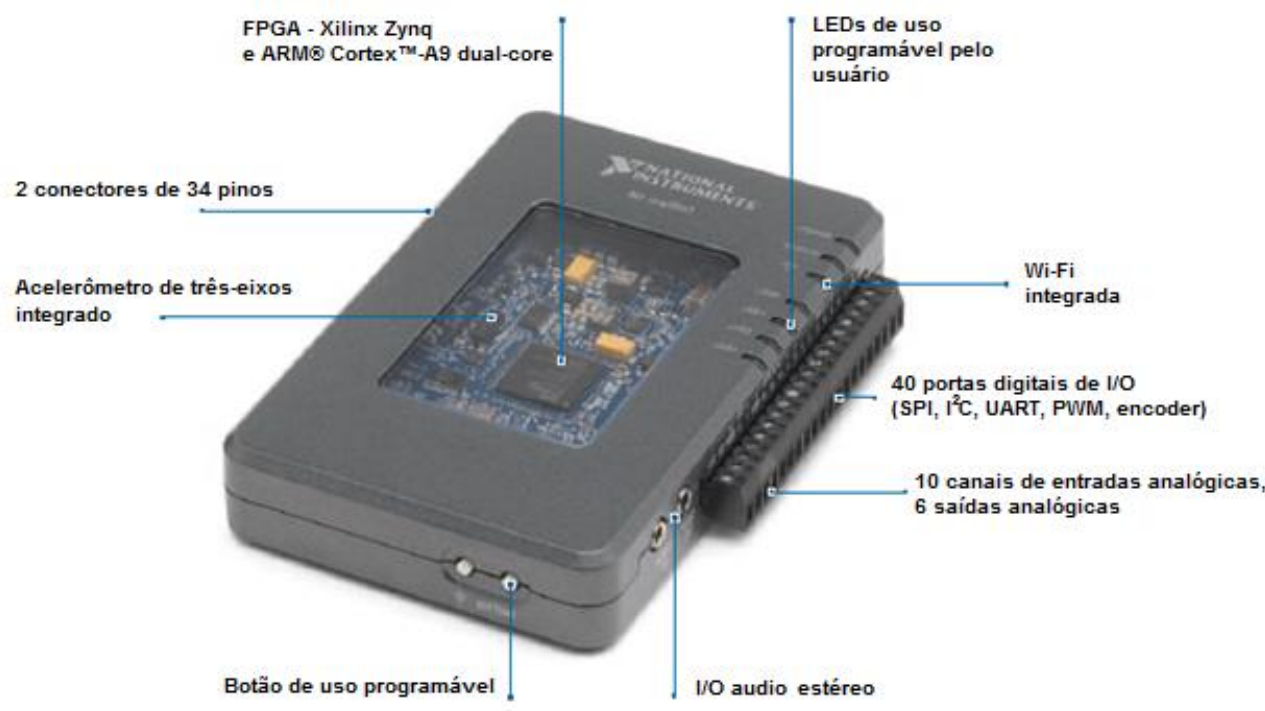

Figura 48 -Módulo eletrônico de aquisição e processamento de sinais NI myRIO-1900 (HUSSAIN; ZEPHERIN, 2015)

No processo de medição dos sinais provenientes dos sensores multiespectrais, as intensidades da emissão fotoluminescente das moléculas ativas são transformadas pelos fotodetectores em sinais elétricos de baixa intensidade e, assim, estarão sujeitas às interferências de diferentes fontes de ruídos. Por esta razão, diversas técnicas e equipamentos (D'AMICO et al., 2010, FU et al, 2013) têm sido empregados com a finalidade de minimizar os efeitos da baixa relação sinal/ruído, permitindo quantificar pequenos sinais $\mathrm{AC}$, obscurecidos por ruídos com valores de amplitudes, até mesmo de ordem de grandezas maiores.

Dentro desse contexto, um sistema denominado de amplificador LOCK-IN digital foi tema para o desenvolvimento em conjunto com Daniela de Souza Dairiki, sob estratégias, direcionamentos e colaborações da presente tese para a conclusão do seu trabalho de mestrado (SANTOS, 2010), realizado no grupo de Sensores Integráveis e Microsistemas da Escola Politécnica da USP. O sistema implementado possibilitou a medição e amplificação de pequenos sinais $A C$ dos fotodetectores integrados, a uma dada frequência definida, eliminando sinais indesejáveis de outras frequências como ruídos. A descrição do sistema $L O C K-I N$ e das configurações dos blocos funcionais (Filtro CIC e Filtro MA) estão disponíveis em Santos (2010).

A técnica comumente empregada em laboratórios de caracterização óptica se baseia na demodulação da função de correlação do sinal de entrada $V_{\mathbb{I N}}$, com um sinal de sincronismo (SYNC), de mesma frequência. Neste caso, os sinais de ruídos em 
frequências diferentes da frequência de referência são rejeitados por um filtro passabaixa e não interferem na medida dos sinais.

O método $L O C K$-IN se inicia com a amostragem do sinal de entrada $V_{I N}$ pela entrada analógica da $\mathrm{NI}$-myRIO, com taxa de aquisição de $500 \mathrm{kS} / \mathrm{s}$, e na sequência é multiplicado em um estágio detector sensível à fase (PSD) pelo sinal de referência de sincronismo (SYNC). Todo processamento matemático de multiplicação e filtragem dos sinais é realizado dentro da unidade FPGA (myRIO-1900). Filtrando a componente CA e mantendo somente a DC, a amplitude $V_{\text {RMS }}(\mathrm{V})$ e a fase do sinal $\theta$ $\left({ }^{\circ}\right)$, com mesma frequência do sinal de sincronismo, podem ser calculadas e armazenadas. Na Figura 49 é apresentado o diagrama de blocos da arquitetura do sistema LOCK-IN (SANTOS, 2010).

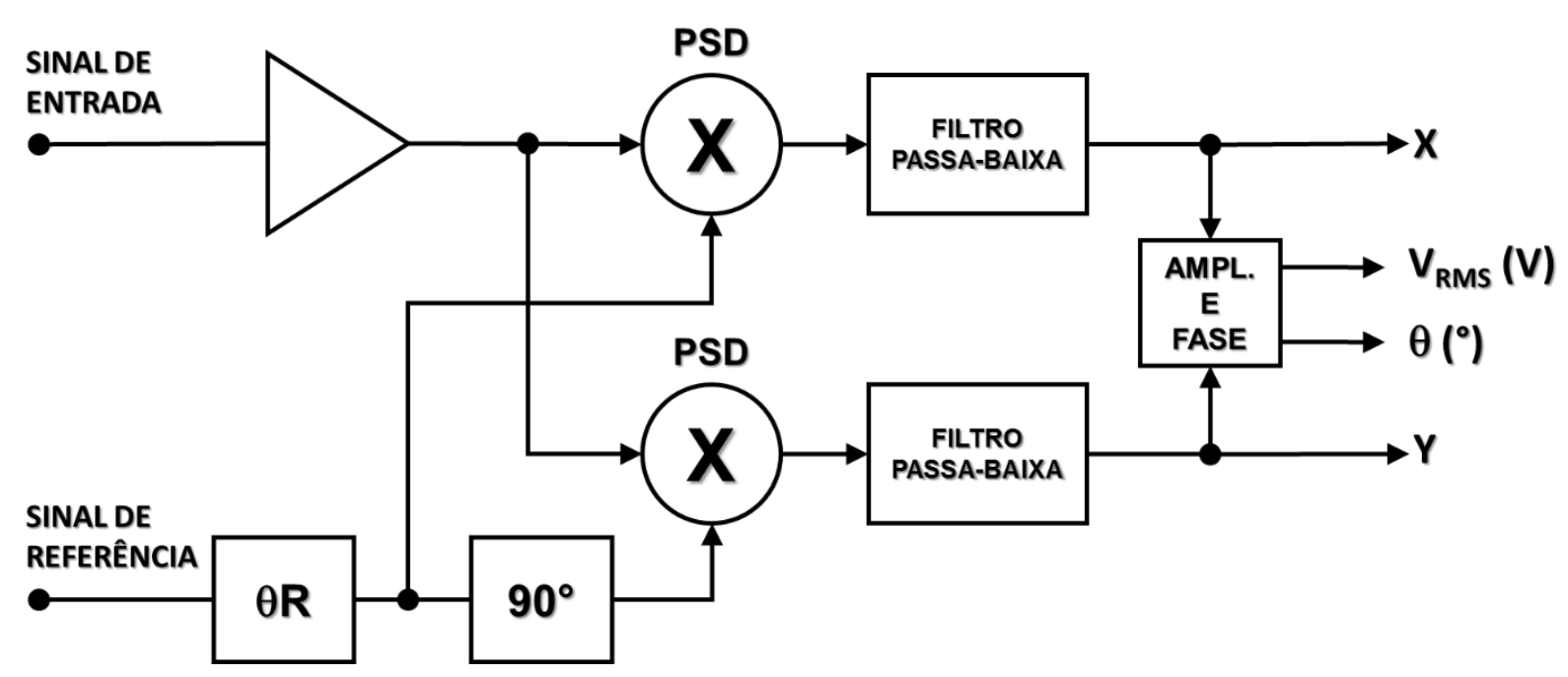

Figura 49 -Diagrama de blocos da arquitetura do sistema LOCK-IN.

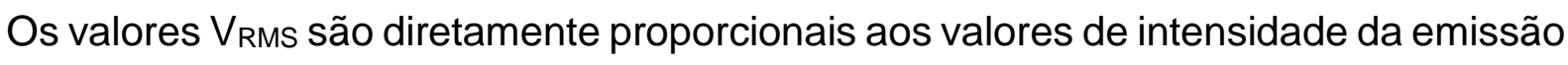
fotoluminescente; já os valores de fase estão relacionados com a mudança de tempo de vida da emissão fotoluminescente dos fluoróforos utilizados durante os ensaios de medidas de fluorescência.

Diferentemente dos reagentes fluoróforos, onde foram aplicados aos LEDs sinais AC (onda senoidal) de excitação, nos reagentes cromógenos, os sinais alimentados foram contínuos e constantes (DC). Desta forma, o princípio de detecção foi baseado nas medidas de tensão em nível DC, obtidas pelos fotodetectores integrados ao sensor multiespectral. Na Figura 50 são mostrados os campos de leituras dos sinais de tensão eficaz $A C\left(\mathrm{~V}_{\mathrm{RMS}}\right)$, fase $\left({ }^{\circ}\right)$, tensão em nível $\mathrm{DC}(\mathrm{V})$, bem como os campos de configuração dos filtros passa-baixas, modo de operação (local/web), frequência 
nominal de excitação dos LEDs e taxa de amostragem real. Todas as informações contidas nos campos de leitura foram utilizadas e armazenadas nos processos de detecção dos gases de $\mathrm{O}_{2}$ e $\mathrm{NO}_{2}$ (capítulo 6) e dos íons metálicos pelos métodos de colorimetria e fluorimetria (capítulo corrente).

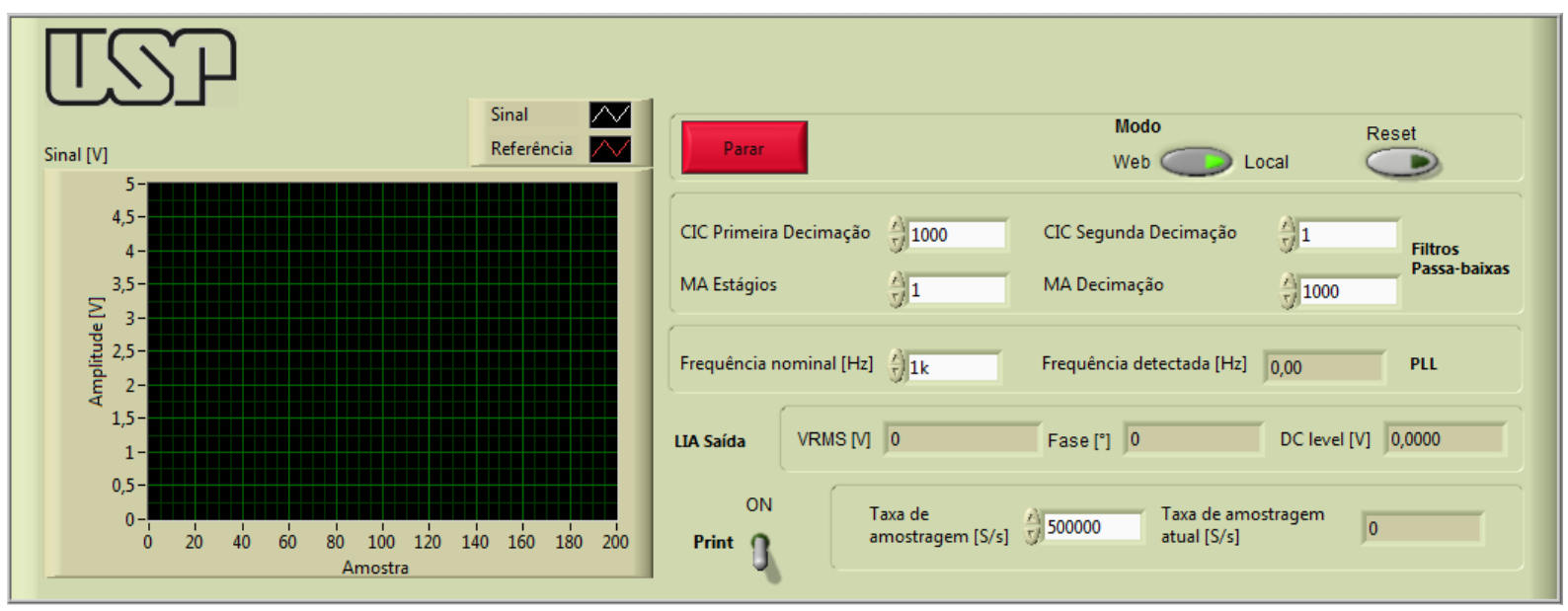

Figura 50 -Tela de leitura dos sinais de tensão eficaz $A C\left(V_{\mathrm{RMS}}\right)$, fase $\left(^{\circ}\right)$ e tensão em nível $D C$ (V) desenvolvida em ambiente LabVIEW - National Instruments

Como visto anteriormente, toda funcionalidade do sistema LOCK-IN se baseia no processamento realizado pelo algoritmo matemático para obtenção das medidas dos parâmetros de amplitude $\mathrm{V}_{\mathrm{RMS}}$, do valor da defasagem entre os sinais de saída dos sensores multiespectrais $(425,475,525,575,625,675 \mathrm{~nm}$ e s/filtro (PW)) e o sinal de sincronismo (SYNC) e dos valores de tensão em nível DC, aplicados à entrada analógica $\left(\mathrm{V}_{\mathrm{IN}}\right)$ da NI-myRIO. Para tal fim, o sistema conta com um modo de operação automático de varredura que seleciona uma única saída, das 28 (vinte oito) possíveis, da matriz $2 \times 2$, composta de 4 (quatro) sensores MMCS6CS. Esta seleção é realizada por um código binário de 5 (cinco) bits (DO1-DO5) e permite que seja extraído do circuito multiplexador apenas o sinal de um único sensor por ciclo de processamento do $L O C K$-IN, com suas respectivas saídas de comprimentos de onda $425,475,525$, 575, 625, $675 \mathrm{~nm}$ e s/filtro (PW). Adicionalmente, cada um dos LEDs a serem utilizados como excitação luminosa sobre os dispositivos multiespectrais são selecionados por saídas digitais da NI-myRIO e aplicadas no módulo gerador de função e condicionamento de sinais de 4 (quatro) canais para alimentação dos LEDs (LED1-LED4).

O aplicativo permite ainda, o ajuste de tempo em que cada LED é habilitado (aceso), durante a varredura de acionamentos das saídas dos sensores multiespectrais que compõem a matriz. 
Na Figura 51 é apresentada a tela de seleção dos sensores multiespectrais, com os campos de configuração do tempo de permanência em cada uma das saídas individuais $(425,475,525,575,625,675 \mathrm{~nm}$ e s/filtro (PW)).

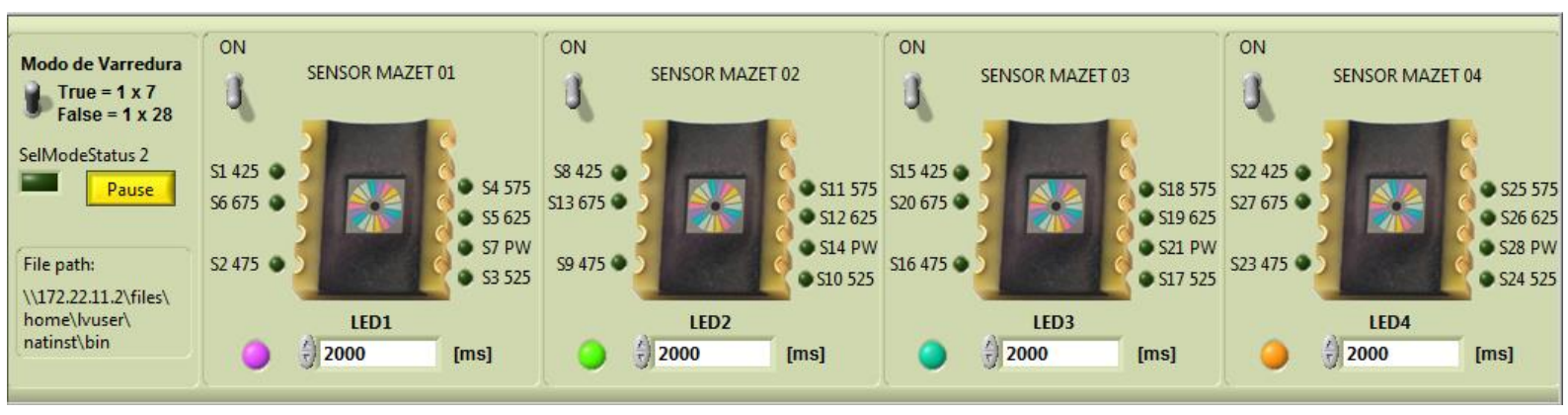

Figura 51 -Tela de seleção dos sensores multiespectrais, com os campos de configuração do tempo de permanência em cada uma das saídas

\subsubsection{Sistema embarcado portátil de detecção de íons de metais pesados por métodos colorimétricos e uso de sensor óptico multiespectral}

Método colorimétrico de identificação e quantificação de íons de metais pesados é uma estratégia analítica que utiliza propriedades seletivas de reagentes cromógenos a partir da análise da absorção da intensidade de luz, situada na região visível do espectro eletromagnético.

Alguns metais de transição ou corantes orgânicos quando submetidos a feixes de luz de certos comprimentos de onda promovem transições eletrônicas de um nível de menor energia para outro de maior energia. Esta "interferência", convertida em energia absorvida pelo meio, dá-se pela distância entre os níveis de energia e pode ser determinada pela medida de intensidade da luz, antes e depois de atravessar um meio sob análise. Segundo a lei de Beer-Lambert, a absorção da luz (absorbância) é proporcional ao caminho atravessado pela luz e a concentração molar da espécie química em solução, seguindo a Equação 10 (FUWA; VALLEE, 1963) e ilustrada na Figura 52.

$$
A=\varepsilon \cdot l \cdot C
$$

Onde: A - Medida de absorbância

$\varepsilon$-Absorvidade molar 
I- Distância do caminho óptico

C - Concentração molar da espécie química

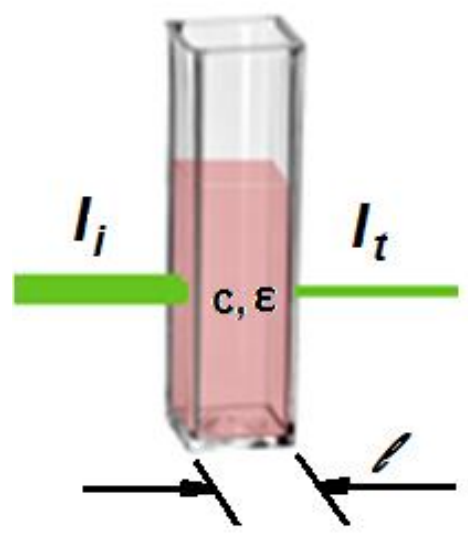

Figura 52 -Demonstração da lei de Beer-Lambert através da absorção da luz em meios líquidos

Outro fenômeno que ocorre na incidência de luz sobre uma amostra é a transmitância, o qual está diretamente relacionada à absorbância. Portanto, ela consiste na radiação luminosa não absorvida pelo meio e que chega até o outro lado da cubeta, conforme Equação 11:

$$
T=\frac{I_{t}}{I_{i}}
$$

Onde: $l_{i}$ - Intensidade de luz incidente a um dado comprimento de onda $(\lambda)$

$I_{t}$ - Intensidade de luz transmitida

$T$ - Transmitância

O espectrômetro de absorção UV-VIS é um instrumento utilizado como referência em análises colorimétricas, sendo possível realizar medidas de absorbância, transmitância e reflectância. O funcionamento se baseia na medida de absorção da luz quando um feixe de uma fonte luminosa é separado em comprimentos de onda individuais por um prisma ou rede de difração. Esta luz monocromática obtida é dividida em dois feixes de igual intensidade por um dispositivo semiespelhado (beamsplitter). De um lado, a luz é encaminhada através de uma cubeta de referência (branco) e, de outro, através da amostra sob análise. Neste caso, o espectrômetro UV-VIS é chamado de duplo feixe (Figura 53). 


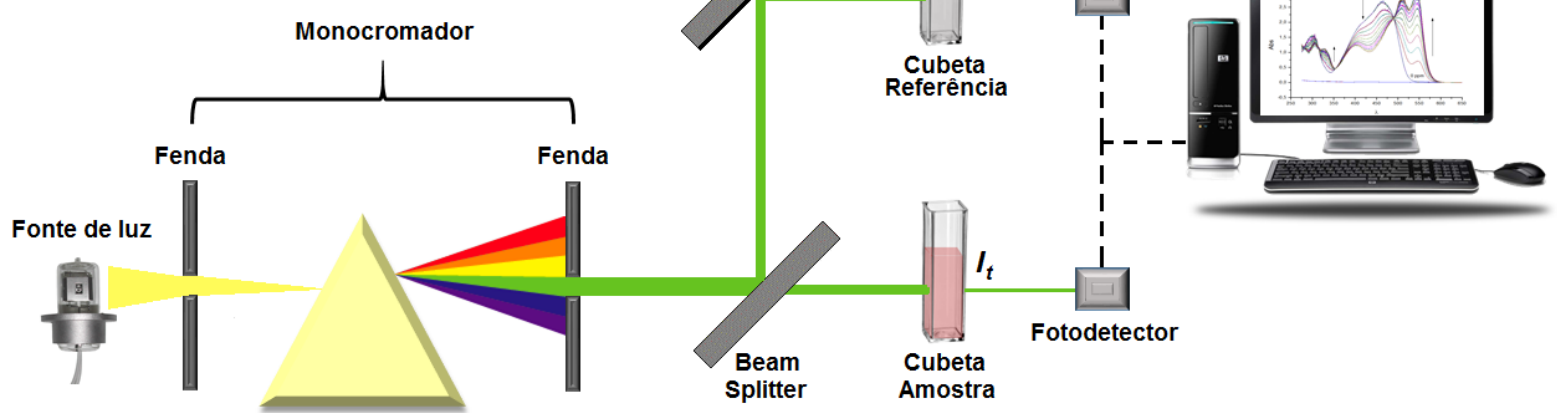

Figura 53 -Representação esquemática do espectrômetro UV-VIS de duplo feixe.

Ambos os raios de luz são direcionados a detectores que comparam suas intensidades como relação (taxa) da intensidade de luz que passa pela amostra e pelo meio de referência. O logaritmo dessa "taxa" corresponde à energia absorvida, em certo comprimento de onda particular e pode ser calculado pela Equação 12 (FUWA; VALLEE, 1963).

$$
A=\log _{10}\left(I_{i} / I_{t}\right)=-\log _{10}(T)
$$

Onde: $\quad$ A - Medida de absorbância

$l_{i}$ - Intensidade de luz incidente a um dado comprimento de onda $(\lambda)$

$I_{t}$ - Intensidade de luz transmitida

T - Transmitância

Durante um curto período de tempo, o espectrômetro de absorção UV-VIS submete a amostra, automaticamente, à incidência de luz em comprimentos de onda, normalmente na região ultravioleta (UV) de 200 a $400 \mathrm{~nm}$ e, incluindo, espectros visíveis de 400 a $800 \mathrm{~nm}$.

De maneira similar ao método descrito acima, dispositivos detectores de cores (RGB, true color e sensores multiespectrais) também têm sido empregados em análise colorimétrica, por medidas de intensidade luminosa das condições de absorbância ou transmitância no meio. Eles utilizam elementos fotodetectores com filtros sintonizados em diferentes regiões do espectro da luz visível, a fim de reproduzir com precisão, comportamento muito próximo ao encontrado na visão humana. 
Os projetos de desenvolvimento desses sensores normalmente se baseiam nas regras estabelecidas do padrão CIE1931, que foi criado pela Comissão Internationale de l'Eclairage, através de protocolos experimentais, para definir, a partir da combinação dos três estímulos $X Y Z$, a percepção natural do olho humano pela interpretação das cores no espectro da luz visível. A Figura 54 mostra os resultados empíricos para um observador de campo de visão limitado em $2^{\circ}$.

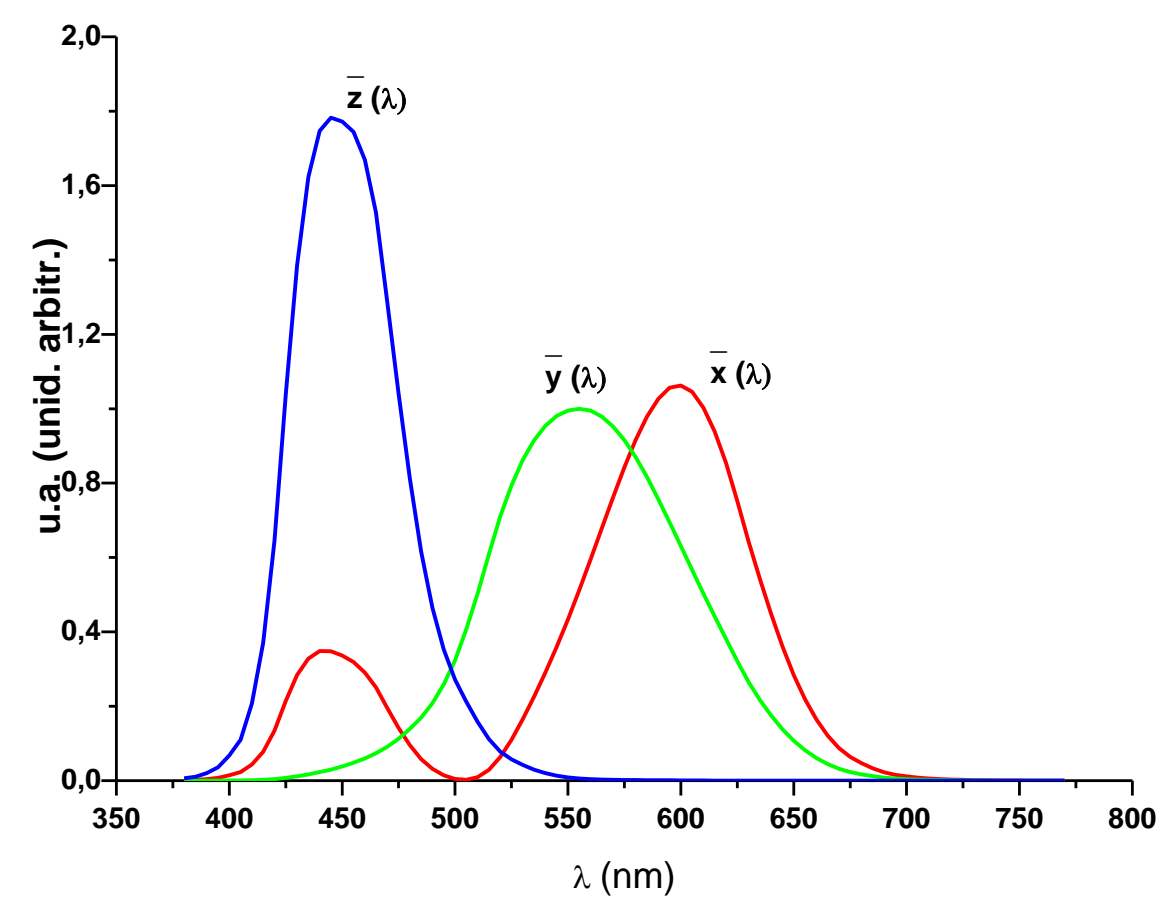

Figura 54 -Funções de combinações de cores CIE1931XYZ.

Os espectros das cores, conforme o padrão CIE1931XYZ definem todas as cores em três primárias imaginárias, com o qual as funções de combinações de cores $\bar{x}(\lambda), \bar{y}$ $(\lambda)$ e $\bar{z}(\lambda)$ podem ser representadas no diagrama de cromaticidade CIExy (Equações 16 e 17) que define um espaço de cor do espectro visível em duas ou três dimensões, de acordo com as Equações 13, 14 e 15 e ilustrada em 2D, na Figura 55 (SMITH; GUILD, 1932).

$$
\begin{aligned}
& X=\int_{380}^{770} L_{w}(\lambda) \bar{x}(\lambda) d \lambda \\
& Y=\int_{380}^{770} L_{w}(\lambda) \bar{y}(\lambda) d \lambda
\end{aligned}
$$




$$
Z=\int_{380}^{770} L_{w}(\lambda) \bar{z}(\lambda) d \lambda
$$

Onde: $\bar{x}(\lambda), \bar{y}(\lambda), \bar{z}(\lambda)$ - funções de combinações de cores primárias necessárias para descrever uma cor espectral $L_{w}$ - Espectro de luz incidente

$$
\begin{aligned}
& x=\frac{X}{X+Y+Z} \\
& y=\frac{Y}{X+Y+Z}
\end{aligned}
$$

Onde: $\mathrm{x}$ e y são as coordenadas de cromaticidade

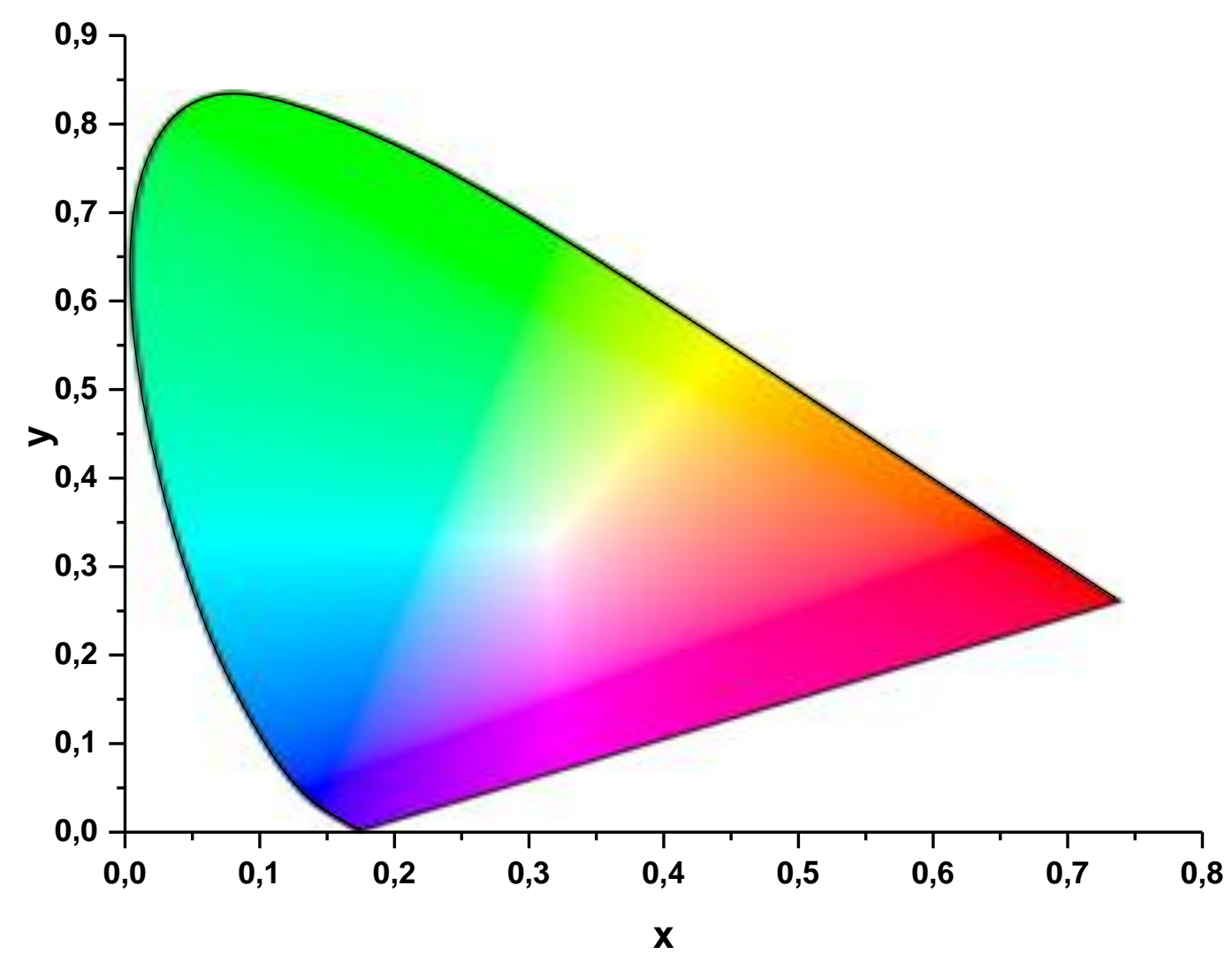

Figura 55 -Diagrama de cromaticidade CIExy.

No CIExyY, Y é definido como luminância e indica a eficácia luminosa espectral, sendo associado à percepção do claro/escuro (Equação 18). 


$$
Y=X \cdot \frac{y}{x}
$$

Onde: $Y$ - Luminância

$X$ - Parâmetro triestímulo $X$

$x$ e $y$-Coordenadas de cromaticidade

\subsubsection{Arranjo experimental colorimétrico com uso sensor multiespectral MMCS6CS}

O sistema embarcado portátil de detecção de íons de metais pesados pelo método colorimétrico utiliza como elemento fotodetector um dispositivo optoeletrônico, descrito na seção 5.2.1.1. O circuito integrado é composto por conjunto de 18 (dezoito) fotodiodos $(3 \times 6)$ encapsulados em um mesmo invólucro, tipo MMCS6CS, fabricado pela empresa MAZeT. Neste dispositivo há três grupos de 6 (seis) fotodiodos seccionados simetricamente em uma estrutura circular de $2 \mathrm{~mm}$ de diâmetro. Para cada fotodiodo há um filtro espectral dielétrico que seleciona o comprimento de onda específico a ser detectado. A faixa espectral sensível dos fotodiodos está sintonizada entre $380 \mathrm{~nm}$ a $780 \mathrm{~nm}$, tendo como picos máximos os valores de 425, 475, 525, 575, 625, $675 \mathrm{~nm}$ e sem filtro (PW). Os fotodiodos são conectados diretamente em 7 (sete) dos 16 (dezesseis) canais do módulo amplificador de transimpedância com ganho programável, descrito na seção 5.2.1.2. O módulo é composto por amplificadores de transimpedância (seção 5.2.1.2) integrados de 4 (quatro) canais e ganhos programáveis, tipo MTI04CS, fabricado pela MAZeT. A seleção dos ganhos é realizada pela combinação binária de 3 bits de entrada no circuito integrado MTI04CS e permite até 8 (oito) estágios diferentes de amplificação. Após a etapa de amplificação, os sinais dos fotodiodos são selecionados pelo multiplexador (seção 5.2.1.3) e direcionados ao $L O C K$-IN para extração dos parâmetros de valores de tensão em nível DC. Como fonte luminosa foi utilizado um diodo LED branco ( $P_{M A ́ X}=120 \mathrm{~mW}, I_{F}=30 \mathrm{~mA}$ ), fabricado pela empresa Roithner Laser Technik (B3B440-JB) e posicionado frontalmente a uma cubeta de quartzo. $O$ sinal recebido pelo LED branco provém da fonte de corrente constante $\mathrm{DC}$, situada internamente ao módulo gerador de função e condicionamento de sinais, descrito na seção 5.2.1.4. A 
aquisição, controle e o processamento dos sinais são realizados com base em tecnologia FPGA, tendo como ambiente de desenvolvimento a utilização de softwares baseados em instrumentação virtual ( $\mathrm{NI}$ LabView $\left.{ }^{\circledR}\right)$, fabricado pela National Instruments, modelo NI myRIO-1900. O sistema utiliza um dos quatro sensores da matriz de dispositivos MMCS6CS, associado à instrumentação disponível para armazenamento dos sinais de intensidade de valores de tensão em nível DC a serem processadas pelo $L O C K$-IN.

A Figura 56 mostra o diagrama esquemático de interconexão do sistema embarcado portátil de detecção de íons de metais pesados $\left(\mathrm{Cu}^{2+}, \mathrm{Zn}^{2+}, \mathrm{Ni}^{2+}, \mathrm{Cd}^{2+}, \mathrm{Pb}^{2+}\right.$ e $\left.\mathrm{Fe}^{3+}\right)$ pelo método colorimétrico com uso de reagente cromógeno e sensor óptico multiespectral. Em seguida, na Figura 57 é mostrada a fotografia ilustrativa real do arranjo experimental montado.

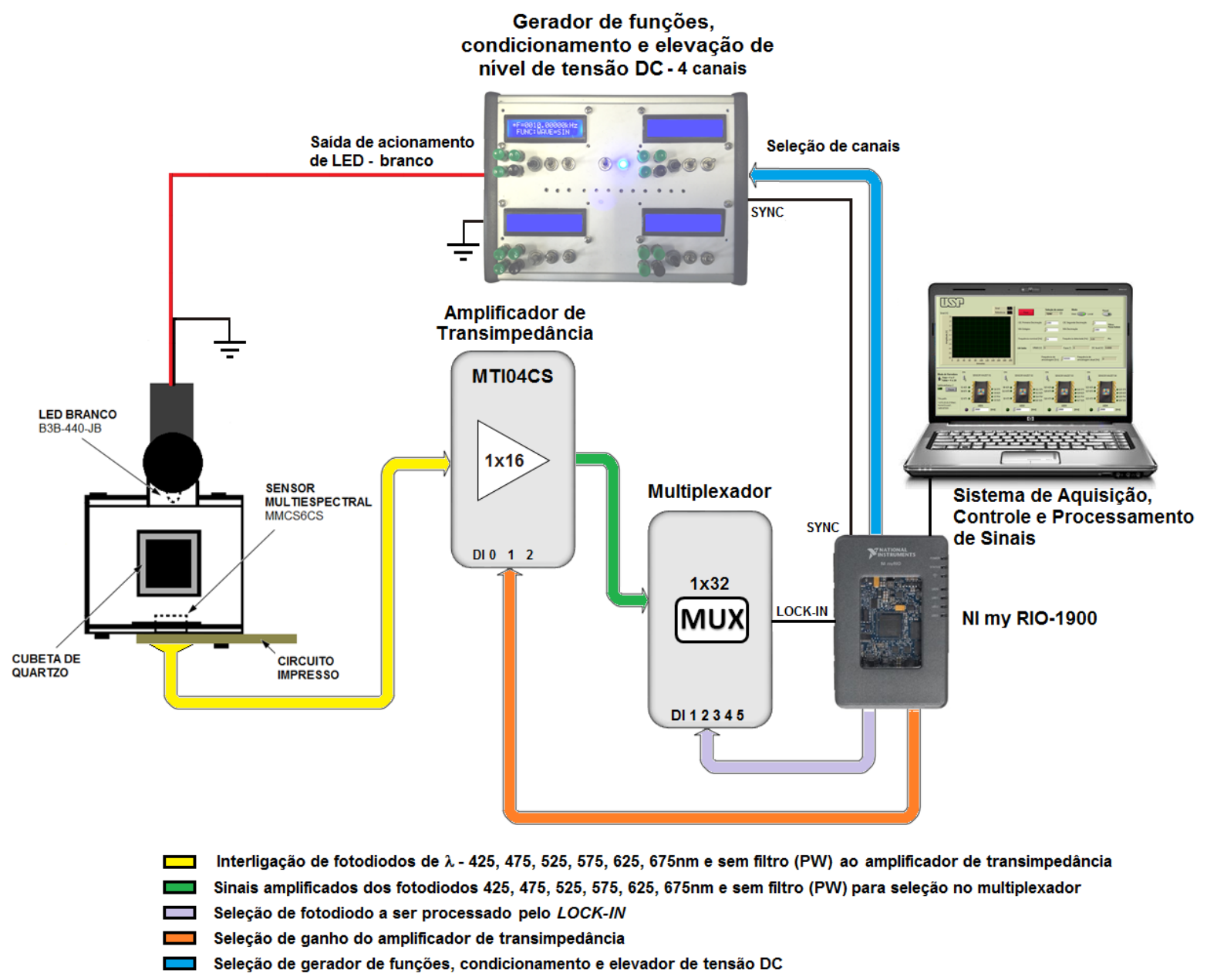

Figura 56 -Diagrama esquemático de ligação do sistema embarcado portátil de detecção de íons de metais pesados pelo método colorimétrico com de reagente cromógeno e sensor óptico multiespectral. 


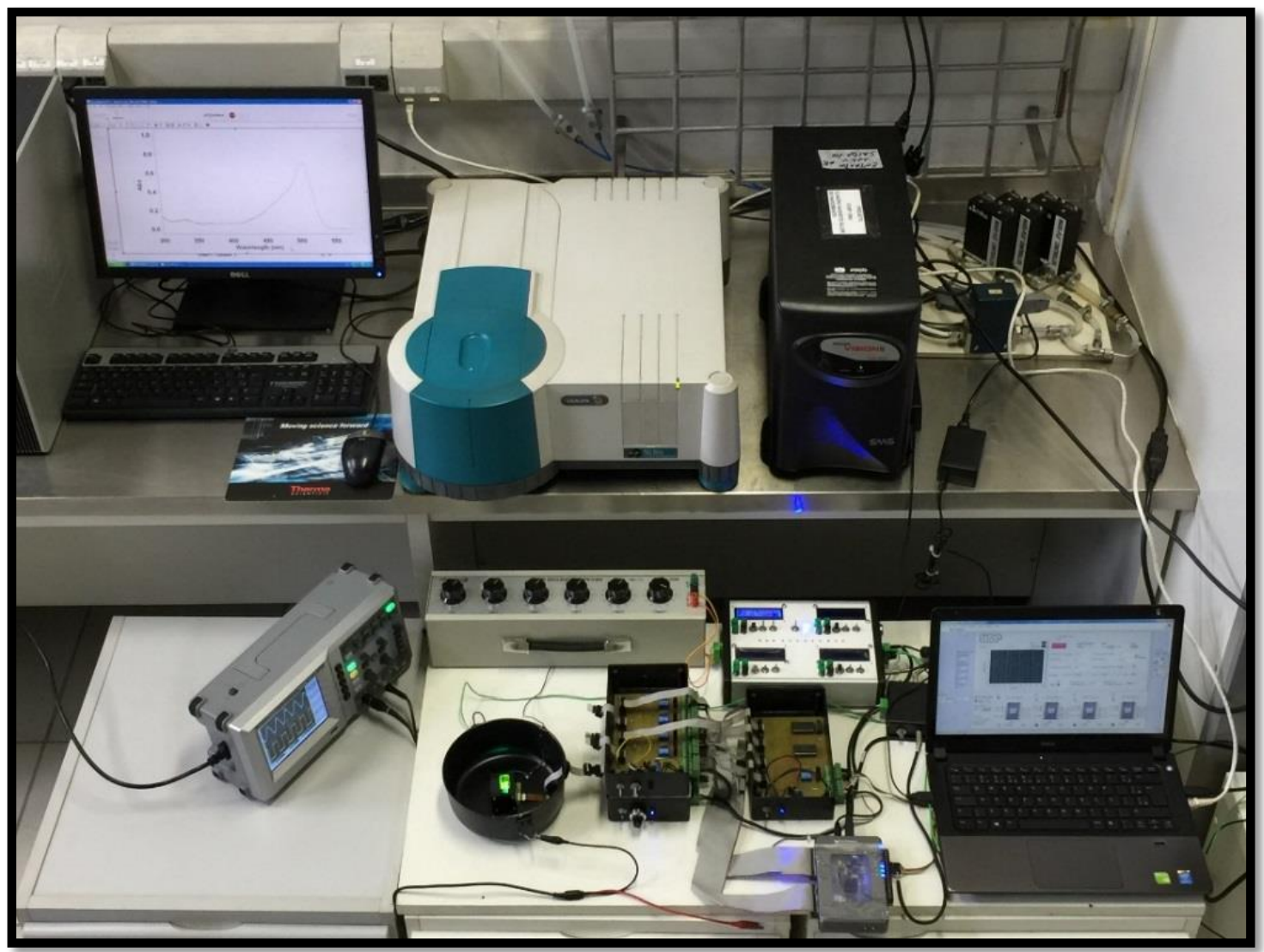

Figura 57 -Fotografia ilustrativa real do sistema embarcado portátil de detecção de íons de metais pesados pelo método colorimétrico.

$\mathrm{Na}$ Figura 58 são mostrados detalhes construtivos da câmara de ensaios para medidas de colorimetria, com sensor MMCS6CS posicionado frontalmente ao LED branco.

a)

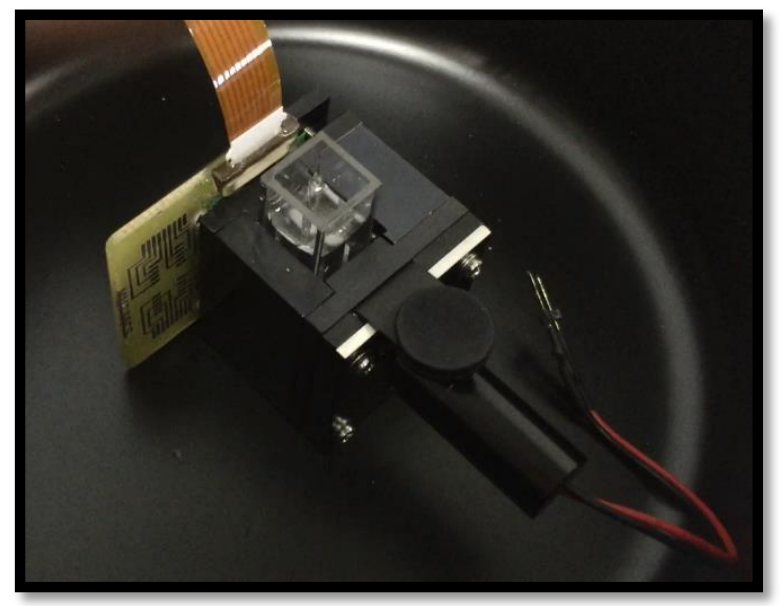

b)

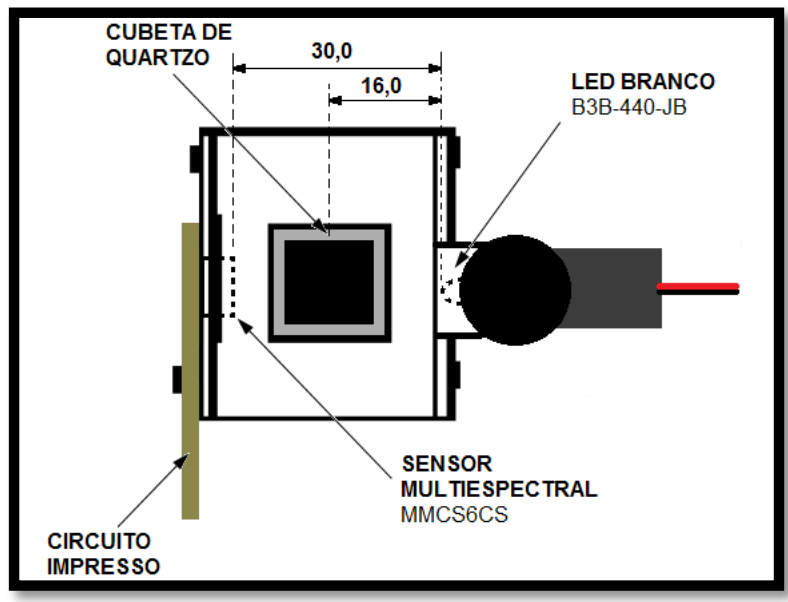

Figura 58 -a) Detalhes construtivos da câmara de ensaios para medidas de colorimetria com sensor MMCS6CS posicionado frontalmente ao LED branco; b) Esquema ilustrativo da câmara de ensaios com dimensões equivalentes ao posicionamento do sensor MMCS6CS/LED. 


\subsubsection{Reagentes e materiais - 1-(2-pyridylazo)-2-naphthol (PAN)}

Todos os reagentes foram adquiridos pela Sigma-Aldrich Química (São Paulo, Brasil) e a água DI, purificada com um sistema Milli-Q Gradient. As soluções padrões para os diferentes metais foram preparados em água DI, com apropriada diluição de 250 ppm dos sais de sulfato de cobre $\left(\mathrm{CuSO}_{4}\right)$, sulfato de zinco $\left(\mathrm{ZnSO}_{4}\right)$, cloreto de níquel $\left(\mathrm{NiCl}_{2}\right)$, cloreto de cádmio $\left(\mathrm{CdCl}_{2}\right)$, nitrato de chumbo $\left(\mathrm{Pb}\left(\mathrm{NO}_{3}\right)_{2}\right)$, nitrato de ferro III ( $\mathrm{FeN}_{3} \mathrm{O}_{9}$ ). Os valores de $\mathrm{pH}$ das soluções iônicas foram lidos por um pHmetro, modelo LUCA-210, fabricante Lucadema e mantidos inalterados de acordo com aqueles obtidos após o processo de diluição dos sais em água DI, conforme a Tabela 13.

Tabela 13 - Valores de pH das soluções iônicas preparadas para os ensaios de colorimetria.

\begin{tabular}{lr}
\hline Solução iônica de 250ppm & $p H$ \\
\hline $\mathrm{Cu}^{2+}$ & 4,0 \\
$\mathrm{Zn}^{2+}$ & 4,5 \\
$\mathrm{Ni}^{2+}$ & 4,5 \\
$\mathrm{Cd}^{2+}$ & 4,5 \\
$\mathrm{Pd}^{2+}$ & 4,5 \\
$\mathrm{Fe}^{3+}$ & 3,0 \\
\hline
\end{tabular}

O reagente cromógeno de 1-(2-pyridylazo)-2-naphthol (PAN) foi diluído em metanol a fim de se obter uma concentração de $100 \mu \mathrm{M}$. Antes de cada leitura, um volume de $2,5 \mathrm{ml}$ da solução preparada de PAN foi adicionada no interior de uma cubeta de quartzo e, em seguida, pequenas adições de volumes apropriados dos íons metálicos de $\mathrm{Cu}^{2+}, \mathrm{Zn}^{2+}, \mathrm{Ni}^{2+}, \mathrm{Cd}^{2+}, \mathrm{Pb}^{2+}, \mathrm{Fe}^{3+}$ foram realizadas para compor concentrações de 1 a $10 \mathrm{ppm}$.

\subsubsection{Sistema embarcado portátil de detecção de íons de metais pesados por métodos fluorimétricos e uso de sensor óptico multiespectral}

O sistema embarcado portátil de deteç̧ão de íons de metais pesados pelo método fluorimétrico utiliza também como elemento fotodetector um dispositivo optoeletrônico, 
descrito na seção 5.2.1.1. O circuito integrado é composto por conjunto de 18 (dezoito) fotodiodos $(3 \times 6)$ encapsulados em um mesmo invólucro, tipo MMCS6CS, fabricado pela empresa MAZeT. Neste dispositivo há três grupos de 6 (seis) fotodiodos seccionados simetricamente em uma estrutura circular de $2 \mathrm{~mm}$ de diâmetro. Para cada fotodiodo há um filtro espectral dielétrico que seleciona o comprimento de onda específico a ser detectado. A faixa espectral sensível dos fotodiodos está sintonizada entre $380 \mathrm{~nm}$ e $780 \mathrm{~nm}$, tendo como picos máximos valores de 425, 475, 525, 575, 625, $675 \mathrm{~nm}$ e sem filtro (PW). Os fotodiodos são conectados diretamente em 7 (sete) dos 16 (dezesseis) canais do módulo amplificador de transimpedância com ganho programável, descrito na seção 5.2.1.2. O módulo é composto por amplificadores de transimpedância (seção 5.2.1.2) integrados de 4 (quatro) canais e ganhos programáveis, tipo MTI04CS, fabricado pela MAZeT. A seleção dos ganhos é realizada pela combinação binária de 3 bits de entrada no circuito integrado MTI04CS e permite até 8 (oito) estágios diferentes de amplificação. Após a etapa de amplificação, os sinais dos fotodiodos são selecionados pelo multiplexador (seção 5.2.1.3) e direcionados ao $L O C K$-IN para extração dos parâmetros de intensidade luminosa e Fase pelas medidas de Tensão Eficaz ( $\mathrm{V}_{\mathrm{RMS}}$ ) e defasagem (graus), respectivamente. Como fonte luminosa foram utilizados os LEDs 6XTO46UV3C $\left(\lambda=415 \mathrm{~nm}, P_{M A ́ X}=200 \mathrm{~mW}, I_{F}=30 \mathrm{~mA}\right.$, Lumex) e B5-433-B505 ( $\lambda=505 \mathrm{~nm}, \mathrm{P}_{\mathrm{MÁX}}=120$ $\mathrm{mW}, \mathrm{I}_{\mathrm{F}}=30 \mathrm{~mA}$, Roithner Laser Technik) posicionados ortogonalmente a uma cubeta de quartzo para excitação dos reagentes fluoróforos de 5,10,15,20-tetra-(3-bromo-4hidroxifenil)-porfirina e 2,7-Dichlorofluorescein, respectivamente. O sinal recebido pelos LEDs provém de um gerador de sinais de forma de onda senoidal, modelo SG1003, acoplado a um circuito de condicionamento e elevação de nível de tensão DC (seção 5.2.1.4). A aquisição, controle e processamento dos sinais são realizados com base em tecnologia FPGA, tendo como ambiente de desenvolvimento a utilização de softwares baseados em instrumentação virtual (NI LabView®), fabricado pela National Instruments, modelo NI myRIO-1900. O sistema utiliza um dos quatro sensores da matriz de dispositivos MMCS6CS, associado à instrumentação disponível para armazenamento dos sinais de intensidade $V_{\mathrm{RMS}}$ e fase a serem processadas pelo LOCK-IN.

A Figura 59 mostra o diagrama esquemático de ligação do sistema embarcado portátil de detecção dos íons de metais pesados pelo método fluorimétrico com uso dos 
reagentes fluoróforos e sensor óptico multiespectral. Em seguida, na Figura 60 é mostrada a fotografia ilustrativa real do arranjo experimental montado.

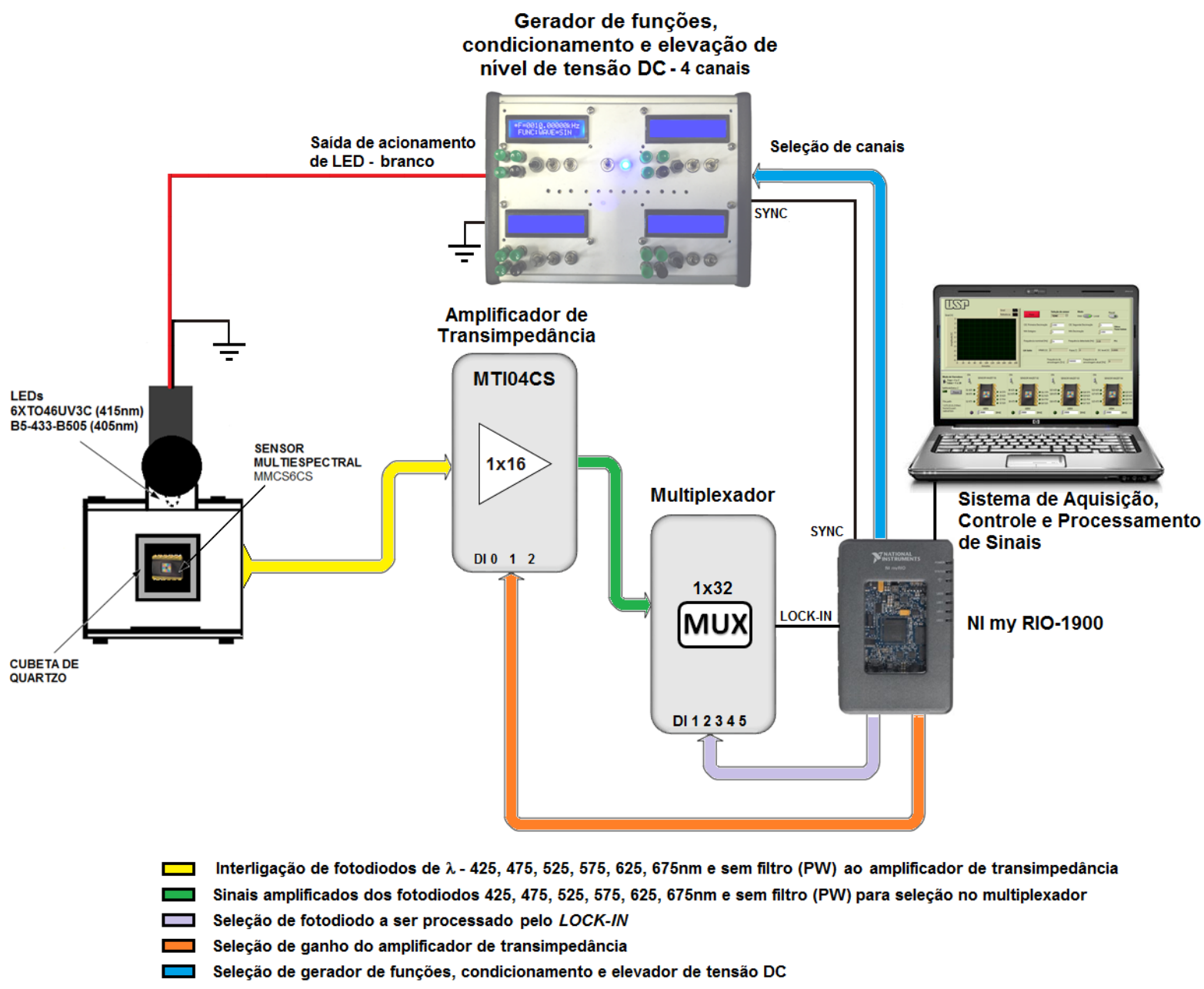

Figura 59 -Diagrama esquemático de ligação do sistema embarcado portátil de detecção de íons de metais pesados pelo método fluorimétrico com uso de reagente fluoróforo e sensor óptico multiespectral. 
a)

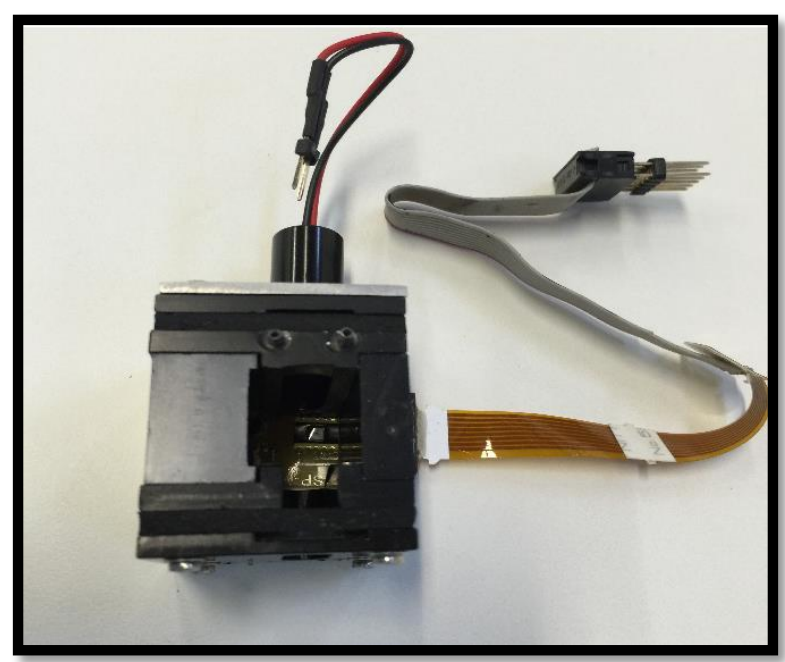

b)

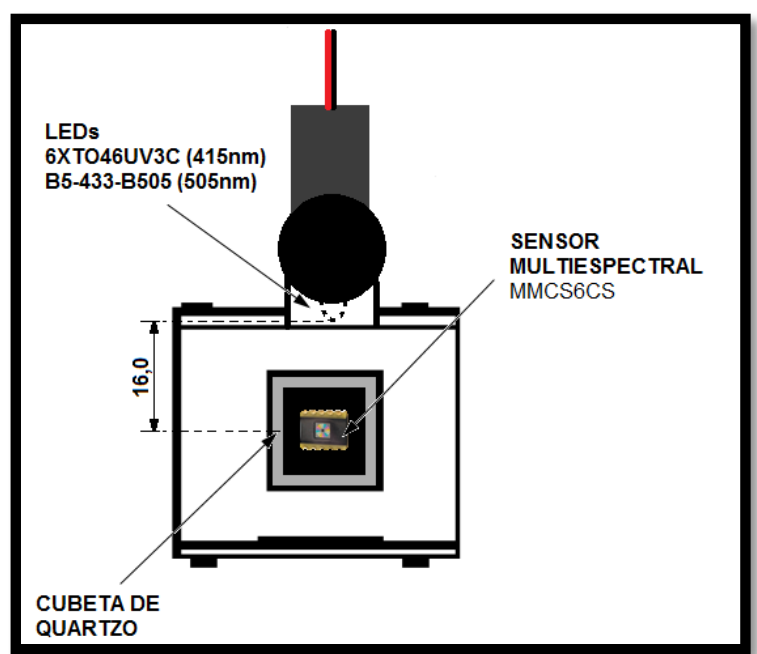

Figura 60 -a) Detalhes construtivos da câmara de ensaios para medidas de fluorimetria com sensor MMCS6CS posicionado $90^{\circ}$ em relação aos LEDs de excitação fluorescente; b) Esquema ilustrativo da câmara de ensaios com dimensões equivalentes ao posicionamento ortogonal do sensor MMCS6CS/LED.

\subsubsection{Reagentes e materiais - Síntese e caracterização do tetra-(3- bromo-4-hidroxifenil)-porfirina (TBHPP)}

A reação foi adaptada, conforme Bozkurt et al. (2009). Todos os reagentes utilizados na etapa sintética foram obtidos pela Sigma-Aldrich Química (São Paulo, Brasil) ou Merck e possuem alto grau de pureza. Em um balão de fundo redondo foram dissolvidos, em $150 \mathrm{ml}$ de tetrahidroxifurano (THF), 0,170 g de 5,10,15,20-tetra-(4hidroxifenil)-porfirina (THPP) e adicionados $1,2 \mathrm{ml}$ de $\mathrm{H}_{2} \mathrm{SO}_{4}$ (conc.). A mistura foi mantida sob agitação magnética e refluxo a $70{ }^{\circ} \mathrm{C}( \pm 2)$ durante $3 \mathrm{~h}$. Após resfriar, foram adicionados $5 \mathrm{ml}$ de $\mathrm{NaOH}$ (aq.) $\left(0,6 \mathrm{~mol}^{-\mathrm{l}^{-1}}\right)$ e gotejados $250 \mu \mathrm{l}$ de bromo $\left(\mathrm{Br}_{2}\right)$, por mais $1 \mathrm{~h}$. A nova mistura permaneceu sob refluxo a $70 \stackrel{\circ}{\mathrm{C}}( \pm 2 \stackrel{\circ}{\circ})$, completando a reação demonstrada na Figura 61. 


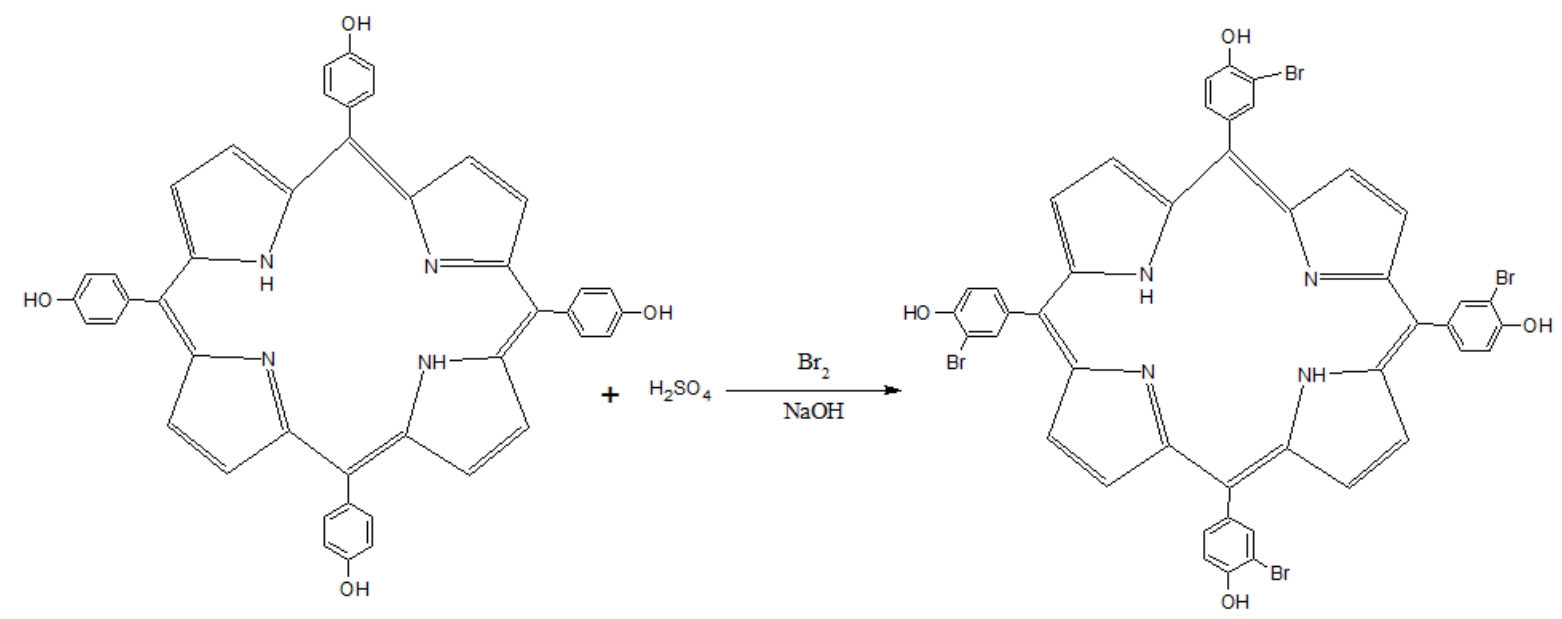

Figura 61 -Síntese do fluoróforo de 5,10,15,20-tetra-(3-bromo-4-hidroxifenil)-porfirina (TBHPP).

Na Figura 62a é mostrado um registro fotográfico da etapa final de refluxo da reação. Posteriormente, foram adicionados $5 \mathrm{ml} \mathrm{de}_{2} \mathrm{SO}_{4}$ (aq.) (1 mol..-1-1), mantendo a mistura sob agitação magnética por 30 min e o produto foi isolado com éter dietílico. A Figura $62 \mathrm{~b}$ demonstra a separação das fases, onde o subproduto residual está contido na fase inferior do funil de separação. A secagem do produto foi realizada sob vácuo em rotaevaporador, resultando no sólido de cor marrom de 5,10,15,20-tetra-(3-bromo-4hidroxifenil)-porfirina (TBHPP), com rendimento de $83 \%$ e pureza cromatográfica superior a 96\%. A confirmação do produto foi realizada por LTQXL Thermo HPLC-MS (cromatografia líquida acoplada à espectrometria de massas) caracterizada pelo $[\mathrm{M}+\mathrm{H}]+$ de $990,1 \mathrm{~m} / \mathrm{z}$. 
a)

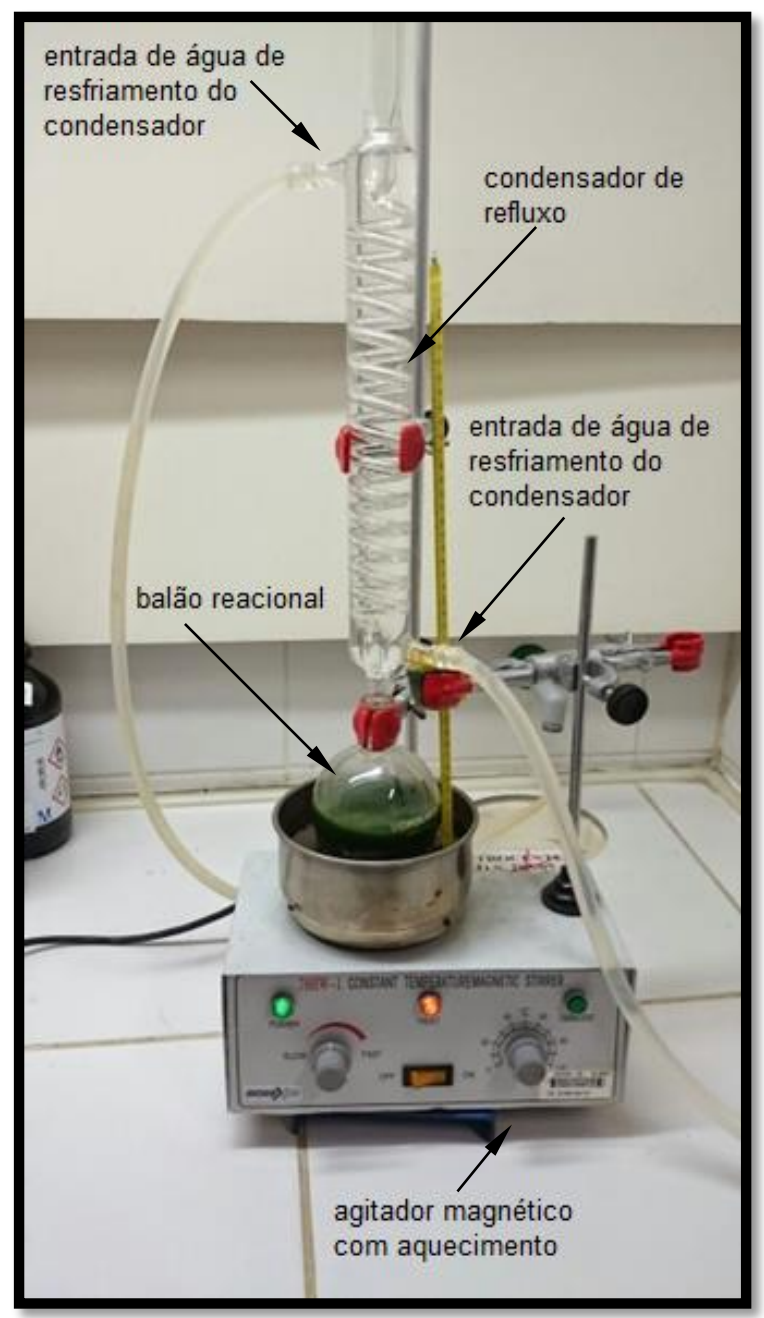

b)

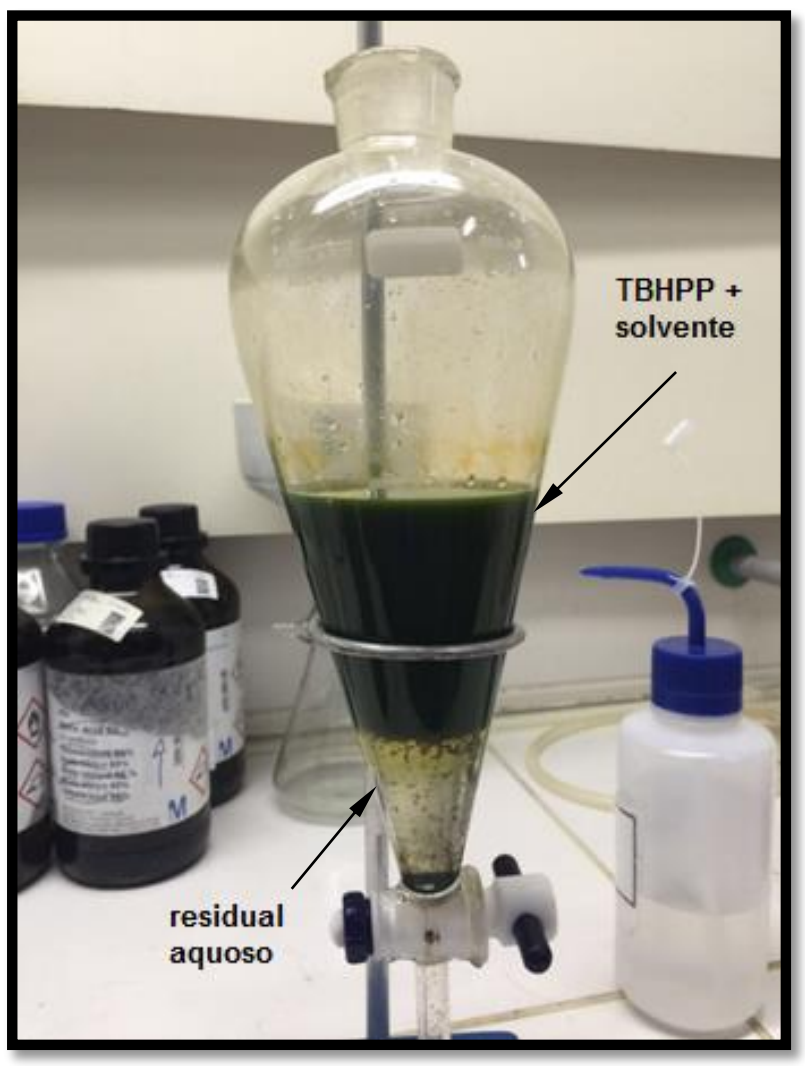

Figura 62 -a) Registro fotográfico da etapa final de refluxo da reação. b) Separação das fases do TBHPP em funil.

Para realização dos ensaios e detecção dos íons metálicos, o reagente fluoróforo de tetra-(3-bromo-4-hidroxifenil)-porfirina (TBHPP) foi diluído em metanol a fim se obter uma concentração de $9 \mu \mathrm{M}$. Antes de cada leitura, um volume de $2,5 \mathrm{ml}$ da solução preparada de TBHPP foi adicionada no interior de uma cubeta de quartzo e, em seguida, pequenas adições de volumes apropriados dos íons metálicos de $\mathrm{Pb}^{2+}, \mathrm{Ni}^{2+}$, $\mathrm{Cd}^{2+} \mathrm{e} \mathrm{Zn}^{2+}$ foram realizadas para compor concentrações de 0,02 a 0,2 ppm.

As soluções padrões dos diferentes metais foram preparados em água DI, com diluição de $5 \mathrm{ppm}$ dos sais de sulfato de zinco $\left(\mathrm{ZnSO}_{4}\right)$, cloreto de níquel $\left(\mathrm{NiCl}_{2}\right)$, cloreto de cádmio $\left(\mathrm{CdCl}_{2}\right)$ e nitrato de chumbo $\left(\mathrm{Pb}\left(\mathrm{NO}_{3}\right)_{2}\right)$.

Em todos os ensaios experimentais com uso do TBHPP, as soluções iônicas padrões foram mantidas em pH 9,5 (nove e meio), confirmando os resultados apresentados 
por Bozkurt (2009), onde as melhores condições de valores de pH na detecção dos íons metálicos foram entre 8,0 (oito) e 10,0 (dez).

Para não haver a precipitação dos sais utilizados nas soluções padrões, em pH alcalino, uma quantidade de massa equivalente ao metal, de um quelante de ácido de etilenodiaminotetracético (EDTA) foi adicionado na proporção 1:1 (metal:EDTA). Na correção do pH em condições de ensaio utilizou-se solução tampão de pH 10,0 (dez) formada por cloreto de amônio, hidróxido de amônio e água DI.

\subsubsection{Reagentes e materiais - 2,7-Dichlorofluorescein}

Os reagentes utilizados nos ensaios com o 2,7-Dichlorofluorescein foram adquiridos pela Sigma-Aldrich Química (São Paulo, Brasil) e a água DI, purificada com um sistema Milli-Q Gradient. As soluções padrões dos diferentes metais foram preparados em água $\mathrm{DI}$, com apropriada diluição de $500 \mu \mathrm{M}$ dos sais de sulfato de cobre $\left(\mathrm{CuSO}_{4}\right)$, sulfato de zinco $\left(\mathrm{ZnSO}_{4}\right)$, cloreto de níquel $\left(\mathrm{NiCl}_{2}\right)$, cloreto de cádmio $\left(\mathrm{CdCl}_{2}\right)$ e nitrato de chumbo $\left(\mathrm{Pb}\left(\mathrm{NO}_{3}\right)_{2}\right)$.

Os ensaios foram realizados com as soluções iônicas metálicas em pH 7,0 (sete). Para não haver a precipitação dos sais utilizados nas soluções padrões, uma quantidade em mols equivalente a cada íon metálico, de ácido de etilenodiaminotetracético (EDTA) foi adicionado na proporção 1:1 (metal:EDTA). $\mathrm{Na}$ correção do pH em condições de ensaio utilizou-se solução tampão de pH igual a 10,0 (dez) formada por cloreto de amônio, hidróxido de amônio e água DI.

Para realização dos ensaios e detecção dos íons metálicos, o reagente fluoróforo de 2,7-Dichlorofluorescein foi diluído em solução de metanol e água na proporção 1:1 $\left(\mathrm{CH}_{3} \mathrm{OH}: \mathrm{H}_{2} \mathrm{O}\right)$ a fim se obter uma concentração de 16,6 $\mu \mathrm{M}$. Antes de cada leitura, uma alíquota de 2,5 ml da solução preparada de 2,7-Dichlorofluorescein foi adicionada no interior de uma cubeta de quartzo e, em seguida, pequenas adições de volumes

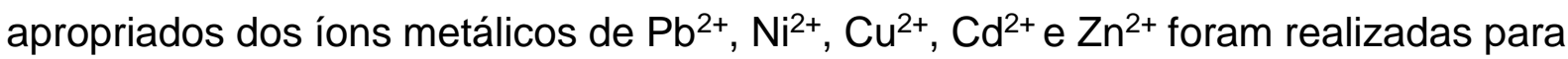
compor concentrações de 1,99 a $9,80 \mu \mathrm{M}$. 


\subsection{Resultados e Discussões}

\subsubsection{Análise de resposta de sensibilidade do sensor Multiespectral MMCS6CS na detecção de íons de metais pesados de $\mathrm{Pb}^{2+}, \mathrm{Cd}^{2+}$, $\mathrm{Zn}^{2+}, \mathrm{Cu}^{2+}, \mathrm{Fe}^{3+}, \mathrm{Ni}^{2+}$ pelo método colorimétrico e uso de reagente cromógeno de 1-(2-pyridylazo)-2-naphthol (PAN).}

A resposta do sensor multiespectral MMCS6CS na presença dos íons metálicos de $\mathrm{Pb}^{2+}, \mathrm{Cd}^{2+}, \mathrm{Zn}^{2+}, \mathrm{Cu}^{2+}, \mathrm{Fe}^{3+}$ e $\mathrm{Ni}^{2+}$ foi baseada nas medidas de mudança espectral da transmitância óptica de uma solução de PAN, devido à ação dos diferentes íons analisados. Neste caso, as intensidades de luz transmitidas foram convertidas em valores de tensão em nível DC pelo sistema de aquisição e detecção, descrito nas seções 5.2.1.5, 5.2.2. e 5.2.2.1. Desta forma, a transmitância foi determinada em relação à referência escolhida, como sendo a resposta de cada fotodiodo sensível à luz branca, transmitida pelo solvente utilizado na preparação das soluções em análise. Antes de cada leitura, um volume de $2,5 \mathrm{ml}$ da solução preparada de PAN $(100 \mu \mathrm{M})$ foi adicionada no interior de uma cubeta de quartzo, com perfil quadrado, medindo 10 mm de lado. Logo após, uma pipeta calibrada, modelo P100 (20-100 $\mu \mathrm{l})$, Gilson Pipetman, foi utilizada para dosar pequenas adições volumétricas dos íons metálicos diluídos em água $\mathrm{DI}$, compondo concentrações de 1 a $10 \mathrm{ppm}$. A temperatura ambiente foi mantida em $26^{\circ} \mathrm{C}$. Os detalhes do processo de preparação das soluções iônicas e os valores do pH, podem ser conferidos na seção 5.2.2.2.

Com a finalidade de se comparar o desempenho do nosso colorímetro, proposto na presente tese, primeiramente foram obtidos os espectros das mudanças de transmitância ( $T$ ) da molécula de PAN (molécula sensível) e de soluções desta molécula em ambientes contendo os íons metálicos de $\mathrm{Pb}^{2+}, \mathrm{Cd}^{2+}, \mathrm{Zn}^{2+}, \mathrm{Cu}^{2+}, \mathrm{Fe}^{3+} \mathrm{e}$ $\mathrm{Ni}^{2+}$, respectivamente. Os espectros foram obtidos pelo espectrômetro UV-VIS, modelo Cary 50, Varian e apresentadas na Figura 63a, Figura 64a, Figura 65a, Figura 66a, Figura 67a e na Figura 68a, respectivamente.

Em seguida, com o uso do sensor multiespectral MMCS6CS e tendo as mesmas condições anteriores dos íons metálicos sob análise com o reagente PAN foram obtidos os sinais pelo sistema de amplificação LOCK-IN digital, extraídos pelos 6 
(seis) terminais de saídas do fotodetector MAZeT que correspondem às respostas dos fotodiodos com os filtros ópticos de 425, 475, 525, 575, 625 e 675 nm, respectivamente. Na Figura 63b, Figura 64b, Figura 65b, Figura 66b, Figura 67b e na Figura 68b são mostrados os gráficos dos espectros de transmitância (Equação 19), obtidos no sistema proposto.

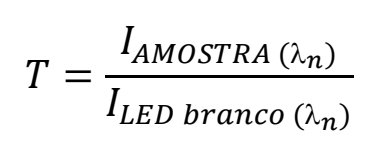

Onde: I IMOSTRA - corrente gerada pelo fotodiodo de comprimento de onda $\left(\lambda_{n}\right)$ a uma dada condição do íon metálico, sob análise com o reagente PAN

ILED branco - corrente gerada pelo fotodiodo de comprimento de onda $\left(\lambda_{n}\right)$ sob condição de excitação do LED branco, através do solvente (metanol) utilizado na preparação das soluções em análise. (B3B-440-JB)

$\left(\lambda_{n}\right)$ - saídas de respostas dos fotodiodos com os filtros ópticos de $425,475,525,575$, 625 e $675 \mathrm{~nm}$

$\mathrm{Pb}^{2+}$

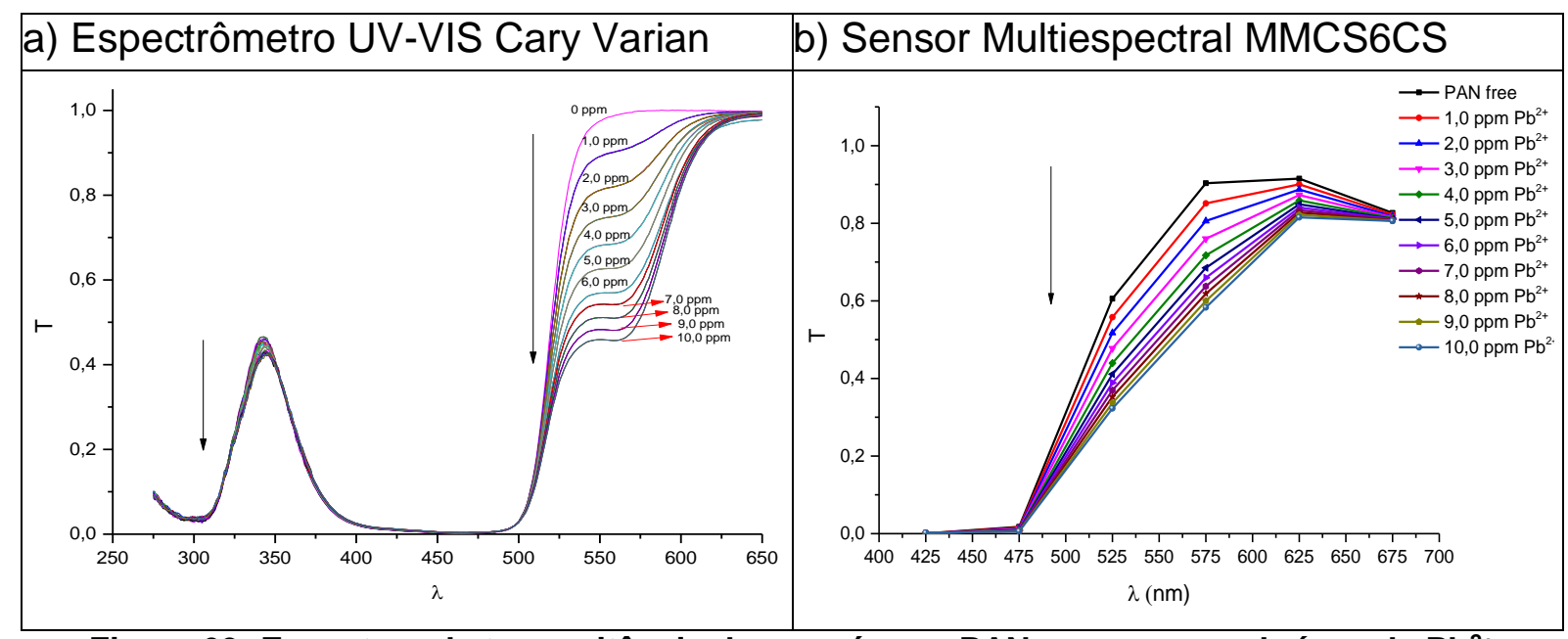

Figura 63 -Espectros de transmitância do cromógeno PAN na presença de íons de $\mathrm{Pb}^{2+}$ a) Espectrômetro UV-VIS Cary 50 - Varian b) Sensor Multiespectral MMCS6CS. 
$\mathrm{Cd}^{2+}$

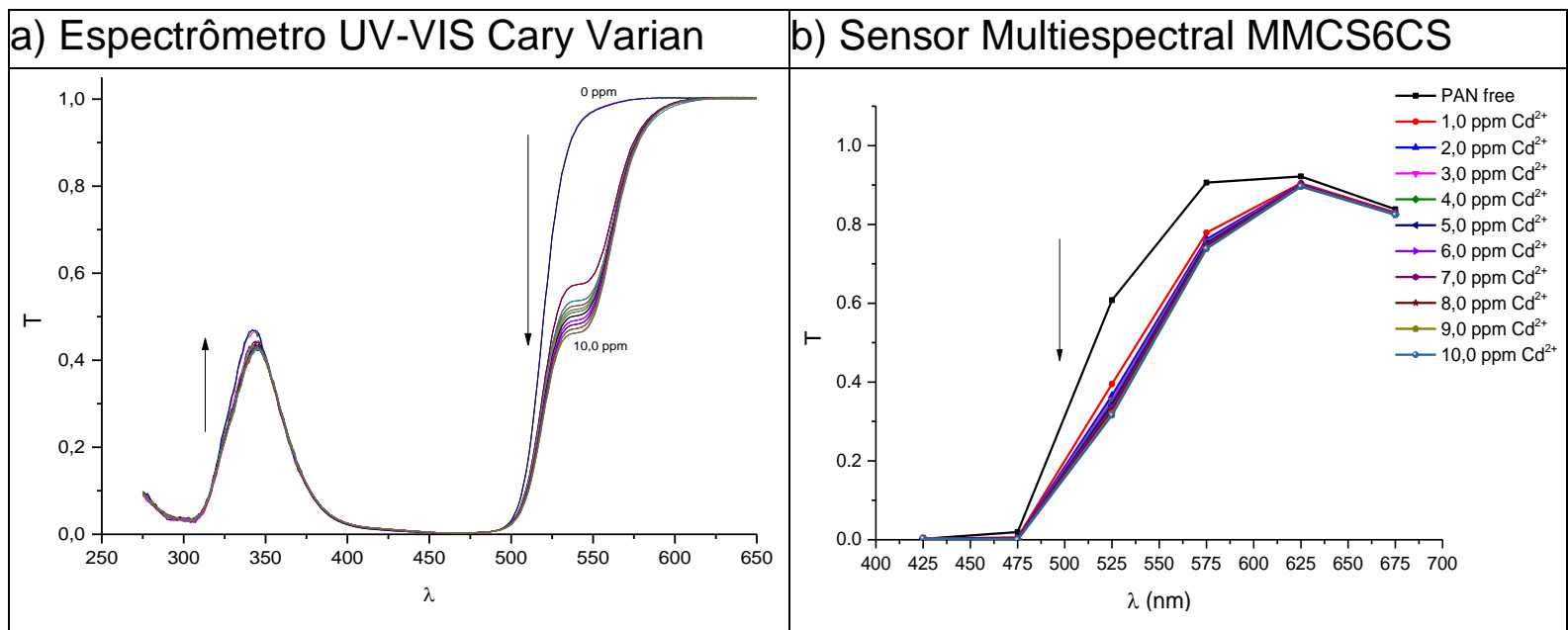

Figura 64 -Espectros de transmitância do cromógeno PAN na presença de íons de $\mathrm{Cd}^{2+}$ a) Espectrômetro UV-VIS Cary 50 - Varian b) Sensor Multiespectral MMCS6CS.

$\mathrm{Zn}^{2+}$

a) Espectrômetro UV-VIS Cary Varian

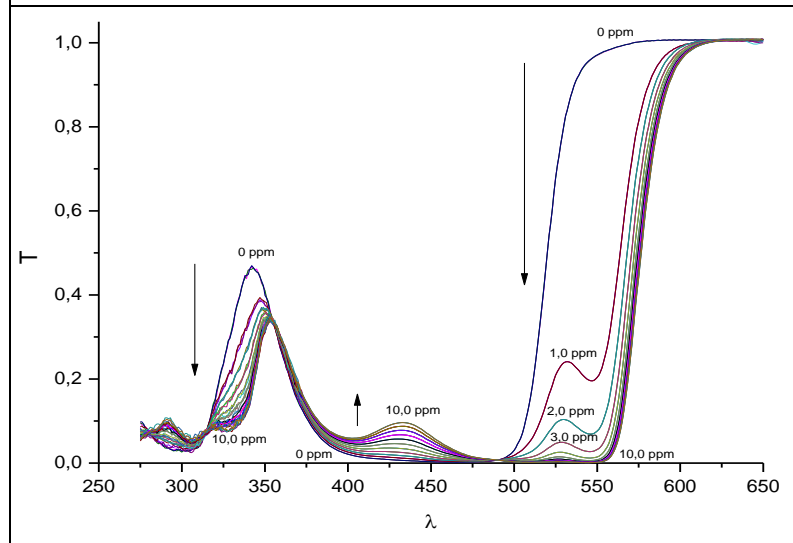

b) Sensor Multiespectral MMCS6CS

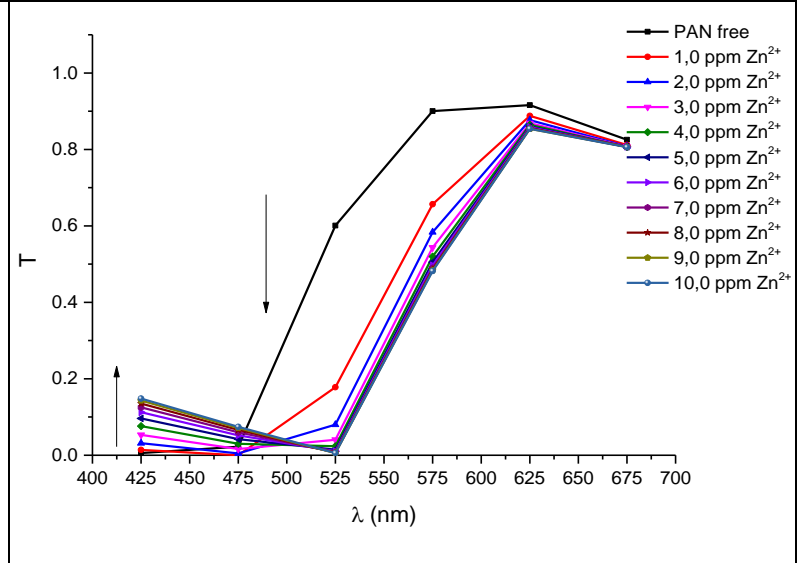

Figura 65 -Espectros de transmitância do cromógeno PAN na presença de íons de $\mathrm{Zn}^{2+}$ a) Espectrômetro UV-VIS Cary 50 - Varian b) Sensor Multiespectral MMCS6CS. $\mathrm{Cu}^{2+}$

a) Espectrômetro UV-VIS Cary Varian

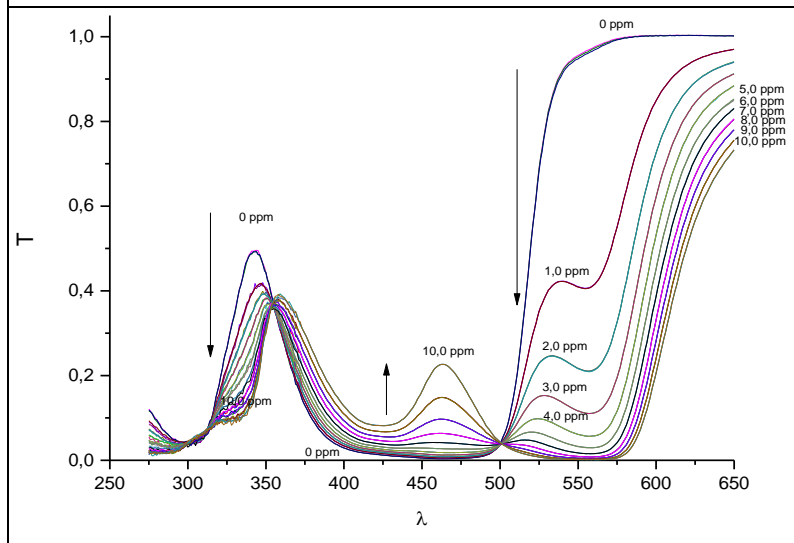

b) Sensor Multiespectral MMCS6CS

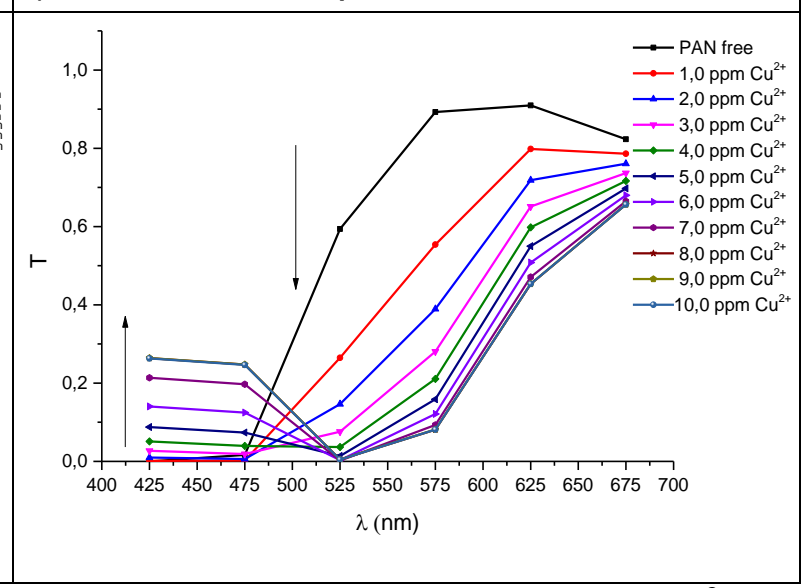

Figura 66 -Espectros de transmitância do cromógeno PAN na presença de íons de $\mathrm{Cu}^{2+}$ a) Espectrômetro UV-VIS Cary 50 - Varian b) Sensor Multiespectral MMCS6CS. 
$\mathrm{Fe}^{3+}$

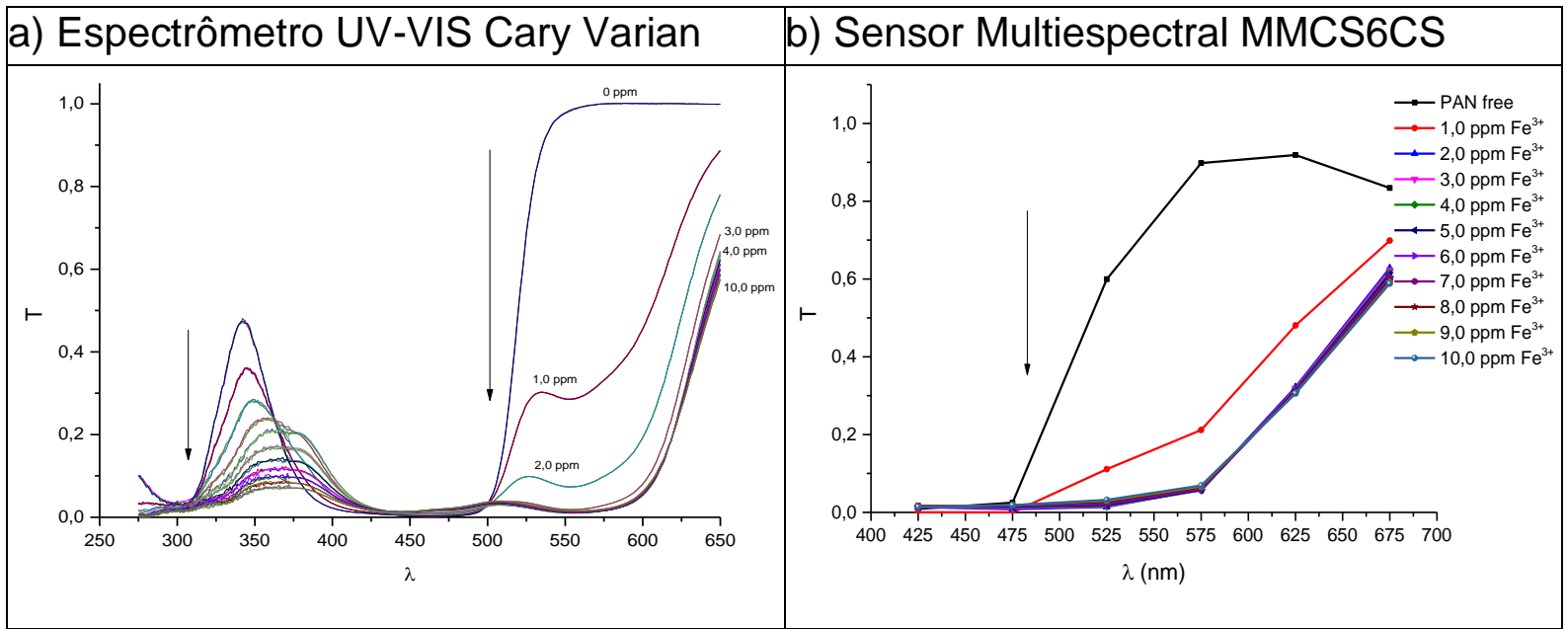

Figura 67 -Espectros de transmitância do cromógeno PAN na presença de íons de $\mathrm{Fe}^{3+}$ a) Espectrômetro UV-VIS Cary 50 - Varian b) Sensor Multiespectral MMCS6CS. $\mathrm{Ni}^{2+}$

a) Espectrômetro UV-VIS Cary Varian b) Sensor Multiespectral MMCS6CS

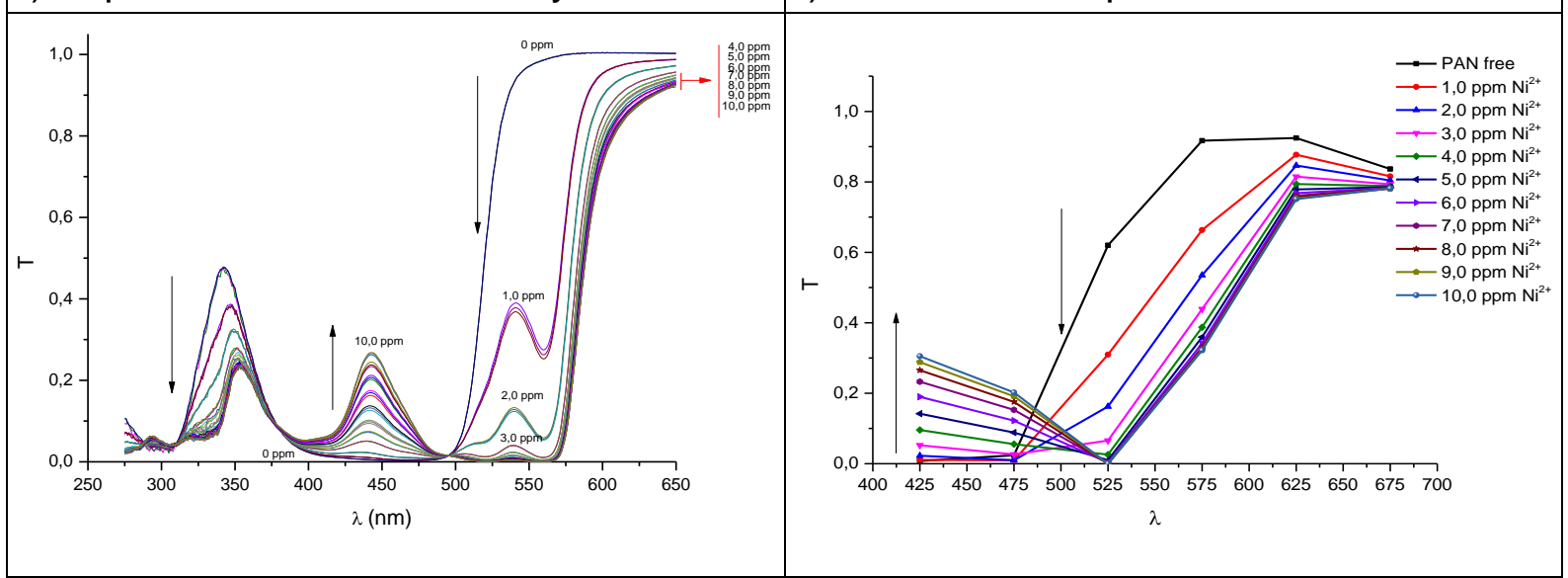

Figura 68 -Espectros de transmitância do cromógeno PAN na presença de íons de $\mathrm{Ni}^{2+}$ a) Espectrômetro UV-VIS Cary 50 - Varian b) Sensor Multiespectral MMCS6CS.

Nos espectros obtidos pelo espectrômetro UV-VIS são identificadas três regiões de bandas bem definidas (275-375 nm, 375-500 nm e 500-650 nm), onde os valores de transmitância variam de acordo com mudanças nas concentrações dos íons metálicos, adicionados internamente à cubeta de quartzo, contendo o reagente PAN. Há de se notar que em todas as análises dos íons de metais pesados, as regiões de bandas de comprimentos de onda no ultravioleta (275-375 nm) e na região compreendida entre 500 e $650 \mathrm{~nm}$ tiveram decréscimo nas intensidades de transmitância. Entretanto, nas análises dos íons de $\mathrm{Zn}^{2+}, \mathrm{Cu}^{2+}$ e $\mathrm{Ni}^{2+}$, a região de banda entre 375 e $500 \mathrm{~nm}$ houve comportamento contrário, mostrando aumento na transmitância da luz e total absorção para a mesma região nos demais íons $\left(\mathrm{Pb}^{2+}\right.$, $\mathrm{Cd}^{2+}$ e $\mathrm{Fe}^{3+}$ ). Estes resultados espectrais mostram claramente que a presença de íons 
nas soluções das moléculas PAN altera as tonalidades de cor da solução original (solução de PAN livre de íons) pela complexação com o íon metálico, através do grupo orto-hidroxilo, situado o mais proximamente do anel fenólico e o átomo de nitrogênio heterocíclico (CHENG; BRAY, 1955; MALIK et al, 2004).

No caso das análises com o sensor multiespectral MMCS6CS, os espectros obtidos certamente têm menor qualidade de detalhes espectrais, devido ao número discreto de pontos espectrais (6 sensores). No entanto, observa-se na Figura 63b, Figura 64b, Figura 65b, Figura 66b, Figura 67b e na Figura 68b que o perfil dos espectros do nosso sistema preserva as mudanças observadas no espectrômetro (de alta resolução). Por outro lado, é importante indicar que a faixa espectral do conjunto dos 6 (seis) sensores é limitada entre 380 e $780 \mathrm{~nm}$. Neste sentido, com a finalidade de obter uma comparação mais precisa, as regiões de bandas de comprimentos de onda no ultravioleta (275-375 nm), vistas nas análises com o espectrômetro UV-VIS foram suprimidas. Apesar disso, o comportamento relacionado às variações de acréscimo e decréscimo da transmitância, observado no espectrômetro UV-VIS foi integralmente reproduzido e sem perdas significativas, uma vez que as tonalidades das cores observadas em ensaios de análises de compostos químicos com o uso de reagentes cromógenos, somente compreendem leituras na faixa da região visível do espectro (370-750 nm), não havendo, portanto, prejuízos na quantificação e classificação dos metais, como poderão ser comprovados nos próximos itens da tese.

Nos espectros de transmitância, a região de maior variação na intensidade de transmitância, em função da mudança de concentração dos diferentes íons analisados, está situada em torno de 525 nm (Figura 63a à Figura 68a e Figura 63b à Figura 68b). Assim, definimos uma função resposta neste ponto, tanto do espectrômetro, quanto do sistema multiespectral MMCS6CS, através da seguinte Equação 20:

$$
\text { Resposta }=\frac{T_{0}-T}{T_{0}}
$$

Onde: $T_{0}$ e $T$ referem-se aos coeficientes de transmitância na ausência e presença dos íons metálicos da solução de PAN, respectivamente. 
Na Figura 69 e na Figura 70 são apresentadas as curvas de calibração de respostas (curvas tracejadas) obtidas pelo espectrômetro UV-VIS e sensor multiespectral MMCS6CS, em diferentes concentrações de íons de metais pesados, no comprimento de onda de $525 \mathrm{~nm}$, respectivamente. Observa-se que, para ambos os sistemas, as curvas de resposta para este ponto espectral $(525 \mathrm{~nm})$ apresentam o mesmo perfil, mostrando a compatibilidade do nosso sistema com sistemas mais complexos (espectrômetro).

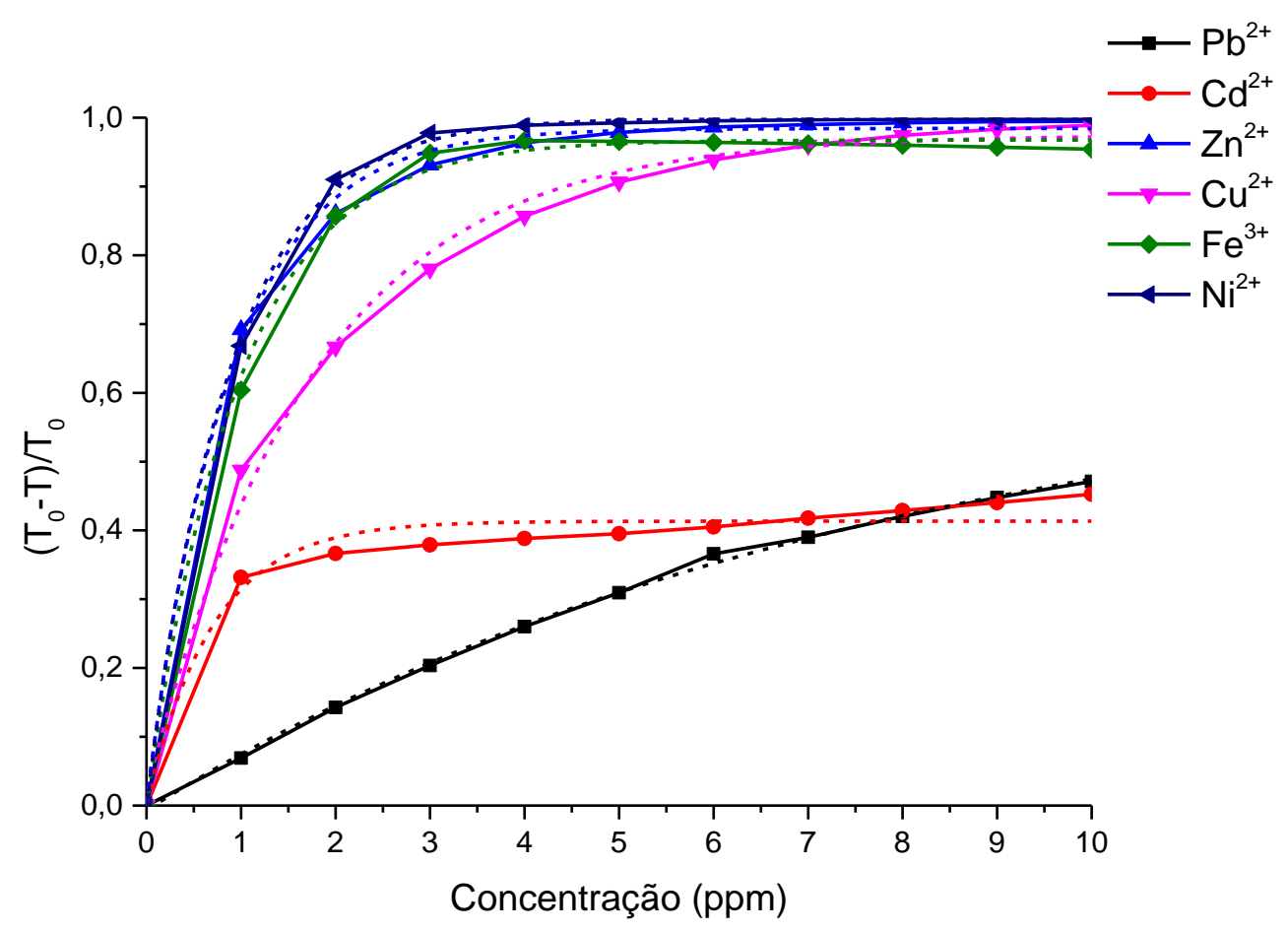

Figura 69 -Curvas de respostas obtidas pelo espectrômetro UV-VIS em diferentes concentrações de íons de metais pesados no comprimento de onda de $525 \mathrm{~nm}$. 


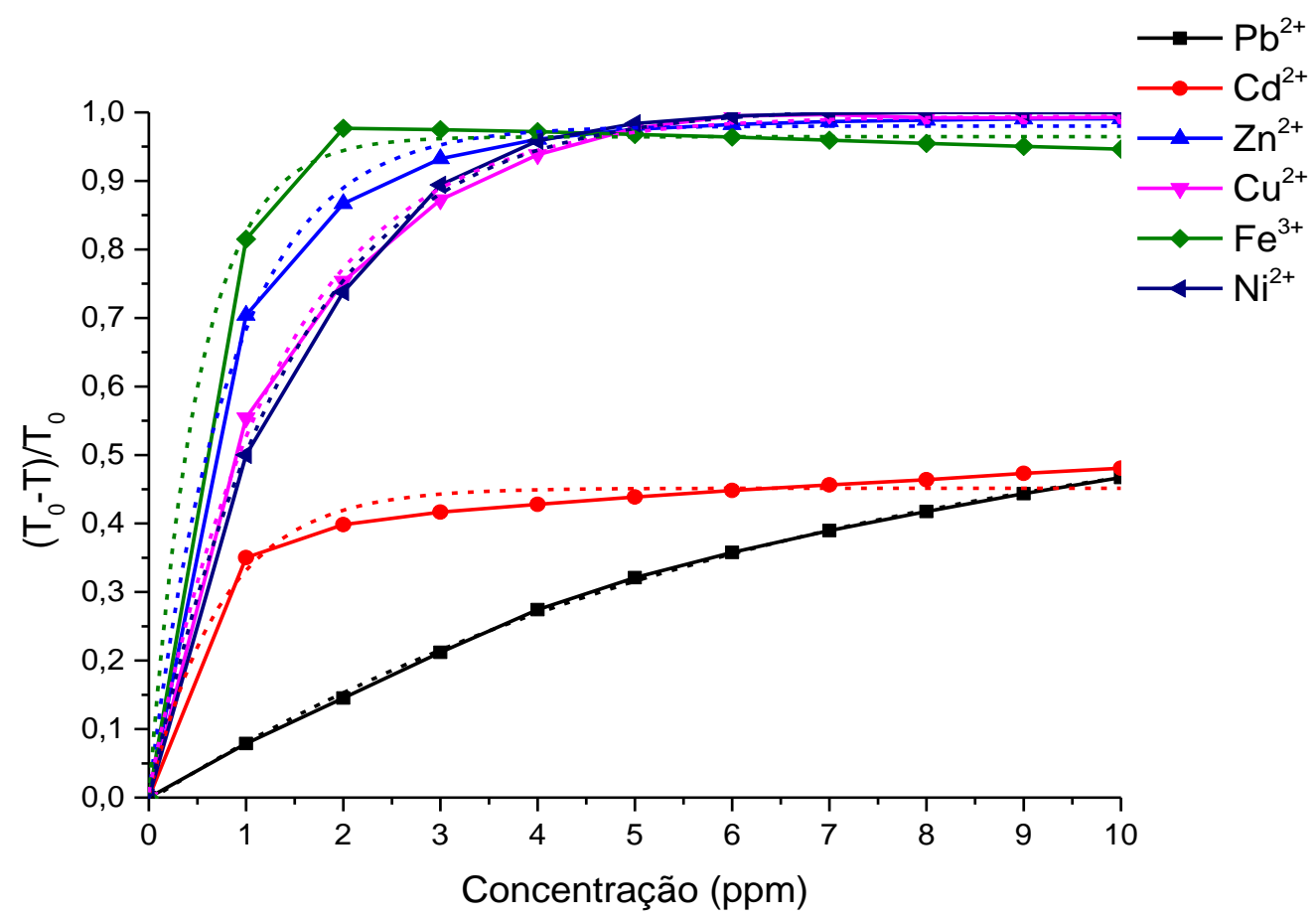

Figura 70 -Curvas de respostas obtidas pela saída de $525 \mathrm{~nm}$ do sensor multiespectral MMCS6CS em diferentes concentrações de íons de metais pesados.

$\mathrm{Na}$ seção 5.2.2, foi descrita a metodologia de uma representação quantitativa das diferentes tonalidades de cor, através dos parâmetros xyY de cromaticidade. A literatura reporta que, na maioria das vezes, o espectro de cores é representado apenas no plano xy (IWAl et al., 2016; KIM et al., 2015). No entanto, uma representação tridimensional xyY apresenta maior riqueza de detalhes, principalmente relacionando a dependência da concentração dos agentes que promovem a mudança de cor em um sistema determinado. Nesse sentido, primeiro apresentamos o comportamento da mudança de cor da solução de PAN, em metanol, sob a ação dos diferentes íons analisados no plano de cromaticidade bidimensional xy, obtidos a partir dos espectros de transmitância do espectrômetro (Figura 63a à Figura 68a e dos espectros de transmitância obtidos com o sistema MMCS6CS Figura $63 \mathrm{~b}$ à Figura 68b), respectivamente. A compilação da resposta dos sistemas (cromaticidade bidimensional) aos diferentes íons e em diferentes concentrações são mostradas na Figura 71a, Figura 72a, Figura 73a, Figura 74a, Figura 75a e na Figura 76a para o espectrômetro UV-VIS e na Figura 71b, Figura 72b, Figura 73b, Figura 74b, Figura 75b e na Figura 76b (MMCS6CS), para o MMC6CS, respectivamente. 
$\mathrm{Pb}^{2+}$

a)

b)

CIE XYZ - Espectrômetro - $\lambda$ (425-650nm) CIE XYZ - MMCS6CS - $\lambda$ (425-675nm)
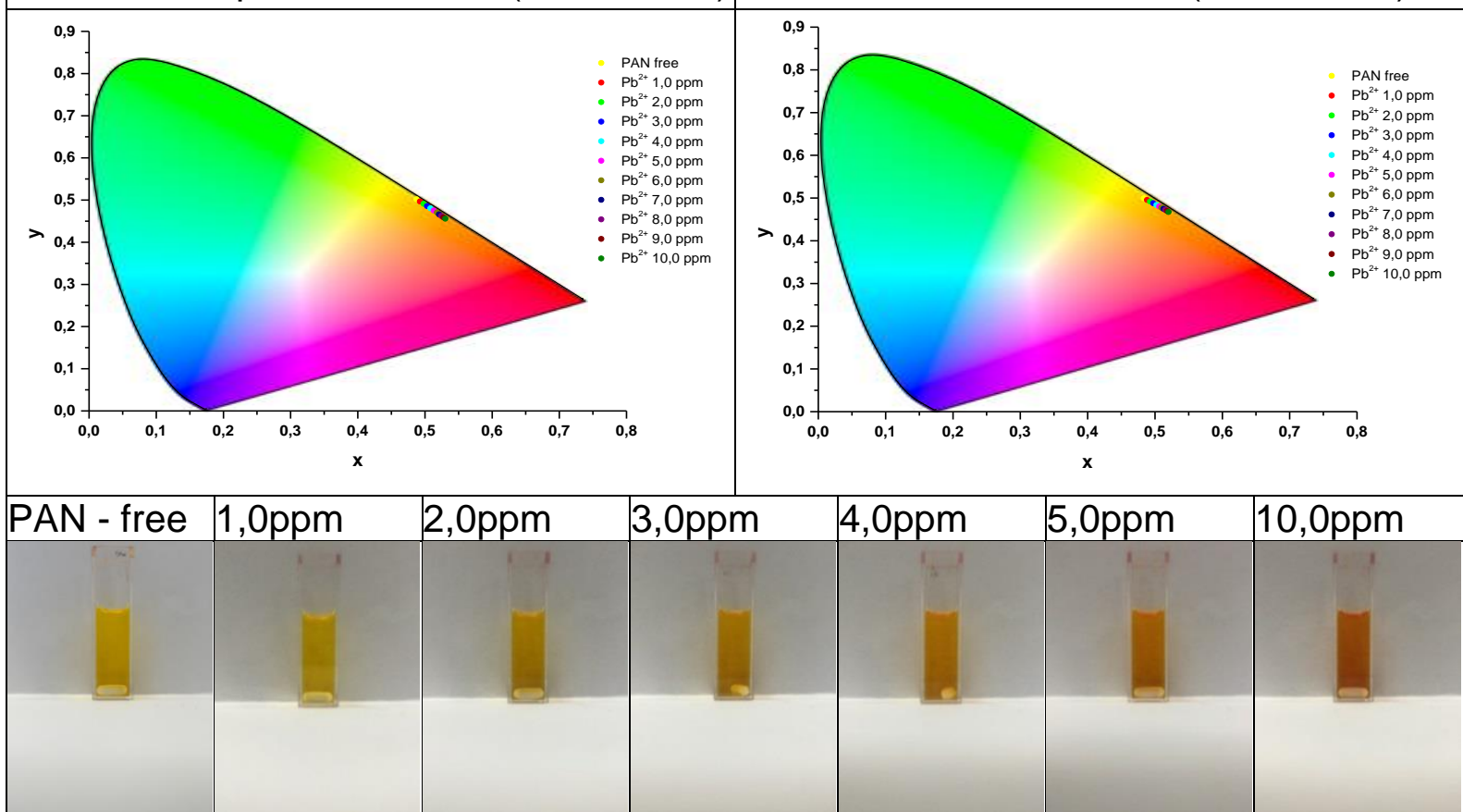

Figura 71 -Plano de cromaticidade bidimensional xy para concentrações iônicas de $\mathbf{P b}^{2+}$. a) CIE1931XYZ - espectrômetro (425-650nm); b) CIE1931XYZ - MMCS6CS - $\lambda$ (425-675nm).

$\mathrm{Cd}^{2+}$

a)

b)

CIE XYZ - Espectrômetro - $\lambda(425-650 \mathrm{~nm})$ CIE XYZ - MMCS6CS - $\lambda$ (425-675nm)
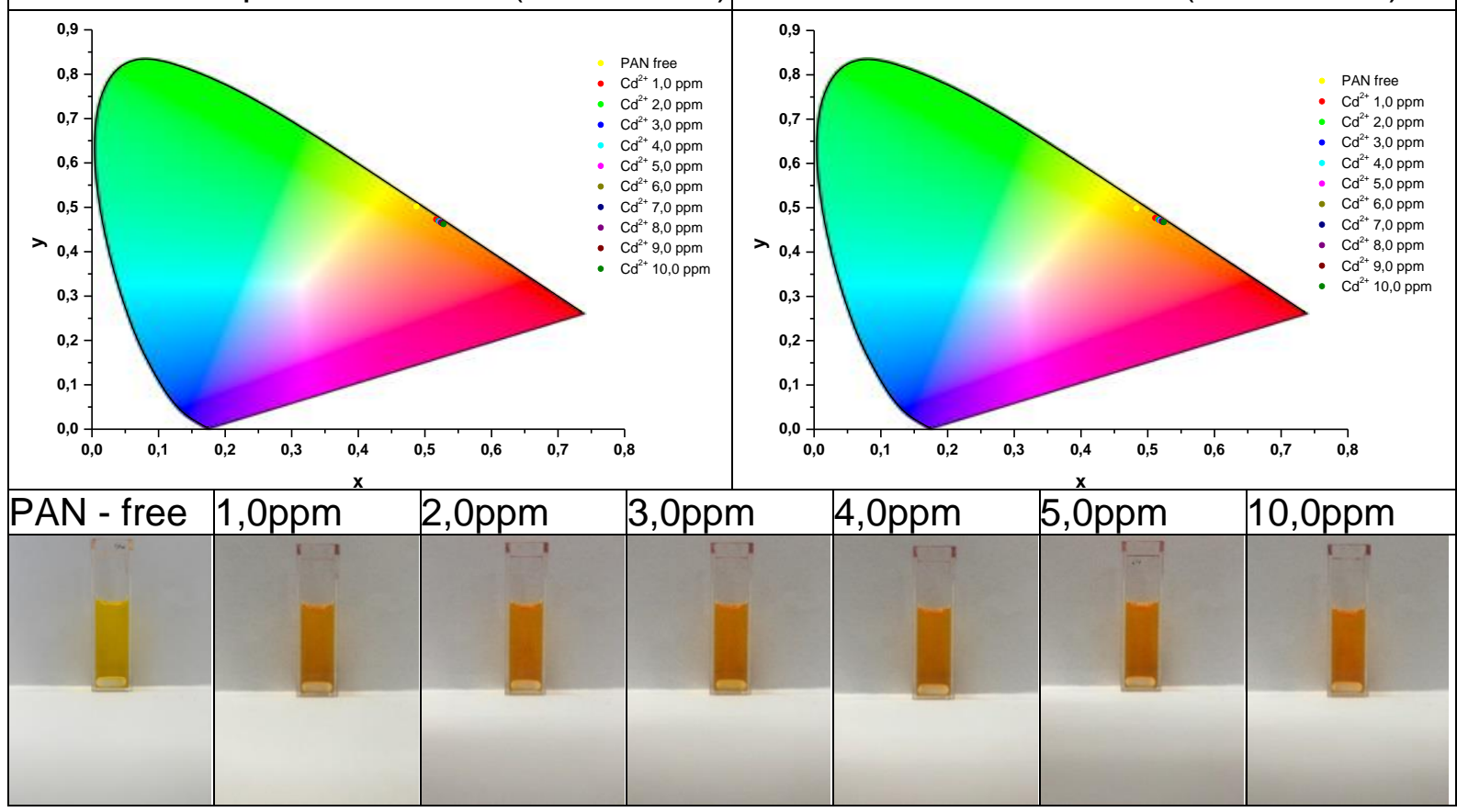

Figura 72 -Plano de cromaticidade bidimensional xy para concentrações iônicas de $\mathrm{Cd}^{2+}$. a) CIE1931XYZ - espectrômetro (425-650nm); b) CIE1931XYZ - MMCS6CS - $\lambda$ (425-675nm). 
$\mathrm{Zn}^{2+}$

a)

b)

CIE XYZ - Espectrômetro - $\lambda$ (425-650nm) CIE XYZ - MMCS6CS - $\lambda$ (425-675nm)
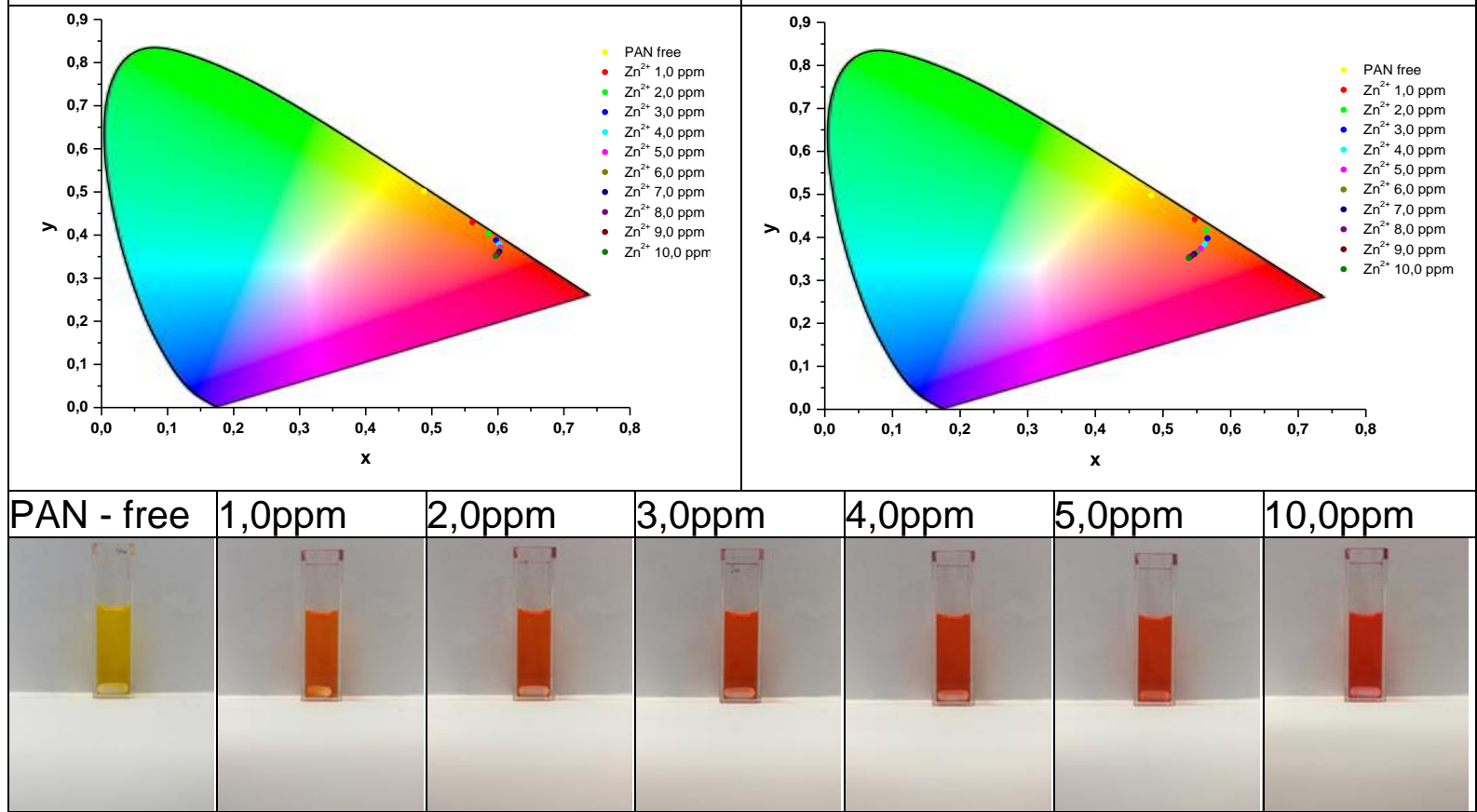

Figura 73 -Plano de cromaticidade bidimensional xy para concentrações iônicas de $\mathrm{Zn}^{2+}$. a) CIE1931XYZ - espectrômetro (425-650nm); b) CIE1931XYZ - MMCS6CS - $\lambda$ (425-675nm).

$\mathrm{Cu}^{2+}$

a)

b)

CIE XYZ - Espectrômetro - $\lambda$ (425-650nm) CIE XYZ - MMCS6CS - $\lambda$ (425-675nm)

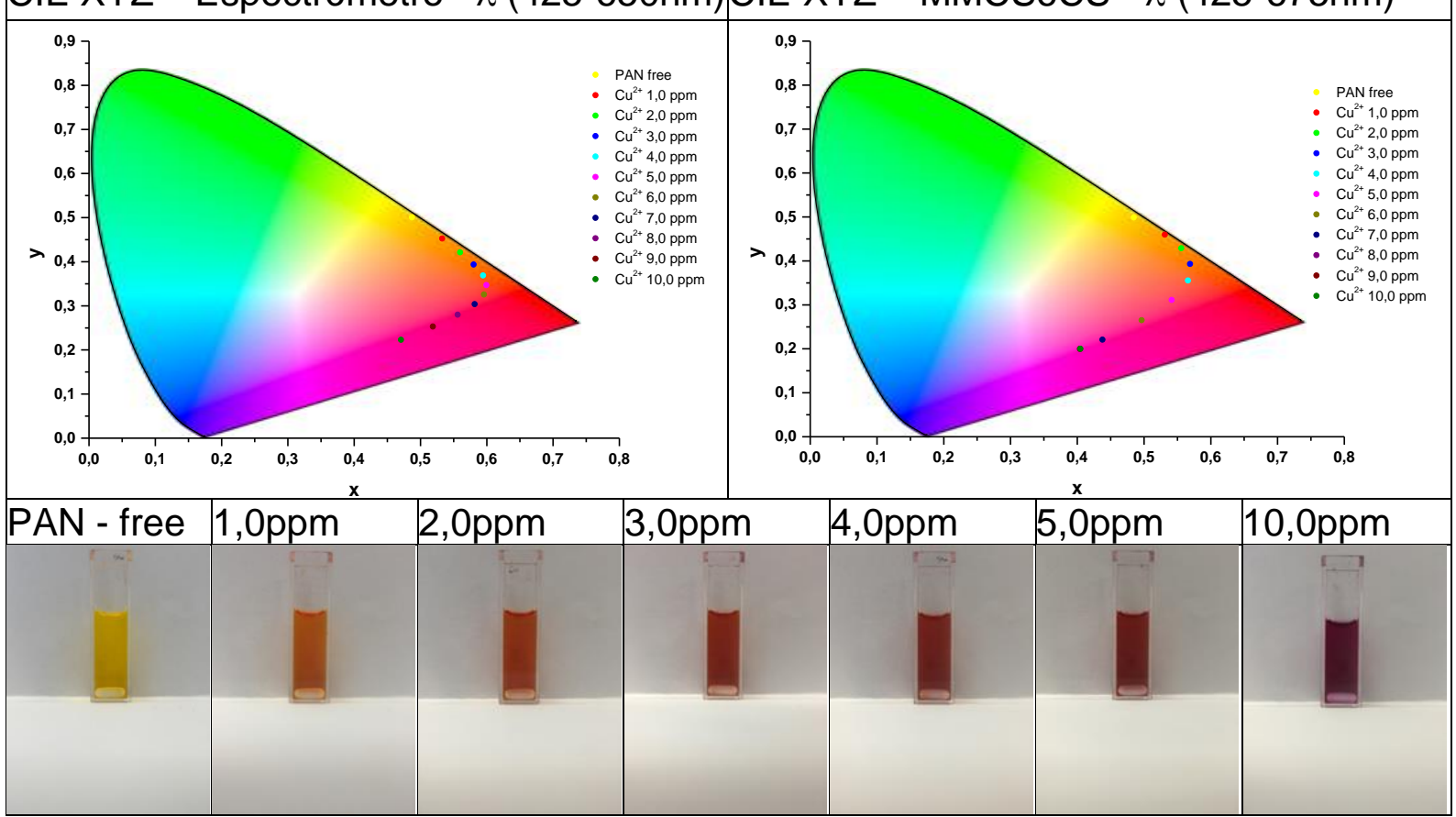

Figura 74 -Plano de cromaticidade bidimensional xy para concentrações iônicas de $\mathrm{Cu}^{2+}$. a) CIE1931XYZ - espectrômetro (425-650nm); b) CIE1931XYZ - MMCS6CS - $\lambda$ (425-675nm). 
$\mathrm{Fe}^{3+}$

a)

b)

CIE XYZ - Espectrômetro - $\lambda$ (425-650nm) CIE XYZ - MMCS6CS - $\lambda$ (425-675nm)
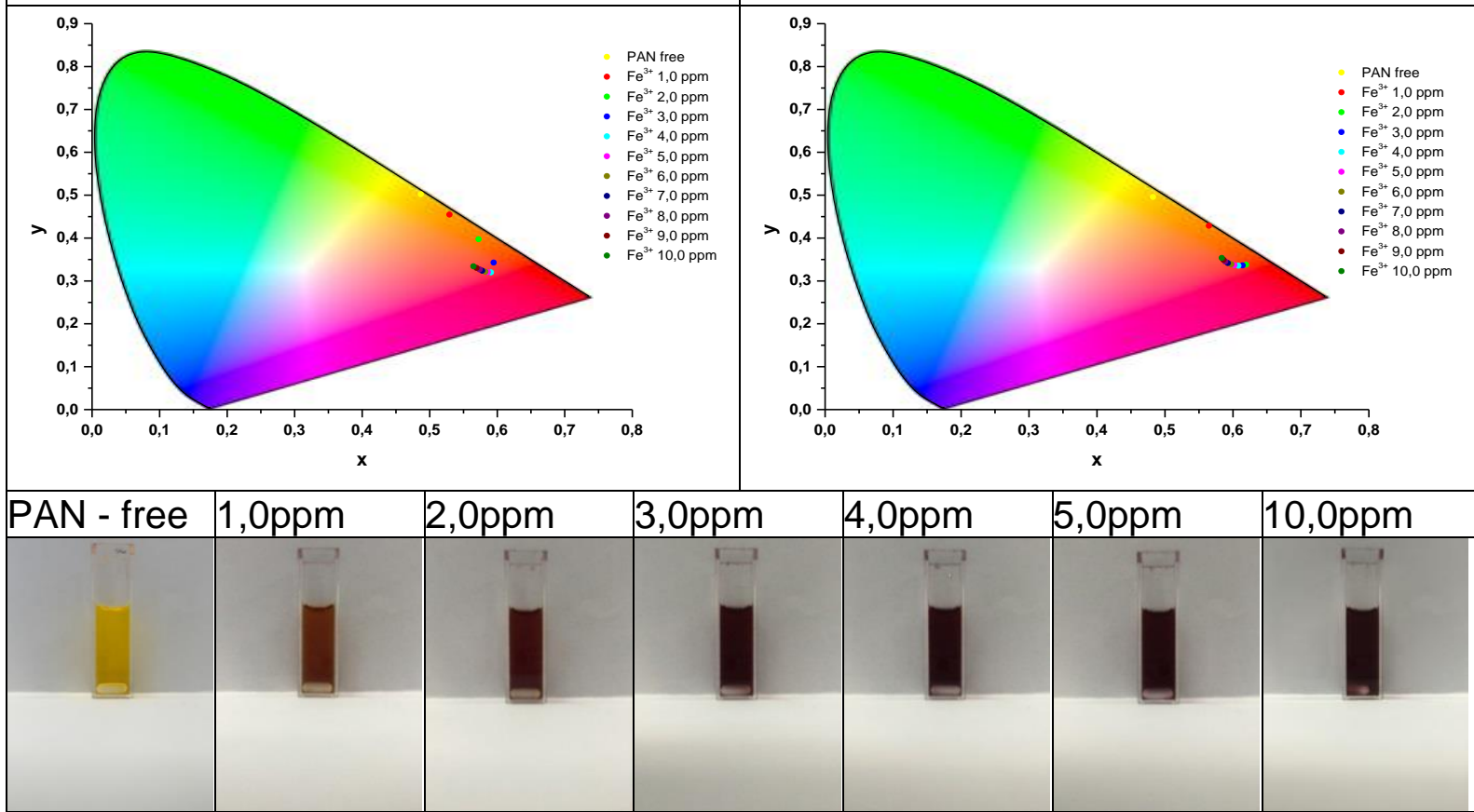

Figura 75 -Plano de cromaticidade bidimensional xy para concentrações iônicas de $\mathrm{Fe}^{3+}$. a) CIE1931XYZ - espectrômetro (425-650nm); b) CIE1931XYZ - MMCS6CS - $\lambda$ (425-675nm).

$\mathrm{Ni}^{2+}$

a)

b)

CIE XYZ - Espectrômetro - $\lambda$ (425-650nm) CIE XYZ - MMCS6CS - $\lambda$ (425-675nm)
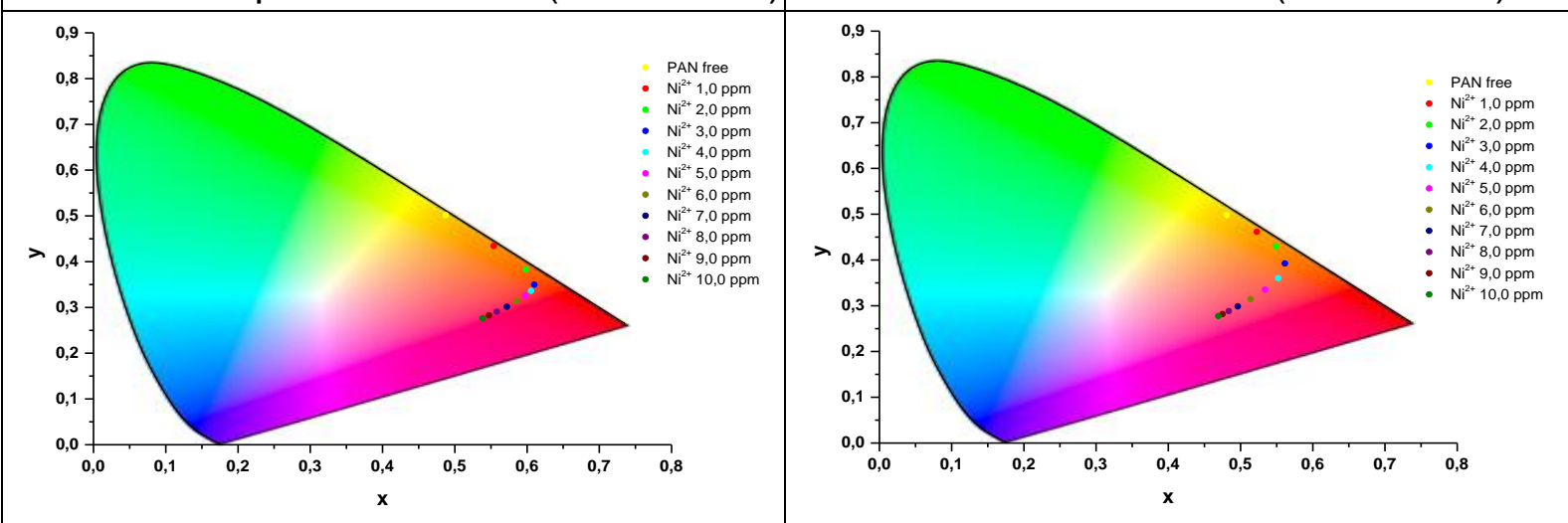

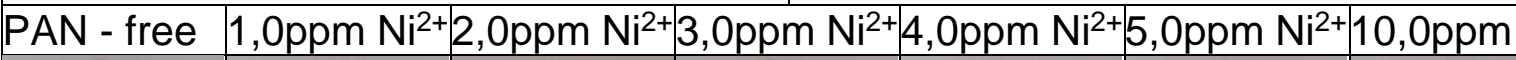

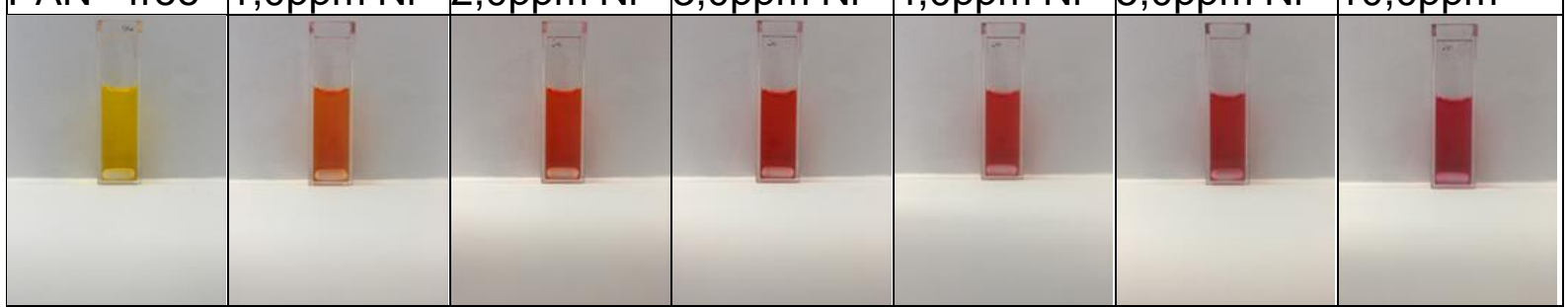

Figura 76 -Plano de cromaticidade bidimensional xy para concentrações iônicas de $\mathrm{Ni}^{2+}$. a) CIE1931XYZ - espectrômetro (425-650nm); b) CIE1931XYZ - MMCS6CS - $\lambda$ (425-675nm). 
Os perfis de cromaticidade xy para os diferentes íons analisados, obtidos a partir dos espectros do espectrômetro UV-VIS (Figura 71a à Figura 76a) são semelhantes aos obtidos no sistema MMCS6CS (Figura 71b à Figura 76b), exceto para os íons de Fe ${ }^{3+}$. Isto pode ser atribuído à condição espectral discreta do sistema MMCS6CS, o que leva à perda de detalhes mais finos na mudança espectral. No entanto, isto não inviabiliza a aplicação do sistema MMCS6CS como colorímetro de elevado desempenho, como veremos nos seguintes itens da presente tese.

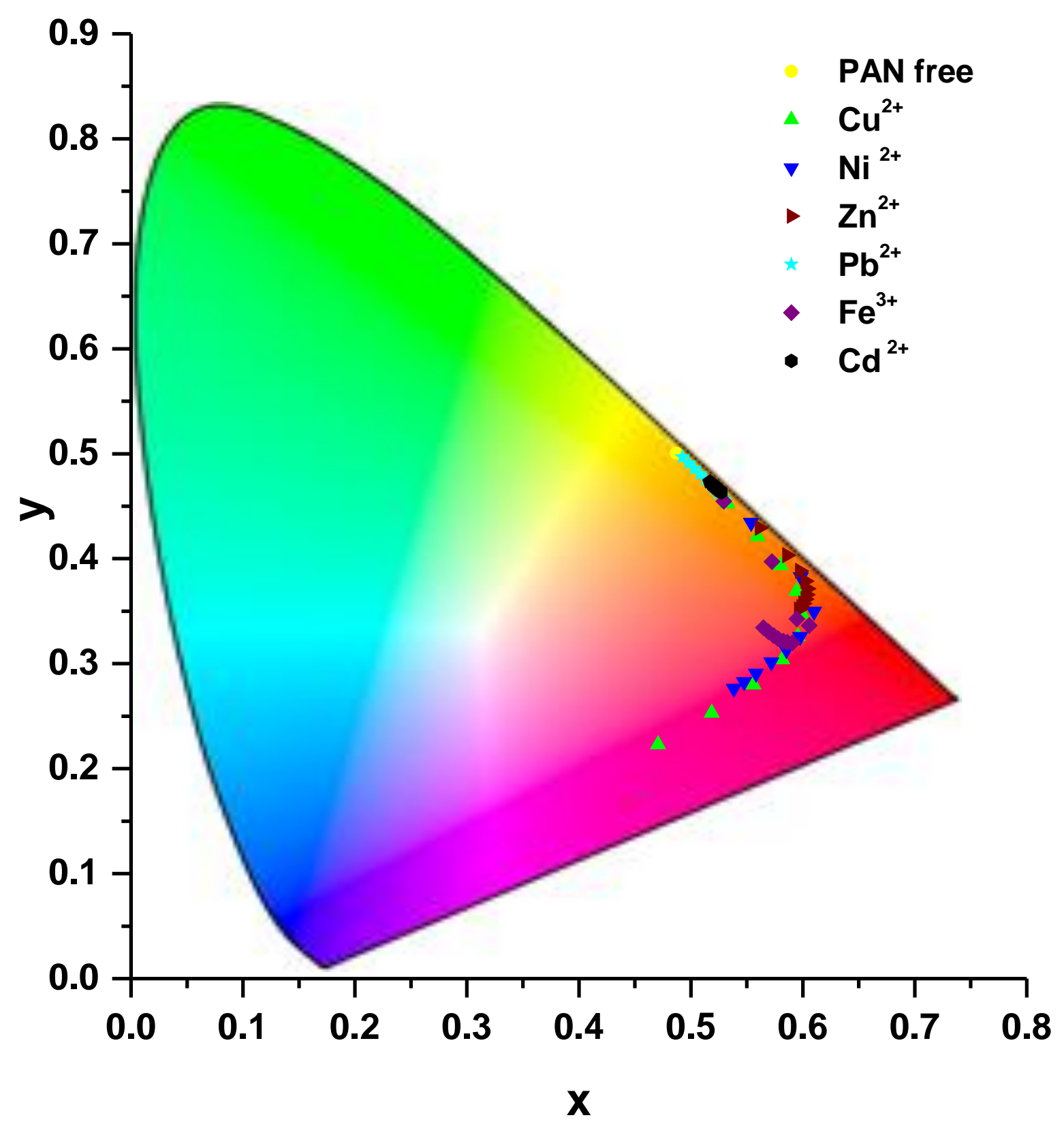

Figura 77 -CIE1931XYZ - espectrômetro UV-VIS (425-650nm) 


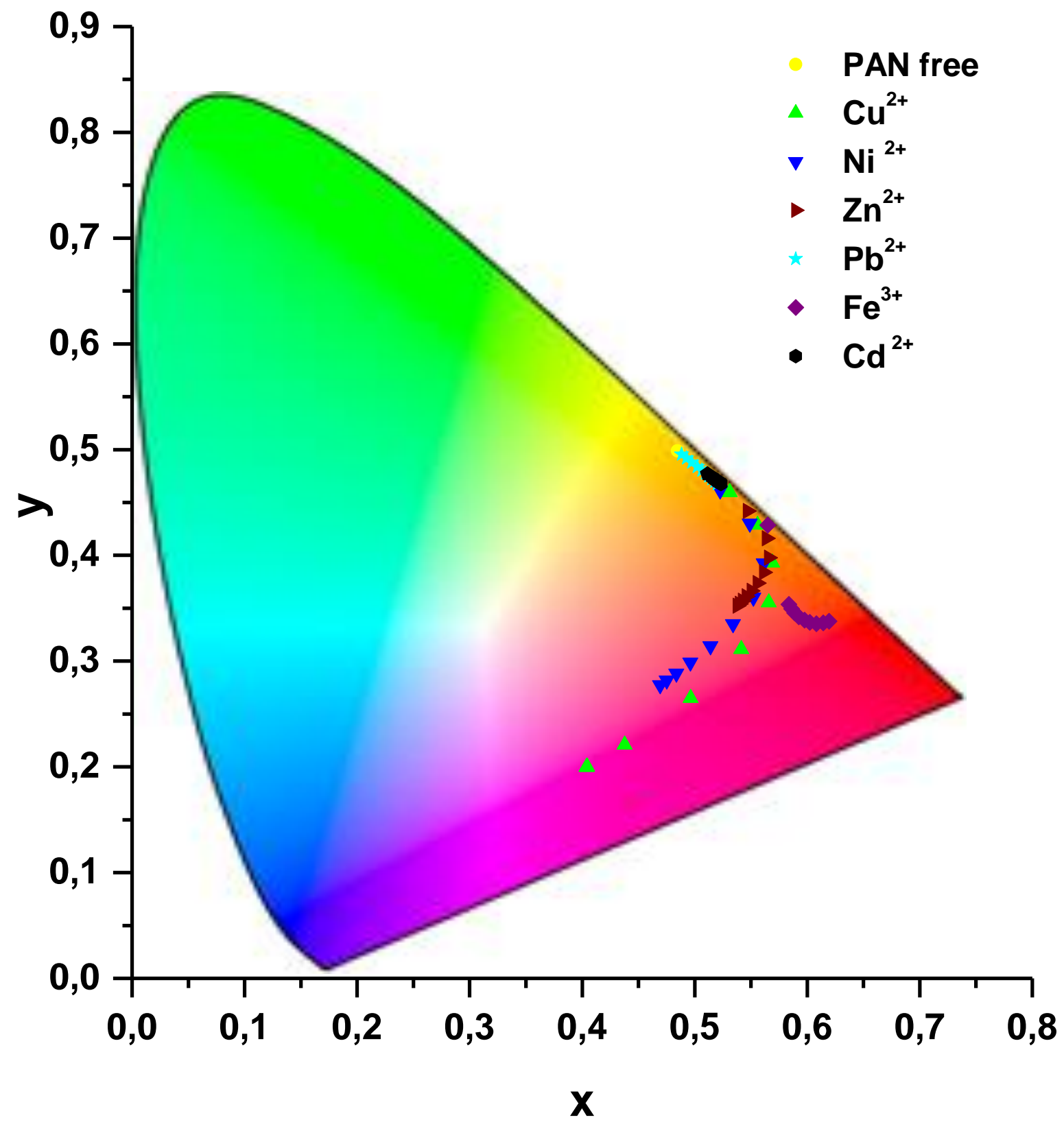

Figura 78 -CIE1931XYZ - MMCS6CS (425-675nm)

Na Figura 77 e na Figura 78, aparentemente o poder classificador da ação dos diferentes íons analisados na molécula PAN apresenta uma classificação parcial (separação dos coeficientes de cromaticidade entre diferentes íons). Por exemplo, o padrão de cromaticidade do íon de $\mathrm{Pb}^{2+}$, em diferentes concentrações, distingue-se bem em relação aos padrões dos outros íons analisados. Já os padrões de cromaticidade bidimensional dos demais íons apresentam-se sobrepostos uns sobre os outros, não havendo, portanto, uma separação plena dos seus padrões. Nesse sentido, a análise de padrões de cromaticidade tridimensional foi realizada. A Figura 
79 e a Figura 80 mostram o comportamento dos padrões de cromaticidade tridimensional, obtidos a partir dos espectros com o espectrômetro, e os obtidos com o sistema MMCS6CS, respectivamente.

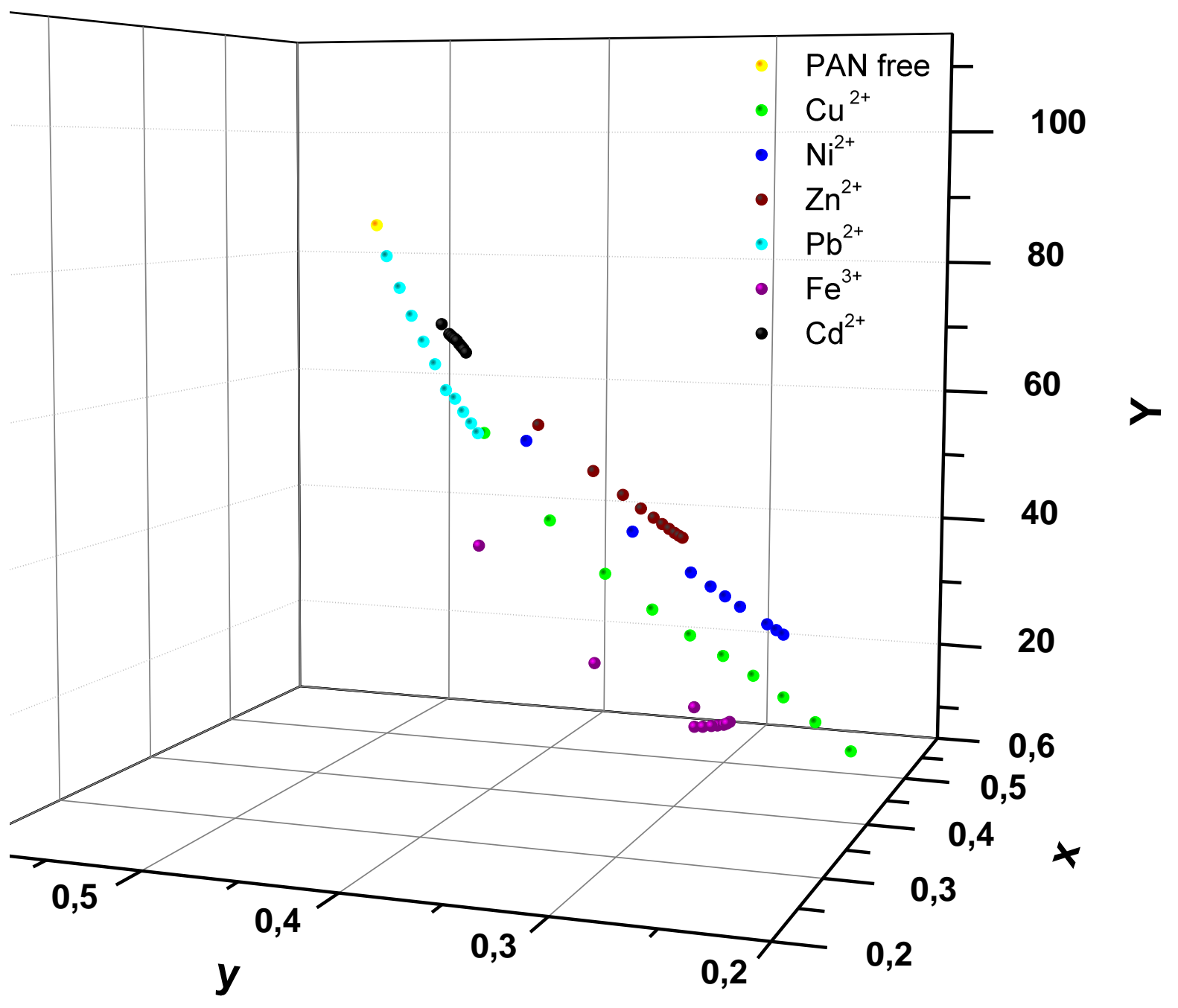

Figura 79 -CIExyY - Espectrômetro UV-VIS (425-650nm) 


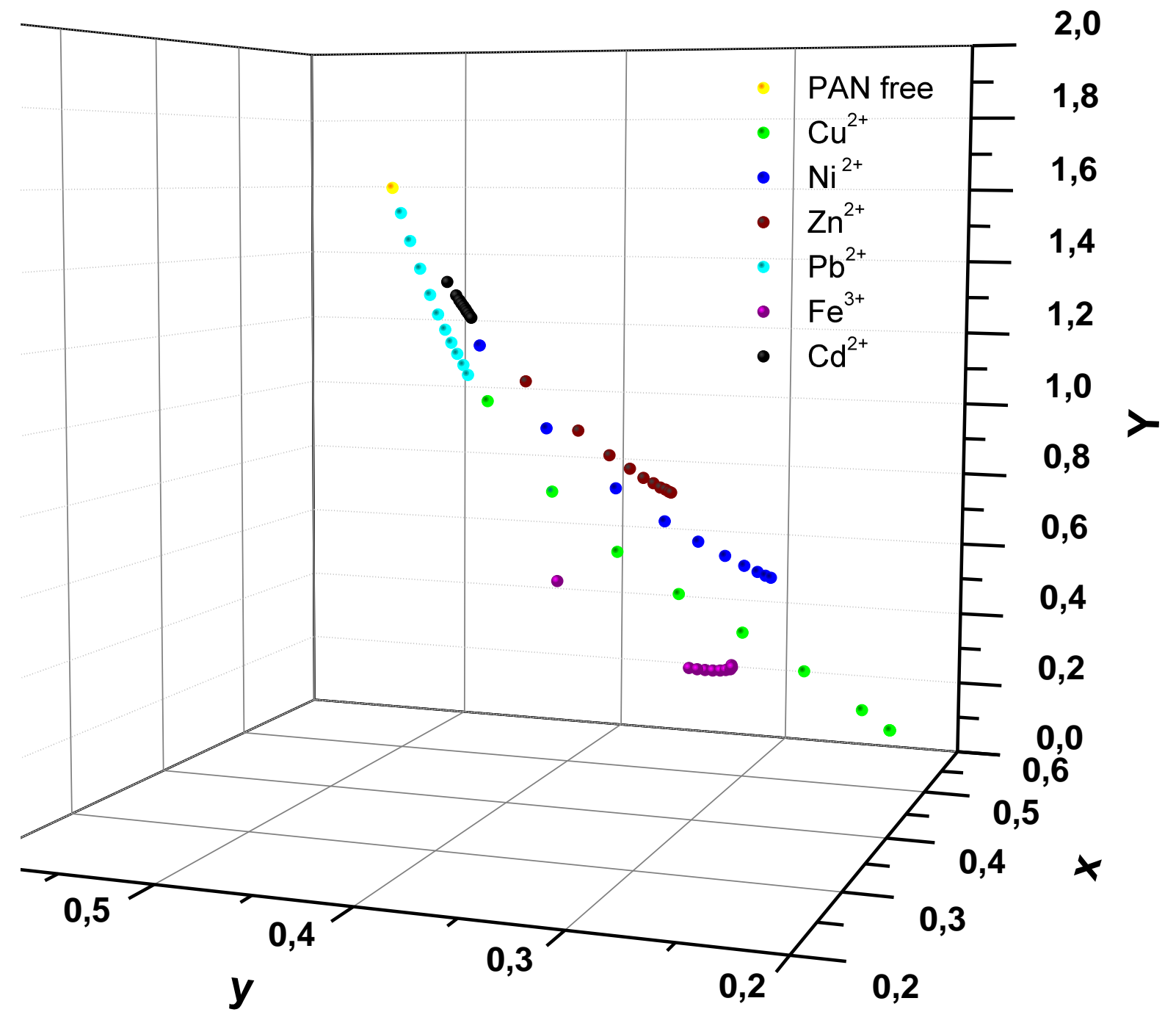

Figura 80 -CIExyY - MMCS6CS (425-675nm)

Como pode ser observado, em ambos os casos, os padrões de cromaticidade tridimensional apresentam semelhanças, mostrando que o nosso sistema proposto reproduz os mesmos resultados aos obtidos, com o equipamento de elevada precisão (espectrômetro). Adicionalmente, vemos também que a Figura 79 e a Figura 80 mostram uma clara separação entre os padrões correspondentes aos diferentes íons analisados, isto é, o sistema MMCS6CS é um colorímetro que pode identificar os diferentes íons analisados, classificando-os plenamente, quando se utiliza a molécula PAN, como sistema sensível. É importante mencionar que a literatura reporta resultados de detecção de íons analisados na presente tese, utilizando-se a molécula PAN (VUKOVIĆ; AVIDAD; CAPITÁN-VALLVEY, 2012). No entanto, em todos estes trabalhos foram reportadas deteç̧ões especificas de alguns íons com a molécula PAN 
(ABOLHASANI; BEHBAHANI, 2015; CHENG; BRAY, 1955; ISLAM; LASKAR; AHMAD, 2010; SRIJARANAl et al., 2011; THARAKESWAR et al.,2012) sem mencionar métodos ou processos de classificação, de tal forma que apenas utilizando a molécula PAN fosse possível identificar e classificar simultaneamente diferentes íons. Neste trabalho, o sistema MMCS6CS proposto como colorímetro também permite identificar e classificar diferentes tipos de íons metálicos nocivos ao meio ambiente.

Para melhor apresentação dos grupos de classificação mostrados na Figura 79 e na Figura 80 foi proposto um método de redução de dimensão. Para tal fim, os dados acima foram submetidos a processo de treino e validação, utilizando-se o método de análises discriminante linear de Fisher (BROWN; WICKER, 2000; MCLACHLAN, 2004). A análise discriminante foi realizada no software OriginPro, versão 9.0, desenvolvido por OriginLab Corporation. Neste método, a classificação é determinada pela probabilidade condicional de um evento pertencer a uma dada classe, sendo conhecida previamente a probabilidade de existência desta classe, também chamada de probabilidade a priori. O método consiste em maximizar a probabilidade condicional de forma recursiva, tendo como resultado final, o cálculo dos coeficientes das variáveis canônicas correspondentes a cada característica do evento. Em nosso caso, os eventos são os íons analisados, representados pelas características de cromaticidade xyY. Assim, temos três características e, como consequência, o modelo de discriminante linear calculará três variáveis canônicas. Cada uma dessas variáveis apresentam um peso determinado no evento, sendo possível, na maioria dos casos, desprezar algumas dessas variáveis canônicas, processo este, chamado de diminuição de dimensão. Certamente, diminuir a dimensão acarreta perda de precisão no processo de classificação. Mas, sendo tolerável o erro (<10\%), o decrescimento de dimensão passa a ser uma ferramenta importante da engenharia na tarefa de mineração e classificação de dados. Na Figura 81 e na Figura 82 são mostrados os mapas de classificação dos íons metálicos, identificados com o espectrômetro e o sistema proposto MMCS6CS, respectivamente. 


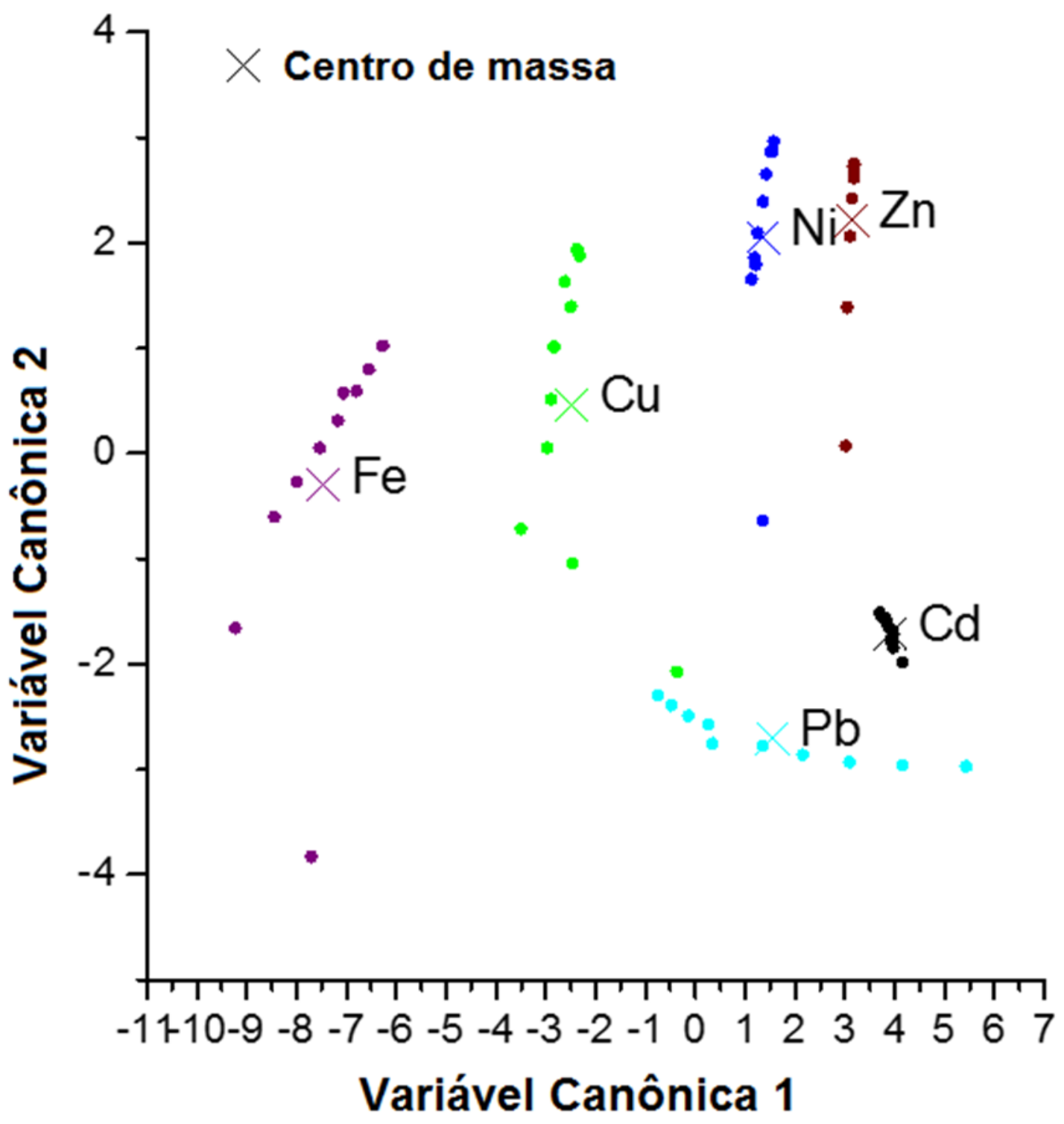

Figura 81 -Representação das classes correspondentes aos íons $\mathrm{Pb}^{2+}, \mathrm{Cd}^{2+}, \mathrm{Zn}^{2+}, \mathrm{Cu}^{2+}, \mathrm{Fe}^{3+} \mathrm{e}$ $\mathrm{Ni}^{2+}$ obtidas pelo método descriminante linear de Fisher, respectivamente. Dados de treino obtidos dos parâmetros de cromaticidade xyY, correspondente aos espectros do espectrômetro UV-VIS. 


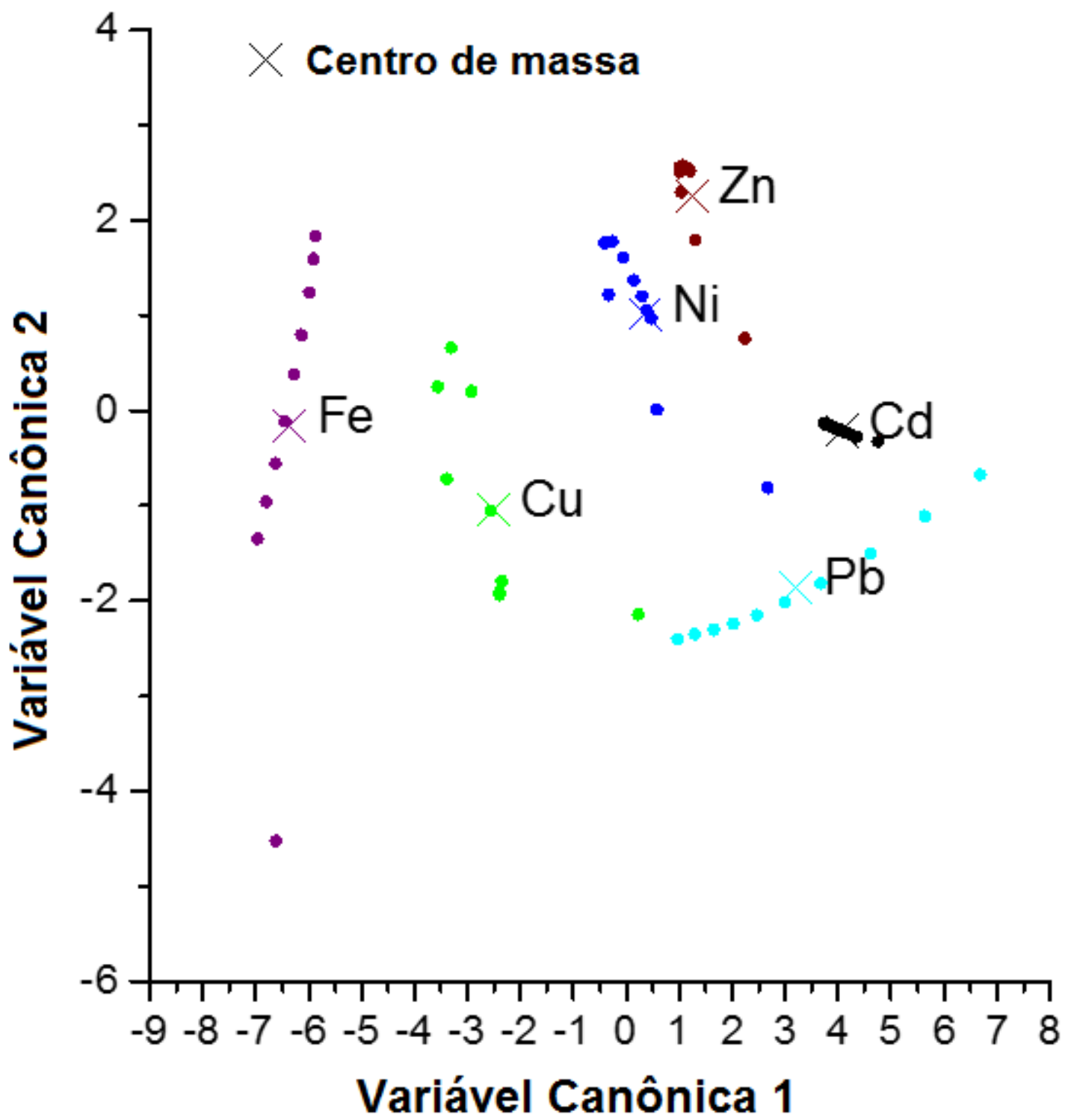

Figura 82 -Representação das classes correspondentes aos íons $\mathrm{Pb}^{2+}, \mathrm{Cd}^{2+}, \mathrm{Zn}^{2+}, \mathrm{Cu}^{2+}, \mathrm{Fe}^{3+} \mathrm{e}$ $\mathrm{Ni}^{2+}$ obtidas pelo método descriminante linear de Fisher, respectivamente. Dados de treino obtidos dos parâmetros de cromaticidade xyY, correspondente aos espectros do sistema MMCS6CS.

Nestes casos utilizamos o recurso de diminuição de dimensão, introduzindo um erro de $10 \%$ por conta desta diminuição, ou seja, o peso das duas variáveis canônicas é de $90 \%$. Na Figura 81 se observa que praticamente todas as classes estão completamente separadas umas das outras, onde apenas no caso dos íons de $\mathrm{Cu}^{2+}$ e $\mathrm{Pb}^{2+}$ apresenta-se um ponto de cada classe muito próximo àquela que corresponde aos íons que não são de sua classe. Na Figura 82, observa-se que todas as classes estão bem separadas umas das outras, exceto no caso dos íons de $\mathrm{Cu}^{2+} \mathrm{e} \mathrm{Pb}^{2+}$, onde é possível observar erros de reconhecimento de um elemento de cada classe de íons $\left(\mathrm{Cu}^{2+}\right.$ e $\left.\mathrm{Pb}^{2+}\right)$, correspondente à baixa e à alta concentração destes íons, 
respectivamente. Assim, os resultados apresentados neste capítulo mostram que o sistema proposto MMCS6CS foi aplicado com sucesso na detecção de íons $\mathrm{Pb}^{2+}$, $\mathrm{Cd}^{2+}, \mathrm{Zn}^{2+}, \mathrm{Cu}^{2+}, \mathrm{Fe}^{3+}$ e $\mathrm{Ni}^{2+}$, mesmo que a resposta deste dispositivo seja formada por espectros discretos, se comparado ao sistema do espectrômetro que possui uma elevada resolução espectral $(0,1 \mathrm{~nm})$.

\subsubsection{Análise de resposta de sensibilidade do sensor Multiespectral MMCS6CS na deteç̧ão de íons de metais pesados de $\mathrm{Pb}^{2+}, \mathrm{Ni}^{2+}, \mathrm{Cd}^{2+}$ e $\mathrm{Zn}^{2+}$ pelo método fluorimétrico e uso de reagente fluoróforo de tetra- (3-bromo-4-hidroxifenil)-porfirina (TBHPP)}

O sistema MMCS6CS, dado sua flexibilidade de projeto, também foi aplicado como um sistema fluorimétrico na detecção de íons metálicos associado à emissão fotoluminescente de moléculas corantes sensíveis a íons metálicos. Particularmente neste trabalho, foram utilizadas as moléculas de TBHPP e de 2,7-Dichlorofluorescein como corantes sensíveis a íons metálicos (BOZKURT; AYATA; KAYNAK, 2009; GOSWANI; BARUAH; DAS, 2010).

Na primeira parte da aplicação do sistema MMCS6CS pelo método de detecção por fluorimetria, analisaremos os resultados do efeito de supressão da emissão da molécula TBHPP, devido à interação de diferentes íons metálicos e compararemos estes resultados com os obtidos por um fluorímetro convencional de bancada, descrito na seção 2.2.7. Para este fim, primeiro identificamos as condições espectrais de absorção e emissão óptica da molécula de TBHPP. Este processo é necessário para poder definir os pontos adequados de excitação e emissão da molécula TBHPP e assim configurar a montagem experimental mais eficiente do sistema MMCS6CS.

A Figura 83 apresenta o espectro de absorção a partir do reagente fluoróforo de tetra(3-bromo-4-hidroxifenil)-porfirina (TBHPP) dissolvido em metanol.

O ensaio para obtenção do espectro foi realizado com o uso de um espectrômetro UV-VIS, modelo Cary 50, Varian, em temperatura de $25^{\circ} \mathrm{C}$. Um volume de $2,5 \mathrm{ml}$ do TBHPP $(9 \mu \mathrm{M})$ foi acondicionado em uma cubeta de quartzo e verificada a condição de absorbância na faixa de varredura entre $200 \mathrm{~nm}$ e $800 \mathrm{~nm}$. 


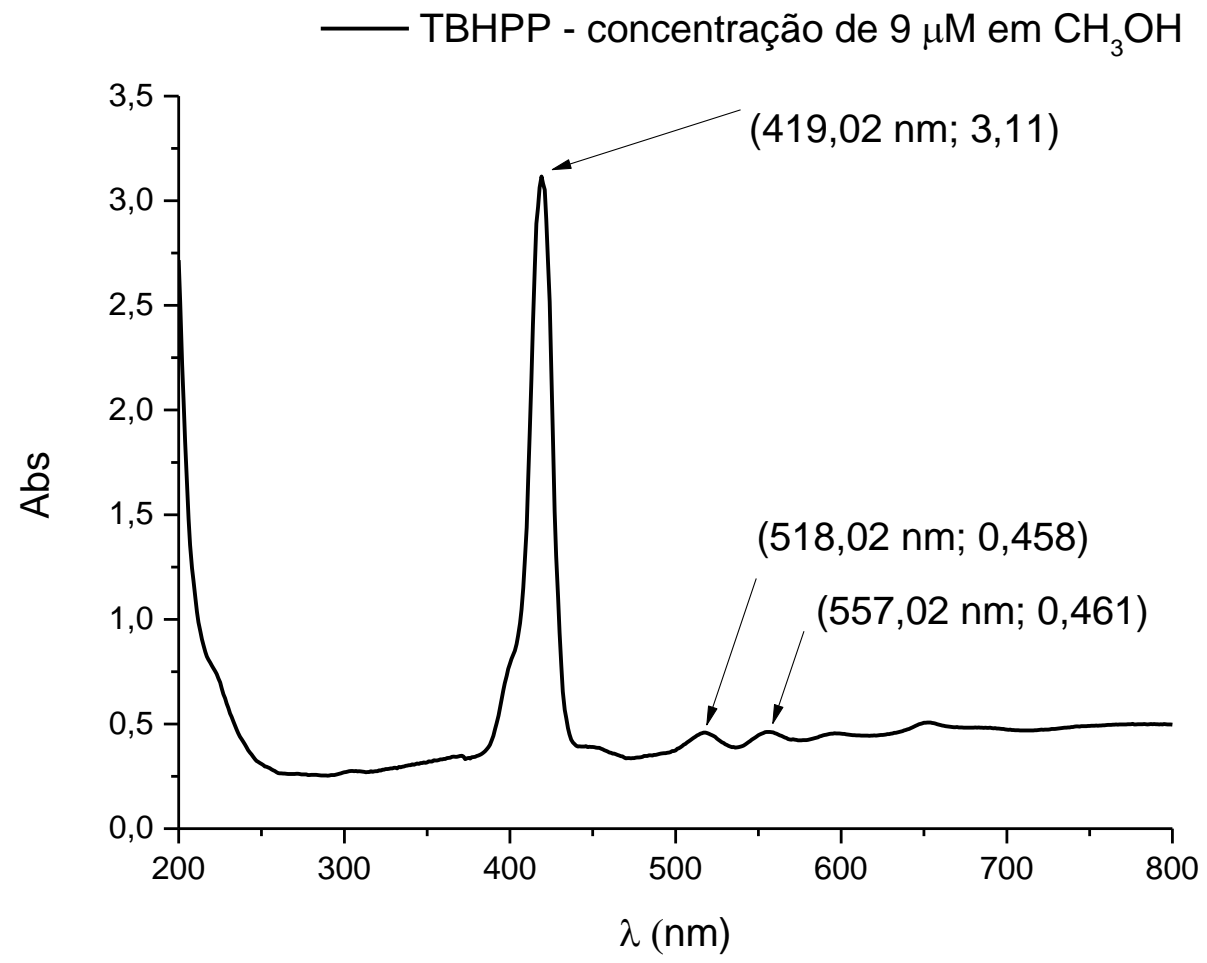

Figura 83 -Espectro de absorção do reagente fluoróforo de tetra-(3-bromo-4-hidroxifenil)porfirina (TBHPP) diluído em metanol $(9,0 \mu \mathrm{M})$.

A molécula de TBHPP caracteriza-se por uma banda Soret de alta intensidade próxima a $419 \mathrm{~nm}$, seguida por duas outras bandas Q, com picos menores (518 e 557 nm). Para o sistema de detecção, a escolha da fonte de excitação (LED) foi definida pelo ponto de maior absorção do espectro, sendo definido um LED de $415 \mathrm{~nm}$. É importante mencionar que nos dias atuais, os LEDs com comprimentos de onda acima de $380 \mathrm{~nm}$ são facilmente encontrados no mercado e possuem custos bem reduzidos, comparados a outras tecnologias de fontes luminosas. Isso oferece alta possibilidade de aplicação em sistemas sensores, além de possuir longos tempos de vida de utilização.

Os ensaios de sensibilidade do sensor multiespectral MMCS6CS na detecção dos íons de $\mathrm{Pb}^{2+}, \mathrm{Ni}^{2+}, \mathrm{Cd}^{2+}$ e $\mathrm{Zn}^{2+}$ pelo método fluorimétrico e uso de reagente fluoróforo de TBHPP seguiram os procedimentos e métodos relatados nos itens 5.2.3 e 5.2.3.1. Assim, também, os espectros das mudanças na intensidade de fotoluminescência pela presença dos íons metálicos, sob interações eletrônicas com a molécula de TBHPP, podem ser vistos, sob análise referencial do fluorímetro, modelo Cary Eclipse, Varian, na Figura 84 (a, b, c e d). 
Antes de cada leitura, uma pipeta calibrada, modelo P100 (20-100 $\mu \mathrm{l})$, Gilson Pipetman foi utilizada para dosar pequenas adições volumétricas dos íons metálicos diluídos em água DI, compondo concentrações de 0,02 a 0,2 ppm. A temperatura ambiente foi mantida em $25 \stackrel{\circ}{ } \mathrm{C}$ e monitorada com uso de um termômetro, durante todo o procedimento de ensaio.

a)

b)

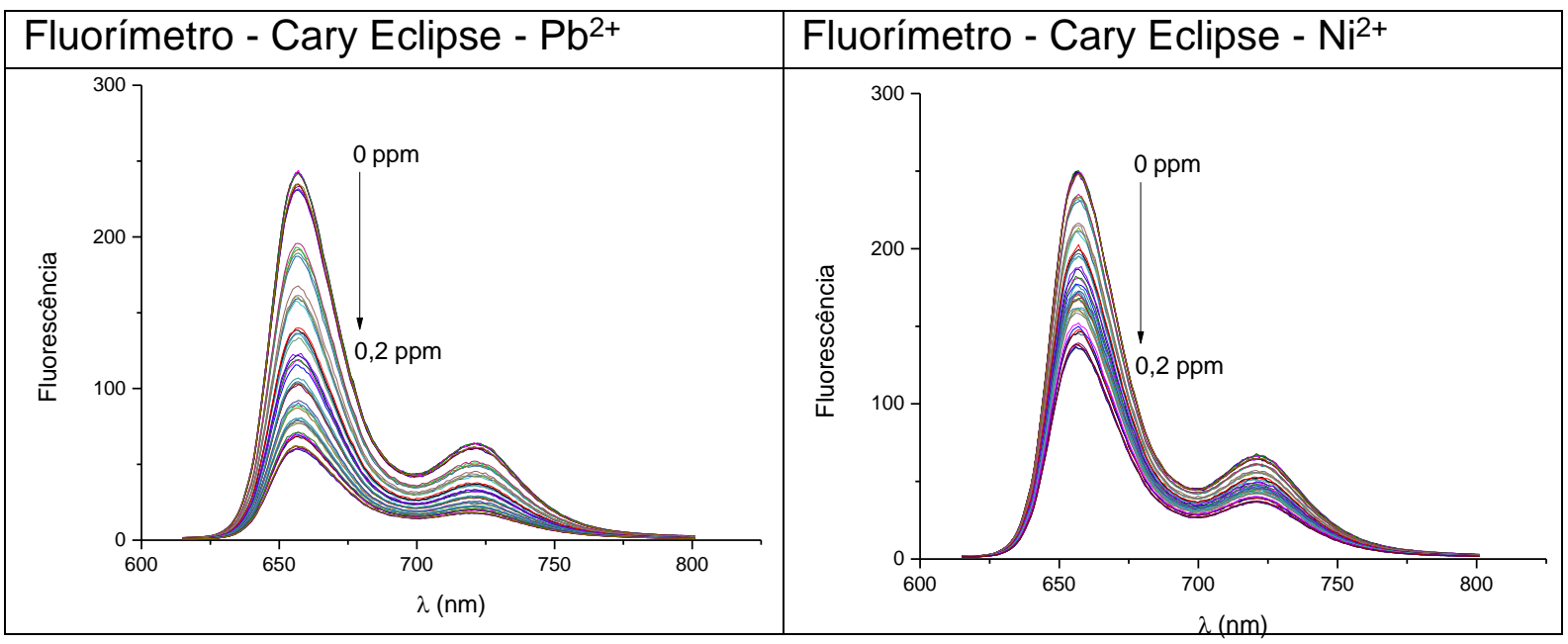

c)

d)

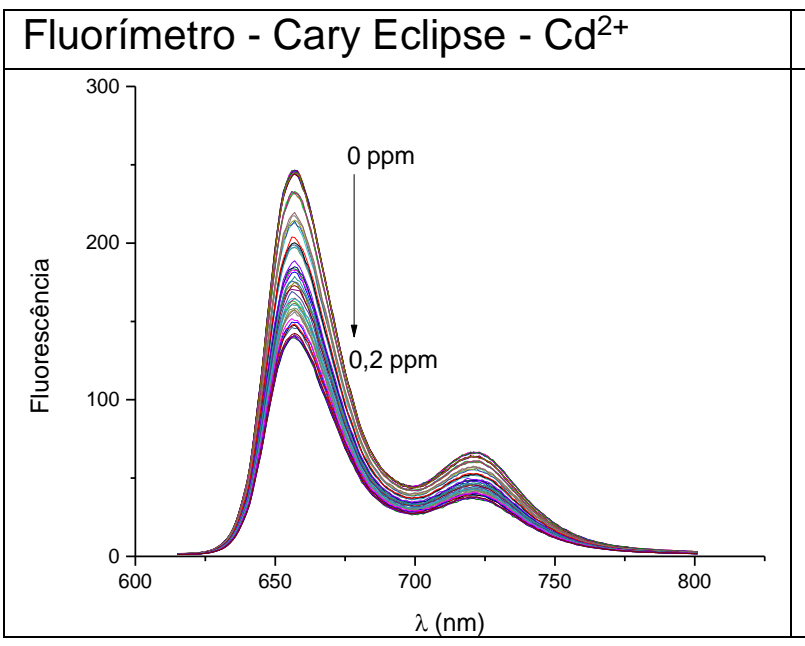

Fluorímetro - Cary Eclipse - $\mathrm{Zn}^{2+}$

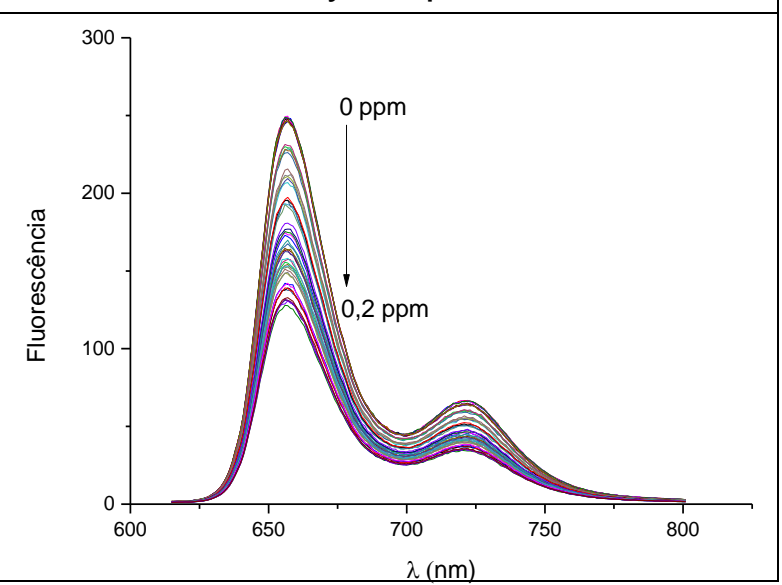

Figura 84 -Espectro de fluorescência do reagente fluoróforo de TBHPP sob interação com diferentes íons metálicos. a) $\mathrm{Pb}^{2+}$, b) $\mathrm{Ni}^{2+}$, c) $\mathrm{Cd}^{2+}$ e d) $\mathrm{Zn}^{2+}$

Nos gráficos apresentados, podem ser vistas duas bandas de emissão fluorescente de picos máximos em 656 e $720 \mathrm{~nm}$, quando as moléculas foram excitadas pelo LED de $415 \mathrm{~nm}$. Isso se deve ao sistema de dupla ligação conjugada e a alta mobilidade dos m-elétrons do fluoróforo de TBHPP (BOZKURT et al., 2009). Nesta condição, a interação molecular do TBHPP com os íons metálicos pode levar a um estado de 
supressão estática da fluorescência, devido à desativação da conversão interna dos estados excitados do TBHPP (BOZKURT et al., 2009).

Para melhor representação e análise comparativa entre as sensibilidades aos íons metálicos, os gráficos foram plotados com base nas intensidades fluorescentes no comprimento de onda de $675 \mathrm{~nm}$ lidas no fluorímetro, uma vez que neste comprimento de onda temos uma saída correspondente no sensor multiespectral MMCS6CS (fotodetector de $675 \mathrm{~nm}$ ). Os sinais dessa saída foram utilizados para a obtenção dos gráficos de respostas de intensidade fluorescente pelas medidas de amplitude (VRMS) e fase (graus), conforme as Equações 21 e 22:

$$
\operatorname{Resposta}_{T B H P P}=\frac{I_{0}-I}{I_{0}}
$$

Onde: $I_{0}$ e / referem-se às tensões eficazes medidas do sinal emitido na ausência e presença dos íons metálicos, respectivamente.

$$
\text { Resposta }_{\text {fase (TBHPP) }}=\frac{\theta_{0}-\theta}{180}
$$

Onde: $\theta_{0}$ e $\theta$ referem-se às fases do sinal emitido na ausência e presença dos íons metálicos, respectivamente.

No caso das intensidades de valores de fluorescência lidos pelo fluorímetro, os gráficos de resposta normalizada utilizaram de maneira similar a equação 21 , sendo lo e I correspondentes às intensidades de fluorescência na ausência e presença dos íons metálicos. Desta forma, na Figura 85 são apresentadas as curvas de resposta de sensibilidades do TBHPP na presença dos íons de $\mathrm{Pb}^{2+}, \mathrm{Ni}^{2+}, \mathrm{Cd}^{2+}$ e $\mathrm{Zn}^{2+}$, obtidas no Fluorímetro Cary Eclipse. 


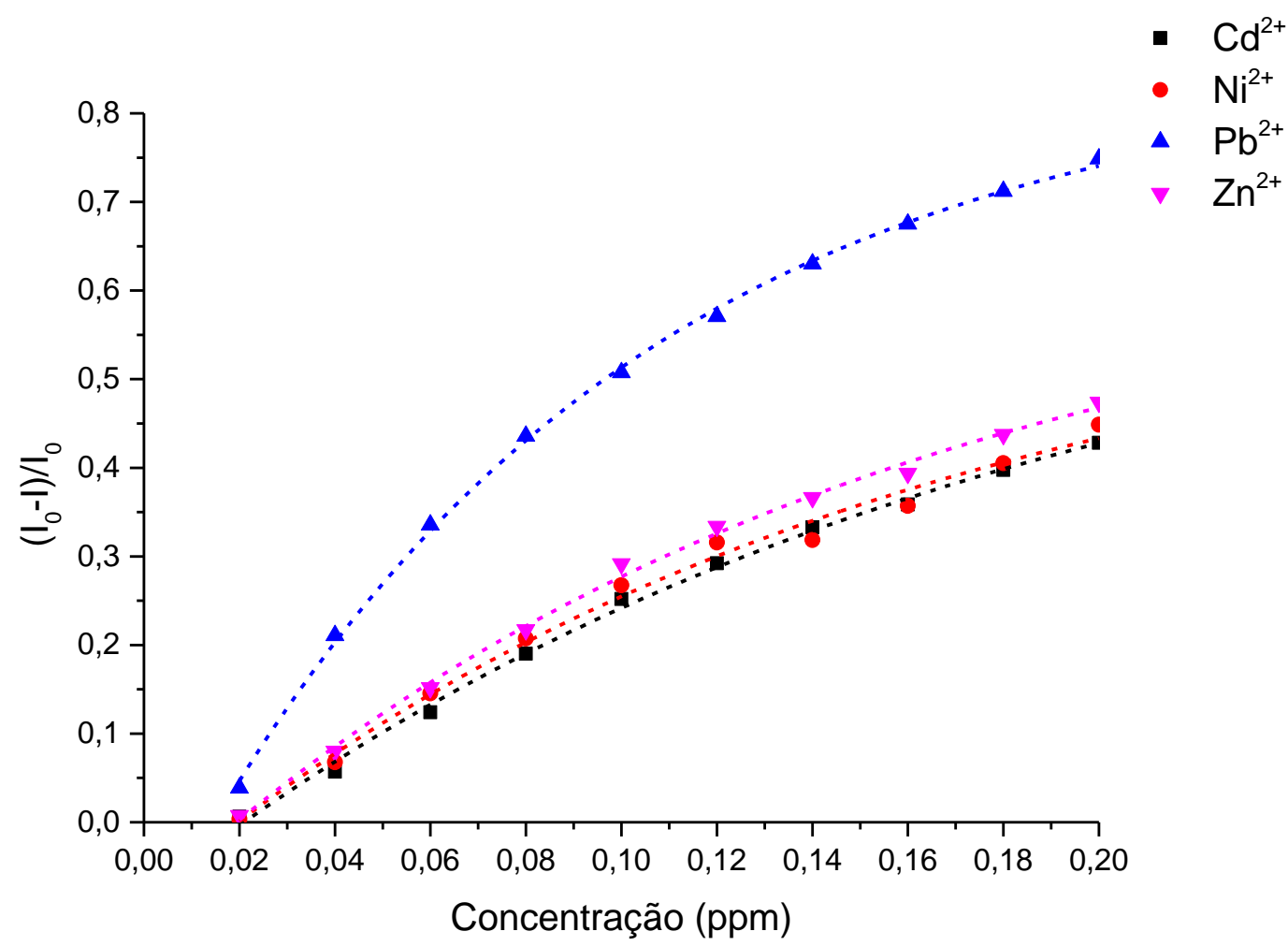

Figura 85 -Curvas de calibração de respostas obtidas pelo fluorímetro em diferentes concentrações de íons de metais pesados no comprimento de onda de $675 \mathrm{~nm}$. As curvas tracejadas correspondem aos ajustes exponenciais do reagente fluoróforo de TBHPP sob interação com diferentes íons metálicos.

A Tabela 14 apresenta os parâmetros dos ajustes exponenciais das curvas de calibração de respostas obtidas pelo fluorímetro em diferentes concentrações de íons de metais pesados no comprimento de onda de $675 \mathrm{~nm}$.

Tabela 14 - Parâmetros dos ajustes exponenciais das curvas de calibração de respostas obtidas pelo fluorímetro em diferentes concentrações dos íons de metais pesados no comprimento de onda de $675 \mathrm{~nm}$.

\begin{tabular}{cccccc}
\hline Equação & \multicolumn{4}{c}{$y=a+b * \exp \left({ }^{-x} / c\right)$} \\
\hline \multirow{4}{*}{ Valores } & & $\mathbf{P b}^{2+}$ & $\mathbf{C d}^{2+}$ & $\mathbf{Z n}^{2+}$ & $\mathbf{N i}^{2+}$ \\
& $\mathbf{b}$ & 0,86 & 0,68 & 0,67 & 0,63 \\
& $\mathbf{c}$ & $-1,00$ & $-0,76$ & $-0,76$ & $-0,72$ \\
& 0,094 & 0,18 & 0,15 & 0,16 \\
\hline
\end{tabular}

O coeficiente exponencial "c" das curvas de ajuste está relacionado com a sensibilidade do sistema. Quanto menor este valor, mais sensível será a resposta do sistema. Os resultados da Tabela 14 mostram que a molécula TBHPP apresenta maior sensibilidade para os íons de $\mathrm{Pb}^{2+}$ em relação aos outros íons, conforme também mostrado na Figura 85. 
$\mathrm{Na}$ Figura 86 são apresentadas as curvas de resposta (VRMS) de sensibilidade do TBHPP obtidas pelo sensor multiespectral MMCS6CS na presença dos íons de $\mathrm{Pb}^{2+}$, $\mathrm{Ni}^{2+}, \mathrm{Cd}^{2+} \mathrm{e} \mathrm{Zn}^{2+}$ e suas respectivas curvas de ajuste com aproximações exponenciais.

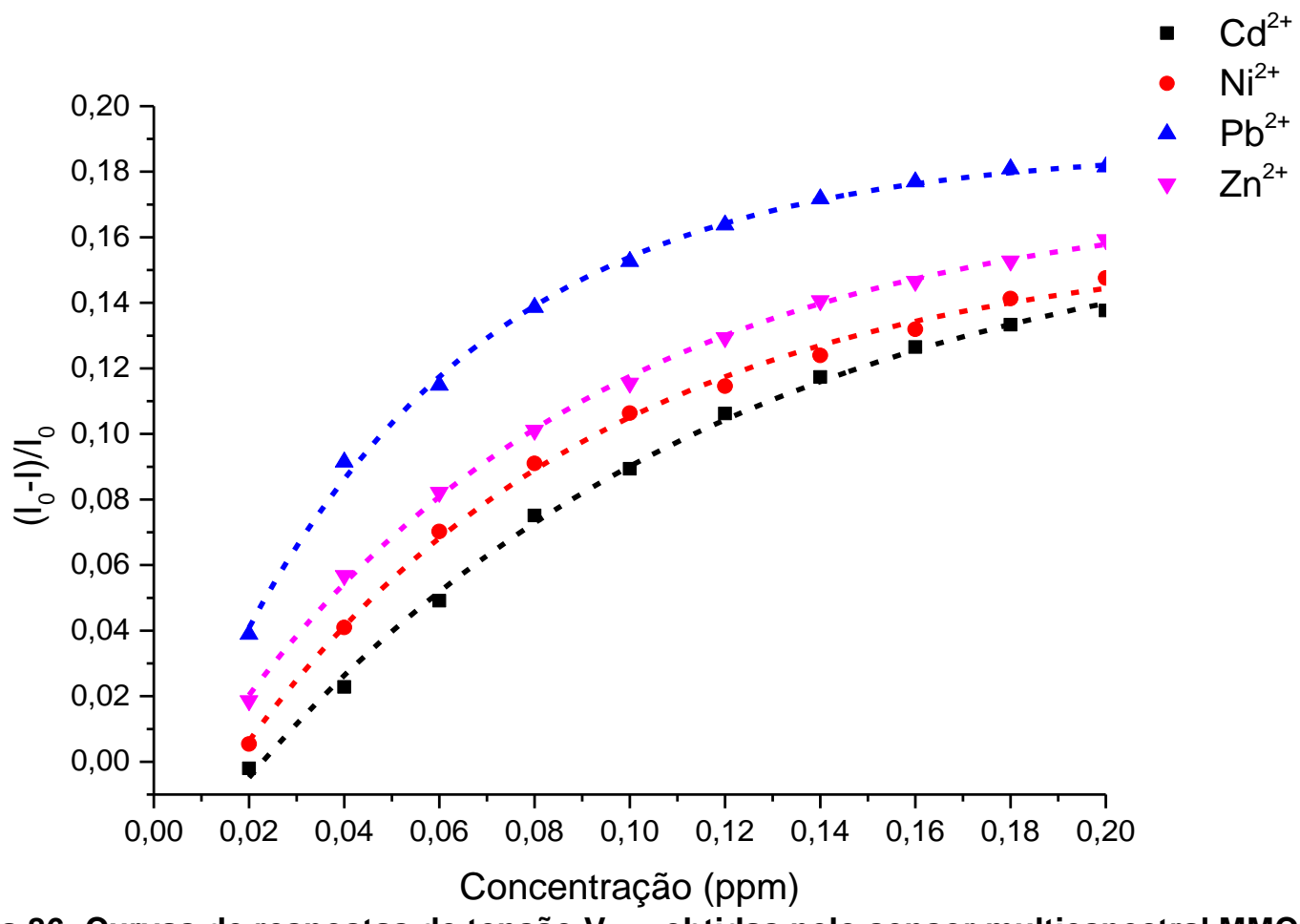

Figura 86 -Curvas de respostas de tensão $V_{\text {RMS }}$ obtidas pelo sensor multiespectral MMCS6CS em diferentes concentrações de íons de metais pesados na saída de comprimento de onda de

$675 \mathrm{~nm}$. As curvas tracejadas correspondes às curvas de ajuste exponenciais do reagente fluoróforo de TBHPP, sob interação com diferentes íons metálicos.

A Tabela 15 apresenta os parâmetros dos ajustes exponenciais das curvas de calibração de respostas $V_{\text {RMS }}$ obtidas pelo sensor multiespectral em diferentes concentrações de íons de metais pesados na saída de comprimento de onda de 675 $\mathrm{nm}$. O valor do coeficiente "c" aponta a mesma tendência observada anteriormente, sendo maior a sensibilidade da molécula TBHPP aos íons de $\mathrm{Pb}^{2+}$.

Tabela 15 - Parâmetros dos ajustes exponenciais das curvas de calibração de respostas $V_{\text {RMS }}$ obtidas pelo sensor multiespectral em diferentes concentrações dos íons de metais pesados na saída de comprimento de onda de $675 \mathrm{~nm}$.

\begin{tabular}{cccccc}
\hline Equação & \multicolumn{4}{c}{$y=a+b * \exp \left({ }^{-x} / c\right)$} \\
\hline \multirow{4}{*}{ Valores } & & $\mathbf{P b}^{2+}$ & $\mathbf{C d}^{2+}$ & $\mathbf{Z n}^{2+}$ & $\mathbf{N i}^{2+}$ \\
& $\mathbf{b}$ & 0,19 & 0,17 & 0,17 & 0,16 \\
& $\mathbf{c}$ & $-0,21$ & $-0,21$ & $-0,20$ & $-0,20$ \\
& 0,054 & 0,10 & 0,080 & 0,077 \\
\hline
\end{tabular}

Como mencionado anteriormente, o sistema MMCS6CS também está configurado para a medida de tempo de vida pela emissão fotoluminescente de moléculas 
corantes, através da medida da mudança de fase do sinal, correspondente à emissão fotoluminescente e, como esta mudança apresenta uma relação com o efeito de supressão fotoluminescente, então a resposta do sistema pode ser analisada através da mudança de fase da emissão fotoluminescente. Na Figura 87 são apresentadas as curvas de resposta (fase) de sensibilidade do TBHPP obtidas pelo sensor multiespectral MMCS6CS na presença dos íons de $\mathrm{Pb}^{2+}, \mathrm{Ni}^{2+}, \mathrm{Cd}^{2+}$ e $\mathrm{Zn}^{2+}$ e suas respectivas curvas de ajuste exponenciais.

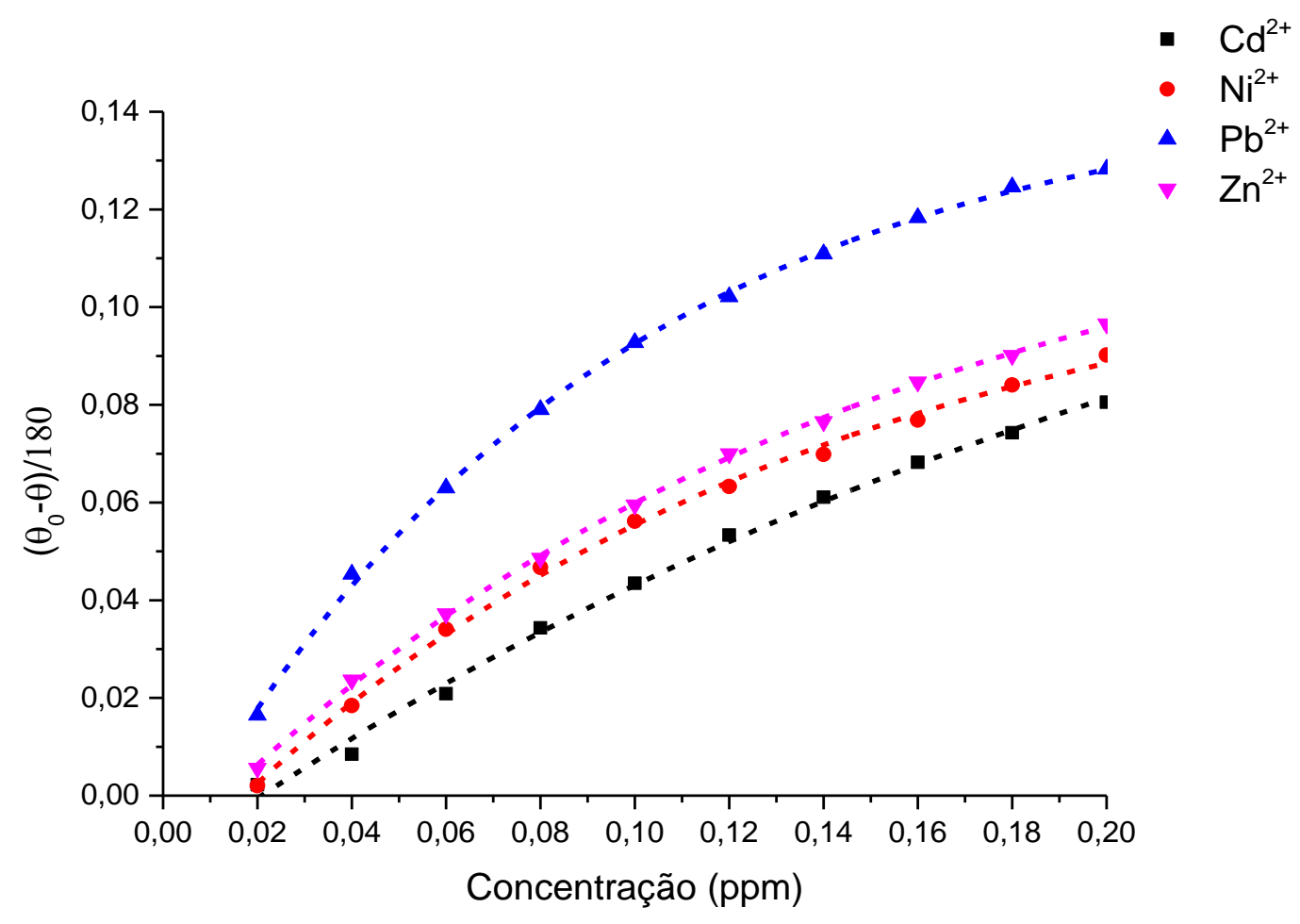

Figura 87 -Pontos experimentais das respostas de fase obtidas pelo sensor multiespectral MMCS6CS em diferentes concentrações de íons de metais pesados na saída de comprimento de onda de $675 \mathrm{~nm}$ e suas curvas de ajuste exponenciais do reagente fluoróforo de TBHPP, sob interação com diferentes íons metálicos.

A Tabela 16 apresenta os parâmetros dos ajustes exponenciais das curvas de calibração de respostas de fase obtidas pelo sensor multiespectral em diferentes concentrações de íons de metais pesados na saída de comprimento de onda de 675 $\mathrm{nm}$. Novamente, observa-se que o sistema é mais sensível aos íons de $\mathrm{Pb}^{2+}$. 
Tabela 16 - Parâmetros dos ajustes exponenciais das curvas de calibração de respostas de fase obtidas pelo sensor multiespectral em diferentes concentrações dos íons de metais pesados na saída de comprimento de onda de $675 \mathrm{~nm}$.

\begin{tabular}{rrrccc}
\hline Equação & \multicolumn{4}{c}{$y=a+b * \exp \left({ }^{-x} / c\right)$} \\
\hline \multirow{4}{*}{ Valores } & & $\mathbf{P b}^{2+}$ & $\mathbf{C d}^{2+}$ & $\mathbf{Z n}^{2+}$ & $\mathbf{N i}^{2+}$ \\
& $\mathbf{b}$ & 0,15 & 0,16 & 0,13 & 0,12 \\
& $\mathbf{c}$ & $-0,16$ & $-0,17$ & $-0,14$ & $-0,13$ \\
& 0,092 & 0,25 & 0,14 & 0,13 \\
\hline
\end{tabular}

5.3.3. Análise de resposta de sensibilidade do sensor Multiespectral MMCS6CS na detecção de íons de metais pesados de $\mathrm{Pb}^{2+}, \mathrm{Ni}^{2+}, \mathrm{Cd}^{2+}$, $\mathrm{Zn}^{2+}$ e $\mathrm{Cu}^{2+}$ pelo método fluorimétrico e uso de reagente fluoróforo de 2,7-Dichlorofluorescein

A Figura 88 apresenta o espectro de absorção a partir do reagente fluoróforo de 2,7Dichlorofluorescein dissolvido em metanol.

O ensaio para obtenção do espectro foi realizado com o uso de um espectrômetro UV-VIS, modelo Cary 50, Varian, em temperatura de $25 \stackrel{\circ}{\circ}$. Um volume de $2,5 \mathrm{ml}$ do 2,7-Dichlorofluorescein $(16,6 \mu \mathrm{M})$ foi acondicionado em uma cubeta de quartzo e verificada a condição de absorbância na faixa de varredura entre 300 nm e $600 \mathrm{~nm}$.

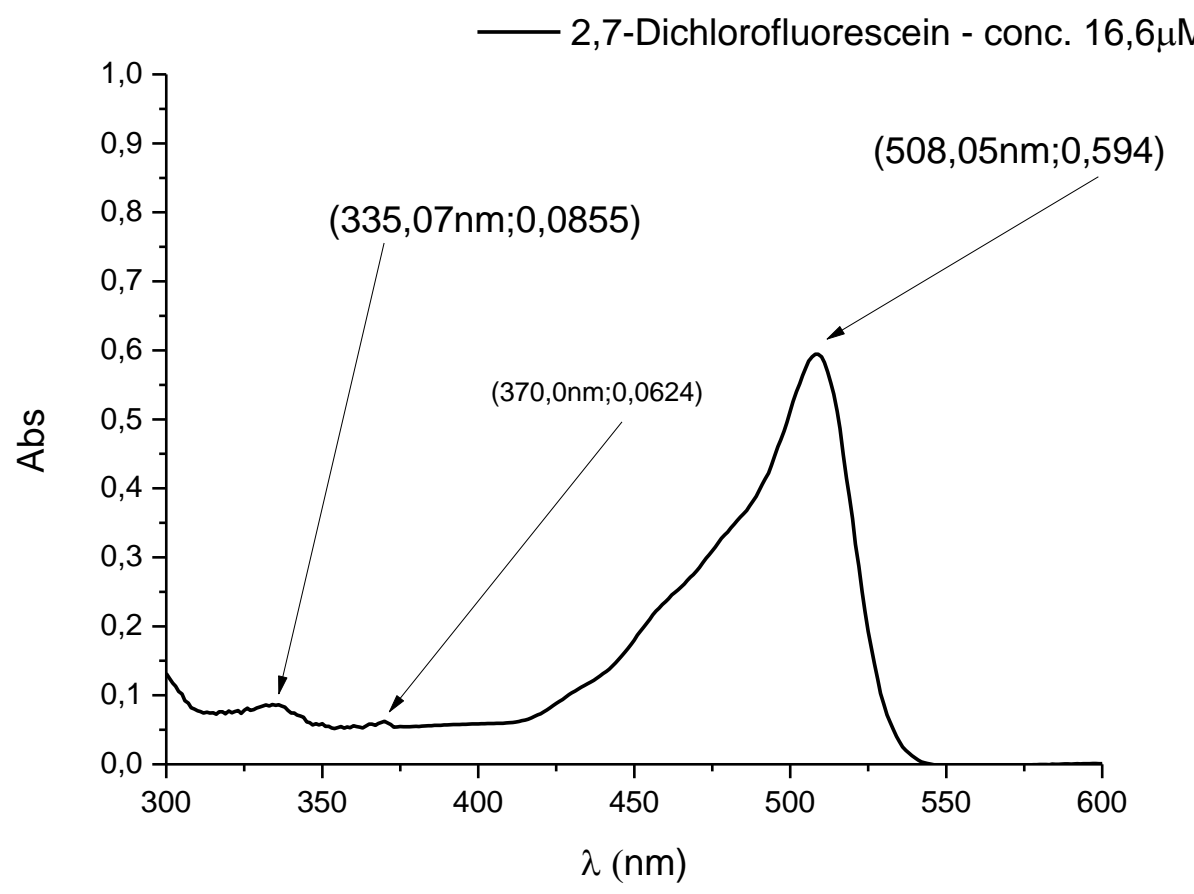

Figura 88 -Espectro de absorção do reagente fluoróforo de 2,7-Dichlorofluorescein diluído em metanol $(16,6,0 \mu \mathrm{M})$. 
A molécula de 2,7-Dichlorofluorescein caracteriza-se por uma banda Soret de alta intensidade próxima a $508 \mathrm{~nm}$, seguida por duas outras bandas $Q$, com picos menores (335 e $370 \mathrm{~nm}$ ). Para o sistema de detecção, a escolha da fonte de excitação (LED) foi definida pelo ponto de maior absorção do espectro, sendo definido um LED de $505 \mathrm{~nm}$.

Neste caso, a intensidade de emissão fotoluminescente da molécula 2,7Dichlorofluorescein se intensifica devido à interação com os íons metálicos.

Os ensaios de sensibilidade do sensor multiespectral MMCS6CS na detecção dos íons de $\mathrm{Pb}^{2+}, \mathrm{Ni}^{2+}, \mathrm{Cd}^{2+}, \mathrm{Zn}^{2+}$ e $\mathrm{Cu}^{2+}$ pelo método fluorimétrico e uso de reagente fluoróforo de 2,7-Dichlorofluorescein seguiram os procedimentos e métodos relatados nos itens 5.2.3 e 5.2.3.2. Os espectros das mudanças na intensidade de fotoluminescência pela presença dos íons metálicos, sob análise referencial do fluorímetro, modelo Cary Eclipse, Varian, podem ser vistos na Figura 89 (a, b, c, d e e). Antes de cada leitura, uma pipeta calibrada, modelo P100 (20-100 $\mu$ l), Gilson Pipetman, foi utilizada para dosar pequenas adições volumétricas dos íons metálicos diluídos em água $\mathrm{DI}$, compondo concentrações de 1,99 a 9,8 $\mu \mathrm{M}$. A temperatura ambiente foi mantida em $25 \stackrel{\circ}{\circ}$ e monitorada com uso de um termômetro, durante todo o procedimento de ensaio.

a)

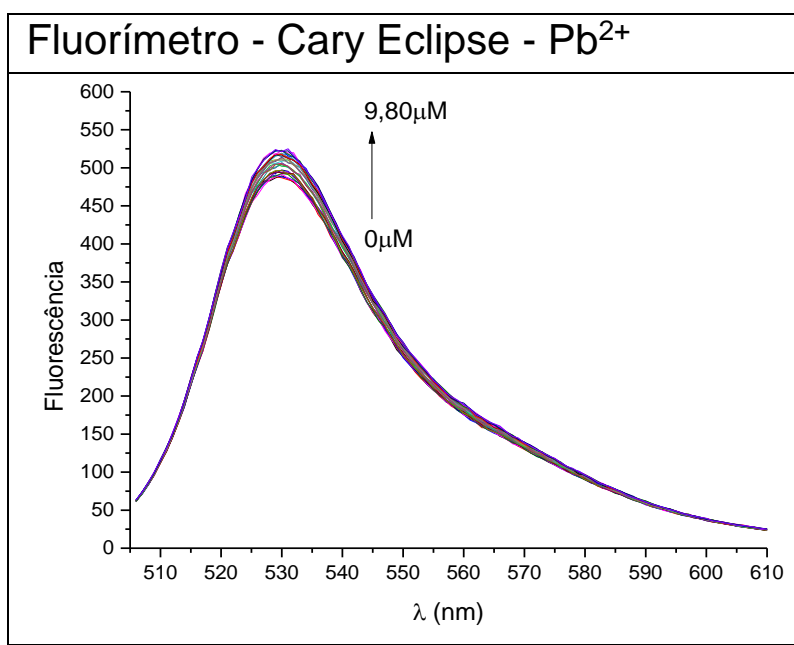

b)

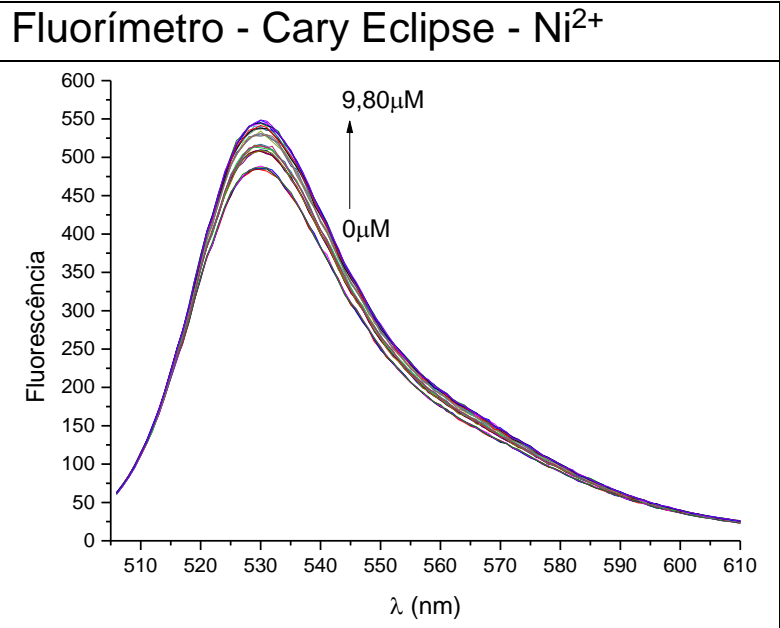


c)

d)

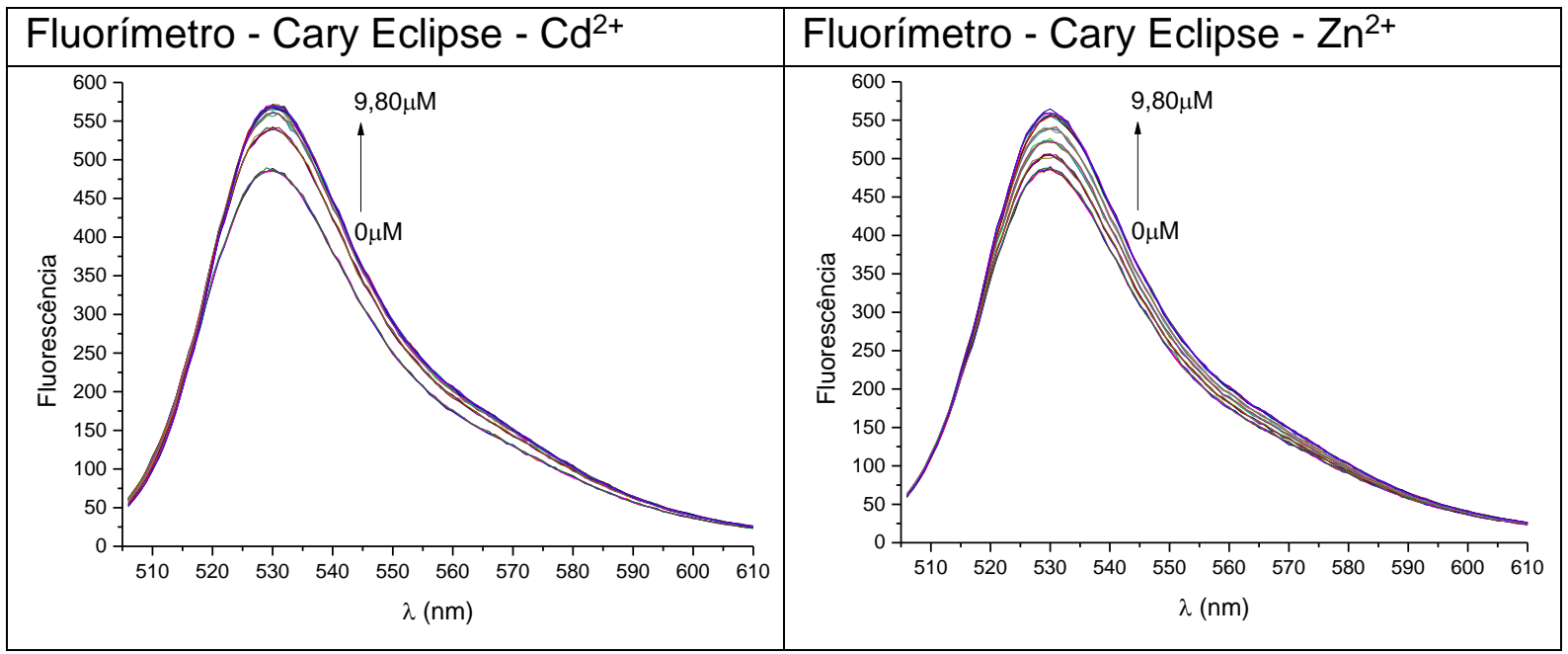

e)

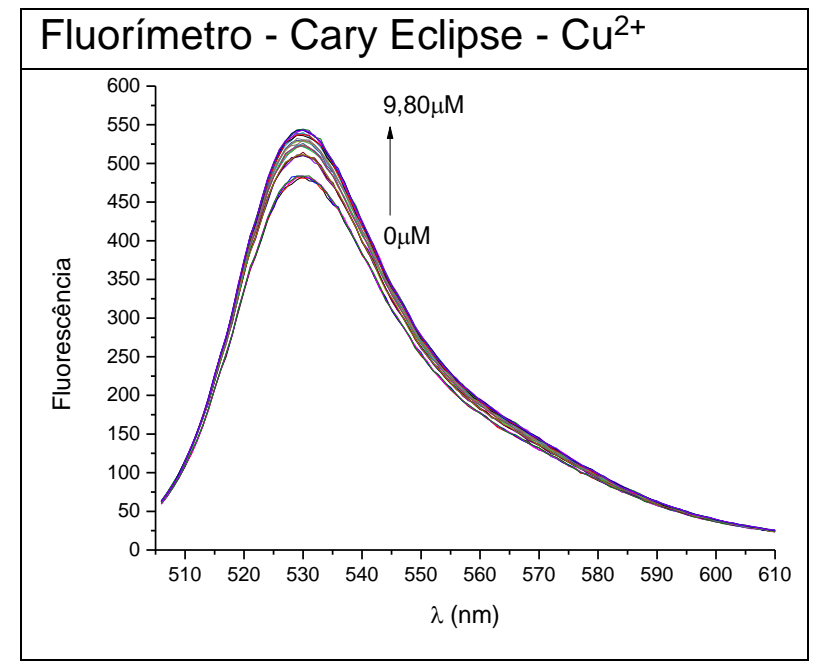

Figura 89 -Espectro de fluorescência do reagente fluoróforo de 2,7-Dichlorofluorescein sob interação com diferentes íons metálicos. a) $\mathrm{Pb}^{2+}$, b) $\mathrm{Ni}^{2+}$, c) $\mathrm{Cd}^{2+}, \mathrm{Zn}^{2+}$ e $\mathrm{Cu}^{2+}$.

Nos gráficos apresentados podem ser vistos acréscimos nas bandas de emissão fluorescente de pico máximo em $530 \mathrm{~nm}$ ( $\lambda_{\text {ex }}=505 \mathrm{~nm}$ ), quando a solução de 2,7Dichlorofluorescein foi submetida aos diferentes meios iônicos, sob análise.

$\mathrm{O}$ aumento na intensidade de fluorescência de 2,7-diclorofluoresceína sob interação preferencial com os íons de $\mathrm{Cd}^{2+}$ pode ser explicado com base nos mecanismos de transferência de elétrons fotoinduzidos (PET) (VALEUR, 2001).

Para melhor representação e análise comparativa entre as sensibilidades dos íons metálicos, os gráficos foram plotados com base nas intensidades fluorescentes no comprimento de onda de $525 \mathrm{~nm}$ lidas no fluorímetro, uma vez que neste comprimento de onda há uma saída correspondente no sensor multiespectral MMCS6CS 
(fotodetector de $525 \mathrm{~nm}$ ). Os sinais desta saída foram utilizados para a obtenção dos gráficos de respostas pelas medidas de amplitude ( $\mathrm{V}_{\mathrm{RMS}}$ ) e fase (graus), conforme as Equações 23 e 24:

$$
\text { Resposta }_{2,7 \text { Dichlorofluorescein }}=\frac{I_{0}-I}{I_{0}}
$$

Onde: $I_{0} \mathrm{e} /$ referem-se às tensões eficazes medidas do sinal emitido na ausência e presença dos íons metálicos, respectivamente.

$$
\text { Resposta }_{\text {fase (2,7 Dichlorofluorescein })}=\frac{\theta_{0}-\theta}{180}
$$

Onde: $\theta_{0}$ e $\theta$ referem-se às fases do sinal emitido na ausência e presença dos íons metálicos, respectivamente.

No caso das intensidades de valores de fluorescência lidos pelo fluorímetro, os gráficos de resposta normalizada utilizaram de maneira similar a Equação 23, sendo lo e I correspondentes às intensidades de fluorescência na ausência e presença dos íons metálicos. Desta forma, na Figura 90 são apresentadas as curvas de resposta de calibração, obtidas pelo fluorímetro, referentes às sensibilidades do 2,7Dichlorofluorescein na presença dos íons de $\mathrm{Pb}^{2+}, \mathrm{Ni}^{2+}, \mathrm{Cd}^{2+}, \mathrm{Zn}^{2+} \mathrm{e} \mathrm{Cu}^{2+}$, com suas respectivas curvas de aproximação exponencial. 


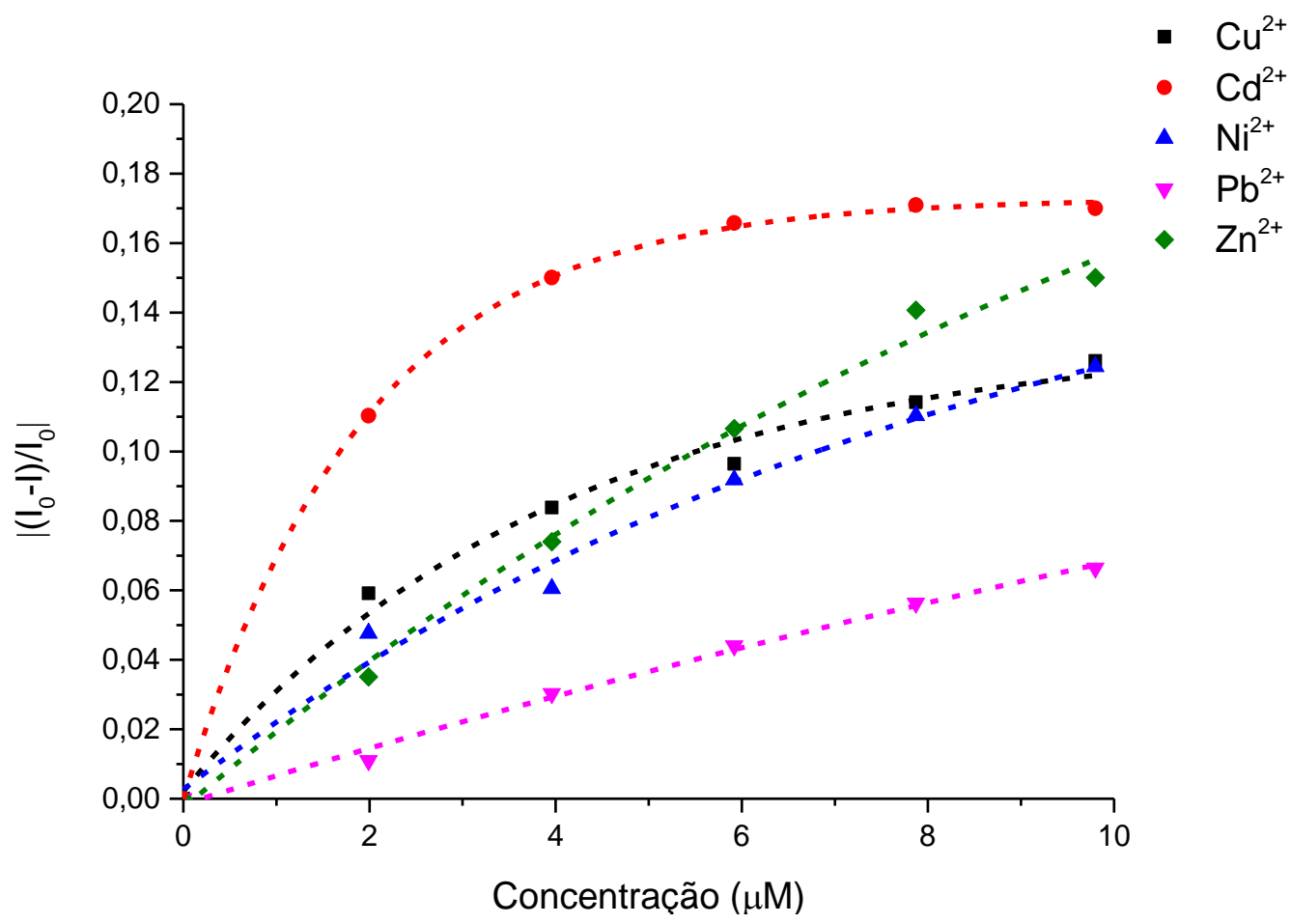

Figura 90 -Pontos experimentais das respostas de calibração com ajustes exponenciais obtidas pelo fluorímetro em diferentes concentrações de íons de metais pesados $\left(\mathrm{Pb}^{2+}, \mathrm{Ni}^{2+}\right.$, $\mathrm{Cd}^{2+}, \mathrm{Zn}^{2+} \mathrm{e} \mathrm{Cu}^{2+}$ ) sob interação com o reagente fluoróforo de 2,7-Dichlorofluorescein no comprimento de onda de $525 \mathrm{~nm}$. As curvas tracejadas correspondem ao ajuste por curvas exponenciais.

A Tabela 17 apresenta os parâmetros dos ajustes exponenciais das curvas de calibração de respostas obtidas pelo fluorímetro em diferentes concentrações de íons de metais pesados no comprimento de onda de $525 \mathrm{~nm}$.

Tabela 17 - Parâmetros dos ajustes exponenciais das curvas de calibração de respostas obtidas pelo fluorímetro em diferentes concentrações dos íons de metais pesados no comprimento de onda de $525 \mathrm{~nm}$.

\begin{tabular}{ccccccc}
\hline Equação & \multicolumn{5}{c}{$y=a+b * \exp \left({ }^{-x} / c\right)$} \\
\hline \multirow{4}{*}{ Valores } & & $\mathbf{P} \mathbf{P b}^{2+}$ & $\mathbf{N i}^{2+}$ & $\mathbf{C d}^{2+}$ & $\mathbf{Z n}^{2+}$ & $\mathbf{C u}^{2+}$ \\
& $\mathbf{b}$ & 0,23 & 0,18 & 0,17 & 0,30 & 0,13 \\
& $\mathbf{c}$ & $-0,23$ & $-0,18$ & $-0,17$ & $-0,30$ & $-0,13$ \\
& 27,46 & 8,83 & 1,95 & 13,27 & 4,022 \\
\hline
\end{tabular}


Na Figura 91 são apresentadas as curvas de resposta ( $\mathrm{V}_{\mathrm{RMS}}$ ) de sensibilidade do 2,7Dichlorofluorescein obtidas pelo sensor multiespectral MMCS6CS na presença dos íons de $\mathrm{Pb}^{2+}, \mathrm{Ni}^{2+}, \mathrm{Cd}^{2+}, \mathrm{Zn}^{2+}$ e $\mathrm{Cu}^{2+}$, com suas respectivas curvas de aproximação exponencial. O comportamento do parâmetro "c" mostra claramente que a molécula 2,7-Dichlorofluorescein é mais sensível aos íons de $\mathrm{Cd}^{2+}$.

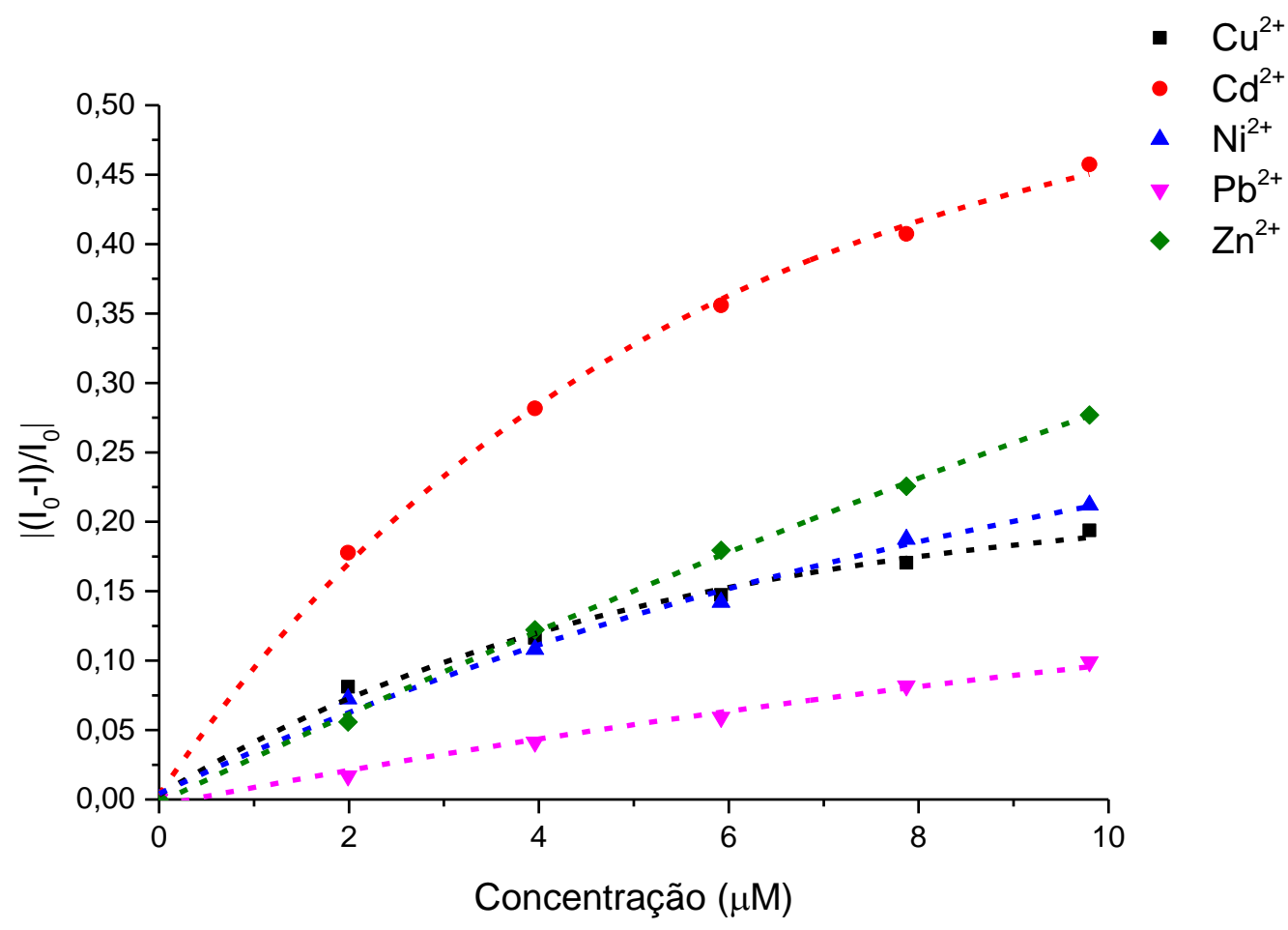

Figura 91 -Curvas de respostas de calibração ( $\left.\mathrm{V}_{\mathrm{RMS}}\right)$ com ajustes exponenciais obtidas pelo sensor multiespectral MMCS6CS em diferentes concentrações de ions de metais pesados $\left(\mathrm{Pb}^{2+}, \mathrm{Ni}^{2+}, \mathrm{Cd}^{2+}, \mathrm{Zn}^{2+} \mathrm{e} \mathrm{Cu}{ }^{2+}\right)$ sob interação com o reagente fluoróforo de 2,7-

Dichlorofluorescein no comprimento de onda de $525 \mathrm{~nm}$. As curvas tracejadas correspondem aos ajustes dos pontos experimentais com curvas exponenciais.

A Tabela 18 apresenta os parâmetros dos ajustes exponenciais das curvas de calibração (VRMS) de respostas obtidas pelo sensor multiespectral MMCS6CS em diferentes concentrações de íons de metais pesados no comprimento de onda de 525 $\mathrm{nm}$. Os resultados apresentados na Figura 91 mostram que seguem a mesma tendência das curvas de resposta obtidas no fluorímetro.

Tabela 18 - Parâmetros dos ajustes exponenciais das curvas de calibração ( $\left.V_{\mathrm{RMS}}\right)$ de respostas obtidas pelo sensor multiespectral MMCS6CS em diferentes concentrações dos íons de metais pesados no comprimento de onda de $525 \mathrm{~nm}$.

\begin{tabular}{lllllll}
\hline Equação & \multicolumn{5}{c}{$y=a+b * \exp \left({ }^{-x} / c\right)$} \\
\hline & & $\mathbf{P b}^{2+}$ & $\mathbf{N i}^{2+}$ & $\mathbf{C d}^{2+}$ & $\mathbf{Z n}^{2+}$ & $\mathbf{C u}^{2+}$ \\
Valores & $\mathbf{a}$ & 0,22 & 0,35 & 0,53 & 1,10 & 0,22 \\
& $\mathbf{b}$ & $-0,22$ & $-0,35$ & $-0,53$ & $-1,10$ & $-0,22$ \\
& $\mathbf{C}$ & 16,62 & 10,89 & 5,28 & 33,41 & 5,25 \\
\hline
\end{tabular}


Na Figura 92 são apresentadas as curvas de resposta (fase) de sensibilidade do 2,7Dichlorofluorescein obtidas pelo sensor multiespectral MMCS6CS na presença dos íons de $\mathrm{Pb}^{2+}, \mathrm{Ni}^{2+}, \mathrm{Cd}^{2+}, \mathrm{Zn}^{2+}$ e $\mathrm{Cu}^{2+}$, com suas respectivas curvas de aproximação exponencial.

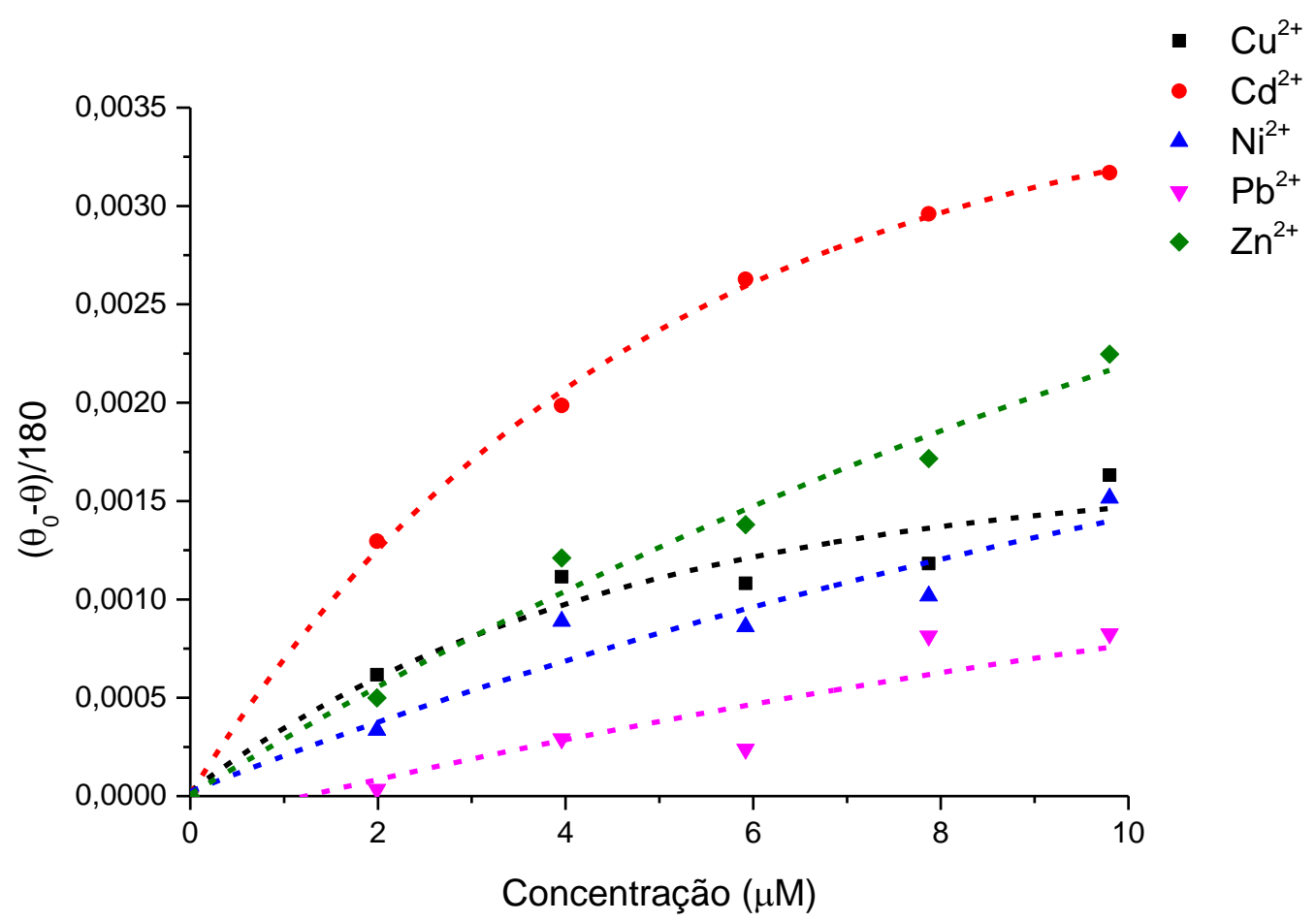

Figura 92 -Curvas de respostas de calibração (fase) com ajustes exponenciais obtidas pelo sensor multiespectral MMCS6CS em diferentes concentrações de íons de metais pesados $\left(\mathrm{Pb}^{2+}, \mathrm{Ni}^{2+}, \mathrm{Cd}^{2+}, \mathrm{Zn}^{2+} \mathrm{e} \mathrm{Cu}^{2+}\right)$ sob interação com o reagente fluoróforo de 2,7Dichlorofluorescein no comprimento de onda de $525 \mathrm{~nm}$.

A Tabela 19 apresenta os parâmetros dos ajustes exponenciais das curvas de calibração (fase) de respostas obtidas pelo sensor multiespectral MMCS6CS em diferentes concentrações de íons de metais pesados no comprimento de onda de 525 $\mathrm{nm}$. Similarmente estas curvas mostram a mesma tendência observada nos procedimentos anteriores.

Tabela 19 - Parâmetros dos ajustes exponenciais das curvas de calibração (fase) de respostas obtidas pelo sensor multiespectral MMCS6CS em diferentes concentrações dos íons de metais pesados no comprimento de onda de $525 \mathrm{~nm}$.

\begin{tabular}{ccccccc}
\hline Equação & \multicolumn{5}{c}{$y=a+b * \exp (-x / c)$} \\
\hline & & $\mathbf{P b}^{2+}$ & $\mathbf{N i}^{2+}$ & $\mathbf{C d}^{2+}$ & $\mathbf{Z n} \mathbf{2}^{2+}$ & $\mathbf{C u}^{2+}$ \\
Valores & $\mathbf{a}$ & 0,0019 & 0,0030 & 0,0037 & 0,0049 & 0,0017 \\
& $\mathbf{b}$ & $-0,00207$ & $-0,003$ & $-0,00364$ & $-0,00488$ & $-0,0016$ \\
& $\mathbf{C}$ & 17,21 & 15,99 & 4,79 & 16,80 & 4,55 \\
\hline
\end{tabular}


A literatura reporta que as moléculas de TBHPP e 2,7-Dichlorofluorescein, efetivamente mostram serem mais sensíveis aos íons de $\mathrm{Pb}^{2+} \mathrm{e} \mathrm{Cd}^{2+}$, respectivamente (BOZKURT; AYATA; KAYNAK, 2009; GOSWANI; BARUAH; DAS, 2010), resultados completamente equivalentes aos obtidos no fluorímetro e pelo sistema proposto MMCS6CS. Os resultados reportados na literatura e os nossos apontam que a detecção dos íons de $\mathrm{Pb}^{2+}$ e $\mathrm{Cd}^{2+}$, utilizando-se as moléculas de TBHPP e 2,7Dichlorofluorescein, não é seletiva, já que estas moléculas também são sensíveis a outros íons como ao $\mathrm{Ni}^{2+}, \mathrm{Zn}^{2+}$ e $\mathrm{Cu}^{2}$, respectivamente. Neste caso, será necessária a formulação de novas estratégias no preparo das amostras ou mudanças estruturais das moléculas corantes, assuntos que estão fora do escopo do presente trabalho, cuja principal contribuição está direcionada na instrumentação portátil para aplicação em sistemas colorimétricos e fluorimétricos.

\subsection{Conclusões}

Nesta parte do trabalho foi projetado e fabricado um sistema optoeletrônico portátil colorimétrico e fluorimétrico, utilizando-se como detector um sistema multiespectral, constituído de seis fotodetectores com respostas em 6 (seis) diferentes comprimentos de onda da luz. Os resultados de colorimetria obtidos com o sistema proposto mostraram o mesmo nível de seletividade e sensibilidade daquelas obtidas em um espectrômetro convencional de bancada, de elevada precisão espectral. A detecção e classificação de íons de $\mathrm{Pb}^{2+}, \mathrm{Cd}^{2+}, \mathrm{Zn}^{2+}, \mathrm{Cu}^{2+}, \mathrm{Fe}^{3+}$ e $\mathrm{Ni}^{2+}$ com o sistema proposto foi equivalente ao obtido com o espectrômetro de bancada, embora o sistema proposto esteja constituído apenas com um sistema de detecção multiespectral discreto. O poder de classificação e detecção pelo sistema portátil proposto dos íons metálicos mencionados anteriormente, foi obtido através da proposta da metodologia de análises de discriminante linear de Fisher, aplicada aos parâmetros quantitativos da cromaticidade xyY, correspondente à resposta do sistema aos diferentes íons analisados. Finalmente, a característica flexível do sistema portátil permitiu obter medidas de fluorescência de corantes aplicadas na detecção de íons metálicos com o mesmo desempenho que ao obtido em um fluorímetro de bancada. Em resumo, o sistema colorimétrico e fluorimétrico portátil junto com o processamento de sinais e 
métodos de classificação de discriminante linear de Fisher substitui satisfatoriamente a dois equipamentos de bancada (espectrômetro absorção e fluorímetro), caros e complexos, adicionalmente a portabilidade que o sistema poderá permitir no monitoramento de íons metálicos em sistemas hidrográficos como rios, lagoas, mares e estuários, sendo possível realizar este monitoramento in-situ e em tempo real, comunicando e transmitindo informações a centros de controle ambiental.

\subsection{Referências}

BROWN, M.T.; WICKER, L.R. Discriminant analysis, Chap. 8. In: TINSLEY, H. E. A.; BROWN, S, D. (Eds). Handbook of applied multivariate statistics and mathematical modelin. San Diego: Academic Press, p. 209-234, 2000.

ABOLHASANI, J.; BEHBAHANI, M. Application of 1-(2-pyridylazo)-2-naphtholmodified nanoporous silica as a technique in simultaneous trace monitoring and removal of toxic heavy metals in food and water samples. Environ Monit Assess, v. 187:4176, 2015.

BOZKURT, S. S.; AYATA, S.; KAYNAK, I. Fluorescence-based sensor for $\mathrm{Pb}$ (II) using tetra-(3-bromo-4-hydroxyphenyl)porphyrin in liquid and immobilized medium. Spectrochimica Acta Part A, v. 72, p. 880-883, 2009.

CHENG, K. L.; BRAY, R. H. 1-(2-Pyridylazo)-2-naphthol as Possible Analytical Reagent. Anal. Chem., v. 27 (5), pp. 782-785, 1955.

D'AMICO, A. et al. Low-voltage low-power integrated analog lock-in amplifier for gas sensor applications. Sensors and Actuators B, v. 144, pp. 400-406, 2010.

DITTRICH, P.-G et al. Mobile micro-colorimeter and micro-spectrometer sensor modules as enablers for the replacement of subjective inspections by objective measurements for optically clear colored liquids in-field. Proc. of. SPI-IS\&T Electronic Imaging, v. 9411, 2015. doi: 10.1117/12.2075089.

FU, S. et al. Generalized lock-in amplifier for precision measurement of high frequency signals, Review of Scientific Instruments, v. 84, 115101, 2013. 
FUWA, K.; VALLEE, B. The Physical Basis Absorption Spectrometry of Analytical Atomic. Analytical Chemistry, v. 35, n. 8, pp. 942-946, 1963.

GOSWAMI, P.; BARUAH, S.; DAS, D. K. 2,7-Dichlorofluorescein, a fluorescent sensor to detect $\mathrm{Cd}^{2+}$ over $\mathrm{Na}^{+}, \mathrm{K}^{+}, \mathrm{Ca}^{2+}, \mathrm{Cu}^{2+}, \mathrm{Ni}^{2+}$ and $\mathrm{Zn}^{2+}$. Indian Journal of Chemistry, $\mathrm{v}$. 49a, pp. 1617-1620, 2010.

$\mathrm{HU}$, Z. et al. An integrated microspectrometer for localized multiplexing measurements. Lab Chip, v. 15, pp. 283-289, 2015.

HUSSAIN K. M.; ZEPHERIN, R. A. R. Control and Interfacing of Motors With NILabView Using NI-MYRIO. International Journal for Innovative Research in Science \& Technology, v. 1, Issue 8, 2015.

ISLAM, A.; LASKAR, A.; AHMAD, A. Characterization and Application of 1-(2Pyridylazo)-2-naphthol Functionalized Amberlite XAD-4 for Preconcentration of Trace Metal lons in Real Matrices. J. Chem. Eng. Data, v. 55, p. 5553-5561, 2010.

IWAI, D. et al. Availability of color calibration for consistent color display in medical images and optimization of reference brightness for clinical use. Proceedings of SPIE, v. 8673, 867310-1, doi: 10.1117/12.2007169, 2013.

JÄRUP, L. Hazards of heavy metal contamination. British Medical Bulletin, v. 68, pp. 167-182, 2003.

KIM, Ji-Sun et al. Simple LED spectrophotometer for analysis of color information. BioMedical Materials and Engineering, v. 26, pp.1773-1780, 2015.

MALIK, A. K. et al. Column Preconcentration and Spectrophotometric Determination of Ziram and Zineb in Commercial Samples and Foodstuffs Using 1-(2-Pyridylazo)-2naphthol (PAN)-Naphthalene as Adsorbate. J. Agric. Food Chem., v. 52, p. 7763-7767, 2004.

MAZET GmbH, 6-Channel Multiple Color Sensor - LCC10 - MMCS6CS (Data sheet), v. 6.0, n. 1, 2013a.

MAZET GmbH, Multi-channel Programmable Gain Transimpedance Amplifier MTI04CS/MTI04CQ (Data sheet), v. 2.2, n. 1, $2013 \mathrm{~b}$. 
MCLACHLAN, G. J. Discriminant Analysis and Statistical Pattern Recognition. Wiley Interscience. ISBN 0-471-69115-1, 2004.

PINHEIRO, S. C. L. et al. Simultaneous determination of copper, mercury and zinc in water with a tailored fluorescent bipyridine ligand entrapped in silica sol-gel. Anal Bioanal Chem v. 398, p. 3127-3138, 2010.

PRESTEL, H.; GAHR A.; NIESSNER, R. Detection of heavy metals in water by fluorescence spectroscopy: On the way to a suitable sensor system. Fresenius $\mathrm{J}$ Anal Chem., v. 368, p. 182-191, 2000.

SANTOS, D. S. Sistema de aquisição de sinais e geração de imagens químicas para sensores LAPS baseado em Dispositivos Lógicos Programáveis FPGA. 2014. 92p. Dissertação (Mestrado). Escola Politécnica da Universidade de São Paulo. São Paulo. 2014.

SANTOS, L. F.; PEREIRA, C. J. Composição de cores através da calibração radiométrica e fotométrica de LEDs: Teoria e experimento. Revista Brasileira de Ensino de Física, v. 35, n. 2, p. 2314, 2013.

SMITH, T.; GUILD, J. The C.I.E. Colorimetric Standards and their Use. Transactions of the Optical Society, v. 33, n. 3, p. 73, 1932.

SRIJARANAI, S. et al. Use of 1-(2-pyridylazo)-2-naphthol as the post column reagent for ion exchange chromatography of heavy metals in environmental samples. Microchemical Journal, v. 99, p. 152-158, 2011.

THARAKESWAR, Y. et al. Optical Chemical Sensor for Screening Cadmium(II) in Natural Waters. Journal of Sensor Technology, v. 2, pp. 68-74, 2012.

UDB1203S, Direct Digital Synthesis (DDS) Signal Generator, v. 1, 2012.

VALEUR, B. Molecular Fluorescence - Principles and Applications. Wiley-VCH Verlag GmbH, ISBNs: 3-527-29919-X, 2001. 


\section{Capítulo 6}

\section{Sensor Óptico Multiespectral Integrado para Detecção de $\mathrm{O}_{2}$ e $\mathrm{NO}_{2}$}

\subsection{Introdução}

O monitoramento de oxigênio $\left(\mathrm{O}_{2}\right)$ e do dióxido de nitrogênio $\left(\mathrm{NO}_{2}\right)$ por sensoriamento óptico (Jl et al., 2009; MONDAL; KUMAR, 2014) tem atraído grande interesse como alternativa aos tradicionais métodos empregados nas aplicações de monitoramento e controle ambiental. Várias técnicas têm sido empregadas: para detecção de $\mathrm{NO}_{2}$, sensores baseados em estruturas MOS (Metal-Óxido-semicondutor) (FILIPPINI; LUNDSTRÖM, 2003), óxido de estanho (SnO) (SUMAN et al., 2013), nanofibras híbridas de $\mathrm{SnO}_{2}-\mathrm{ZnO}$ (PARK et al., 2010) e detecção de O2: óxido de zircônia (CHEN; CHANG, 2012), tipo Clark (WU et al, 2005). Porém, e em geral, os sensores baseados em resposta elétrica e eletroquímica apresentam tempos de resposta elevados e degradação rápida (WU et al, 2005).

A necessidade do monitoramento destes gases no ambiente é importante uma vez que a presença de altas taxas de óxidos de nitrogênio (acima de 5 ppm para $\mathrm{NO}_{2}$ ) pode promover reações com outros compostos químicos, presentes na atmosfera, produzindo compostos nocivos à saúde e ao meio ambiente (VALLERO, 2014). Da mesma forma, o monitoramento do oxigênio é imprescindível devido ao oxigênio ser fonte principal para a existência de vida tanto em ambiente gasoso ou aquoso.

Neste capítulo reportamos a resposta de sensibilidade de um dispositivo portátil optoeletrônico multiespectral comercial com membrana ativa integrada ao dispositivo, para detecção de $\mathrm{O}_{2}$ e $\mathrm{NO}_{2}$ em ambiente inerte de nitrogênio, quando funcionalizado com moléculas corantes de octaetilporfirina de platina, imobilizada em matriz hospedeira de PVC. Esta estratégia permitiu obter medições de duas diferentes faixas de concentrações de $\mathrm{O}_{2}$ e $\mathrm{NO}_{2}$ para o mesmo dispositivo, além de integrar a parte ativa do sensor com o detector da emissão fotoluminescente visando à fabricação de um sistema de sensoriamento portátil. 


\subsection{Procedimentos Experimentais}

Nesta seção são apresentados os materiais, procedimentos para a fabricação do sensor óptico multiespectral integrado para detecção de $\mathrm{O}_{2}$ e $\mathrm{NO}_{2}$ e a metodologia de ensaios para caracterização dos dispositivos em diferentes concentrações de $\mathrm{O}_{2} \mathrm{e}$ $\mathrm{NO}_{2}$.

\subsubsection{Sistema de Detecção de $\mathrm{O}_{2}$ e $\mathrm{NO}_{2}$ e Fabricação do Sensor Multiespectral com Membrana de PtOEP imobilizada em PVC}

O sistema produzido no presente capítulo utiliza como elemento fotodetector um dispositivo optoeletrônico, descrito na seção 5.2.1.1. O circuito integrado é composto por conjunto de 18 fotodiodos $(3 \times 6)$ encapsulados em um mesmo invólucro, tipo MMCS6CS, fabricado pela empresa MAZeT. Neste dispositivo há três grupos de 6 fotodiodos seccionados simetricamente em uma estrutura circular de $2 \mathrm{~mm}$ de diâmetro. Para cada fotodiodo há um filtro espectral dielétrico que seleciona o comprimento de onda específico a ser detectado. A faixa espectral sensível dos fotodiodos está sintonizada entre $380 \mathrm{~nm}$ a $780 \mathrm{~nm}$, tendo como picos máximos valores de 425, 475, 525, 575, 625, $675 \mathrm{~nm}$ e sem filtro (PW). Os fotodiodos são conectados diretamente em 7 (sete) dos 16 (dezesseis) canais do módulo amplificador de transimpedância com ganho programável, descrito na seção 5.2.1.2. O módulo é composto por amplificadores de transimpedância (seção 5.2.1.2) integrados de 4 canais e ganhos programáveis, tipo MTI04CS, fabricado pela MAZeT. A seleção dos ganhos é realizada pela combinação binária de 3 bits de entrada no circuito integrado MTI04CS e permite até 8 estágios diferentes de amplificação. Após a etapa de amplificação, os sinais dos fotodiodos são selecionados pelo multiplexador (seção 5.2.1.3) e direcionados ao $L O C K$-IN para extração dos parâmetros de intensidade luminosa e Fase pelas medidas de Tensão Eficaz ( $V_{\text {RMS }}$ ) e defasagem (graus), respectivamente. Como fonte luminosa para excitação dos sensores foi utilizado um diodo UV-LED (1,3 mW, $\lambda=377 \mathrm{~nm})$, fabricado pela empresa Lumex. O sinal recebido pelo UV-LED provém de um gerador de sinais de forma de onda senoidal, modelo 
SG1003, acoplado a um circuito de condicionamento e elevação de nível de tensão DC (seção 5.2.1.4). A aquisição, controle e processamento dos sinais são realizados com base em tecnologia FPGA, tendo como ambiente de desenvolvimento a utilização de softwares baseados em instrumentação virtual ( $\mathrm{NI}$ LabView( $\left.{ }^{\circledR}\right)$, fabricado pela National Instruments, modelo NI myRIO-1900. O sistema utiliza um dos quatro sensores da matriz de dispositivos MMCS6CS, associado a instrumentação disponível para armazenamento dos sinais de intensidade $V_{\text {RMS }}$ e fase a serem processadas pelo LOCK-IN. A Figura 93 mostra o diagrama esquemático de ligação do sistema de detecção de $\mathrm{O}_{2}$ e $\mathrm{NO}_{2}$.

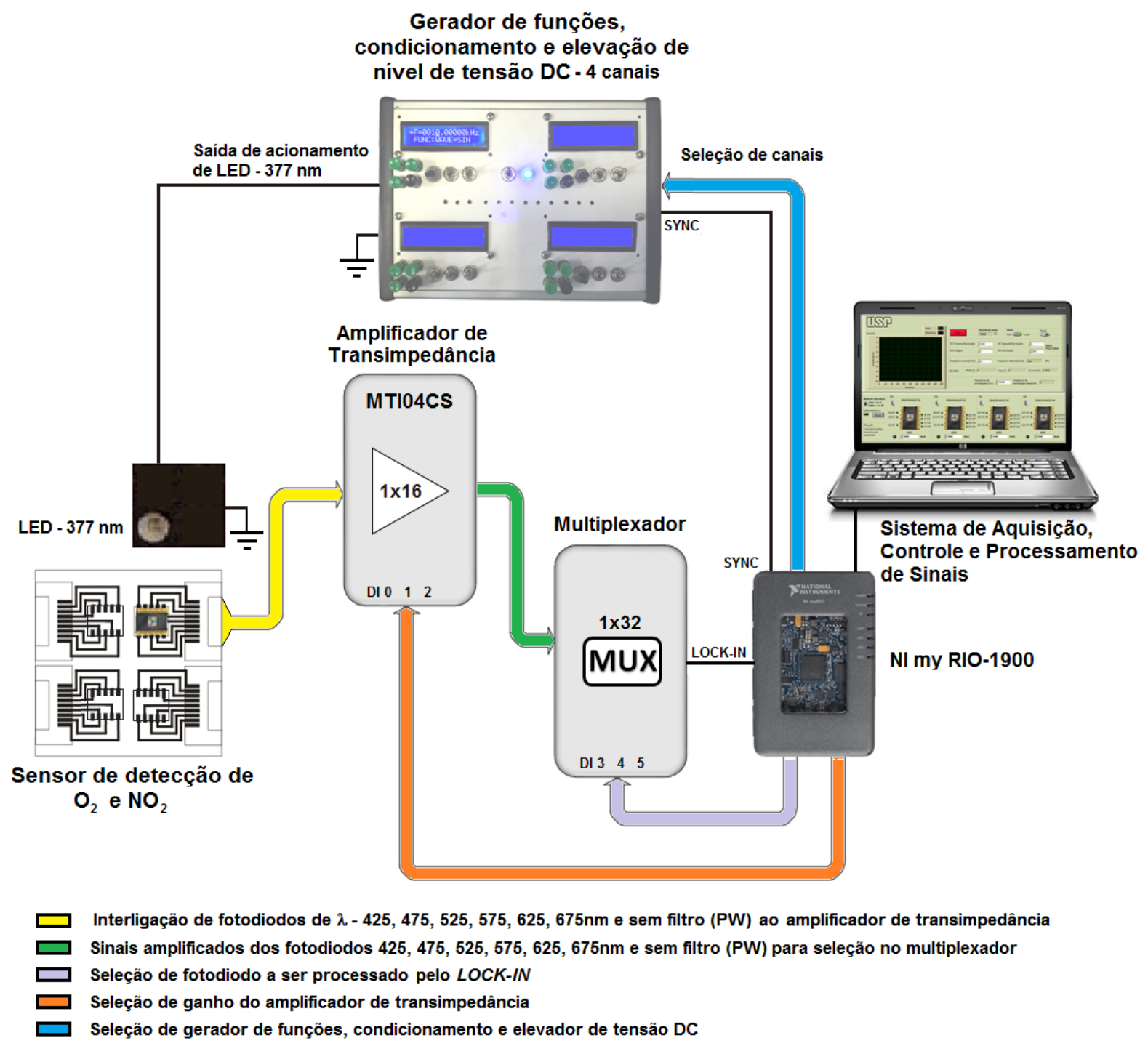

Figura 93 -Diagrama de ligação do sistema de detecção de $\mathrm{O}_{2}$ e $\mathrm{NO}_{2}$ com base em dispositivo óptico MMCS6CS para medidas de intensidade luminosa $\left(\mathrm{V}_{\mathrm{RMS}}\right)$ e fase (graus) realizadas por aplicativo LOCK-IN desenvolvido em placa de aquisição embarcada NI myRIO-1900.

O sensor óptico para detectar $\mathrm{O}_{2}$ e $\mathrm{NO}_{2}$ foi fabricado a partir de um fotodetector comercial MAZeT. Para este fim, foi depositada por gotejamento sobre a superfície 
ativa do fotodetector uma membrana de PVC, dopada com moléculas sensíveis de Octaetilporfirina de Platina (PtOEP). No preparo da solução, utilizada para a formação da membrana ativa do sensor, realizou-se a diluição de 2,2 mg de PtOEP e $75 \mathrm{mg}$ de PVC em $1,5 \mathrm{ml}$ de THF $\left(2,0.10^{-3} \mu \mathrm{M}\right)$ com $82 \mu \mathrm{l}$ de Bis(2-ethylhexyl) sebacate (DOS). Na sequência, a solução da mistura foi colocada em recipiente fechado e submetido a uma agitação mecânica por ultrassom para homogeneização e diluição completa da solução por 30 min.

A seguir, um volume de $4 \mu \mathrm{l}$ do composto foi gotejada diretamente no lado superior do encapsulamento sobre a pequena janela de vidro de proteção do arranjo dos fotodiodos. Para secagem do filme, o dispositivo foi inserido em forno térmico a vácuo em temperatura de $60 \stackrel{\circ}{\mathrm{C}}$ por $2 \mathrm{~h}$. A Figura 94 mostra detalhes do filme formado sobre o dispositivo.
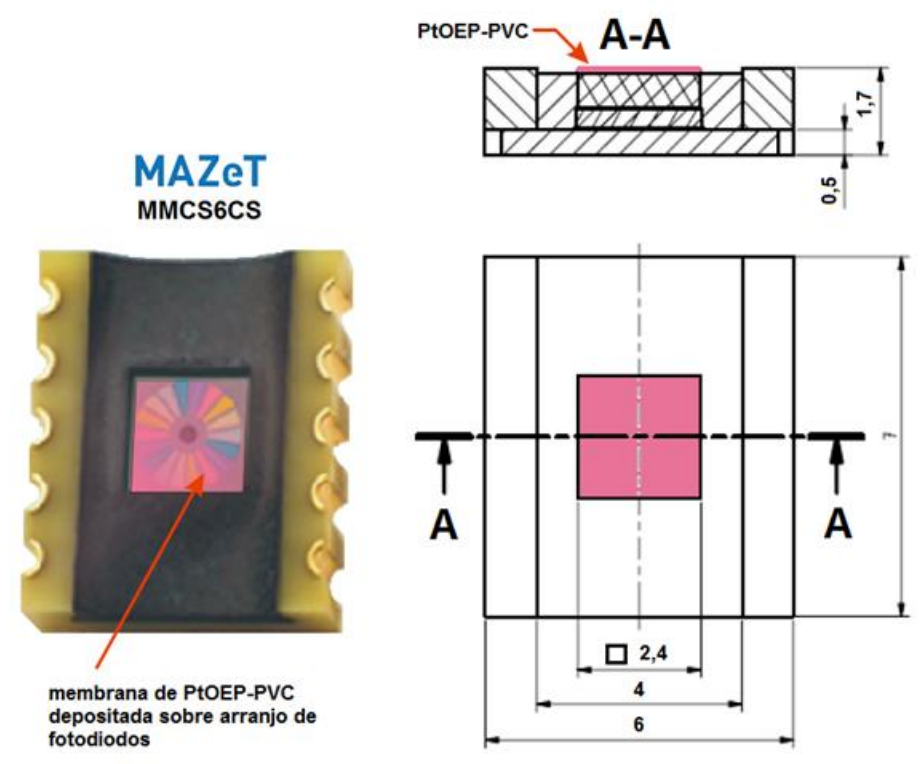

Figura 94 -Perfil de deposição de membrana ativa de PtOEP imobilizada em matriz hospedeira de policloreto de vinila (PVC).

\subsubsection{Sistema de diluição dos gases de $\mathrm{O}_{2}$ e $\mathrm{NO}_{2}$ em N2 para ensaios de sensibilidade}

Nos ensaios de sensibilidade do sensor MAZeT/PVC(PtOEP) para ambientes com diferentes concentrações de oxigênio e dióxido de nitrogênio em nitrogênio utilizou-se um arranjo semelhante ao utilizado em Braga et al., 2014 contendo três controladores 
de fluxos MFC-1, MFC-2 e MFC-3 da marca MKS Instruments Type 1179 A, alimentados por cilindros de $\mathrm{N}_{2}\left(99,999 \%\right.$ de pureza), $\mathrm{O}_{2}$ (99,999\% de pureza) e $\mathrm{NO}_{2}$ (140 ppm ou $0,014 \%$ de $\mathrm{NO}_{2}$ em $\mathrm{N}_{2}$ ).

Para o controle e temporização do sistema de diluição de $\mathrm{O}_{2}$ e $\mathrm{NO}_{2}$ em N $\mathrm{N}_{2}$ foi uma ferramenta semelhante àquela utilizada na seção 2.2.3, desenvolvida em ambiente LabView® com uso de placa de aquisição mod. NI-6009. Os valores de setpoint de cada um dos controladores para se obter uma determinada concentração foram enviados por saídas analógicas (AO1-3) situadas na placa de aquisição. Os sinais de vazões correspondentes foram fornecidos pelos controladores MFC-1, MFC-2 e MFC3 e conectados eletricamente em três entradas analógicas (Al1-3) para monitoramento contínuo durante os ensaios. A Figura 95 mostra o diagrama esquemático do sistema utilizado para a obtenção de diferentes concentrações de $\mathrm{O}_{2}$ e $\mathrm{NO}_{2}$. Todo o processo de controle de vazão e diluição dos gases é realizado simultaneamente ao sistema de detecção $\mathrm{O}_{2}$ e $\mathrm{NO}_{2}$, onde, além de ser formado pelo sensor MAZeT, também o é pelos módulos de tratamento e condicionamento de sinais (gerador de função, condicionamento e elevação de nível de tensão DC, amplificador de transimpedância e multiplexador) e NI-myRIO 1900.

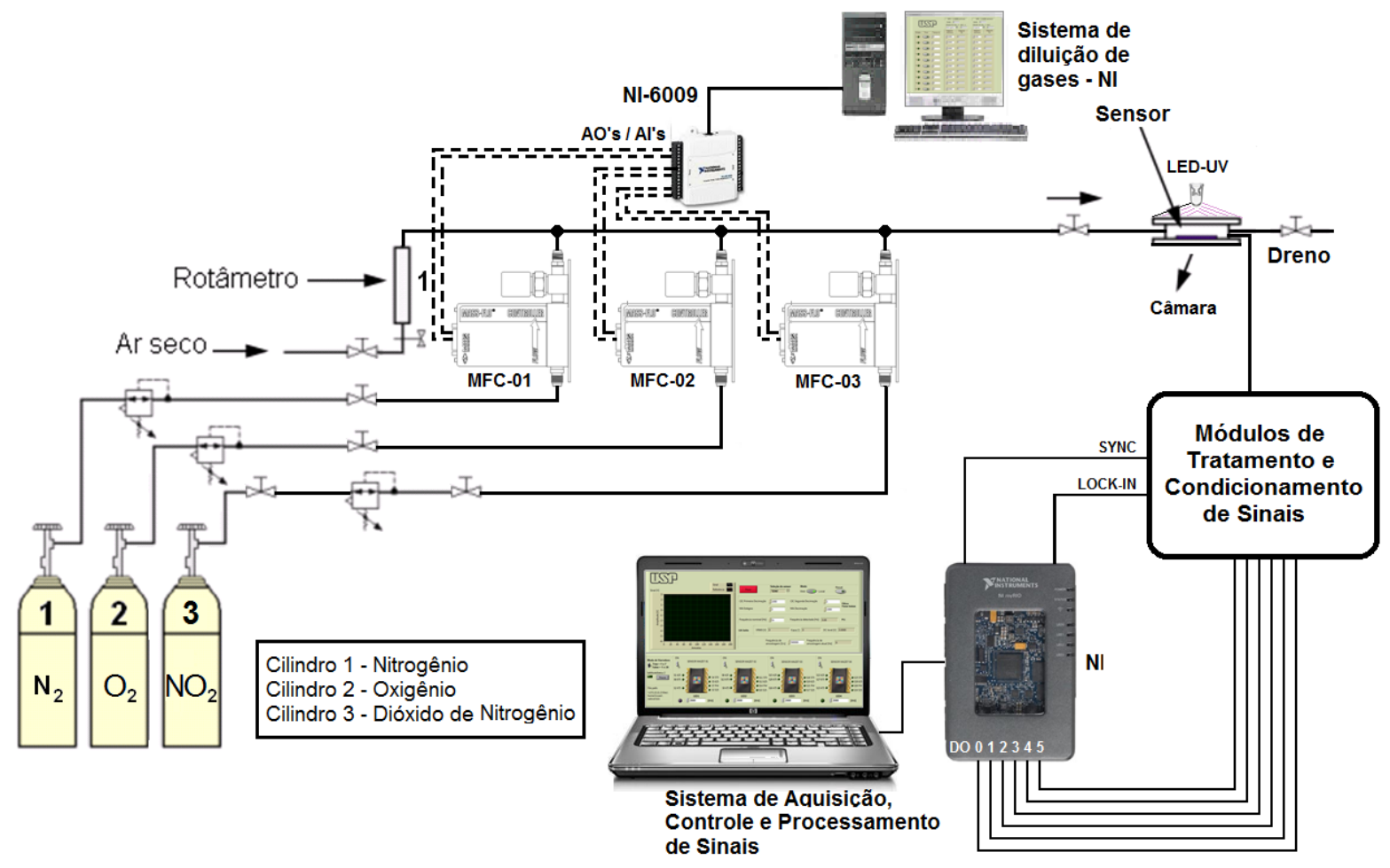

Figura 95 -Diagrama esquemático do arranjo do sistema de diluição de gases de $\mathrm{O}_{2}$ e $\mathrm{NO}_{2}$ e do sistema de aquisição, controle e processamento de sinais provenientes do sensor multiespectral (MMCS6CS). 
Os ensaios foram feitos com os dispositivos no interior de uma câmara de aço inox com uma janela de vidro polido para entrada da luz. A escolha do comprimento de onda $(\lambda)$ da luz de excitação sobre a molécula teve como referência a análise da resposta fotoluminescente obtida pelo espectrofotômetro de fluorescência, mostrada na seção 2.3.1.

\subsection{Resultados e Discussões}

\subsubsection{Análise de Resposta de Sensibilidade do Sensor Multiespectral MAZeT/PVC(PtOEP) na Presença de $\mathrm{O}_{2}$ e $\mathrm{NO}_{2}$ em $\mathrm{N}_{2}$}

A resposta do sensor está baseada na mudança da emissão fotoluminescente ("quenching") das moléculas de PtOEP contidas na membrana de PVC que foi integrada diretamente sobre superfície ativa do fotodetector. Os ensaios de sensibilidade do sensor na presença de $\mathrm{O}_{2}$ e $\mathrm{NO}_{2}$ em $\mathrm{N}_{2}$ foram realizados seguindo os procedimentos e métodos relatados anteriormente. Para ambas as análises dos gases, a vazão foi mantida constante em $500 \mathrm{ml} / \mathrm{min}$ e o sensor excitado por uma fonte de luz (LED) com comprimento de onda de $377 \mathrm{~nm}$. As intensidades de emissão fotoluminescente das moléculas ativas foram transformadas em sinais elétricos pelo fotodetector. Os sinais elétricos assim obtidos foram previamente processados num sistema LOCK-IN, descrito na seção 5.2.1.5, onde foram fornecidas saídas em valores $V_{\text {RMS }}$ ou fase (em relação a uma referência). Os valores $V_{\text {RMS }}$ são diretamente proporcionais aos valores de intensidade da emissão fotoluminescente, já os valores de fase estão relacionados com a mudança de tempo de vida da emissão fotoluminescente das moléculas de PtOEP. Assim, a resposta do sensor pôde ser monitorada através da mudança da intensidade fotoluminescente ou pela mudança do tempo de vida desta emissão.

Para melhor representação e análise comparativa entre as sensibilidades dos gases, os gráficos foram plotados com base nos sinais obtidos pelo sistema de amplificação LOCK-IN, extraídos pelos 07 terminais de saídas do fotodetector MAZeT que correspondem às respostas dos fotodiodos com os filtros ópticos de 425, 475, 525, 
575, 625, 675nm e PW (sem filtro), respectivamente. As respostas do sensor para medidas de amplitude ( $V_{\text {RMS }}$ ) e fase (graus) foram definidas, conforme as Equações 25 e 26 :

$$
\text { Resposta }_{\text {amplitude }}=\frac{I_{0}-I}{I_{0}}
$$

Onde: $I_{0} \mathrm{e} /$ referem-se às tensões eficazes medidas do sinal emitido na ausência e presença de $\mathrm{O}_{2}$ ou $\mathrm{NO}_{2}$, respectivamente.

$$
\text { Resposta }_{\text {fase }}=\frac{\theta_{0}-\theta}{180}
$$

Onde: $\theta_{0}$ e $\theta$ referem-se às fases do sinal emitido na ausência e presença de $\mathrm{O}_{2}$ ou $\mathrm{NO}_{2}$, respectivamente.

As respostas do sensor, devido às mudanças na tensão eficaz e fase relacionadas com as mudanças da emissão fotoluminescente e tempo de vida (das moléculas de PtOEP) pela presença do oxigênio e do dióxido de nitrogênio, são mostradas na Figura 96 e na Figura 97.

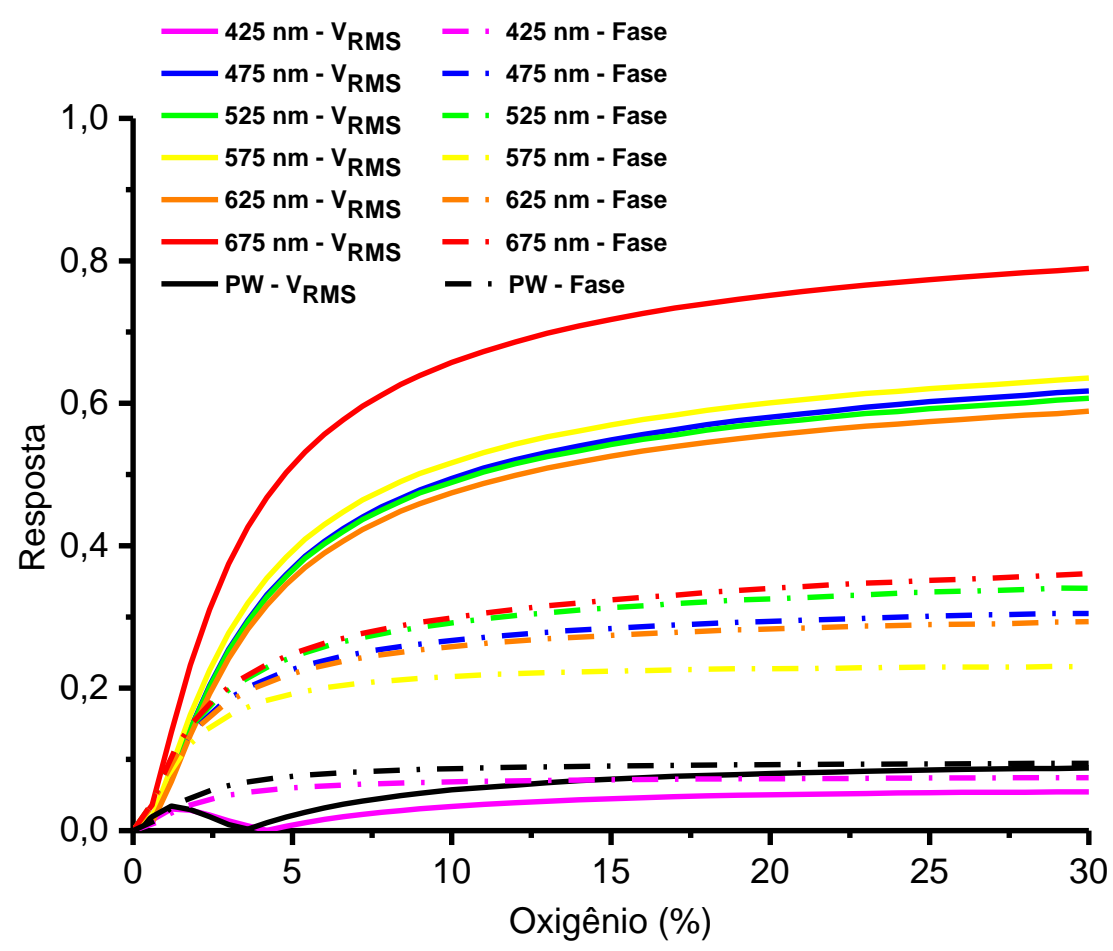

Figura 96 -Curvas de respostas normalizadas do filme ativo de PtOEP imobilizado em matriz hospedeira de policloreto de vinila (PVC) depositados sobre dispositivo multiespectral (MMCS6CS) em diferentes concentrações de oxigênio em nitrogênio. 


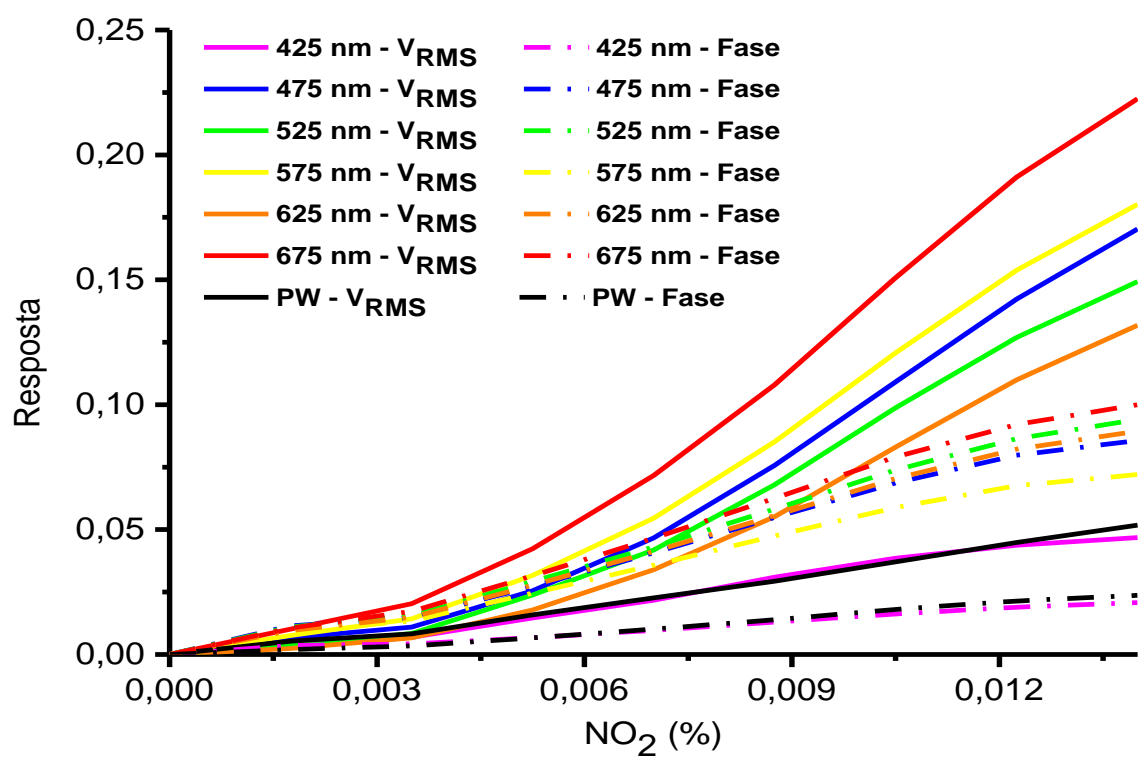

Figura 97 -Curvas de respostas normalizadas do filme ativo de PtOEP imobilizado em matriz hospedeira de policloreto de vinila (PVC) depositados sobre dispositivo multiespectral

(MMCS6CS) em diferentes concentrações de dióxido de nitrogênio em nitrogênio.

As curvas de resposta de intensidade (VRMS) e fase (graus) da emissão fotoluminescente obtidas pelo sensor MAZeT na presença de concentrações entre 0 e 30\% de oxigênio (Figura 96) e 0 a 140 ppm (0,014\% de $\mathrm{NO}_{2}$ em $\mathrm{N}_{2}$ ) (Figura 97) mostram que o sensor apresenta uma resposta não linear em ambos os casos, sendo mais sensível para $\mathrm{NO}_{2}$. A resposta do sensor está diretamente ligada ao elevado tempo de vida do estado excitado triplete da molécula PtOEP, permitindo a interação com oxigênio ou dióxido de nitrogênio que suprime a emissão fosforescente (KOSE, 2005; LEE; OKURA, 1997).

A interação dos gases, acima mencionados, com o estado triplete da molécula de PtOEP promove a supressão da emissão fotoluminescente, cuja intensidade é medida em nosso caso pelo $V_{\text {RMS }}$ do sinal pré-processado. Em adição à interação gasesPtOEP também muda o tempo de vida da emissão fotoluminescente (MCDONAGH et al., 2001) e esta mudança foi monitorada pela medida de mudança de fase do sinal de saída do sensor. Assim, com um sinal senoidal de excitação proveniente do LED de comprimento de onda de $377 \mathrm{~nm}$, foi promovida uma emissão fotoluminescente modulada à mesma frequência, porém com um deslocamento no tempo em relação ao sinal de excitação, isto é, o sinal elétrico que alimenta o diodo LED de excitação foi utilizado como referência e comparada com o sinal pré-processado da resposta do sensor.

Como descrito anteriormente, o sensor está constituído de uma matriz de fotodiodos (integrados no chip) com filtros para diferentes comprimentos de onda. Assim, a 
resposta para o comprimento de onda de $675 \mathrm{~nm}$ apresenta maior sensibilidade em ambos os casos de medida de VRMs e Fase, respectivamente. Este resultado era esperado já que a molécula de PtOEP apresenta seu pico de emissão em $644 \mathrm{~nm}$ (BRAGA et al., 2014).

$\mathrm{A}$ análise da sensibilidade da resposta do sensor em relação à concentração do $\mathrm{O}_{2} \mathrm{e}$ $\mathrm{NO}_{2}$ foi determinada através da derivada de Tensão Eficaz "VRMs" (saída do amplificador de transimpedância) em função da concentração dos gases. O gráfico das curvas da $\mathrm{dV} \mathrm{R}_{\mathrm{RMS}} / \mathrm{dO}_{2}$ em função de $\% \mathrm{O}_{2}$ e da $\mathrm{dV} \mathrm{R}_{\mathrm{RMS}} / \mathrm{dNO}_{2}$ em função de $\% \mathrm{NO}_{2}$ é apresentado na Figura 98 ( $a, b$ e c).

D
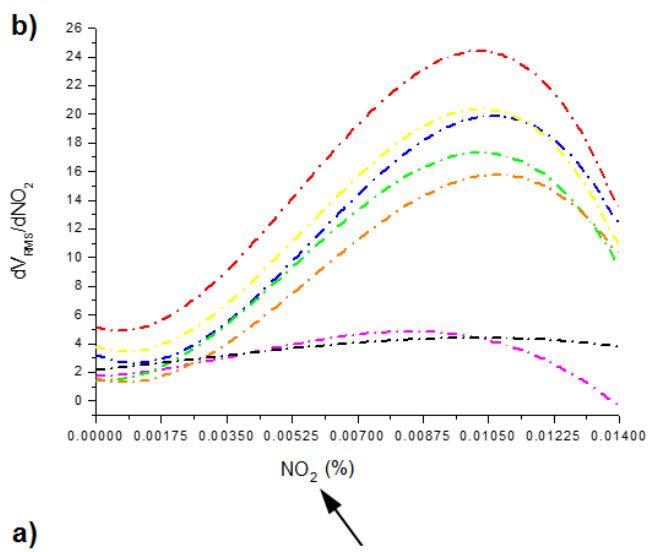

.

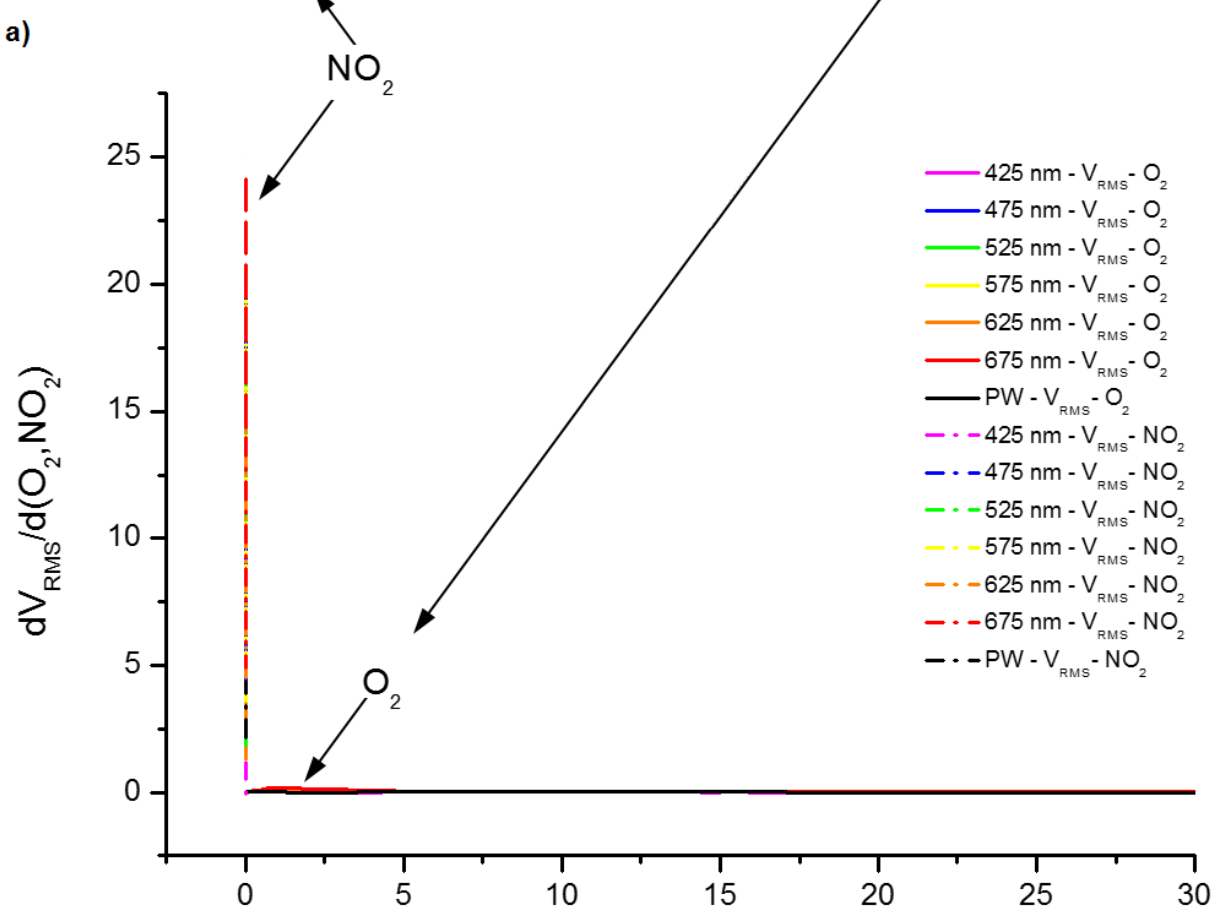

(\%)

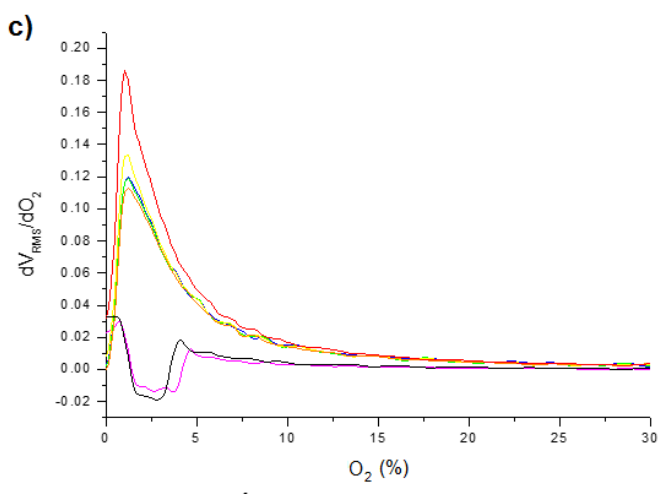

$-425 \mathrm{~nm}-\mathrm{V}_{\mathrm{RMS}}-\mathrm{O}$

$475 \mathrm{~nm}-\mathrm{V}_{\mathrm{PMS}}-\mathrm{O}$

$625 \mathrm{~nm}-\mathrm{V}-\mathrm{O}$

$-675 \mathrm{~nm}-\mathrm{V}_{\mathrm{pMS}}-\mathrm{O}$

$-\cdot-475 \mathrm{~nm}-\mathrm{V}_{\mathrm{Pus}}-\mathrm{NO}$

$--525 \mathrm{~nm}-\mathrm{V}_{\text {PMS }}-\mathrm{NO}$

$-575 \mathrm{~nm}-\mathrm{V}_{2}-\mathrm{NO}$

$-\cdot-625 \mathrm{~nm}-\mathrm{V}_{\text {RMS }}-\mathrm{NO}$

$-\cdot 675 \mathrm{~nm}-\mathrm{V}_{\mathrm{PMS}}-\mathrm{NO}$

$-\cdot-P W-V_{p M S}-N O$

Figura 98 -a) Derivada das curvas de resposta de saída do dispositivo multiespectral para medidas de INTENSIDADE ( $\left.\mathrm{V}_{\mathrm{RMS}}\right)$; b) Curvas da derivada de resposta à presença de diferentes concentrações de $\mathrm{NO}_{2}$ em $\mathrm{N}_{2} ; \mathrm{C}$ ) Curvas da derivada de resposta à presença de diferentes concentrações de $\mathrm{O}_{2}$ em N $\mathrm{N}_{2}$. 
A partir das curvas mostradas nos detalhes b) e c) da Figura 98 observam-se duas regiões distintas de maior sensibilidade do sensor, que está entre 0 e $5 \%$ para $\mathrm{O}_{2} \mathrm{e}$ 0,00525 e $0,014 \%$ para $\mathrm{NO}_{2}$. Acima das máximas concentrações as curvas de sensibilidade se aproximam de zero. Há de se notar também que o máximo valor do coeficiente de sensibilidade é de 0,19 para o $\mathrm{O}_{2}$ e de 24 para $\mathrm{NO}_{2}$, representando duas ordens de grandeza maior para detecções de $\mathrm{NO}_{2}$ em relação ao $\mathrm{O}_{2}$.

$\mathrm{Na}$ Figura 99 (a, b e c) são apresentadas as curvas de sensibilidade pela derivada das medidas de Fase "VFASE" em relação a concentração de $\mathrm{O}_{2}$ ou $\mathrm{NO}_{2}$. De maneira semelhante, observam-se duas regiões de maiores sensibilidades, uma relacionada a detecção do oxigênio com faixa de 0 a 2,5\% e 0,00525 a 0,01225\% para $\mathrm{NO}_{2}$.
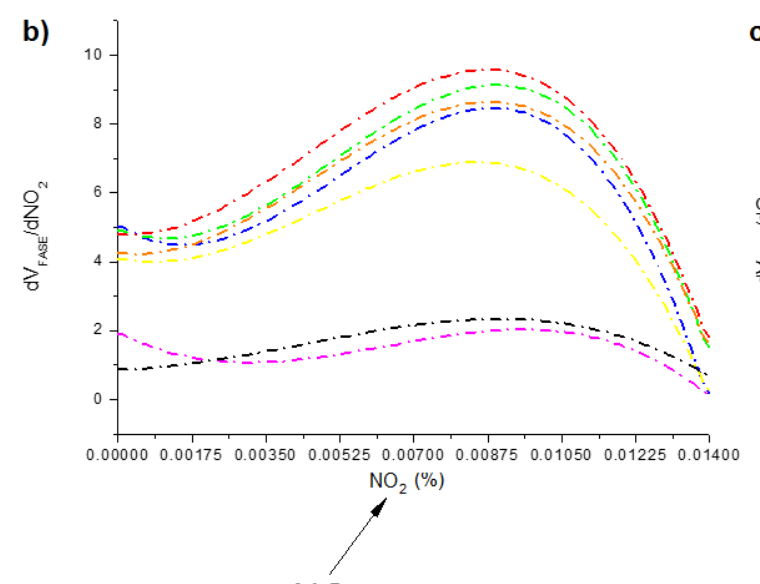

a)

? c)

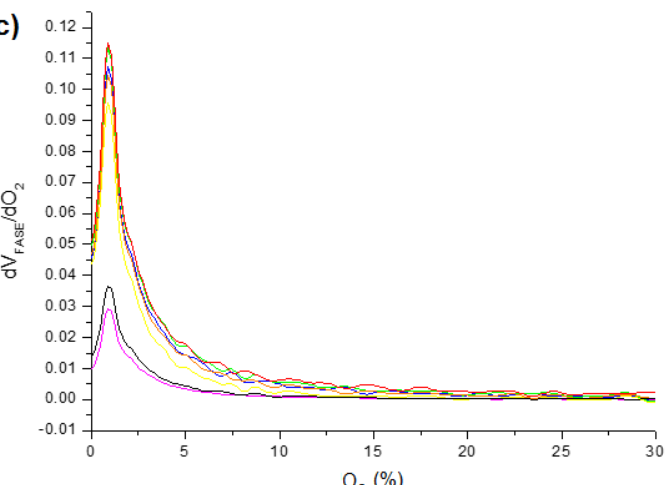

$425 \mathrm{~nm}$ - FASE - $O$

$-475 \mathrm{~nm}$ - FASE - O

$-525 \mathrm{~nm}$ - FASE - O

$575 \mathrm{~nm}$ - FASE - O

$-625 \mathrm{~nm}$ - FASE - $\mathrm{O}_{2}$

$-675 \mathrm{~nm}$ - FASE - O

— PW - FASE - O

- - $425 \mathrm{~nm}$ - FASE - NO

- - $-475 \mathrm{~nm}$ - FASE - NO

$--525 \mathrm{~nm}$ - FASE - $\mathrm{NO}_{2}$

- $-575 \mathrm{~nm}$ - FASE - NO

- - $625 \mathrm{~nm}$ - FASE- NO

- - $675 \mathrm{~nm}$ - FASE - NO

- - PW - FASE - $\mathrm{NO}_{2}$

Figura 99 -a) Derivada das curvas de resposta de saída do dispositivo multiespectral para medidas de FASE (graus); b) Curvas da derivada de resposta à presença de diferentes concentrações de $\mathrm{NO}_{2}$ em $\mathrm{N}_{2}$; c) Curvas da derivada de resposta à presença de diferentes concentrações de $\mathrm{O}_{2}$ em $\mathrm{N}_{2}$. 


\subsubsection{Resposta dinâmica do dispositivo MMCS6CS com estrutura de MAZeT/PVC(PtOEP) na presença de diferentes concentrações de $\mathrm{O}_{2} \mathrm{e}$ $\mathrm{NO}_{2}$}

Na Figura 100 é apresentada a resposta dinâmica do sensor após submetê-lo às diferentes concentrações de oxigênio, alternados pelas injeções de 0, 10, 20 e 30\% de oxigênio em nitrogênio. Neste ensaio, a temperatura permaneceu constante em $26^{\circ} \mathrm{C}$. O tempo de resposta do sensor obtido para a transição de um ambiente inerte de nitrogênio $\left(0 \% \mathrm{O}_{2}\right)$ até $30 \%$ de $\mathrm{O}_{2}$ foi de $2,05 \mathrm{~s}$. Já o tempo de recuperação na inversão de $30 \%$ de $\mathrm{O}_{2}$ para ambiente inerte foi de 3,2 s. Os tempos foram obtidos por meio de avaliação dos instantes de 10\% e 90\% da distância da fase inicial e final no processo de troca, este resultado mostra que a resposta do sensor proposto é rápida e com uma recuperação de $100 \%$.

Transições de $5 \mathrm{~s}$ a cada mudança de estado

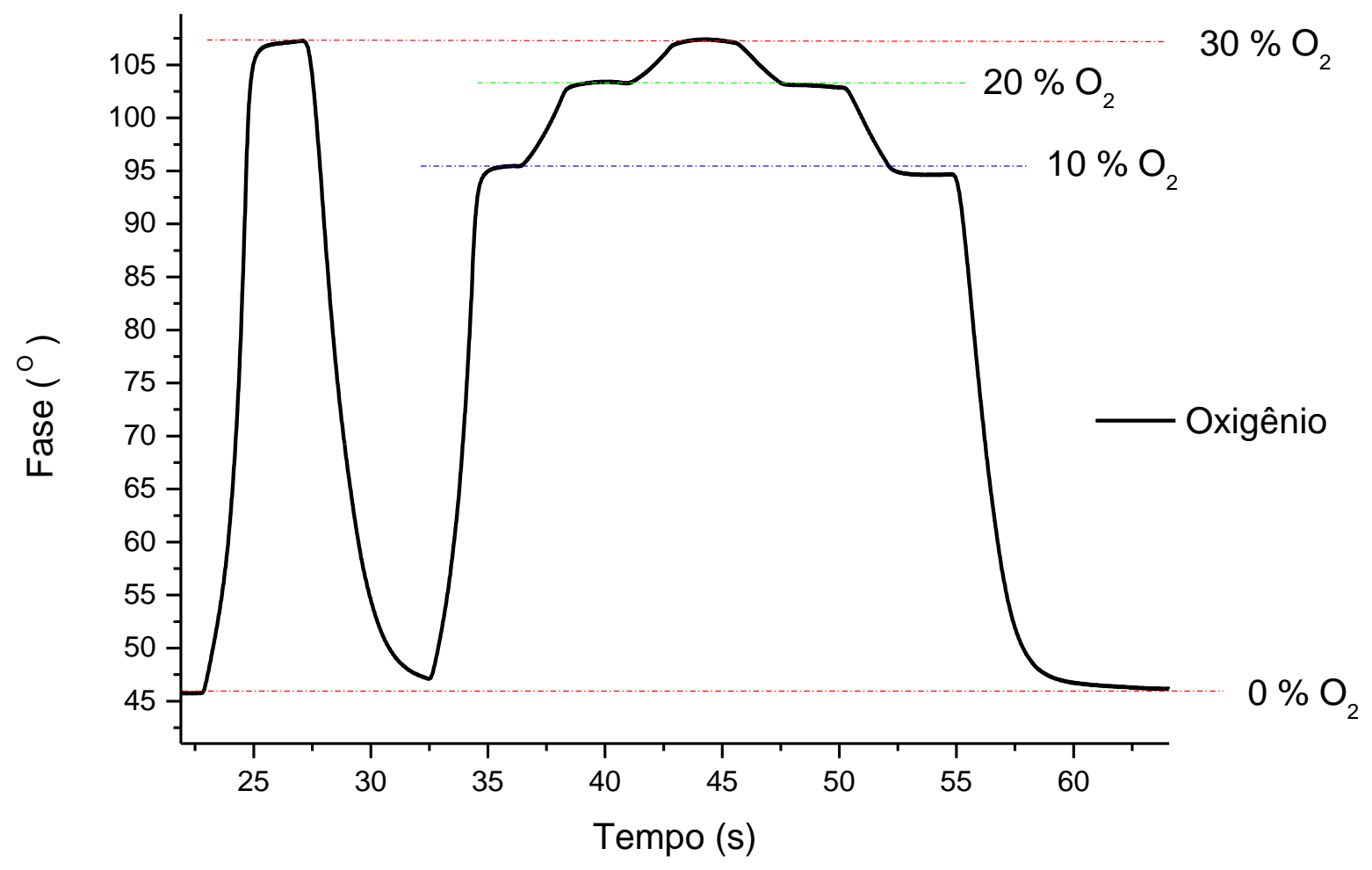

Figura 100 -Resposta dinâmica do dispositivo MMCS6CS com estrutura MAZeT/PVC(PtOEP) na presença de diferentes concentrações de $\mathrm{O}_{2}$.

Diferentemente do comportamento de detecção e recuperação do sensor aos ambientes contendo $\mathrm{O}_{2}$, o resultado da análise do tempo de resposta para $\mathrm{NO}_{2}$ mostra 
longos tempos de detecção e recuperação (Figura 101). Após a injeção de $0,014 \%$ de $\mathrm{NO}_{2}$ o valor de fase atinge $90 \%$ do valor máximo após $155 \mathrm{~s}$, desconsiderando o pico momentâneo de valor $76,9^{\circ}$ que pode estar relacionado à alguma instabilidade no controle do fluxo do gás.

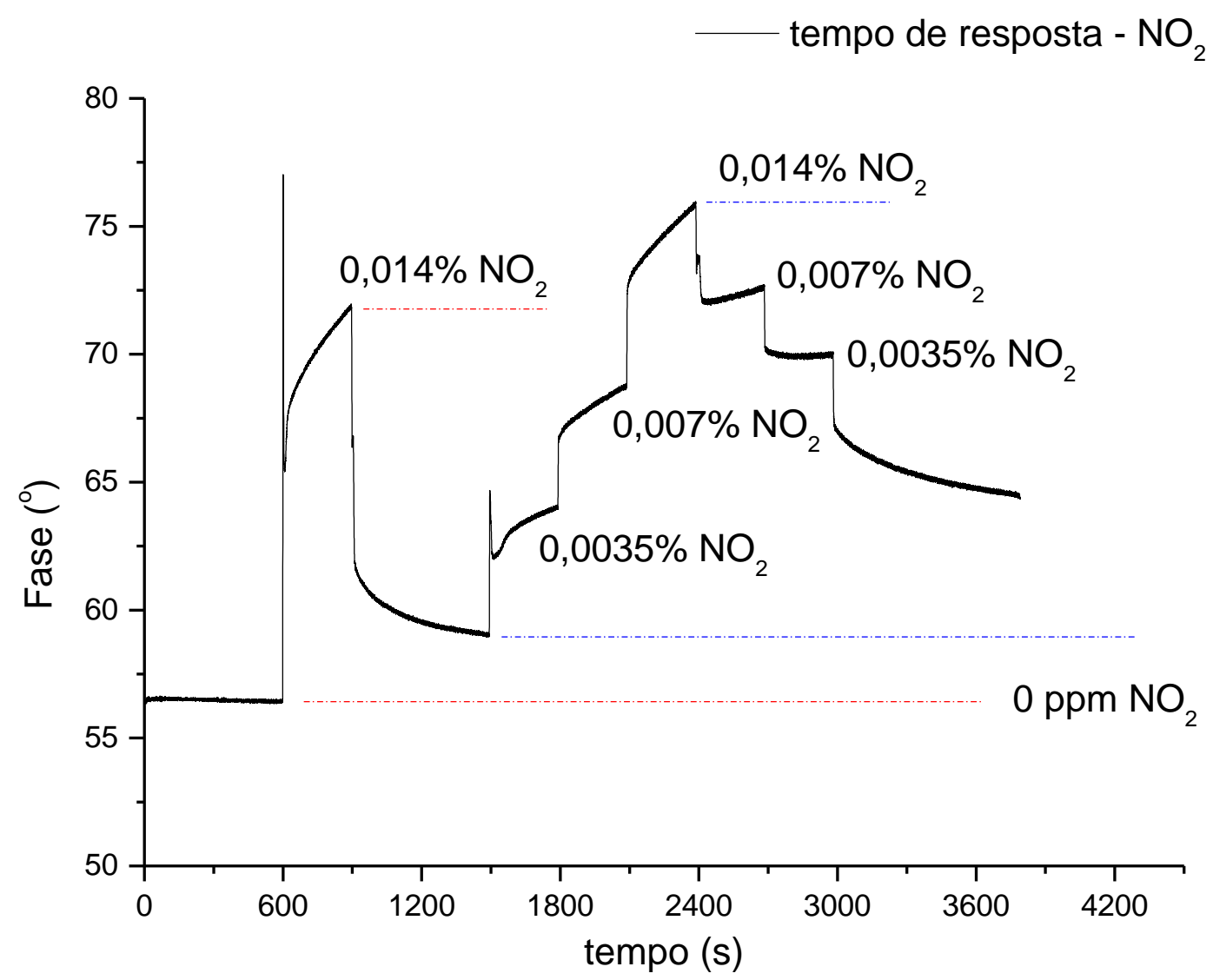

Figura 101 -Resposta dinâmica do dispositivo MMCS6CS com estrutura MAZeT/PVC(PtOEP) na presença de diferentes concentrações de $\mathrm{NO}_{2}$.

$\mathrm{Na}$ recuperação do sensor para condições iniciais do ensaio $\left(0 \% \mathrm{NO}_{2}\right)$, a fase inicial encontrada de $56,43^{\circ}$ deslocou-se para $59^{\circ}$. Segundo Papkovsky et al. (1995), este comportamento indica duas componentes atribuídas ao efeito da supressão da fotoluminescência pelo $\mathrm{NO}_{2}$ : a primeira, devido à supressão física (colisionais); enquanto que a segunda (irreversível por interações químicas com o $\mathrm{NO}_{2}$ ) está relacionada à possível degradação da membrana formada pela matriz hospedeira de PVC e o fluoróforo de PtOEP. Assim, o tempo encontrado para a recuperação do sensor para $10 \%$ acima da fase inicial de $\mathrm{NO}_{2}\left(59^{\circ}\right)$ é de $232 \mathrm{~s}$. 


\subsection{Conclusões}

O sensor optoeletrônico proposto neste capítulo, que integra a camada sensível e o fotodetector no mesmo dispositivo, mostrou-se altamente sensível aos gases de $\mathrm{O}_{2} \mathrm{e}$ $\mathrm{NO}_{2}$. A sensibilidade do sensor para $\mathrm{NO}_{2}$ foram duas ordens de grandeza maior do que para o $\mathrm{O}_{2}$. O sistema eletrônico projetado e fabricado para medir a resposta do sensor utilizando a intensidade de emissão fotoluminescente ( $\left.V_{\mathrm{RMS}}\right)$ ou o tempo de vida da molécula sensível (Fase) mostrou resultados totalmente compatíveis, podendo assim, utilizar-se um ou outro parâmetro para a medida da resposta do sensor.

O sensor mostrou um tempo de resposta rápida (2 s) para o oxigênio se comparado com a sua resposta ao $\mathrm{NO}_{2}$ (155 s). Desta forma, destaca-se que estes tempos de resposta são menores que os reportados em outros dispositivos propostos na literatura.

A diferença no tempo de resposta para $\mathrm{O}_{2}$ e $\mathrm{NO}_{2}$ se justifica por estar diretamente relacionada ao processo de difusão destes gases na camada sensível do sensor, já que as concentrações de $\mathrm{NO}_{2}$ foram de duas ordens de grandeza menores que a do $\mathrm{O}_{2}$, proporcionando uma resposta do sensor mais lenta no $\mathrm{NO}_{2}$ como efetivamente foi observado.

\subsection{Referências}

BRAGA, M. S.; BORGES, V. F.; GONÇALVES, G. M.; GOMES, O. F.; SALCEDO, W. J. Sensor óptico multifuncional para detecção de $\mathrm{O}_{2}$ e oxigênio dissolvido. Proceedings of Safety, Health and Environment World Congress, vol. 14, pp. 309-313, 2014.

CHEN, C-Y, CHANG, K-H. Temperature independent resistive oxygen sensor prepared using zirconia-doped ceria powders. Sensors and Actuators B, v. 162, pp. 68-75, 2012. 
FILIPPINI, D.; LUNDSTRÖM, I., Distinctive photocurrent chemical images on bare $\mathrm{SiO}_{2}$ between continuous metal gates. Sensors and Actuators B, v. 95, pp. 116-122, 2003.

$\mathrm{JI}, \mathrm{S}$. et al., Real-time monitoring of luminescent lifetime changes of PtOEP oxygen sensing film with LED/photodiode-based time-domain lifetime device. Analyst, v. 134, pp. 958-965, 2009.

KOSE, M. E. Multi-Luminophore Coatings for Pressure Sensitive Paint Applications. 2005. 173p. Tese (Doutorado) - University of Florida, [Gainesville], Florida, EUA, 2005.

LEE, S-K; OKURA, I. Photostable Optical Oxygen Sensing Material: Platinum Tetrakis(pentafluorophenyl) porphyrin Immobilized in polystyrene. Analytical Communications, v. 34, pp. 185-188, 1997.

MCDONAGH, C. et al. Phase fluorometric dissolved oxygen sensor. Sensors and Actuators B, v. 74, 124-130, 2001.

MONDAL, B.; KUMAR, V., A fluorescence turn-on probe for selective detection of nitrogen dioxide. RSC Advances, v. 4, pp. 61944-61947, 2014.

PAPKOVSKY, D. B. et al. Studies with solid-state phosphorescent coatings on their sensitivity to nitrogen oxides. Analytica Chimica Acta, v. 310, pp. 233-239, 1995.

PARK, Jin-Ah et al. $\mathrm{SnO}_{2}-\mathrm{ZnO}$ hybrid nanofibers-based highly sensitive nitrogen dioxides sensor. Sensors and Actuators B, v. 145, pp. 592-595, 2010.

SUMAN, P. H. et al. Giant Chemo-Resistance of SnO disk-like structures. Sensors and Actuators B, v. 186, pp. 103-108, 2013.

VALLERO, D. Fundamentals of Air Pollution. 5th Edition, Academic Press, 2014.

WU, C-C et al. Fabrication of miniature Clark oxygen sensor integrated with microstructure. Sensors and Actuators B, v. 110, pp. 342-349, 2005. 


\section{Conclusões e Perspectivas Futuras}

No presente trabalho foram propostos e desenvolvidos sistemas optoeletrônicos portáteis aplicados na detecção de $\mathrm{O}_{2}, \mathrm{NO}_{2}, \mathrm{OD}$ e íons de metais pesados, visando seu emprego no monitoramento de sistemas hidrológicos como rios, lagos e lençóis freáticos. A definição final da estrutura do sistema portátil foi atingida após o desenvolvimento sistemático de diferentes ensaios experimentais.

Primeiramente, foram estudadas e analisadas matrizes hospedeiras de estado sólido, capazes de hospedar sistemas moleculares de corantes sensíveis às substâncias específicas. Os resultados associados à detecção de $\mathrm{O}_{2}$ e OD mostraram que os filmes de PVC foram mais eficientes para hospedar as moléculas de PtOEP, já que nestes filmes tais moléculas mostraram maior sensibilidade se comparadas a substratos de silício poroso oxidado e poliestireno. Os resultados evidenciaram que esta maior sensibilidade se dá pela facilidade do processo de difusão das moléculas de $\mathrm{O}_{2}$ através do filme de PVC em ambientes gasosos e aquáticos (OD), como verificado com os resultados do tempo de resposta dos sensores desenvolvidos em filmes de PVC.

A seguir, foi proposta e executada a integração direta dos filmes hospedeiros, dopados com moléculas corantes ativas, depositadas diretamente na superfície ativa de dispositivos fotodetectores, eliminando assim a utilização de espectrômetros de bancada. Os resultados obtidos com estes sistemas que integram o detector e o filme ativo mostraram o mesmo nível de desempenho do que os espectrômetros de bancada. Dispositivos detectores de capacitores MOS, utilizando-se fenômenos de fotocorrente induzida, mostraram-se eficientes para integração direta do filme de PVC dopados com PtOEP e sua aplicação na detecção de $\mathrm{O}_{2}$, já que as moléculas de PtOEP foram excitadas com um LED de $377 \mathrm{~nm}$, cuja energia incidente não origina o efeito de fotocorrente induzida, porque esta luz é completamente absorvida na superfície do $\mathrm{Si}$, evitando assim sua incidência na camada de depleção (região ativa do capacitor MOS). Em contrapartida, a emissão fluorescente das moléculas de PtOEP emitem luz na região do vermelho, cuja energia permite que fótons desta luz consigam incidir na camada de depleção do capacitor MOS, promovendo a geração de fotocorrente induzida. Os resultados obtidos com o sistema MOS mostraram elevada sensibilidade na faixa de 0 a $50 \%$ de $\mathrm{O}_{2}$, mostrando um efeito de saturação 
em concentrações acima de 50\%. No entanto, a integração direta dos filmes ativos sobre a superfície de dispositivos optoeletrônicos mostrou ser mais eficiente tanto em sensibilidade quanto em seletividade, já que estes dispositivos apresentam característica multiespectral, o que permite a integração de diferentes moléculas corantes com diferentes características espectrais de emissão. A integração de filmes dopados de PVC e PS com moléculas de PtOEP sobre a região ativa dos dispositivos optoeletrônicos TAOS, constituída por uma matriz de fotodetectores integrados com filtros RBG, mostraram elevada sensibilidade na detecção de $\mathrm{O}_{2}$ na faixa de concentrações de 0 a 20\%, saturando rapidamente acima destas concentrações.

Filmes de PVC dopados com moléculas PtOEP foram também integrados sobre a superfície ativa de dispositivos optoeletrônicos MAZeT, constituída por matrizes de fotodiodos integrados com 6 (seis) diferentes filtros ópticos. Os resultados deste sistema integrado mostraram ter elevada sensibilidade para a detecção de $\mathrm{NO}_{2}$, chegando à saturação para concentrações acima de $0,014 \%$. Já a resposta para o $\mathrm{O}_{2}$ apresentou menor sensibilidade do que para $\mathrm{O} \mathrm{NO}_{2}$, saturando em concentrações acima de $20 \%$, resultado compatível com o obtido com o dispositivo TAOS, tendo em vista que o tempo de resposta para $\mathrm{O}_{2}$ foi mais rápida do que para $\mathrm{NO}_{2}$.

Finalmente de posse destes resultados foi projetado e desenvolvido um sistema colorimétrico e fluorimétrico portátil e embarcado numa placa de aquisição da National Instruments, aplicado na deteç̧ão e classificação de íons metálicos. Destaque principal é outorgado à aplicação do colorímetro que, juntamente com o processamento de sinais e análises de padrões utilizando o método de discriminante de Fisher, permitiram obter resultados excelentes na detecção e classificação dos íns de $\mathrm{Pb}^{2+}, \mathrm{Cd}^{2+}, \mathrm{Zn}^{2+}, \mathrm{Cu}^{2+}, \mathrm{Fe}^{3+}$ e $\mathrm{Ni}^{2+}$, com o mesmo nível de desempenho em relação aos obtidos a partir dos espectrômetros de bancada de elevada resolução espectral.

Toda a tecnologia de quantificação e classificação dos íons de metais pesados com uso de sensores optoeletrônicos multiespectrais foi totalmente integrada a hardware embarcado com tecnologia FPGA (Field Programmable Gate Array) e softwares baseados em instrumentação virtual (NI LabView®), o que permitirá o monitoramento contínuo on line e in loco, sugerindo aplicações no monitoramento de efluentes de rios, estuários, praias e mares.

O sistema portátil desenvolvido no presente projeto sugere sua aplicação no controle ambiental in situ e em tempo real, de tal forma a poder ser integrado numa rede de 
sensores que possam fornecer dados de forma continua e receber comandos de centros de controle de monitoração ambiental, sendo necessária a formulação de algoritmos eficientes no processo de mineração de dados da rede de sensores.

Adicionalmente, o sistema proposto pode ser aplicado para a detecção de vários tipos de gases simultaneamente desde que as diferentes moléculas corantes sensíveis a diferentes tipos de gases e com respostas espectrais diferentes sejam integradas no filme ativo. 